\title{
Epidemiological investigations on the occurrence of Mycobacterium avium subspecies paratuberculosis in different matrices from cattle and zoo animals by IS900 polymerase chain reaction assays
}

\author{
Dissertation \\ to obtain the $\mathrm{Ph}$. D. degree \\ in the Ph. D. Program for Agricultural Sciences in Goettingen (PAG) \\ at the Faculty of Agricultural Sciences, \\ Georg-August-University Göttingen, Germany
}

presented by

Pia Münster

born in Düsseldorf, Germany

Göttingen, March 2012 
D 7

1. Name of supervisor: Prof. Dr. Dr. Claus-Peter Czerny

2. Name of co-supervisor: Prof. Dr. Dr. Matthias Gauly

Date of dissertation: $31^{\text {st }}$ May 2012 


\section{Contents}

1 GENERAL INTRODUCTION

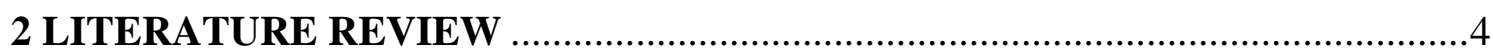

2.1 THE PATHOGEN ........................................................................................................................................ 4

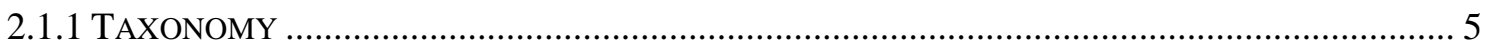

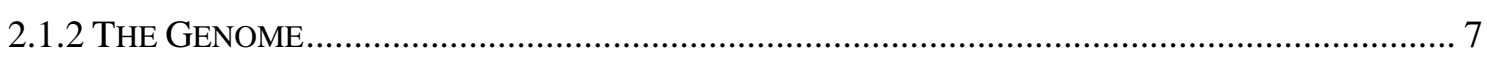

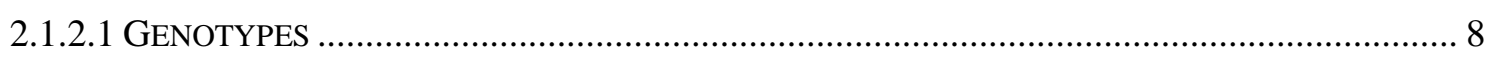

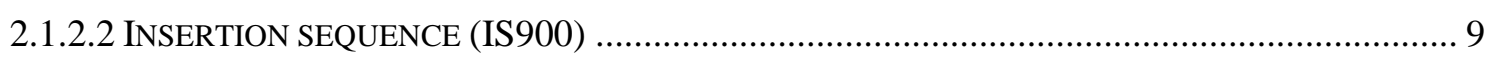

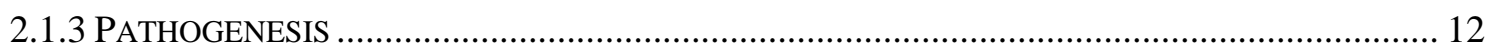

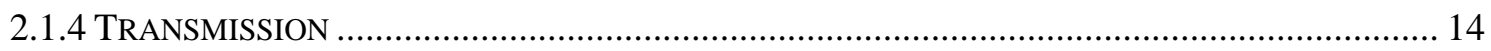

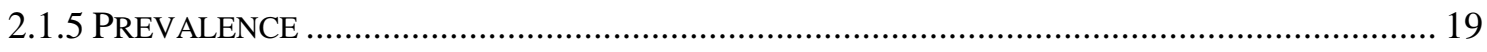

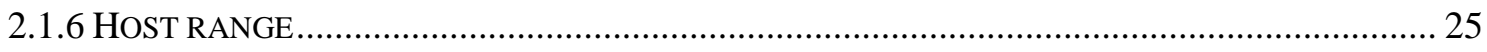

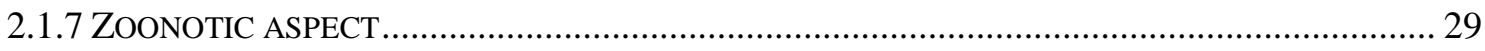

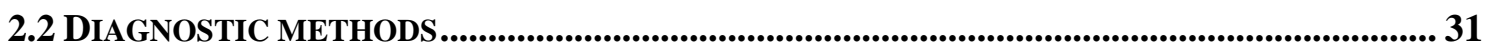

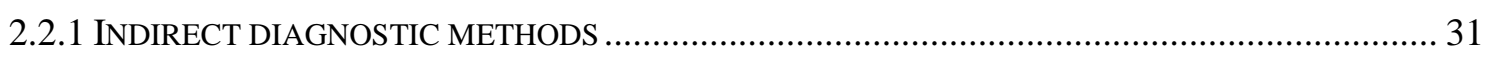

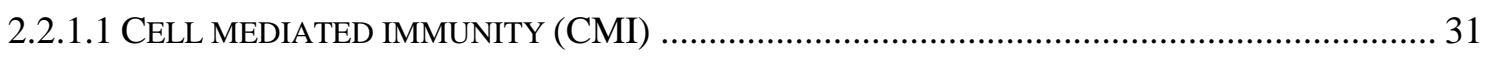

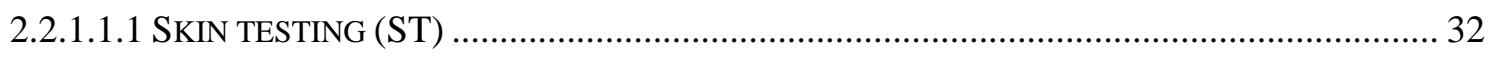

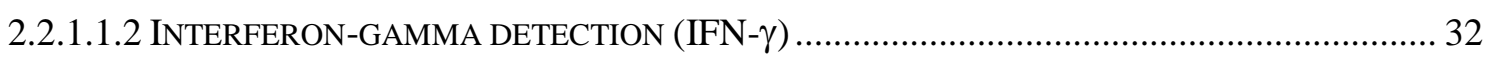

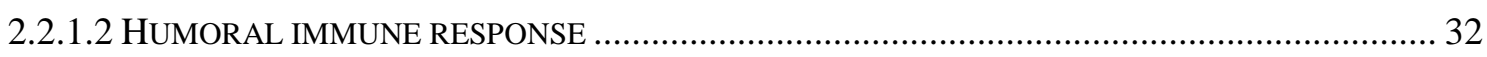

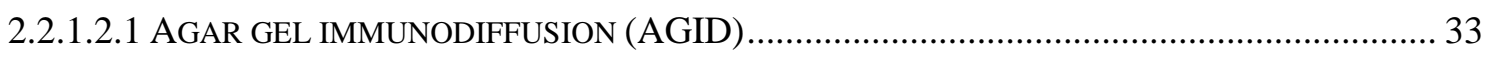

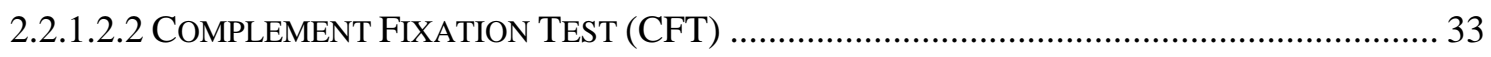

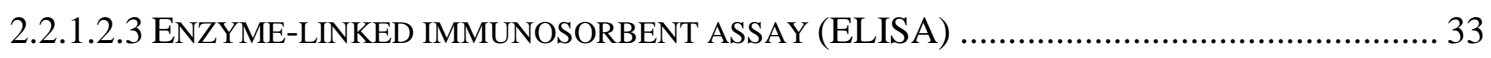

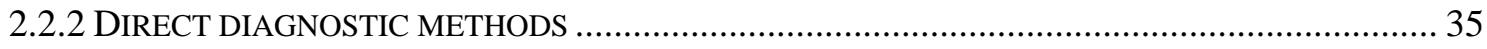

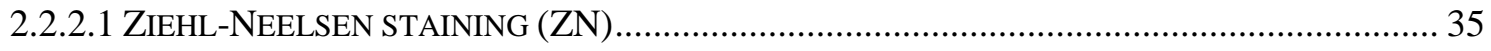

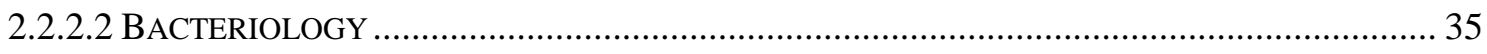

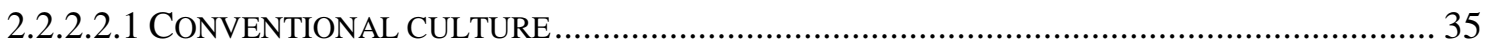

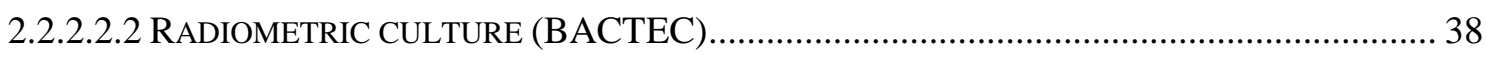

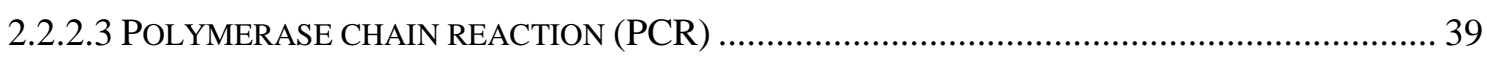

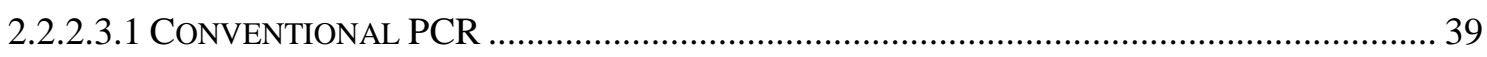

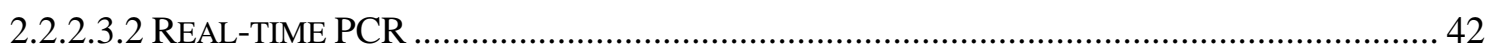

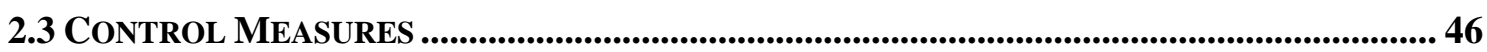


CHAPTER I. 49 SHORT COMMUNICATION: DETECTION OF MYCOBACTERIUM AVIUM SSP. PARATUBERCULOSIS IN ILEOCAECAL LyMPH NODES COLLECTED FROM ELDERLY SLAUGHTER COWS USING A SEMINESTED IS900 POLYMERASE CHAIN REACTION ...

CHAPTER II 60

A LONGITUDINAL STUDY TO CHARACTERIZE THE DISTRIBUTION PATTERNS OF MYCOBACTERIUM AVIUM SSP. PARATUBERCULOSIS IN SEMEN, BLOOD AND FECES OF A NATURALLY INFECTED BULL BY IS900 SEMI-NESTED AND QUANTITATIVE REAL-TIME PCR 60

CHAPTER III. 82

BRIEF COMMUNICATION: DETECTION OF MYCOBACTERIUM AVIUM SUBSPECIES PARATUBERCULOSIS BY IS900-BASED PCR ASSAYS FROM AN ALPACA (VICUGNA PACOS) KEPT IN

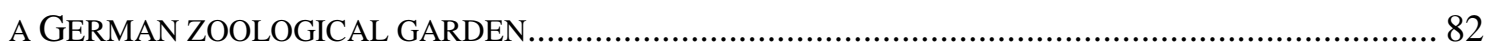

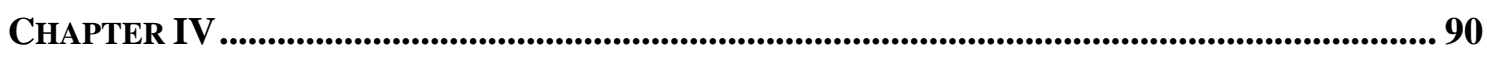

DISTRIBUTION OF MYCOBACTERIUM AVIUM SSP. PARATUBERCULOSIS IN A GERMAN ZOOLOGICAL GARDEN DETERMINED BY IS900 SEMI-NESTED AND QUANTITATIVE REAL-TIME PCR 90

4.1 CONCLUSION

LIST OF PUBLICATIONS ...................................................................................................................... 142

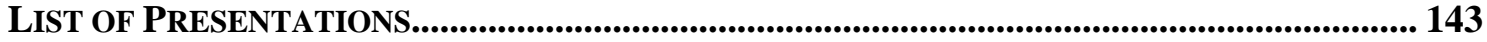

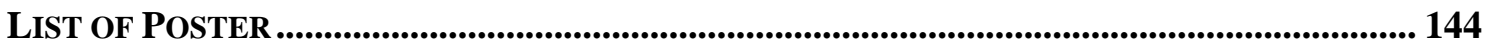

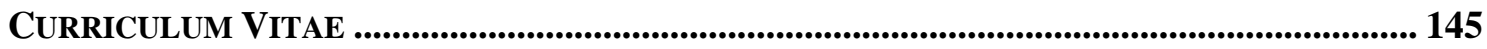

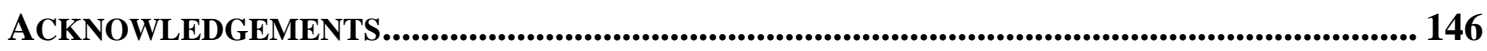

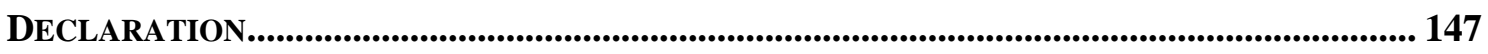




\section{General Introduction}

Mycobacterium avium ssp. paratuberculosis (MAP) is the infectious agent of Johne's disease, a degenerative wasting disorder in cattle and other ruminants. Paratuberculosis is responsible for considerable economic impacts in dairy and beef industry and is of increasing international importance (Harris and Barletta, 2001). Since the first description of the pathogen MAP in 1895 (Johne, 1895), the cattle industry has been trying to stop or to decrease the spread of paratuberculosis. Due to its long incubation time of up to ten years, MAP has a complex epidemiologic profile. MAP can spread unnoticed until the first clinical case is identified because of the existence of asymptomatic carriers and subclinically infected animals in a herd.

Besides suitable molecular biological methods for the early diagnosis of MAP infected cattle, the generation of effective paratuberculosis control programs requires reliable data on MAP prevalence. MAP occurs in most countries of the world with an increasing prevalence. It is assumed that for every cow showing disease manifestation at least 25 other animals are infected (Whitlock and Buergelt, 1996). Current diagnostic methods detect only $15 \%$ to $25 \%$ of those subclinically infected animals. Therefore, the true MAP prevalence might well exceed current estimates. In the past, serological methods were commonly used to estimate MAP prevalences (Nielsen and Toft, 2009). However, since subclinical paratuberculosis infections are characterized by low-level stimulation of the humoral immune response probably resulting in negative antibody detection, serology might lead to false prevalence ratings. Diagnosis is also still based primarily on bacterial culture, requiring a long cultivation period of 4 to 16 weeks. Some strains (sheep and bison) are more difficult to be isolated than others, requiring cultivation times of up to one year (Juste et al., 1991). Alternatively, PCR assays for direct pathogen detection seem to be worthwhile for the fast and effective examination of MAP independent of the matrix tested. It is well-known that IS900 PCR is more sensitive testing tissue samples post mortem than testing other clinical samples, e.g. feces, ante mortem (Stevenson and Sharp, 1997). For that reason, PCR examination of ileocecal lymph nodes (ILN) drawn from slaughter cattle seems to be the most suitable method of determining mycobacterial prevalence. Hence, one aim of this thesis was to investigate the occurrence of subclinical MAP infections in the German federal state of Lower Saxony by testing ILN drawn from slaughter cattle with an IS900 PCR. 
Despite reliable data on MAP prevalences, further information on the role of transmission pathways are also required prior to the generation of effective and comprehensive paratuberculosis control programs. Generally, it is accepted that MAP is predominantly transmitted from infectious cattle to susceptible calves by the fecal-oral route via ingestion of contaminated milk, colostrum, water, and other products (Sweeney, 1996). Therefore, improvement of hygienic measures associated with calving and separation of young stock from adult cattle are usually recommended (Muskens et al., 2003). However, case studies demonstrated that the disease could be reduced, but not eradicated using a "test and cull" strategy combined with improved calf rearing practices (Benedictus et al., 2008; Collins et al., 2010). These reports indicate that MAP may be transmitted via other possible routes that are not controlled by routine hygienic measures.

MAP infection due to vertical transmission could be one significant risk and may hamper control programs mainly focusing on hygienic measurements and calving practices. A meta-analysis indicated that intrauterine MAP transmission is estimated to be high enough to sustain MAP infections on a farm (Whittington and Windsor, 2009). Despite the concern that MAP could be present in semen of breeding bulls (Ayele et al., 2004; Glawischnig et al., 2004), the risk of MAP transmission by semen in vivo has never been assessed before. At the present time, little information is available in the literature regarding the shedding and distribution profile of MAP. Therefore, one scope of the current study was to determine the presence and quantity of MAP in feces, semen, and blood of a naturally and subclinically infected breeding bull candidate in a longitudinal study via PCR assays.

Despite of domestic ruminants, MAP has been reported in an extended range of other animals including non-ruminants (Beard et al., 2001a; Greig et al., 1999). Thus, another significant risk hampering the control of the disease could be the horizontal transmission route via wildlife. Increased wildlife popularity has led to greater transfer of native and exotic animals. Captured wildlife may provide fundamental knowledge in terms of the interspecies transmission of MAP. Although studies on the occurrence of MAP in fecal samples of zoo ruminants have already been published (Erume et al., 2001; Vansnick et al., 2005; Weber et al., 1992), little data concerning its prevalence in zoological gardens is available. Therefore, another scope of the current study was to evaluate the presence of MAP in captured wildlife and to provide further information on the role of interspecies transmission pathways. 
This present thesis was performed to contribute to a more detailed understanding of MAP distribution by providing epidemiological data needed for the development of eradication and control programs.

The objectives of this dissertation were:

1. Evaluation of molecular biological methods for the sensitive and specific detection of MAP independent of the matrix investigated.

2. Determination of the occurrence of subclinical MAP infections at slaughter by testing ileocecal lymph nodes with a semi-nested IS900 PCR.

3. Elucidation of distribution patterns of MAP detected in semen, blood, and feces of a naturally infected bull and the quantification of the infectious disease agent by qualitative and quantitative PCR techniques.

4. Applying qualitative and quantitative PCR techniques to confirm the occurrence of MAP in an alpaca (Vicugna pacos) and differentiation of the MAP-isolate by sequencing.

5. Evaluation of the presence of MAP in captured wildlife including non-ruminants and providing further information on the role of interspecies transmission. 


\section{Literature Review}

\subsection{The Pathogen}

Mycobacterium avium ssp. paratuberculosis (MAP) is the infectious agent of paratuberculosis also known as Johne's disease primarily seen in ruminants resulting in profuse diarrhea, emaciation, and progressive weight loss. Professor Heinrich Albert Johne (Figure 1) and Dr. Langdon Frothingham were the first describing abundant acidfast (red staining) bacteria responsible for a degenerative chronic granulomatous inflammation of the intestinal tract (Johne, 1895).

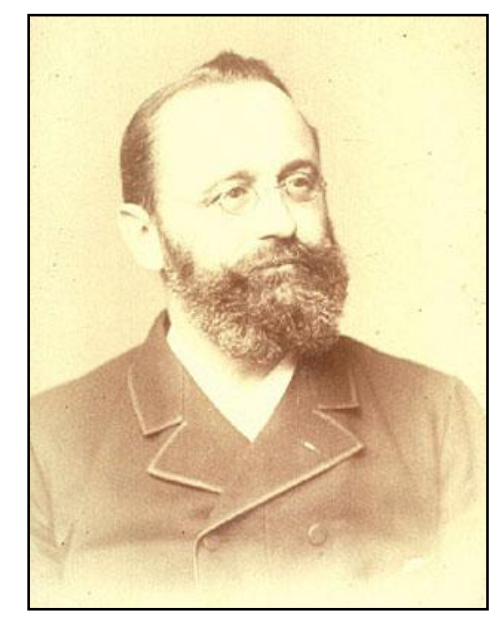

Figure 1: Professor Heinrich Albert Johne (www.johnes.org).

In 1906, Professor Bernhard Bang gave the first detailed description of paratuberculosis. He proved it to be an infectious disease distinct from tuberculosis (Bang, 1906). The first report of successful isolation and cultivation of the bacterium was published in 1912 (Twort and Ingram, 1912). After repeated renaming of the pathogen it was finally called Mycobacterium avium ssp. paratuberculosis (MAP) due to genetic similarities to Mycobacterium avium ssp. avium (MAA).

MAP is a gram-positive, acid-fast, fastidious and extremely slow growing bacillus (Lambrecht et al., 1988). The bacterium is a small $(0.5 \times 1.5 \mu \mathrm{m})$ rod-shaped organism (Figure 2) with a generation time in cell culture of 1.3 to 4.4 days (Lambrecht et al., 1988). 


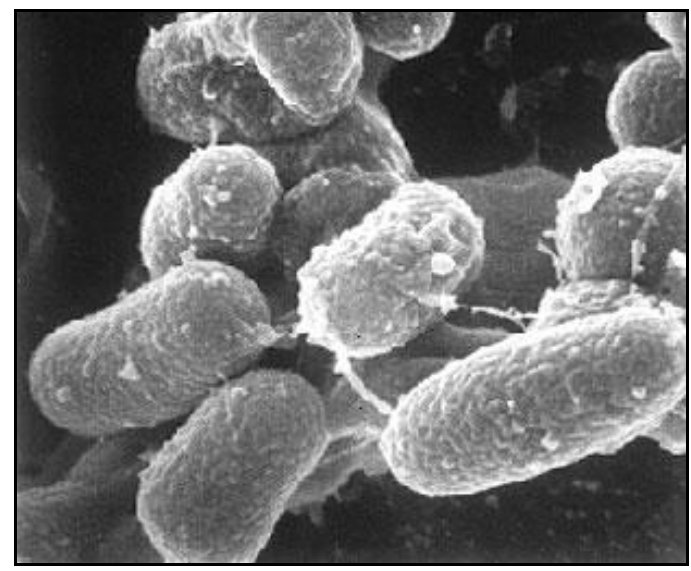

Figure 2: Electron-microscopical image of MAP (Prof. M. Collins, University of Wisconsin).

The organism has a thick, waxy cell wall containing 60\% lipid, giving it a general survival advantage and increased resistance to high temperatures. Therefore, MAP is able to survive pasteurised milk, low $\mathrm{pH}$, salt and chemicals such as chlorine (Donaghy et al., 2004; Grant et al., 2002b; Grant et al., 2005; Rowe and Grant, 2006). A recent study described a new spore-like morphotype in MAP probably being a mechanism to survive unfavourable conditions such as pasteurization (Lamont et al., 2012). Even though the lipid-rich cell wall gives mycobacteria survival advantages, the consequence of this defence is slow growth due to restriction in the uptake of nutrients through the cell wall (Domingue and Woody, 1997).

\subsubsection{Taxonomy}

Mycobacterium is a genus of Actinobacteria, belongs to the family Mycobacteriaceae and includes pathogens known to cause serious diseases in mammals, such as tuberculosis and leprosy. A Runyon classification scheme for mycobacteria other than M. tuberculosis divides species into four groups (Runyon group I-IV). This classification has no clinical or genetic significance but help to identify some clinical isolates.

Mycobacteria belonging to Runyon group I produce a bright yellow color when grown in the presence of light. Organisms belonging to this group include M. kansasii. Mycobacteria that produce a yellow pigment even when grown in the dark and produce an orange pigment when grown in the light are classified as the Runyon group II. 
Mycobacteria that are either colourless or that slowly produce a light yellow pigment when grown in the presence of light belong to the Runyon group III. Organisms placed in this group show slow growth and include $M$. avium ssp. avium (MAA), M. avium ssp. hominis (MAH), and M. ssp. avium paratuberculosis (MAP) generating the M. avium complex (MAC).

Runyon group IV includes mycobacteria that grow rapidly and that do not produce pigments. Organisms placed in this group belong to species such as M. ulcerans and $M$. marinum (Rolle and Mayr, 2002).

The phylogenitically valid taxonomy of the genus Mycobacterium demonstrates that 19 species of mycobateria show high levels of $16 \mathrm{~S}$ rRNA sequence similarity (greater than 94.3\%) (Rogall et al., 1990). The phylogenetic relationship between MAC and some other mycobacteria is based on a comprehensive 16S rRNA gene sequence alignment of all mycobacterial species (Figure 3) (Behr and Collins, 2010).

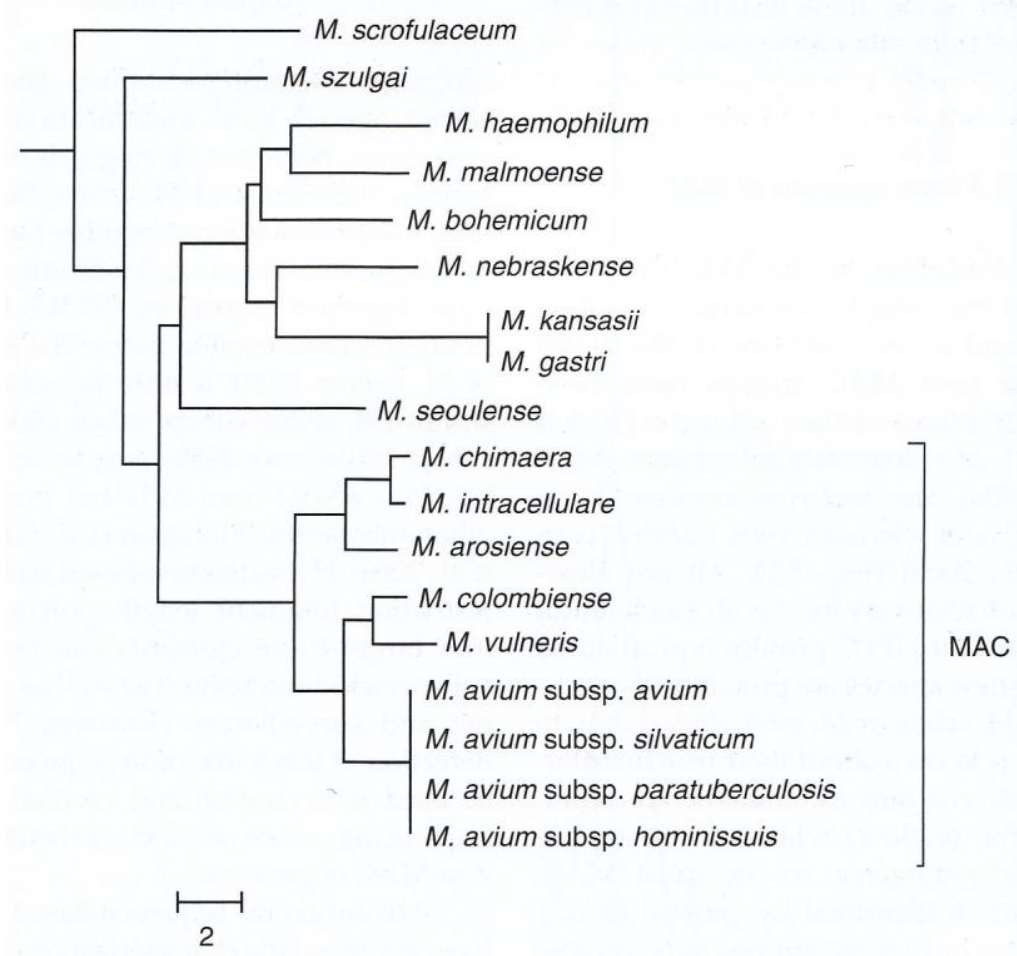

Figure 3: Phylogenetic tree showing the relationships of species belonging to the genus Mycobacterium (Behr and Collins, 2010). 
Paratubeculosis is $99 \%$ genetically related to $M$. avium, but has different phenotypic characteristics such as slower growth, requirement of an iron chemical known as mycobactin when grown in vitro, and infects mammals instead of birds. MAP is also akin to but distinct from M. tuberculosis, the main cause of tuberculosis in humans, and M. bovis, the main cause of tuberculosis in cows and occasionally in humans (Rolle and Mayr, 2002).

\subsubsection{The Genome}

Sequencing of the complete genome of MAP strain K-10 was carried out in Iowa and the MAP genome sequence was released in January 2004 and has been deposited in the GenBank database (Acc. no. AE16958). Analysis showed that the MAP K-10 genome has a single circular sequence of $4,829,781$ base pairs, with a $\mathrm{G}+\mathrm{C}$ content of $69.3 \%$ (Figure 4). The analysis also identified 17 copies of the later described insertion sequence IS900, seven copies of IS1311, and three copies of ISMav2 in the K-10 genome (Li et al., 2005).

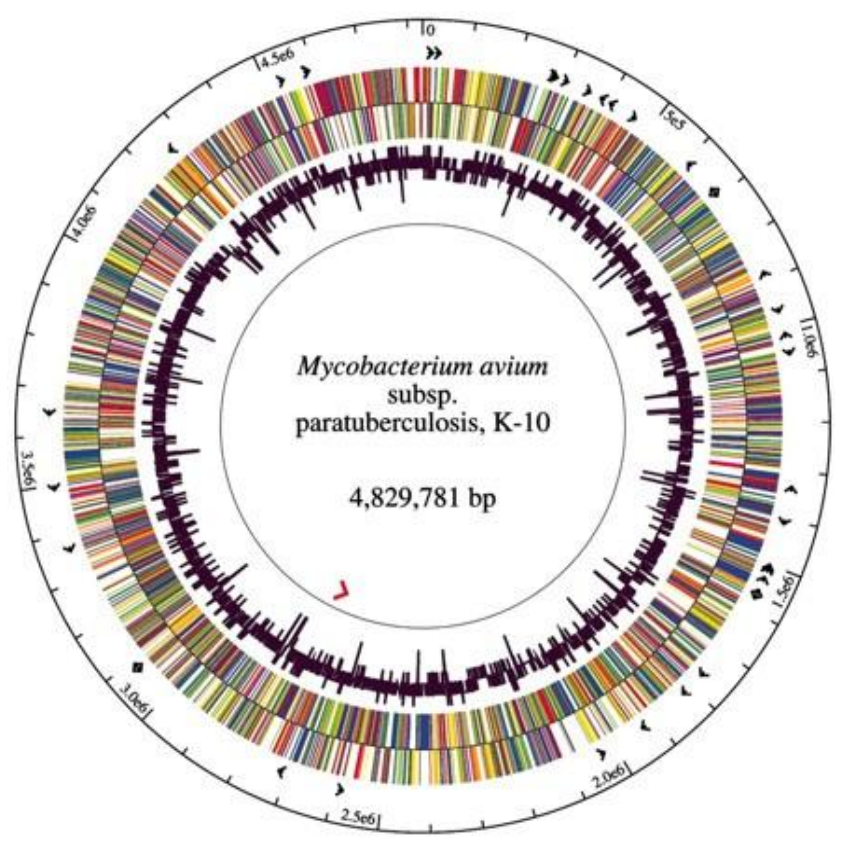

Figure 4: Linear representation of repeat and unique regions within the MAP K-10 genome (Li et al., 2005). 
Later, optical mapping of the MAP ATCC 19698 occurred and was published in 2009 (Wu et al., 2009). Alignments of the two genomes revealed differences between the MAP ATCC 19698 and the MAP K-10 strain. MAP ATCC 19698 showed a genome size of 4,839 kb compared to the previously sequenced MAP K-10 genome of 4,830 bk. MAP K-10 differs from MAP ATCC 19698 in the region starting from 4,197,080 bp to $11,150 \mathrm{bp}$, spanning the origin of replication (Figure 5).

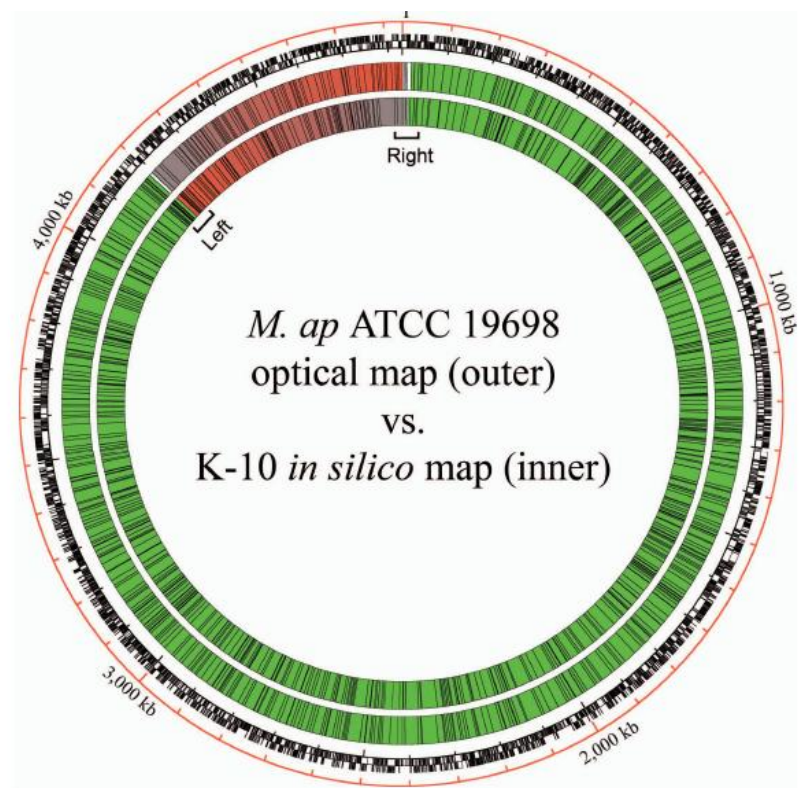

Figure 5: Alignment of the MAP ATCC 19698 and MAP K-10 restriction maps (Wu et al., 2009).

\subsubsection{Genotypes}

Based on restriction fragment length polymorphism analysis (RFLP), macrorestriction analysis by pulsed-field gel electrophoreses (PFGE) and culture characteristics, MAP strains have been classified into three main groups (de Juan et al., 2006; de Juan et al., 2005; de Lisle et al., 1993). The type I (sheep type) strains, characterized by an extremely slow and mostly pigmented growth, have been mainly described in sheep from different parts of the world. The type II (cattle type) strain, characterized by nonpigmented slow growth, have been described in a broad host range including cattle, sheep, goats, deer, rabbits, and humans (de Juan et al., 2006). The type III (intermediate type), comprising non-pigmented strains with a growth time between type I and type II, have been isolated from sheep from Canada, South Africa, Iceland (Collins et al., 1990; de Lisle et al., 1993), and from goats and bullfighting cattle from Spain (Castellanos et al., 2009; de Juan et al., 2005). 
Further IS1311 PCR-REA (restriction enzyme analysis) divide type II isolates into type C (cattle) and type B (bison) based on C/T polymorphisms at position 223 of IS1311 (Whittington et al., 1998; Whittington et al., 2001a). However, this method distinguishes between type II (cattle type) and type I/III (sheep/intermediate type) and does not differentiate between type I (sheep type) and III (intermediate type) isolates. The insertion sequence IS1311 is present in seven copies within the MAP strains of type II (cattle type) and nine copies in MAP strains of type I (sheep type). Although RFLP analysis with IS1311 clearly divides six strains of type I (sheep type) into four subtypes, no differentiation between strains of type II (cattle type) is possible (Collins et al., 1997).

\subsubsection{Insertion sequence (IS900)}

The first insertion sequence (IS) identified in MAP was the IS900, which is specific for MAP (Collins et al., 1989; Green et al., 1989a) and one of the 20 members of the IS110 family. Insertion sequence (IS) elements are small, mobile units of DNA that are usually able to transpose from one genetic locus to another. IS900 is atypical in that, unlike classical IS elements, it lacks inverted terminal repeats and is highly conserved within the genome (Green et al., 1989b). The gene encodes a 399 aa putative transposase, p43, on one strand (Tizard et al., 1992) and a predicted protein, Hed, of unknown functions on the opposite strand (Doran et al., 1997). The IS900 element is a 1,451 bp sequence that is present at 17 copies within the MAP K-10 genome (Li et al., 2005).

Since certain regions of the IS900 sequences of MAP are generally regarded to be highly conserved, unique single nucleotide polymorphisms (SNPs) were recently reviewed and DNA sequencing for the detection of polymorphisms has been considered to be promising for the differentiation of MAP strains (Castellanos et al., 2009; Semret et al., 2006). In comparison to the first published IS900 sequence (Acc. no. X16293) (Green et al., 1989b) six SNPs were found in MAP K-10 (Acc. no. NC002944) (Li et al., 2005) at positions 36, 37, 122, 123, 690, and 726. Additionally, several groups have described unique SNPs of IS900 sequences that differ from the original sequence and from MAP K-10 strain (Table 1). 
Table 1: Published SNPs in the 5' fragments of IS900 sequences relative to the MAP K-10 genome sequence (Acc. no. AE16958).

\begin{tabular}{|c|c|c|c|c|}
\hline Source/Country & SNP & $\begin{array}{l}\text { Position } \\
\text { (bp) }\end{array}$ & $\begin{array}{c}\text { Accession } \\
\text { No. }\end{array}$ & Reference \\
\hline \multirow[t]{2}{*}{ Cattle/India } & $A \rightarrow-$ & 284 & AY974345 & (Bhide et al., 2006) \\
\hline & $A \rightarrow-$ & 284 & & \\
\hline \multirow[t]{3}{*}{ Cattle/India } & $\mathrm{GC} \rightarrow \mathrm{CG}$ & $367-368$ & AY974346 & (Bhide et al., 2006) \\
\hline & $\mathrm{G} \rightarrow \mathrm{C}$ & 232 & & \\
\hline & $\mathrm{A} \rightarrow \mathrm{T}$ & 243 & & \\
\hline Sheep/Slovakia & $\mathrm{GC} \rightarrow \mathrm{CG}$ & $367-368$ & AY974348 & (Bhide et al., 2006) \\
\hline \multirow[t]{2}{*}{ Sheep/-- } & $\mathrm{A} \rightarrow \mathrm{G}$ & 216 & FJ775181 & (Castellanos et al., 2009) \\
\hline & $\mathrm{T} / \mathrm{C}^{\mathrm{a}}$ & 169 & & \\
\hline \multirow[t]{2}{*}{ Cattle, Goat/-- } & $\mathrm{G} / \mathrm{A}^{\mathrm{b}}$ & 216 & FJ775182 & (Castellanos et al., 2009) \\
\hline & $\mathrm{A} \rightarrow \mathrm{G}$ & 216 & & \\
\hline \multirow[t]{2}{*}{ River water/UK } & $\mathrm{A} / \mathrm{G}$ & 216 & -- & (Pickup et al., 2006) \\
\hline & $\mathrm{T} / \mathrm{C}^{\mathrm{a}}$ & 169 & & \\
\hline Sheep/-- & $\mathrm{G} / \mathrm{A}^{\mathrm{b}}$ & 216 & -- & (Semret et al., 2006) \\
\hline \multirow[t]{3}{*}{ Human/Italy } & $\mathrm{C} / \mathrm{T}^{\mathrm{c}}$ & $247^{\mathrm{d}}$ & -- & (Scanu et al., 2007) \\
\hline & $\mathrm{G} \rightarrow-$ & 688 & & \\
\hline & Extra C & 722 & & \\
\hline \multirow[t]{3}{*}{ Buffalo/India } & $\mathrm{A} \rightarrow \mathrm{T}$ & 899 & AY660657 & (Sivakumar et al., 2005) \\
\hline & $\mathrm{A} \rightarrow \mathrm{G}$ & 422 & & \\
\hline & $\mathrm{G} \rightarrow-$ & 688 & & \\
\hline Goats/India & Extra C & 722 & AY660658 & (Sivakumar et al., 2005) \\
\hline \multirow[t]{2}{*}{ Goats/India } & Extra A & $421^{\mathrm{e}}$ & EF514832 & (Sohal et al., 2009) \\
\hline & Extra GC & $35-36$ & & \\
\hline Vaccine & $\mathrm{CG} \rightarrow \mathrm{GC}$ & $119-120$ & AF416985 & (Willemsen et al., 2006) \\
\hline Sheep/Australia & $A \rightarrow G$ & 216 & -- & (Whittington et al., 2001b) \\
\hline
\end{tabular}


Studies reported that less genomic divergence exists among type II (cattle type) isolates than among type I (sheep type) and III (intermediate type) isolates (Castellanos et al., 2009; Sevilla et al., 2007; Turenne et al., 2008). Of special interest are descriptions about variances in the IS900 at nucleotide positions 169 and 216. The first report describing a single base substitution at position 216 ( $\mathrm{G}$ for A) was published in 2001 (Whittington et al., 2001b). Later studies observed same nucleotide exchanges in isolates obtained from river water in the United Kingdom (Pickup et al., 2005; Pickup et al., 2006). Subsequently the insertion sequence IS900 was revisited in 2006 and two ambiguities at base pair position 169 (T/C) and 216 (G/A) within IS900 sequences obtained from type I (sheep type) isolates were reported with respect to those of the type II (cattle type) (Semret et al., 2006) (Figure 6). A recent study followed up on these findings and confirmed SNPs within IS900 sequences in MAP type I (sheep type) strains (Acc. no. FJ775181) compared to the IS900 sequences in type II (cattle type) strains (Acc. no. FJ775182) (Castellanos et al., 2009).

A.

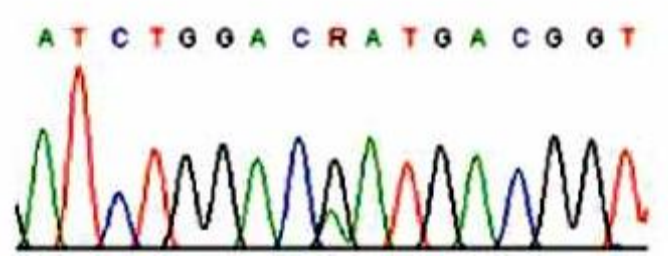

B.

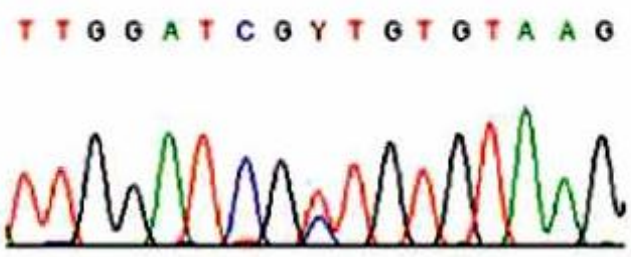

Figure 6: Sequence electropherogram of two sections of the IS900 element from MAP of the type I (sheep type) showing sequence ambiguities (Code R and $\mathrm{Y}$ ) at base pair position 216 (A) and base pair position 169 (B) (Semret et al., 2006). 


\subsubsection{Pathogenesis}

According to Whitlock and Buergelt (1996) four stages of paratuberculosis can be distinguished (Whitlock and Buergelt, 1996). The first stage is the "silent infection" stage that represents young animals to the age of two years without any clinical symptoms of the disease, but shed the organism to an undetectable level. During this silent stage of MAP infection macroscopic alterations of affected tissue are rare and usually seen in animals which have been experimentally infected (Clarke, 1997). However, microgranulomata in the intestine and the lymph nodes may be found via histology (Whitlock and Buergelt, 1996; Wu et al., 2007). The second stage is the "subclinical stage", in which animals do not show weight loss or diarrhea but may have an altered immune response. As a result of immune cell recruitment affected lymph nodes become enlarged and pale in colour (Buergelt et al., 1978). An increase of macrophages and lymphocytes leads to the thickening of the intestine. Intestinal mucosal surfaces become corrugated and granular in appearance. The third stage is characterized by weight loss and chronic or intermittent diarrhea, and known as the “clinical paratuberclosis" (Figure 7). At this stage of the disease high antibody titers and large numbers of MAP in the feces can usually be detected by routine diagnostic tests. While vitality signs usually remain normal, thirst of animals may be increased (Whitlock and Buergelt, 1996). Clinical symptoms are seen in older cows, starting at an age of three years and more. Prominent is also the thickening of the wall of the intestine and corrugation of the intestinal epithelium (Seitz et al., 1989). The fourth stage or "advanced stage of clinical paratuberculosis" is characterized by severe weight loss despite of normal or increased appetite and profuse diarrhea. The developing chronic enteritis is responsible for emaciation, reduced milk production, reduced fertility, and premature culling of dairy cattle (Chiodini et al., 1984). Due to the intestinal damage animals develop hypoproteinemia which can lead to edema especially in the submandibular region known as "bottle jaw". Most animals die soon after the fourth stage due to dehydration and cachexia (Chiodini et al., 1984; Manning and Collins, 2001). 


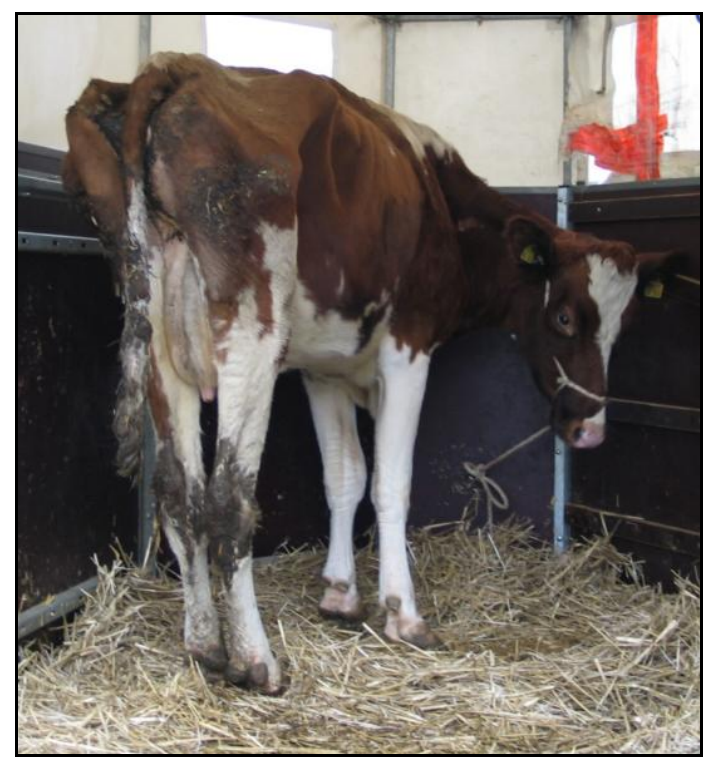

Figure 7: Clinical case of paratuberculosis including progressive weight loss and chronic diarrhea.

Histopathologic findings include that intestinal mucosa and submucosa show signs of granulomatous enteritis with marked cellular infiltrations (Figure 8). Macroscopically, granulomatous lesions are most often seen post mortem within the mestenteric lymph nodes in the region of the ileum, the jejunum, and sporadically within the ileocaecal lymph node (Harris and Barletta, 2001). The lacteal ducts from the jejunum to the adjacent lymph nodes become swollen and often are thick in appearance. In clinical cases the ileum is corrugated and thickened, with enlarged edematous mesenteric lymph nodes. Gross lesions of corrugated ileum, as well as histopathological lesions are typical for MAP confirming paratuberculosis. Generally lesions remain restricted to the intestine as well as to the mesenteric and ileocecal lymph nodes.

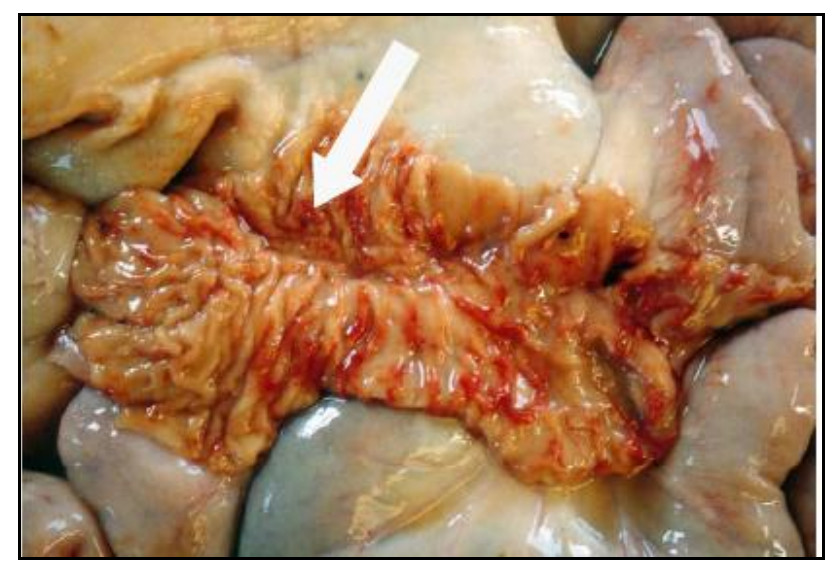

Figure 8: Histopathological findings of paratuberculosis (Dr. H. Köhler, FLI Jena). 


\subsubsection{Transmission}

Transmission of MAP to newborn calves occurs through the ingestion of feces, contaminated milk, feed, and water by introduction of subclinical or persistently infected cattle into the herd. Particularly the contact from dairy cows to newborn calves plays an important role for the carry over of the pathogen. Due to infected livestock shedding the pathogen intermittently in feces and milk, the disease is spreading within the population (Chiodini et al., 1984; Clarke, 1997).

Early studies reported doses including $10^{3}$ MAP colony-forming units (CFU)/g (Gilmour, 1965), and $10^{6}-10^{8}$ MAP CFU (Jorgensen, 1982; Whittington et al., 2000) to be infectious. Another review suggested a dosage of $5.0 \times 10^{1}-10^{3} \mathrm{CFU}$ in order to be infective in young calves (Chiodini, 1996). Experimental studies demonstrated that doses of $1.5 \times 10^{6}$ MAP CFU given orally to 21-day-old calves resulted in MAP infection of multiple tissues (Sweeney et al., 2006). Generally, it can be concluded that a diseased animal shedding $>10^{8}$ CFU MAP per day in feces contributes significantly to environmental contamination (Eamens et al., 2008). Animals are commonly categorized according to bacterial load per gram feces. Low shedders yield in $10^{3}-10^{5}$ $\mathrm{MAP} / \mathrm{g}$ and high-shedders reach $10^{6}-10^{8} \mathrm{MAP} / \mathrm{g}$ (Eamens et al., 2008).

The primary site of bacterial multiplication is the terminal part of the small intestine and the large intestine. MAP is taken up by phagocytic cells overlying Peyer's patches in the ileum and gradually spreads to regional lymph nodes and other body organs in the later stages of the disease (Gilmour, 1976) (Figure 9). The bacteria are carried by macrophages to other sites particularly the uterus, the fetus, the mammary gland, the testes, and semen of bulls (Ayele et al., 2004). Phagocytes containing intracellular mycobacteria disseminate infection to other parts of the body and also probably migrate back onto the mucosal surface to shed bacilli (Lugton, 1999). 


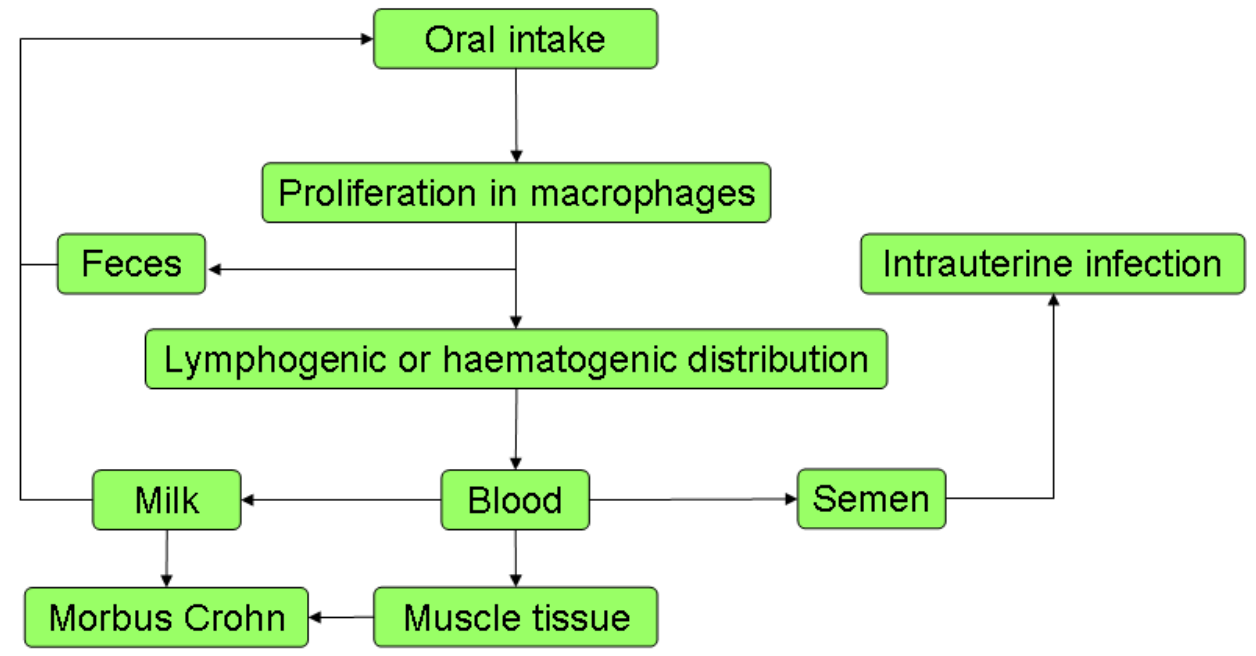

Figure 9: Theoretical dissemination and transmission of MAP.

While the fecal-oral route of infection is generally recognized, reports about intrauterine-derived infection are rare. Bovine fetal infection was first reported in 1929 (Alexejeff-Goloff, 1929). Similarly, the isolation of MAP from cotyledons of a cow infected with MAP was reported in 1953 (Hole, 1953). Others followed describing the isolation of MAP from a wide range of fetal organs and the uterine flush fluids of cows with clinical paratuberculosis (Doyle and Spears, 1951; Kopecky et al., 1967; Lawrence and Schulkins, 1956; Rohde and Shulaw, 1990). In 16 subclinically infected cows classified as moderate fecal shedders of MAP the pathogen could not be isolated from embryos, oocytes, or follicular fluids (Kruip et al., 2003). However, considering a study that isolated MAP from five fetuses of infected cows classified as heavy fecal shedders, but not showing any signs of paratuberculosis (Sweeney et al., 1992), the occurrence of fetal infection is more likely to occur in heavy fecal shedders than in moderate or light shedders. Another working group examined 109 in vitro produced cryopreserved embryos derived from subclinically infected cows and did not detect MAP in any of the examined embryos or freezing media (Perry et al., 2006). The data suggests that the risk of MAP transmission by using such embryos is very low. 
In the past, the risk of fetal infection with MAP was estimated to be $26.4 \%$ (Seitz et al., 1989). In a recent study, the prevalence of fetal infections in cattle was determined through meta-analysis and the incidence of calves infected via the inutero route was estimated (Whittington and Windsor, 2009). Seven studies published between 1980 and 2003 were included in this meta-analysis. Data were summarized in studies of subclinical cases (SC1-SC5), clinical cases (C2-C4), and all cases of cow infection. In total, there were 203 fetuses from cows subclinical infected with MAP (de Lisle et al., 1980; Kruip et al., 2003; Ridge, 1993; Seitz et al., 1989; Sweeney et al., 1992) and 26 from cows with clinical signs of paratuberculosis (Ridge, 1993; Seitz et al., 1989). Studies based only on nested PCR were excluded from meta-analysis due to the risk of false positive results. The mean prevalence of infected fetuses among cows with the subclinical disease was $9 \%$ (95\% confidence limits 6-14\%), while it was increased to $39 \%(20-60 \%)$ among clinically affected cows (Figure 10). The total prevalence of inutero infectetd calves among infected cows was $13 \%$ (9-18\%).

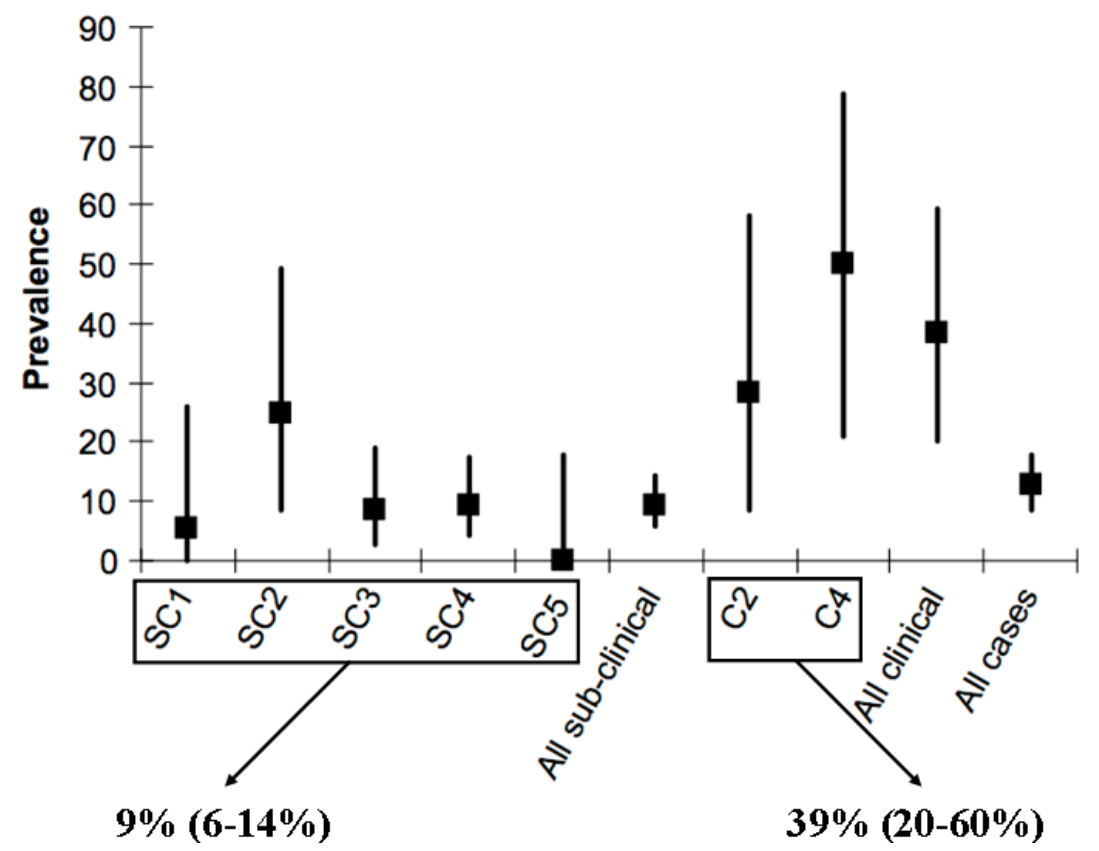

Figure 10: Percentage of infected fetuses and 95\% confidence limits for seven studies included in meta-analysis, with data aggregated for studies of subclinical cases (SC1-SC5), clinical cases (C2-C4) and all cases of cow infection (Whittington and Windsor, 2009). 
Experimental infection of the bovine reproductive tract was achieved by inoculating MAP $\left(5 \times 10^{8} \mathrm{CFU}\right.$, in $5 \mathrm{ml}$ saline) into the uterus of thirteen 3-4-year old cows 24 hours after mating or artificial insemination (Merkal et al., 1982). The isolation of MAP was successful from the uterine body and horns one, two, three, seven, and 14 days post inoculation, indicating that MAP survives in the uterus and moves to adjacent lymph nodes. Another study inoculated three cows with a high dose of MAP (200-400 mg wet weight) at the time of artificial insemination (Owen, 1983). Five months post inoculation, shedding of MAP in feces occurred in one cow and MAP was isolated from liver spleen, mesenteric lymph nodes, and intestine of fetus. However, the assay was not well designed, as the cow may not have been free of MAP when purchased for this study. Another working group reported that MAP injected into the mammary was transported to the supramammary lymph nodes in five of six cows and to the intestine of one cow (Larsen, 1978).

Inutero infection of the fetus in species other than cattle was also reported. MAP was isolated from the uterus of four ewes (Ovis aries), from the fetus of one tule elk (Cervus elaphus nannodes), and from the uterine body of pygmy goats (Capra hircus) (Alinovi et al., 2009; Deutz et al., 2005; Lambeth et al., 2004; Manning et al., 2003). Fetal infection has also been described in farmed red deer (Cervus elaphus) in New Zealand, in wild red deer (Cervus elaphus) and in a chamois (Rupicapra rupicapra) from Austria (Thompson et al., 2007; van Kooten et al., 2006).

The first report about the isolation of MAP from bovine semen was published in 1948 (Edmondson, 1948). Two publications are available culturing MAP from bovine semen. In the first study MAP was detected in only 8 of 31 cultures of semen samples collected from a bull showing clinical signs over a period of 21 months (Larsen et al., 1981). In the second study culture was successful in only 1 of 100 semen samples from a subclinically infected bull (Ayele et al., 2004). MAP was also isolated by culture in testis, epididymides, and seminal vesicle of a naturally infected breeding bull (Ayele et al., 2004) (Figure 11). 


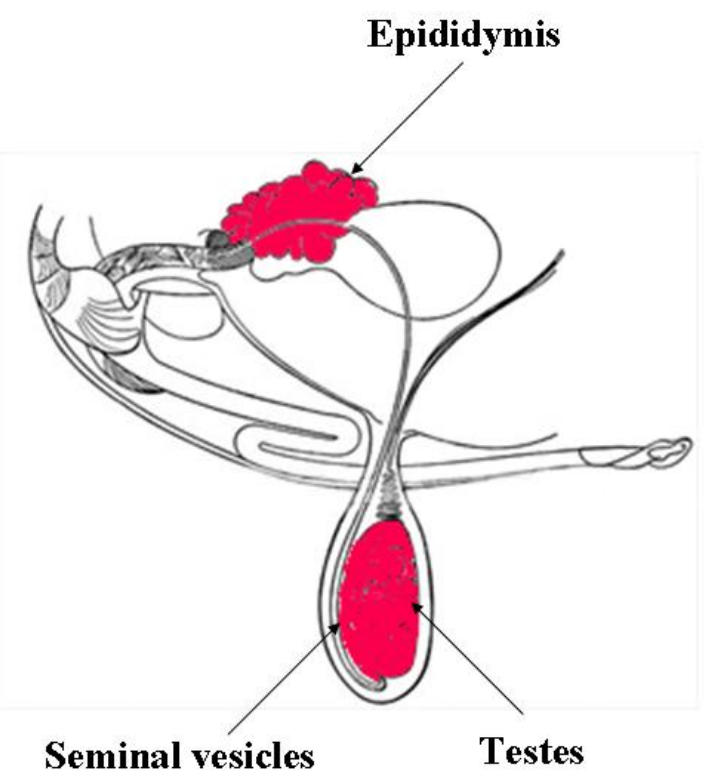

Figure 11: Distribution of MAP in reproductive organs of bulls.

There is evidence that the organism can survive semen conservation procedures using liquid nitrogen containing antibiotic additives (Larsen and Kopecky, 1970; Larsen et al., 1981). No further investigation has been initiated to prove this observation. It may be possible that bulls can be significant sources of the infection (Philpott, 1993). Although bulls are the least in number in a given animal population, they can be significant sources of infection (Amstutz, 1984). The MAP organism may be incorporated into a cow's reproductive tract by direct contact via mating or by indirect contact via artificial insemination (Edmondson, 1948). Moreover, there has been evidence that serving adult cows with semen containing low amounts of MAP leads to hypersensitivity and abortion after performing the Johnin skin test (Merkal, 1981). However, the question if semen can transmit the disease via the uterus has not yet been investigated in detail (Eppleston and Whittington, 2001).

It is known that MAP is extremely resistant and survives in various materials for a long time (Rowe and Grant, 2006). The difficulty to remove MAP from the environment may be its ability to form biofilm-like structures (Bolster et al., 2009). Recent studies demonstrated the survival of MAP in biofilms on livestock watering trough materials or temporal spread of MAP in the environment of a cattle farm through bio-aerosols (Cook et al., 2010; Eisenberg et al., 2010). These abilities induce a persistent source of infection and may complicate preventing further spread and transmission of MAP. 


\subsubsection{Prevalence}

Paratuberculosis is a worldwide disease affecting both, developing as well as developed countries in Europe, North America, South America, Asia, Australia, and Africa (Behr and Collins, 2010). The distribution of MAP from its first report in Europe to dairy herds all over the world demonstrates the rapid spreading of MAP over geographical space and highlights the need for paratuberculosis eradication and control programmes (Figure 12). As over $50 \%$ of dairy cattle herds are infected with MAP, paratuberculosis is considered an endemic disease in Europe and North America (Nielsen and Toft, 2009).

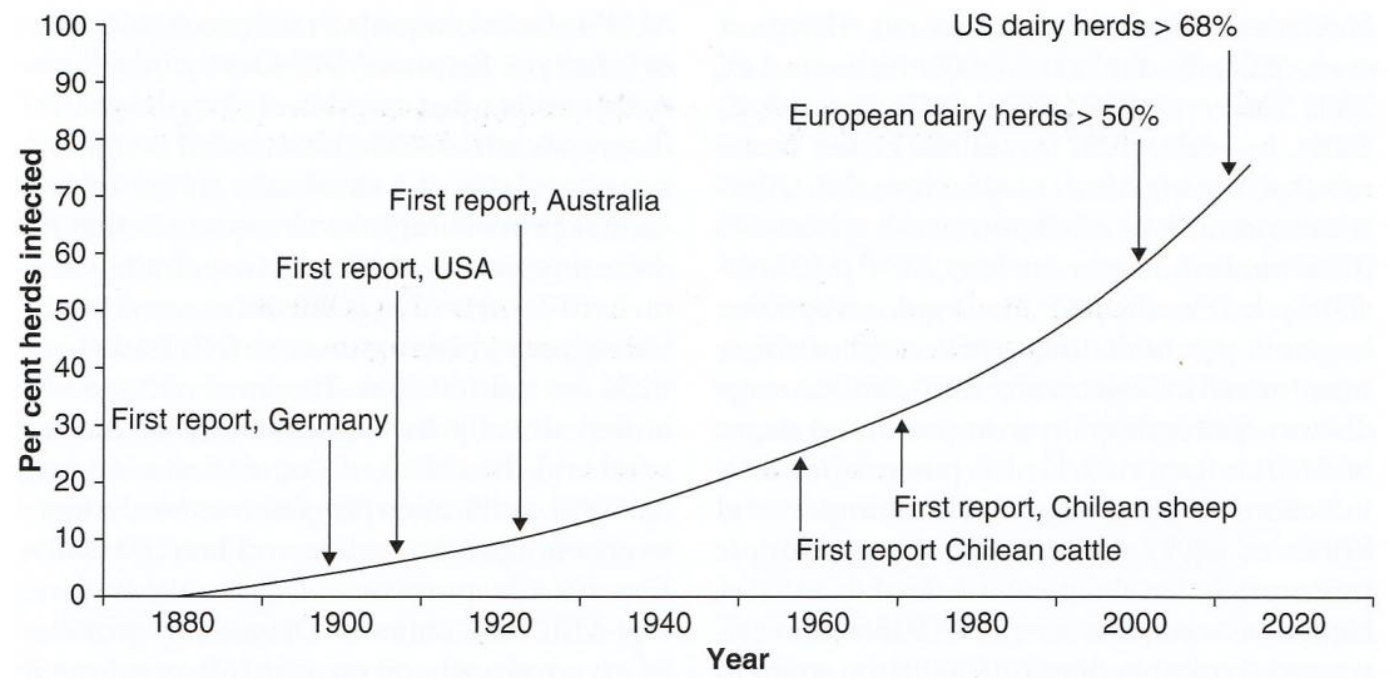

Figure 12: Theoretical global epidemic curve for herd-level paratuberculosis in dairy cattle (Behr and Collins, 2010).

MAP occurs in most parts of the world with an increasing prevalence (Chiodini et al., 1984). A recent study critically reviewed published data representing prevalence of MAP in Europe and estimated the overall prevalence to be $20 \%$ (Nielsen and Toft, 2009). The true prevalence among cattle was measured in serological studies conducted in France (Petit, 2001), Germany (Donat, 2005), Italy (Robbi, 2002), and Turkey (Atala, 2001). Is has been suggested that the prevalence of MAP is at least 3-5\% in several countries (Cetinkaya et al., 1996; Vicenzoni, 1999). However, a proper conclusion with regards to the prevalence of MAP infections in Europe cannot be made, due to study designs unsuitable for prevalence inference (Nielsen and Toft, 2009). 
In Germany paratuberculosis is a notifiable disease according to §78a Abs. 2 of the Tierseuchengesetz. Currently 300 to 450 cases per year are reported. In 2009 and 2010, 361 and 411 MAP cases were reported respectively, whereas most cases occurred in Lower Saxony and North Rhine-Westphalia (TSN Database - Germany) (Figure 13). Between 1997 and 2007, four prevalence studies mainly based on serological methods investigated the MAP prevalence in Germany A study in Mecklenburg-West Pomerania revealed an apparent prevalence of $12.2 \%$ by testing 59 dairy cattle for MAP specific antibodies using the Svanovir ${ }^{\mathrm{TM}}$-ELISA (Svanova Biotech AB, Uppsala, Sweden) (Hacker et al., 2004). In Bavaria 2,748 bovine sera from 119 herds were analysed using two commercially available ELISAs (IDEXX HerdChek, Idexx Gmbh, Wörrstadt, Germany, and Pourquier ELISA, Institut Pourquier, Montpellier, France). An apparent prevalence of $1.5 \%$ and $0.9 \%$, respectively, was defined (Bottcher and Gangl, 2004), whereas in Saxony an estimated prevalence of $4.4 \%$ was calculated by testing 3,454 animals randomly, selected from clinically suspicious herds by the HerdChek ELISA (IDEXX GmbH, Wörrstadt, Germany) (Donat, 2005). In contrast, an apparent MAP prevalence of $14.7 \%$ was determined in the rural district of Arnsberg (North RhineWestphalia) when 517 sera from cattle older than 18 months were investigated in an inhouse ELISA (Böttcher, 1997).
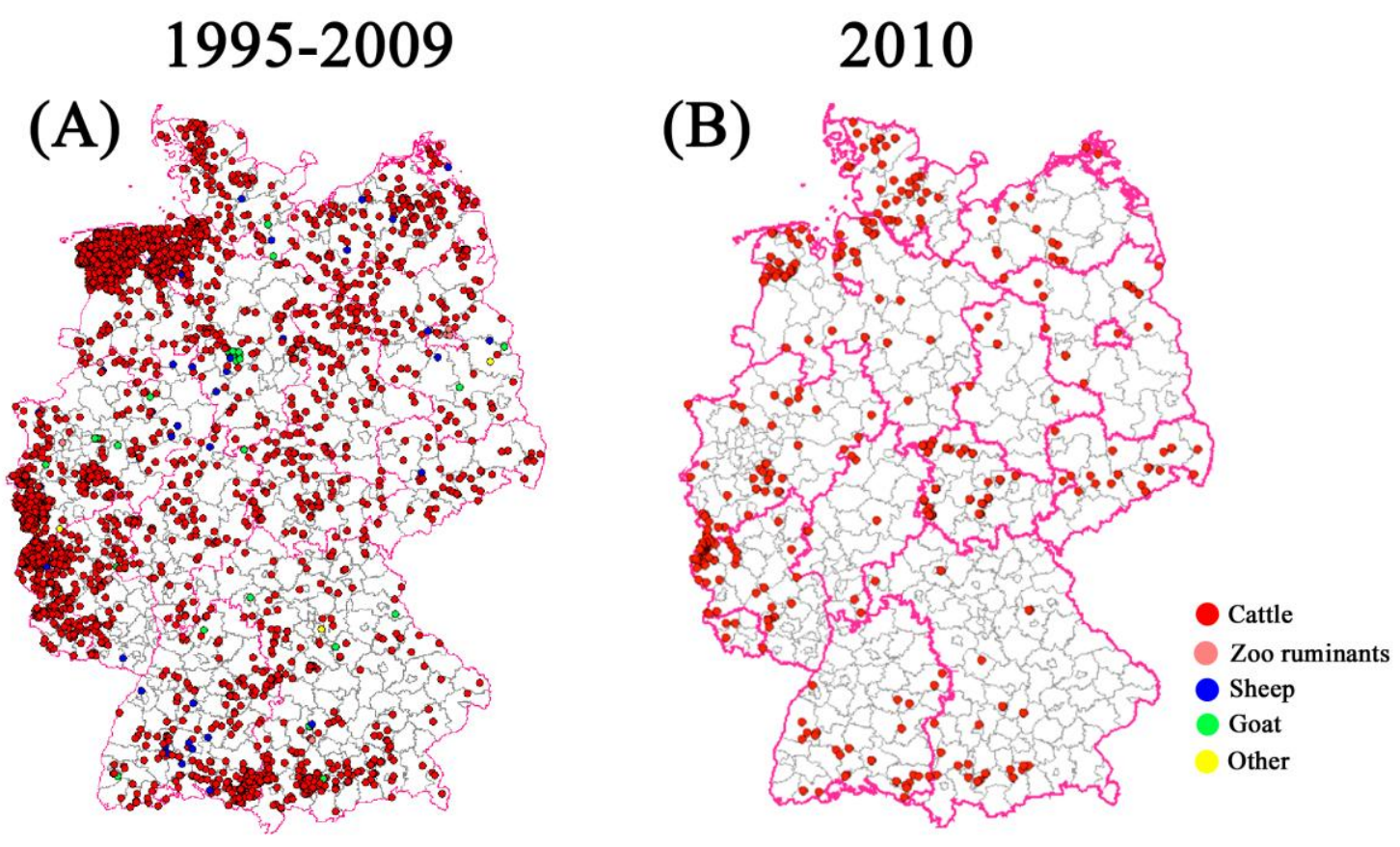

Figure 13: Map of Germany ilustrating reported cases of paratuberculosis. (A) 19952009 and (B) 2010 (TSN: July 2011). 
In Austria a study determined the prevalence of MAP in the regions Mödling, Graz, Linz and Innsbruck. They used an ELISA based on an antigen from Allied Monitor (Fayette, USA) and estimated an average prevalence of $1.99 \%$ and an apparent prevalence in Austrian herds of 6\% (Gasteiner et al., 1999).

In Switzerland, studies have been carried out based on bulk tank milk PCR resulting in prevalence estimates on herd level of $22 \%$ and $20 \%$, respectively (Corti and Stephan, 2002; Stephan et al., 2002). Among the studies based on Parachek ELISA (CSL, Parkville, Victoria, Australia), apparent prevalences of $5.1 \%$ and $0.7 \%$ were estimated, respectively (Meylan et al., 1995; Stark et al., 1997). A later study tested samples of multiple specimens (milk, feces, and tissues) from 101 animals obtained from cull-cattle that were sent to one slaughterhouse. The tests were conducted based on F57 real-time PCR and a prevalence of $20 \%$ was reported (Bosshard et al., 2006).

In Belgium, a stratified random sample of cows was obtained from 511 herds. In these herds, all cattle $>24$ months of age were sampled. The animals were tested by ELISA (HerdChek, IDEXX, France), and it was assumed that the prevalence on animal level was $0.9 \%$ and on herd level 18\% (Boelaert et al., 2000).

One study has been published in The Netherlands based on a region stratified random sample of 15,822 cows belonging to 378 herds using the IDEXX HerdChek test (IDEXX Scandinavia AB, Österbybruk, Sweden) (Muskens et al., 2000). Of these herds, 55\% $(\mathrm{n}=207)$ had one or more serologically positive cows. The percentage of positive cows per herd was estimated to be $2 \%$.

Prevalence estimates from the United Kingdom have only been published in one study in South West England (Cetinkaya et al., 1996). This study was based on cull cattle that were sent to three abattoirs. Of 1,297 adult cattle tested, 3.5\% were positive by an IS900 PCR used for samples of lymph nodes. PCR positive lymph nodes were also cultured, and in 34 cows (2.6\% of the total sample) MAP could be isolated. 
In Spain, 61,069 animals of at least 1-year of age from 2,735 randomly selected herds were bled and their samples analyzed with a commercial ELISA test (Dieguez et al., 2007). The estimated true individual-level prevalence was $3.0 \%$ in dairy cattle, $1.0 \%$ in beef cattle and $2.8 \%$ in animals from farms with both dairy and beef cattle. True herd prevalence was $10.7 \%$ for dairy herds, $0.0 \%$ for beef herds and $2.7 \%$ for mixed herds. In conclusion, these results seem to indicate that a small percentage of cows and a rather high percentage of dairy herds in this region are MAP-seropositive.

In Italy, a true prevalence of $17 \%$ was estimated in the Venetia region based on an apparent prevalence of $3.5 \%$ using an serological assay (Robbi, 2002). This result corresponded with the apparent prevalence of $6.8 \%$, based on histopathology and culture of MAP from tissue samples of the ileocecal valve, that was measured in animals sent to slaughter houses in the Verona province of Venetia (Vicenzoni, 1999).

In the Yonne region of France a study used the ELISA test (Pourquier, Montpellier, France) and estimated a herd prevalence of $68 \%$ and an individual-level prevalence of $3.3 \%$ among a random selection of cattle (Petit, 2001).

In Turkey prevalence studies were carried out in three regions (Central Anatolia, Eastern Anatolia, and Western Anatolia combined with Eastern Thrace), based on ELISA testing (Atala, 2001), PCR in milk samples (Cetinkaya, 2000) and PCR in fecal samples (Ikiz, 2005), respectively. In the study based on ELISA an apparent herd prevalence of $38 \%$ was estimated (Atala, 2001). Individual-level prevalence was $4.6 \%$ in ELISA (Atala, 2001), 0\% in PCR in fecal samples (Ikiz, 2005) and 5\% in PCR milk (Cetinkaya, 2000).

In the Republic of Ireland, $13 \%$ of the samples were found positive by bulk tank milk PCR (O'Reilly et al., 2004). In a survey of MAP in imported animals in the Republic of Ireland, the apparent prevalence on individual-level was estimated to be $3.6 \%$ (O'Doherty et al., 2002). 
However, available prevalence data need to be interpreted with caution due to a long incubation period of up to ten years (Whitlock and Buergelt, 1996). Clinical symptoms may be first seen in animals with an age of 2-5 years (Clarke, 1997). These clinical cases are merely the tip of the iceberg in terms of the total number of infected animals in a herd (Figure 14). It is assumed that for every cow with clinical signs of paratuberculosis, a minimum of 25 other animals are infected (Whitlock and Buergelt, 1996).

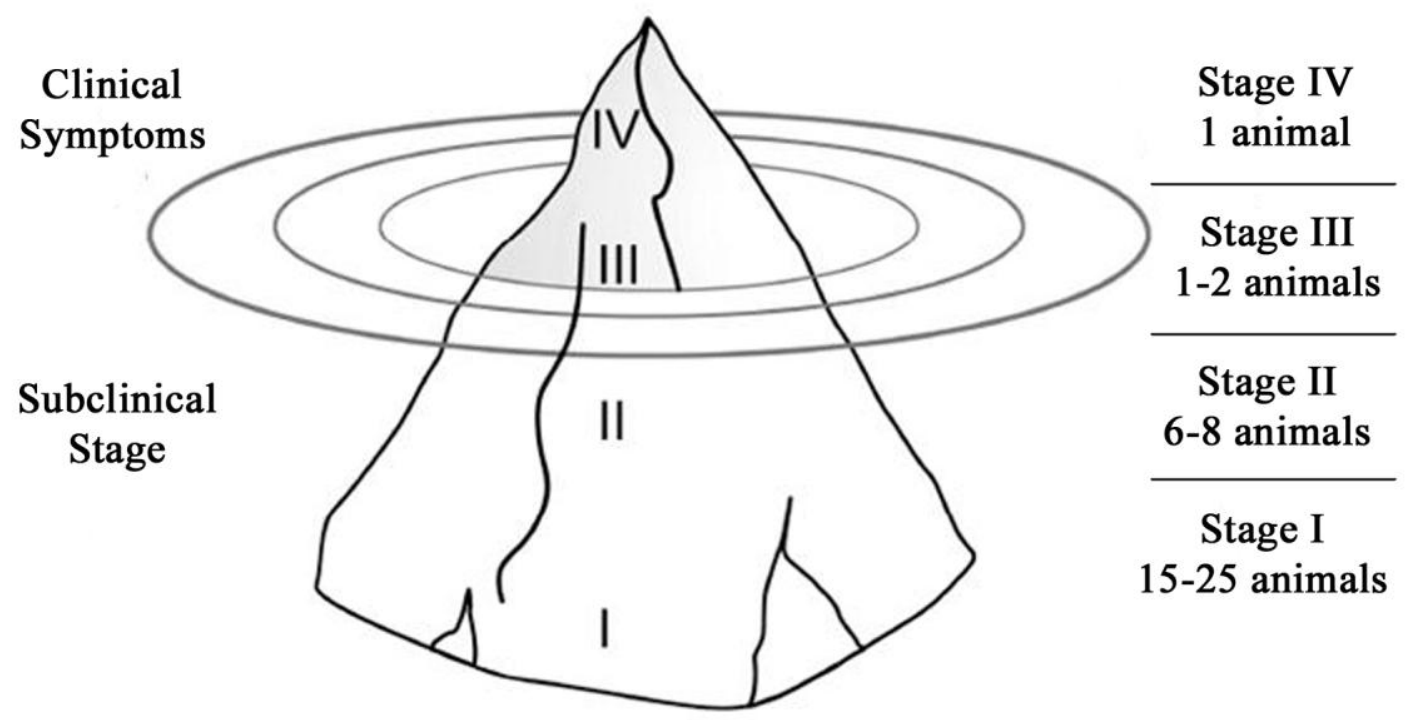

Figure 14: The "Iceberg concept" by Whitlock and Buergelt, 1996.

Current applied diagnostic methods detect only $15 \%$ to $25 \%$ of these infected animals (Whitlock and Buergelt, 1996). Therefore, the true prevalence of MAP might well exceed the current estimates.

Although MAP is considered to be a pathogen growing only inside of a suitable host, published data suggest that MAP survives well in the open environment, persisting for between 300 and 600 days in water and soil (Pickup et al., 2005; Whittington et al., 2005). MAP has been detected in the agricultural environment in pasture soil, manure storage areas, calving and sick pens, lakes, lagoons, and alleyways (Table 2). 
Table 2: Distribution of MAP in environmental samples.

\begin{tabular}{|c|c|c|}
\hline Location & Country & References \\
\hline Pasture soil & USA & $\begin{array}{r}\text { (Johnson-Ifearulundu and Kaneene, 1997) } \\
\text { (Norby et al., 2007) } \\
\text { (Ward and Perez, 2004) }\end{array}$ \\
\hline Manure storage & USA & $\begin{array}{r}\text { (Raizman et al., 2004) } \\
\text { (Jaravata et al., 2006) }\end{array}$ \\
\hline Calving and sick pens & USA & (Raizman et al., 2004) \\
\hline Lakes & UK & (Pickup et al., 2006) \\
\hline River & UK & (Pickup et al., 2005; Pickup et al., 2006) \\
\hline Sediment & Australia & (Whittington et al., 2005) \\
\hline Lagoons & USA & (Berghaus et al., 2006) \\
\hline Alleyways & USA & $\begin{array}{l}\text { (Berghaus et al., 2006) } \\
\text { (Raizman et al., 2004) }\end{array}$ \\
\hline Water & $\begin{array}{l}\text { USA } \\
\text { Ireland } \\
\text { Australia }\end{array}$ & $\begin{array}{r}\text { (Norby et al., 2007) } \\
\text { (Raizman et al., 2004) } \\
\text { (Whan et al., 2005) } \\
\text { (Whittington et al., 2005) }\end{array}$ \\
\hline Slurry & $\begin{array}{l}\text { Australia } \\
\text { Norway }\end{array}$ & $\begin{array}{r}\text { (Gwozdz, 2006) } \\
\text { (Jorgensen, 1977) }\end{array}$ \\
\hline Sewage & Australia & (Gwozdz, 2006) \\
\hline
\end{tabular}

Recent studies have demonstrated the importance of investigating environmental sources of MAP and its effect on prevalence and persistence within affected herds (Berghaus et al., 2006; Cook and Britt, 2007; Gwozdz, 2006; Raizman et al., 2004; Whittington et al., 2004). Some authors even suggest that environmental sampling for MAP may serve as a viable alternative to individual animal testing since it accurately predicts herd status, is lower in cost, and easier to perform (Berghaus et al., 2006; Raizman et al., 2004). 


\subsubsection{Host range}

The disease is predominant in domestic ruminants such as cattle, sheep, and goats, but also occurs in a wide range of other free-ranging and captive ruminants. MAP has been described in red deer (Cervus elaphus), elk (Cervus elaphus), moose (Alces alces), bison (Bison bison), buffalo (Bubalus bubalis), and antelope (Saiga tatarica) (Buergelt and Ginn, 2000; Dukes et al., 1992; Manning et al., 1998; Pavlik et al., 2000; Yadav et al., 2008).

The first report of a wider host range was published in the 1970s, describing the isolation of MAP from a brown hare (Lepus europaeus) (Matthews and Sargent, 1977). However, non-ruminant wildlife hosts of MAP were not confirmed until the late 1990s by PCR studies detecting MAP in wild rabbits (Oryctolagus cuniculus) from cattle farms with a history of paratuberculosis (Beard et al., 2001b; Greig et al., 1999; Greig et al., 1997). Since that time, there is evidence that free-ranging wildlife including nonruminants have become increasingly important in the transmission and maintenance of MAP. Known wildlife reservoirs are rabbits in Scotland (Beard et al., 2001b; Greig et al., 1997) and a wide spectrum of free-ranging birds and mammals in the USA (Corn et al., 2005). Previous studies using molecular genetic typing techniques demonstrated the concept of natural interspecies transmission of MAP between wildlife and domestic ruminants (Florou et al., 2008; Greig et al., 1999; Stevenson et al., 2009). The list of animals susceptible to MAP, including non-ruminant wildlife species such as primates, carnivores, mustelids, camelids, rodents, lagomorphs, and birds around the world, has been expanding in recent years (Table 3-4). 
Table 3: Hosts of paratuberculosis other than domestic ruminants.

\begin{tabular}{|c|c|c|c|}
\hline & Species & Country & References \\
\hline \multirow[t]{2}{*}{ Primates } & Macaque (Macaca arctoides) & US & (McClure et al., 1987) \\
\hline & Mandrill (Papio sphinx) & US & (Zwick et al., 2002) \\
\hline \multirow[t]{6}{*}{ Carnivores } & Red Fox (Vulpes vulpes) & $\begin{array}{l}\text { GB } \\
\text { US } \\
\text { GR }\end{array}$ & $\begin{array}{r}\text { (Beard et al., 2001a) } \\
\text { (Anderson et al., 2007) } \\
\text { (Florou et al., 2008) }\end{array}$ \\
\hline & Feral cat (Elis catus) & US & (Corn et al., 2005) \\
\hline & Racoon (Rocyon lotor) & US & (Corn et al., 2005) \\
\hline & Striped skunk (Mephitis mephitis) & US & $\begin{array}{r}\text { (Corn et al., 2005) } \\
\text { (Anderson et al., 2007) }\end{array}$ \\
\hline & Coyote (Canis latrans) & US & (Anderson et al., 2007) \\
\hline & Brown bear (Ursus arctos) & $\mathrm{CZ}$ & (Kopecna et al., 2006) \\
\hline \multirow[t]{4}{*}{ Mustelids } & Badger (Meles meles) & GB & (Beard et al., 2001a) \\
\hline & Stoat (Mustela erminea) & GB & (Beard et al., 2001a) \\
\hline & Weasel (Mustela nivalis) & GB & (Beard et al., 2001a) \\
\hline & Feral ferret (Mustela putorius furo) & NZ & (de Lisle et al., 2003) \\
\hline \multirow[t]{4}{*}{ Camelids } & Camel (Camelus bacterianus) & US & (Thoen et al., 1977) \\
\hline & Alpaca (Vicugna pacos) & $\begin{array}{l}\text { AU } \\
\text { US }\end{array}$ & $\begin{array}{l}\text { (Ridge et al., 1995) } \\
\text { (Fecteau et al., 2009) }\end{array}$ \\
\hline & Llama (Lama glama) & US & (Belknap et al., 1994) \\
\hline & Guanaco (Lama guanicoe) & $\mathrm{AR}$ & (Salgado et al., 2009) \\
\hline \multirow[t]{4}{*}{ Other } & Armadillo (Dasypus novemcinctus) & US & (Corn et al., 2005) \\
\hline & Opossum (Didelphis virginiana) & US & $\begin{array}{r}\text { (Corn et al., 2005) } \\
\text { (Anderson et al., 2007) }\end{array}$ \\
\hline & Wild boar (Sus scorfa) & $\mathrm{CR}$ & (Kopecna et al., 2008) \\
\hline & Sicilian ass (Equus asinus) & US & (Dierckins et al., 1990) \\
\hline
\end{tabular}


Table 4: Hosts of paratuberculosis other than domestic ruminants.

\begin{tabular}{|c|c|c|c|}
\hline \multirow[t]{8}{*}{ Rodents } & Norway rat (Rattus norvegicus) & $\begin{array}{l}\text { GB } \\
\text { US } \\
\text { CR }\end{array}$ & $\begin{array}{r}\text { (Beard et al., 2001a) } \\
\text { (Corn et al., 2005) } \\
\text { (Kopecna et al., 2008) }\end{array}$ \\
\hline & Hispid cotton rat (Sigmodon hispidus) & US & (Corn et al., 2005) \\
\hline & Black rat (Rattus rattus) & GR & (Florou et al., 2008) \\
\hline & Wood mouse (Apodemus sylvaticus) & GB & (Beard et al., 2001a) \\
\hline & Vole (Mycrotis arvalis) & $\mathrm{CR}$ & (Kopecna et al., 2008) \\
\hline & $\begin{array}{l}\text { Short-tailed shrew (Blarina } \\
\text { brevicauda) }\end{array}$ & US & (Corn et al., 2005) \\
\hline & Shrew (Corcidura suaveolens) & $\mathrm{CZ}$ & (Kopecna et al., 2008) \\
\hline & House mouse (Mus musculus) & GR & (Florou et al., 2008) \\
\hline \multirow[t]{3}{*}{ Lagomorphs } & Rabbit (Oryctolagus cuniculus) & $\begin{array}{l}\text { GB } \\
\text { US } \\
\text { ES }\end{array}$ & $\begin{array}{r}\text { (Greig et al., 1999) } \\
\text { (Raizman et al., 2005) } \\
\text { (Maio et al., 2011) }\end{array}$ \\
\hline & Brown hare (Lepus europaeus) & $\begin{array}{l}\text { GB } \\
\text { CL }\end{array}$ & $\begin{array}{r}\text { (Matthews and Sargent, } \\
\text { 1977) } \\
\text { (Salgado et al., 2011) }\end{array}$ \\
\hline & $\begin{array}{l}\text { Eastern cottontail (Sylvilagus } \\
\text { floridanus) }\end{array}$ & US & (Corn et al., 2005) \\
\hline \multirow[t]{11}{*}{ Birds } & House sparrow (Passer domesticus) & US & (Corn et al., 2005) \\
\hline & European starling (Sturnus vulgaris) & $\begin{array}{l}\text { US } \\
\text { SK }\end{array}$ & $\begin{array}{r}\text { (Corn et al., 2005) } \\
\text { (Gronesova et al., 2008) }\end{array}$ \\
\hline & Common snipe (Gallinago gallinago) & US & (Corn et al., 2005) \\
\hline & Jackdaw (Corvus monedula) & GB & (Beard et al., 2001a) \\
\hline & Rook (Corvus frugilegus) & GB & (Beard et al., 2001a) \\
\hline & Crow (Corvus corone) & GB & (Beard et al., 2001a) \\
\hline & Black-headed gull (Larus ridibundus) & SK & (Gronesova et al., 2008) \\
\hline & European curlew (Numenius arquata) & SK & (Gronesova et al., 2008) \\
\hline & Ruff (Philomachus pugnax) & SK & (Gronesova et al., 2008) \\
\hline & Common cuckoo (Cuculus canorus) & SK & (Gronesova et al., 2008) \\
\hline & $\begin{array}{l}\text { Savi's warbler (Locustella } \\
\text { luscinioides) }\end{array}$ & SK & (Gronesova et al., 2008) \\
\hline
\end{tabular}

GB = Great Britain; US = United States; CZ = Czech Republic; ES = Spain; CL = Chile; SK = Slovakia. 
While gross lesions and clinical signs similar to infected cattle have been described in wild ruminants including tule elk (Cervus elaphus nannodes), red deer (Cervus elaphus hippelaphus), and fallow deer (Dama dama) (Crawford et al., 2006; Glawischnig et al., 2006; Marco et al., 2002), limited information is available in the literature regarding macroscopic lesions in non-ruminant wildlife. Previous studies reported histopathological lesions consistent with MAP in rabbits (Oryctolagus cuniculus), mice (Apodemus sylvaticus), foxes (Vulpes vulpes), weasels (Mustela nivalis), stoats (Mustela erminea), and crows (Corvus corone) (Angus, 1990; Beard et al., 2001a; Greig et al., 1999; Greig et al., 1997). Clinical paratuberculosis was also confirmed in a colony of stumptail macaques (Macaca arctoides) and in a mandrill (Papio sphinx) (McClure et al., 1987; Zwick et al., 2002). Obviously, the pathology of MAP infections in animals other than domestic ruminants is less pronounced, indicating that these animals may be dead-end hosts, serving only as potential mechanical vectors for the organism.

MAP prevalence in wildlife ranged from $1.7 \%$ to $25 \%$ in the USA (Corn et al., 2005) and from $0.03 \%$ to $85 \%$ in the UK (Beard et al., 2001a). In both studies the prevalence of MAP was higher in carnivores such as the fox (Vulpes vulpes) or the racoon (Procyon lotor) compared with prey species such as lagomorphs and rodents. There are always multiple factors involved in the course of a disease. Several host, agent, and environmental factors determine whether the pathogen is resistant or able to sustain in a certain population. Hot spots of MAP in rabbits were reported in Scotland, showing a significant relationship between the distribution of paratuberculosis in cattle and the presence of MAP in rabbits (Greig et al., 1999). A temporal distribution of MAP infections in rabbits, with a peak of $55.4 \%$ in the spring and a low of $19.4 \%$ in the summer, was also demonstrated (Judge et al., 2005), suggesting that the general size of the rabbit population may have a considerable impact on the risk of interspecies transmission. 


\subsubsection{Zoonotic aspect}

The hypothesis postulating that there is a causal link between the organism MAP and the human disease Morbus Crohn (CD) has been first suggested in 1913 (Dalziel, 1913). Since then, there is a controversy regarding the potential zoonotic role of MAP in human CD and its importance as a public health issue (Chiodini et al., 2012; Grant, 2005; Mendoza et al., 2009). CD is a rare chronic inflammatory disease appearing in the last part of the small intestine, but also manifesting itself in other parts of the gastrointestinal tract (Chamberlin and Naser, 2006; Grant, 2005). The pathogenesis of $\mathrm{CD}$ is complex and consists of interacting components such as genetic susceptibility factors, infectious agents, and immune mediated tissue injury (Quirke, 2001; Shanahan and O'Mahony, 2005). Studies indicating that CD may have a genetic link, suggest that the CARD15 gene and the XBP1 gene play a role in the disease (Kaser et al., 2008; Ogura et al., 2001). Environmental factors are also believed to be linked to Crohn's disease. Smoking has been shown to increase the risk of inflammatory diseases (Cosnes, 2004). The immune system is also believed to have an impact on CD. It is thought that $\mathrm{CD}$ is an autoimmune disease, with inflammation stimulated by an overactive $\mathrm{T}_{\mathrm{h}} 1$ cytokine response (Cobrin and Abreu, 2005) and $\mathrm{T}_{\mathrm{h}} 17$, which may have an greater importance in the disease (Elson et al., 2007). Some reports argue that more MAP can be found in patients suffering from $\mathrm{CD}$ than from healthy patients or patients with other bowel diseases (Bull et al., 2003; Naser et al., 2004; Scanu et al., 2007; Schwartz et al., 2000; Sechi et al., 2005; Singh et al., 2008). Especially immunocompromised individuals seem to be susceptible for MAP (Chiodini and Rossiter, 1996; HermonTaylor et al., 2000; Mendoza et al., 2009). The occurrence of MAP in patients does not necessarily stand for a causative disease, but may instead represent a secondary opportunistic invader manifesting in already clinically ill patients. Even though resent studies seem neither to confirm nor refute the association between MAP and CD, MAP may play a role as a public health issue and should be introduced as a potential zoonotic agent to national surveillance programs. 
Potential vehicles of transmission of MAP from cattle to humans are different food products with animal origin (Table 5). MAP was isolated from dairy products such as milk, cheese, and soft curd cheese (Clark et al., 2006; Ikonomopoulos et al., 2005; Smith et al., 2011). There is a controversy regarding the sufficient application of milk pasteurization to kill all viable MAP present in milk (Donaghy et al., 2007; O'Reilly et al., 2004; Smith et al., 2011; Stabel, 2008). Due to contamination with MAP by dissemination into the tissue or fecal contamination of the carcass, meat may be also a possible route of exposure of MAP to humans. Although reports describing MAP in meat tissue are rare, recent studies isolated MAP-DNA from the surface of skinned undressed carcasses and infectious MAP bacteria from muscle tissue of naturally infected cattle and ewes (Alonso-Hearn et al., 2009; Meadus et al., 2008). Although the relationship between MAP and CD has not been proven, a recent review suggested that the likelihood of dairy and meat products being contaminated with MAP on retail sale should not be ignored (Eltholth et al., 2009).

Table 5: Summary of MAP detection from food products.

\begin{tabular}{|c|c|c|}
\hline Product & Country & References \\
\hline \multirow[t]{5}{*}{ Pasteurized milk } & Canada & (Gao et al., 2002) \\
\hline & Czech Republic & (Ayele et al., 2005) \\
\hline & UK & (Grant et al., 2002a) \\
\hline & Ireland & (O'Reilly et al., 2004) \\
\hline & USA & (Ellingson et al., 2005) \\
\hline \multirow[t]{3}{*}{ Retail cheeses } & Greece & (Ikonomopoulos et al., 2005) \\
\hline & Czech Republic & (Ikonomopoulos et al., 2005) \\
\hline & Switzerland & (Spahr and Schafroth, 2001) \\
\hline Raw milk cheese & Switzerland & (Stephan et al., 2007) \\
\hline Soft curd cheese & USA & (Clark et al., 2006) \\
\hline \multirow[t]{3}{*}{ Meat tissue } & Canada & (Meadus et al., 2008) \\
\hline & Spain & (Alonso-Hearn et al., 2009) \\
\hline & New Zealand & (Smith et al., 2011) \\
\hline
\end{tabular}




\subsection{Diagnostic methods}

Generally, there are two categories of diagnostic methods available. One is the direct detection of MAP by cultivation or polymerase chain reaction; the other is the indirect detection of MAP by immune based diagnostic methods. Several other diagnostic methods have been suggested and used for the detection of MAP. However, many of them lack in specificity and sensitivity, due to the slow progress of infection and the different stages of immune response. Considering the complex pathobiology of MAP, it is impossible for any method to perform well during all stages of the disease.

\subsubsection{Indirect diagnostic methods}

As paratuberculosis first triggers the immune response of the host animal in different stages of the disease, various cellular and humoral responses are observed in the course of the clinical development. Detection methods based on immunology indirectly detect the organism MAP through measurement of specific immune responses. It can be distinguished between tests detecting the cell-mediated immunity and tests using humoral mediated immunity.

\subsubsection{Cell mediated immunity (CMI)}

Methods to detect cell-mediated immunity (CMI) include skin testing for delayed type hypersensitivity (Kalis et al., 2003) and measuring interferon-gamma (INF-) release after stimulation of peripheral blood mononuclear cells with specific antigens (BillmanJacobe et al., 1992; Kalis et al., 2003; Stabel and Whitlock, 2001). Two methods using the cellular immunity have been employed to detect MAP infected cattle. 


\subsection{Skin testing (ST)}

The first unspecific immune-reaction to MAP infection is cell mediated (Collins, 1996). When applying the skin test $0.1 \mathrm{ml}$ Johnin PPD (purified protein derivative), a MAP antigen, is injected intradermally. The skin thickness is measured before and after 72 hours after inoculation. A positive reaction is observed as a swelling. This test elicits positive reactions in some animals infected with MAP, but crossreactions are observed with M. avium and M. tuberculosis (Manning and Collins, 2001).

\subsection{Interferon-gamma detection (IFN- $\gamma$ )}

The gamma interferon assay test is based on the release of gamma interferon from sensitised lymphocytes which is one of the earliest detectable reactions to MAP infection. During the last decade, in-vitro tests using released gamma interferon (IFN- $\gamma$ ) as a specific way to measure cell-mediated immune (CMI) response against bovine tuberculosis and paratuberculosis have been introduced (Billman-Jacobe et al., 1992; Collins, 1994). Depending on the interpretation criteria, the reported specificity of the test varied from 67-94\% in cattle (Kalis et al., 2003). The test must be performed on freshly heparinised blood within 16 hours of collection. However, according to some authors production of IFN- $\gamma$ may be more closely related to the pathology than to the immunity of MAP (Stabel, 1996). Non-specific reactions and the time-sensitive nature of the protocol limit the diagnostic value of the IFN- $\gamma$ test (Jungersen et al., 2002).

\subsubsection{Humoral immune response}

Diagnostic tests based on detection of serum antibodies are not particularly useful for early detection, as animals do not develop an antibody response until late in the disease. Humoral immunity emerges ten to 17 months after infection, thus testing before this age should not be recommended (Lepper et al., 1989). In most diagnostic laboratories three serological tests detecting antibodies in serum of cattle infected with MAP such as the Agar gel immunodiffusion (AGID), Enzyme-linked immunosorbent assay (ELISA) and Complement Fixation Test (CFT) are used. 


\subsection{Agar gel immunodiffusion (AGID)}

Agar gel immunodiffusion (AGID) assays use serum that detects antibodies produced in response to MAP infection. The serum and a MAP antigen preparation are used as test components and placed in agar. If the serum sample contains antibodies against MAP, they bind, forming an interlaced antigen-antibody complex that precipitates in the agar. The AGID test is useful for the confirmation of the disease in clinically suspect cattle, sheep and goats (Sherman et al., 1984). The reported specificity and sensitivity of the AGID measured against histological results were $99-100 \%$ (95\% CI) and 38-56\% (95\% CI), respectively (Hope et al., 2000).

\subsection{Complement Fixation Test (CFT)}

The Complement Fixation (CF) test has been the standard test used for cattle for many years. The CF test works well on clinically suspect animals, but lacks in both sensitivity and specificity (Robbe-Austerman et al., 2006). Therefore, the test is not applied for control purposes. Nevertheless, it is often demanded by countries that import cattle and a variety of $\mathrm{CF}$ test procedures are used internationally. The CF test requires that the antigens bind to antibodies and then bind complement. Results are interpreted as follows: $4+=100 \%$ fixation, $3+=75 \%$ fixation, $2+=50 \%$ fixation, $1+=25 \%$ fixation and $0=$ complete haemolysis. A reaction of $2+$ at $1 / 8$ is regarded as positive (de Lisle et al., 1980; Robbe-Austerman et al., 2006).

\subsection{Enzyme-linked immunosorbent assay (ELISA)}

Enzyme-linked immunosorbent assayas (ELISA's) are serological tests that indirectly detect MAP infection by assaying humoral antibody responses in the host. The first ELISA detecting antibodies against MAP was developed 1978 (Jörgensen and Jensen, 1978). One study demonstrated that the ELISA has a significantly higher sensitivity and specificity than that obtained by CF test or AGID (Reichel et al., 1999). 
ELISA tests are commonly used on both, serum and milk samples, providing an effective and low cost diagnostic tool (Weber et al., 2008). Generally, those assays are rapid, easy to perform, and useful to determine specific infections in herds. However, these assays are often limited by issues of specificity and the fact that a variable immunological response is seen during different stages of infection (Collins, 1996; Kalis et al., 2002; Shin et al., 2008). Low sensitivities, particularly in the subclinical stage of infection, have in the past led to constant reassessment (Clark et al., 2008; Collins et al., 2005; Kalis et al., 2002; Shin et al., 2008). Various ELISA tests have been developed for the detection of antibodies to MAP in cattle, some of which are available commercially. Important key parameters of three commercialized ELISA tests are summarized in Table 6 (Köhler and Burkert, 2003). ELISA tests differ in used antigens, ranging from lipoarabinomannan (LAM), whole cell- to protoplasmatic antigen of MAP. LAM is specific for MAP and therefore pre-absorption with $M$. phlei is not necessary, while it is a perquisite for the other antigens in order to avoid crossreactions (Jark et al., 1997; Sugden et al., 1997). For the Svanovir using LAM sensitivity was reported to be $70 \%$ and about $50 \%$ for the Idexx and Pourqier (Harris and Barletta, 2001).

Table 6: Key parameters of three commercialized ELISAs for MAP (Köhler and Burkert, 2003).

\begin{tabular}{cccc}
\hline ELISA & Svanova & IDEXX & Pourquier \\
\hline Antigen & Lipoarabinomannan & & \\
Serum absorption & No & Yes & Yes \\
Antigen for serum absorption & No & M. phlei & M. phlei \\
& $32-53 \%$ & $0.15-0.3$ & $60-70 \%$ \\
Cut-off & $($ OD $\%)$ & $($ S/P-value $)$ & $($ OD $\%)$ \\
Specificity (\%) & $\approx 76$ & $\approx 94$ & $\approx 99$ \\
Sensitivity $(\%)$ & $\approx 70$ & $\approx 55$ & $\approx 53$ \\
\hline
\end{tabular}

It has recently been reported that several commercially available ELISAs have similar sensitivities and specificities (Collins et al., 2005). Some commercial kits offer an option of testing milk samples. The ELISA on bovine and caprine milk has been found to have specificity similar to that of the serum ELISA, but less sensitive than the blood test (Hendrick et al., 2005; Salgado et al., 2005). 


\subsubsection{Direct diagnostic methods}

\subsubsection{Ziehl-Neelsen staining (ZN)}

When infected animals shed bacteria with feces, MAP can be confirmed by the staining of MAP cells known as Ziehl-Neelsen (ZN) staining (Ris et al., 1988). A presumptive diagnosis of paratuberculosis in feces or tissue can be made if clumps (three or more organisms) of small $(0.5-1.5 \mu \mathrm{m})$, strongly acid-fast bacilli are found (Figure 15). The presence of single acid-fast bacilli in the absence of clumps indicates an inconclusive result. Even though $\mathrm{ZN}$ staining enables quick confirmation of clinical disease, this method lacks in sensitivity and specificity. The disadvantages of this test are that it does not differentiate among other mycobacterial species and only a small proportion of cases can be confirmed on microscopic examination of a single fecal sample.

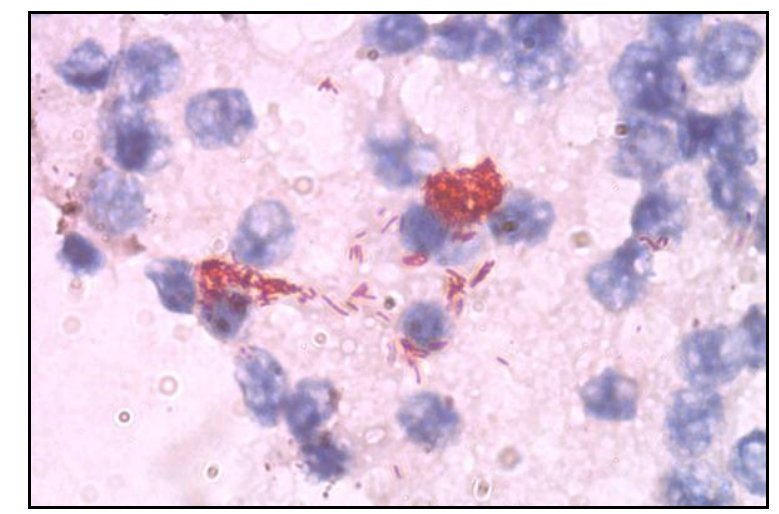

Figure 15: Visualization of MAP in lymphatic tissue (ILN) using Ziehl-Neelsen stain (Dr. Inger Völkel, Georg-August-University Göttingen).

\subsubsection{Bacteriology}

\subsection{Conventional culture}

Bacterial culture is the most common method presently used for MAP detection and generally accepted as a reference test for diagnosis of paratuberculosis. The first report of reliable cultivation of MAP was published in 1912 (Twort and Ingram, 1912). Later the evaluation of alternative culture media, assessment of decontamination solutions, and improvement to sample preparation protocols were published (Merkal et al., 1964; Merkal and Larsen, 1962). 
Important aspects of MAP cultivation are analytical sensitivity, contamination rate, the cost of the test, and the time taken to report results. Culture requires specialized media and a long cultivation period of up to 16 weeks (Whipple et al., 1991). Ovine strains are even more fastidious and difficult to cultivate than those from cattle and can take 12 months or more to show visible growth (Choy et al., 1998; Collins et al., 1993a; Juste et al., 1991). Colonies should be small, raised, firm, glistening, and pale yellow (Merkal et al., 1970) (Figure 16).
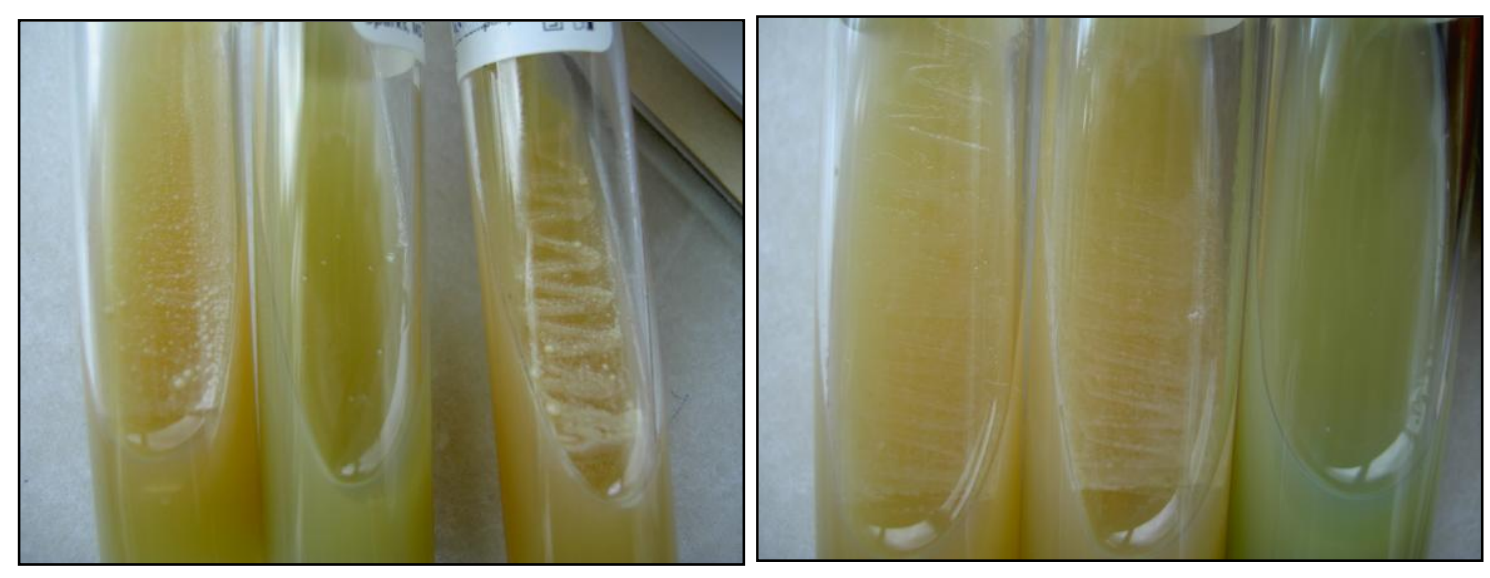

Figure 16: Bacterial culture of MAP on HEYM (Dr. Inger Völkel, Georg-AugustUniversity Göttingen).

Specimens preferentially tested by culture are feces, which are easy to collect and can be obtained from live animals (Whipple et al., 1991). The fecal culture is able to detect most animals in advanced stages of the disease, but identifies only a few animals in early stages of infection (Whitlock et al., 2000). Fecal culture is known to possess an estimated sensitivity of 30-50\% (Kim et al., 1989; Merkal, 1973; Whitlock et al., 2000) and is able to detect 50 to 100 organisms/g in feces (Merkal, 1973; Whipple et al., 1991). Comparative investigations demonstrated that MAP isolation from ileocecal lymph nodes and gut tissues is more sensitive than fecal culture (Pavlik et al., 2000; Whitlock and Buergelt, 1996). 
On solid media, two basic methods are available for the conventional culture of MAP. One method uses oxalic acid and $\mathrm{NaOH}$ for decontamination and Löwenstein-Jensen (LJ) medium and another method uses hexadecylpyridinium chloride (HPC) for decontamination in combination with Herrolds's egg yolk medium (HEYM) for growth. Sodium pyruvate was reported to stimulate the growth of MAP and is included in both the LJ and the HEYM (Eamens et al., 2000; Jorgensen, 1982; Juste et al., 1991; Kim et al., 1989). Although it has been published that HEYM supports growth of bovine isolates of MAP significantly better than LJ (Nielsen et al., 2004), recent studies have shown that certain strains grow better on LJ or Middlebrook media (de Juan et al., 2006). A previous study demonstrated that most of the small ruminant strains grew only on LJ medium without sodium pyruvate, highlighting the need to use different media when working with small ruminants samples (Juste et al., 1991).

Pyruvate enables MAP colonies to grow larger in JL medium, compensating for the inhibitory effects of antibiotics that are included in this medium (Jorgensen, 1982). In addition, the adjuvant mycobactin is needed as a growth factor and is used to distinguish MAP from the faster growing M. avium and M. intracellulare (Merkal and McCullough, 1982). However, MAP dependency for mycobactin should be interpreted with caution, as some MAP strains may grow without mycobactin J (Godfroid et al., 2005; Motiwala et al., 2004).

Contamination by faster growing microflora is reported to be a main problem in the culture of MAP from tissue and fecal samples (Gumber and Whittington, 2007; Gwozdz, 2006; Nielsen et al., 2004; Whittington, 2009; Whittington et al., 2003). Therefore, chemical decontamination prior to cultivation is a usual procedure. However, this step may increase the likelihood of false-negative culture results due to its affect on the viability of MAP. Studies reported that used chemicals for decontamination of faster growing microflora also kill or decrease the viability of MAP by 70-99\% (Grant et al., 2001; Whittington et al., 2003). Recently, it was demonstrated that the growth of the type I (sheep type) strain of MAP was completely inhibited after adding antibiotics to culture media, such as tetracycline and enrofloxacin $(5 \mu \mathrm{g} / \mathrm{ml})$, or it was delayed after adding amoxycillin. Nevertheless, no delay in growth was determined when decontamination with either $0.3 \%$ or $0.75 \%$ HPC occurred (Bower et al., 2010). 
Additionally, the ability of Mycobacterium ssp. to adapt to environmental stress by entering a viable but non-cultivable state (VBNC) has been confirmed previously (Oliver, 2005). Bacteria in the VBNC state show a wide range of metabolic metabolism including changes in the cell wall, down-regulation of DNA replication, or cell division. In animals passing through the subclinical stages of the disease, the most important environmental stress for MAP may be provided by the host's immune response. This phenomenon may explain the inability of MAP to develop colonies on culture media despite positive results in PCR assays.

\subsection{Radiometric culture (BACTEC)}

In addition, there is a technique of radiometric culture where growth in a liquid medium BACTECTM 12B (Middlebrook 7H12), supplemented with egg yolk and mycobactin is measured by recording the release of radioactive $14 \mathrm{CO}_{2}$ from palmitate, which occurs as a consequence of bacterial metabolism. This method reduces the time required for results and is considered more sensitive than the conventional culture methods on solid media for the detection of both ovine and bovine stains of MAP (Eamens et al., 2000; Whittington et al., 1999). The decontamination protocol involving double incubation of fecal samples in HPC and a mixture of antibiotics may further improve culture sensitivity (Eamens et al., 2000; Lambrecht and Collins, 1992). However, as the

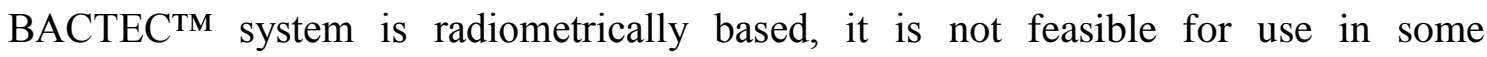
laboratories and has been replaced by alternative methods.

It is known that type I (sheep type) strains are more difficult to grow than type II (cattle type) strains of MAP (Whittington et al., 1999). The BACTEC 460 system has successfully been used to culture $\mathrm{S}$ strains from feces, tissue, and milk using a modified Bactec 12B medium (Lambeth et al., 2004; Lambrecht and Collins, 1992; Whittington et al., 1999). 


\subsubsection{Polymerase chain reaction (PCR)}

\subsection{Conventional PCR}

The invention of the polymease chain reaction (PCR) earned Kary Mullis a shared Nobel Prize in Chemistry in 1993, when the technique soon became immensely important in the field of molecular biology (Mullis and Faloona, 1987). The method of PCR relies on the enzymatically driven and temperature controlled exponential amplification of a specific target sequence in the template DNA that was previously extracted from the sample. Two short, target-specific DNA fragments (primers) are key components to enable selective and repeated amplification. Elongation occurs by acting of Taq polymerase (originally isolated from the thermophilic bacterium Thermus aquaticus).

PCR methods, which have the theoretical potential to detect one single gene copy, have made the rapid identification of MAP in clinical samples possible by reducing detection time (Englund et al., 1999; Fang et al., 2002; Ikonomopoulos et al., 2004; Motiwala et al., 2004; Motiwala et al., 2003; Rajeev et al., 2005). The most important break-through in the diagnostic of paratuberculosis was the identification of a repetitive insertion sequence (IS900), which is specific for MAP (Collins et al., 1989; Green et al., 1989a). The multicopy nature of the sequence makes it an ideal target sequence for the detection of MAP. Due to a booster effect caused by a multiple number of target sequences, a higher level of sensitivity is achieved than what can be achieved with single-copy genes as targets (Reischl et al., 2001). Several investigators established single PCR and nested PCR assays based on IS900 for the rapid detection of MAP with detection limits of 1100 genome equivalents (Table 7; Figure 17) (Bauerfeind et al., 1996; Benazzi et al., 1995; Bull et al., 2003; Collins et al., 1993c; Doran et al., 1994; Ebert et al., 1991; Englund et al., 1999; Gwozdz et al., 1997; Kanazawa et al., 1999; Millar et al., 1995; Moss et al., 1991; Riggio et al., 1997; Sanderson et al., 1992; Slana et al., 2008; Vary et al., 1990). Later, PCR assays were developed based on the sequences F57 (Herthnek and Bolske, 2006; Irenge et al., 2009; Poupart et al., 1993; Schonenbrucher et al., 2008; Slana et al., 2008; Slana et al., 2009; Tasara and Stephan, 2005), ISMAV02 (Schonenbrucher et al., 2008; Stabel and Bannantine, 2005) and 21 other MAP specific coding sequences (Bannantine et al., 2002). 
Table 7: Published PCRs for the detection of MAP based on IS900.

\begin{tabular}{|c|c|c|c|}
\hline Primer & Sequence (5'-3') & Location $^{*}$ & Reference \\
\hline $\mathrm{P} 11$ & CGTCGTTAATAACCATGCAG & $307-288$ & (Moss et al., \\
\hline P36 & GGCCGTCGCTTAGGCTTCGA & $28-49$ & 1991) \\
\hline P90 & GTTCGGGGCCGTCGCTTAGG & $22-43$ & (Sanderson et \\
\hline P91 & GAGGTCGATCGCCCACGTGA & $423-404$ & al., 1992) \\
\hline P1 & GATCGGAACGTCGGCTGGTCAGG & $664-642$ & (Collins et al., \\
\hline $\mathrm{P} 2$ & GATCGCCTTGCTCATCGCTGCCG & $447-469$ & 1993b) \\
\hline P3 & GCAGCTCGACTGCGATGTCATCG & $637-615$ & \\
\hline P4 & GGCAGCGGCTGCTTTATATTCCC & $470-492$ & \\
\hline MK5 & TTCTTGAAGGGTGTTCGGGGCC & $10-31$ & (Doran et al., \\
\hline MK6 & GCGATGATCGCAGCGTCTTTGG & $569-548$ & 1994) \\
\hline P90+ & GAAGGGTGTTCGGGGCCGTCGCTTAGG & $15-43$ & (Millar et al., \\
\hline P91+ & GGCGTTGAGGTCGATCGCCCACGTGAC & $429-403$ & 1995) \\
\hline $\begin{array}{l}\text { MP1 } \\
\text { MP2 } \\
\text { MP3 } \\
\text { MP4 }\end{array}$ & $\begin{array}{c}\text { CGCCTTCGACTACAACAAGA } \\
\text { GTGCGTTTTCGGTCGTAGTA } \\
\text { CTGGCTACCAAACTCCCGA } \\
\text { GAACTCAGCGCCCAGGAT }\end{array}$ & $\begin{array}{c}738-757 \\
1316- \\
1297 \\
782-800 \\
1095-78\end{array}$ & $\begin{array}{r}\text { (Bauerfeind et } \\
\text { al., 1996; } \\
\text { Benazzi et al., } \\
1995 \text { ) }\end{array}$ \\
\hline S204 & TGATCTGGACAATGACGGTTACGGA & $206-230$ & (Englund et al., \\
\hline S749 & CGCGGCACGGCTCTTGTT & $768-751$ & 1999) \\
\hline S347 & GCCGCGCTGCTGGAGTTGA & $349-367$ & \\
\hline S535 & AGCGTCTTTGGCGTCGGTCTTG & $558-537$ & \\
\hline IS-150 & CCGCTAATTGAGAGATGCGATTGG & $141-164$ & (Slana et al., \\
\hline IS-921 & AATCAACTCCAGCAGCGCGGCCTCG & $369-345$ & 2008) \\
\hline AV1 & ATGTGGTTGCTGTGTTGGATGG & $79-100$ & (Corti and \\
\hline AV2 & CCGCCGCAATCAACTCCAG & $376-358$ & Stephan, 2002) \\
\hline TJ1 & GCTGATCGCCTTGCTCAT & $444-461$ & (Bull et al., \\
\hline $\mathrm{TJ} 2$ & CGGGAGTTTGGTAGCCAGTA & $799-780$ & 2003) \\
\hline TJ3 & CAGCGGCTGCTTTATATTCC & $472-491$ & \\
\hline TJ4 & GGCACGGCTCTTGTTGTAGT & $765-746$ & \\
\hline
\end{tabular}




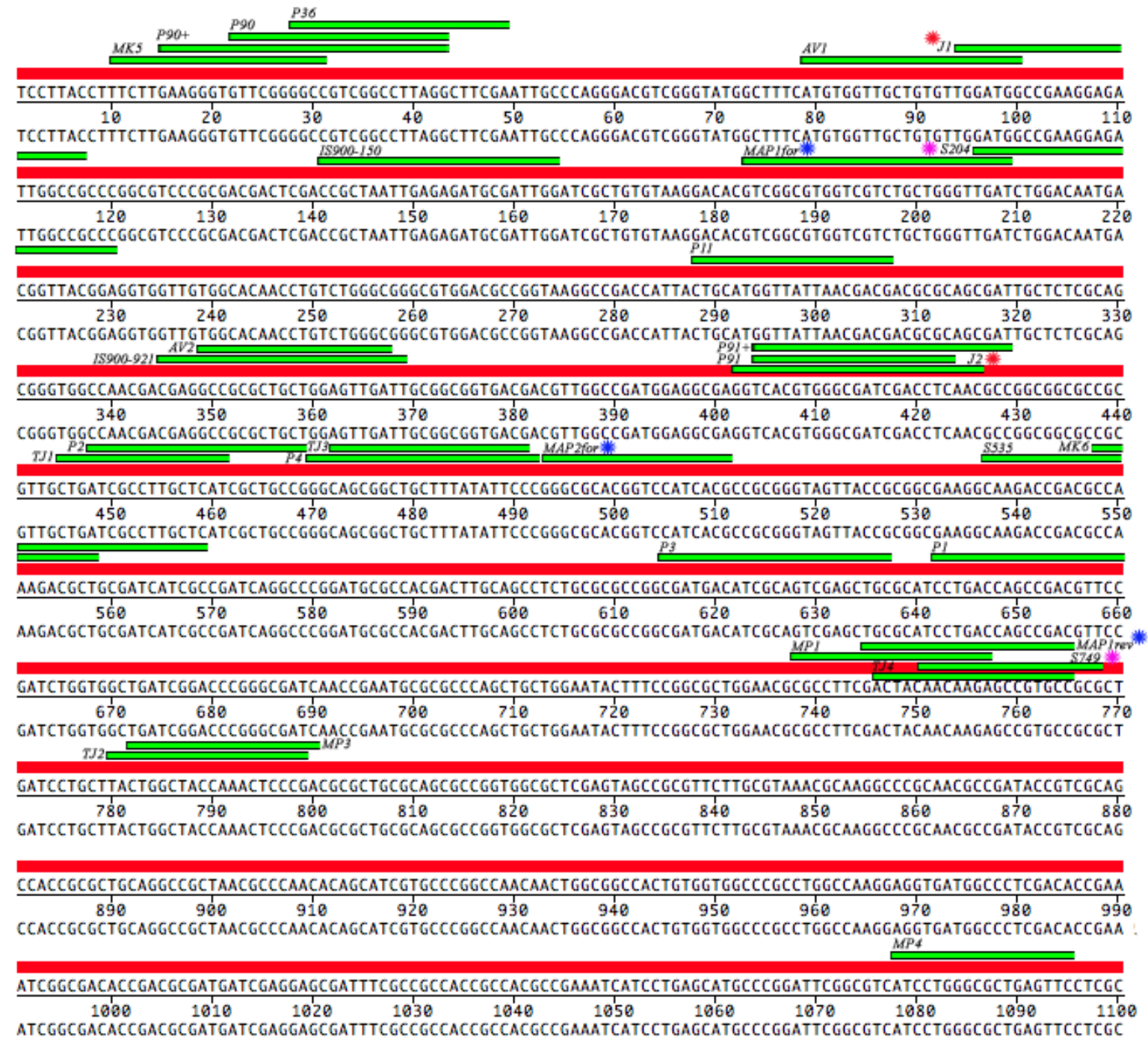

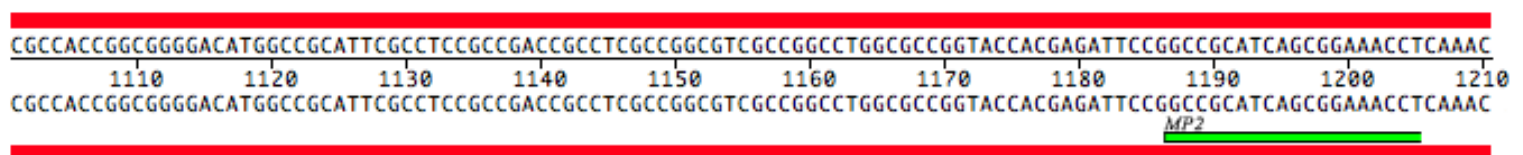

GCCCCCGACGCTACGACCGGCGCCTGCTGCGCGCCTGCTACCTGTCGGCCTTGGTCAGCATCCGCACCGACCCCTCCTCGCGCACCTACTACGACCGAAAACGCACCGAA

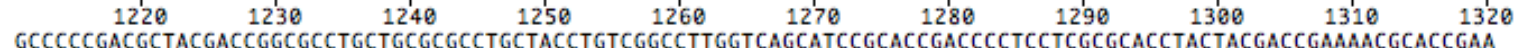

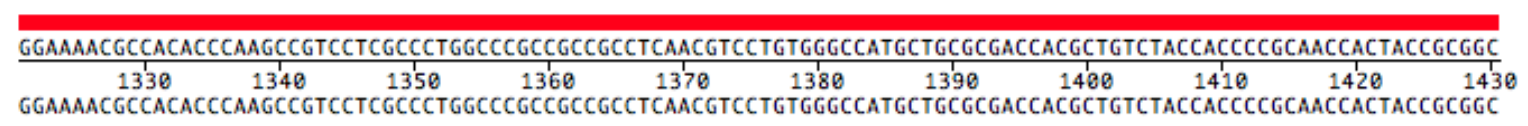

\section{GGCTTGACAACGTCATTGAGAAT \\ $1440 \quad 1450$}

GgCTTGACAACGTCATTGAGAAT

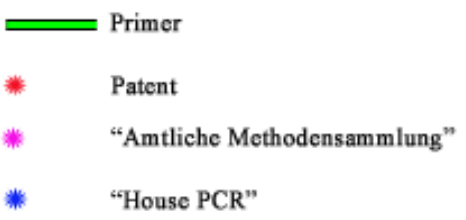

Figure 17: Graph illustrating published IS900 PCRs for the detection of MAP. 


\subsection{Real-time PCR}

PCRs are generally used as a qualitative method to evaluate biological samples. The real-time PCR (rtPCR) is a qualitative and quantitative PCR technique for DNA detection and represents an advanced version of the conventional PCR method. A wide variety of quantitative rtPCRs are applied to determine pathogen load, measure the response to therapeutic agents and characterize gene expression. In comparison to conventional PCR, rtPCR possesses several advantages, such as ability for quantification, high sample throughput, high speed, less handling of PCR products, and subsequently decreased risk of false positive results caused by amplicon carry over.

All real-time PCR systems are based on product detection by using fluorescent dyes. Most commonly SYBR Green I, HybProbe probes, and hydrolysis probes are used for the detection and quantification of DNA (Figure 18).

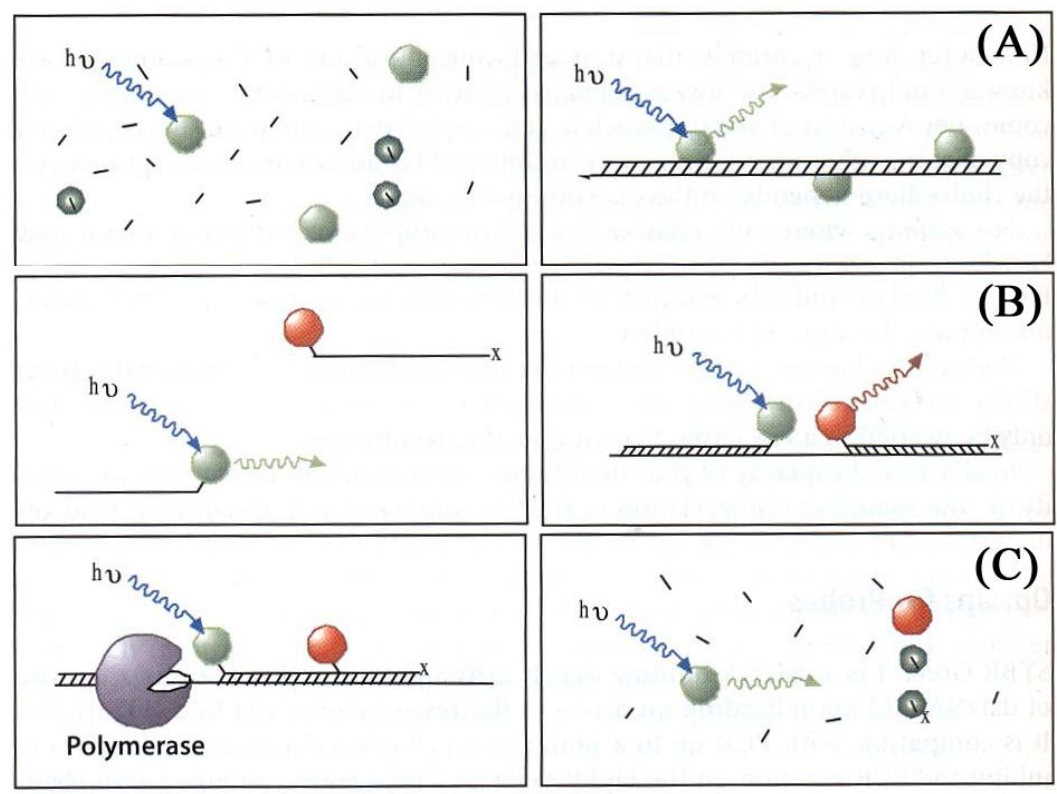

Figure 18: Detection formats for the quantitative real-time PCR. (A) SYBR Green I, (B) Hybridization probes, and (C) Hydrolysis probes (Rasmussen, 2001).

SYBR Green I is a dye that binds to all double-stranded DNA (dsDNA) molecules, regardless of sequence. When SYBR Green I dye intercalates into dsDNA, its fluorescence increases significantly. During the different stages of PCR, the intensity of this fluorescence will vary, depending on the amount of dsDNA present in the sample (Rasmussen, 2001). 
Hibridization probes are two sequence-specific oligonucleotides that are labelled with different dyes (donor and acceptor), and are added to the reaction mix along with the PCR primers. During the annealing phase, HybProbe probes hybridize to the target sequence on the amplified DNA fragment in a head-to-tail arrangement, thereby bringing the two dyes into close proximity (Rasmussen, 2001).

In Hydrolysis probe assays, traditionally called TayMan, a specific probe sequence, with attached fluorescent reporter dye and quencher dye, hybridises to the target sequence near one of the primers. When the probe is intact, the quencher dye is close enough to the reporter dye to suppress the reporter fluorescent signal (FRET). During PCR, the 5'nuclease activity of the polymerase cleaves the hydrolysis probe, separating the reporter and quencher (Rasmussen, 2001).

Several IS900 quantitative PCR tests to detect MAP-DNA have been developed (Brey et al., 2006; Herthnek and Bolske, 2006; Irenge et al., 2009; Jaravata et al., 2006; Kim et al., 2002; O'Mahony and Hill, 2004; Slana et al., 2008; Vary et al., 1990). Some IS900 rtPCR assays achieved similar or even higher sensitivities than culture (Herthnek et al., 2006). Published IS900 rtPCRs for the detection of MAP are presented in table 8 and figure 19. 
Table 8: Published real-time PCRs for the detection of MAP based on IS900.

\begin{tabular}{|c|c|c|c|}
\hline Primer/Probe & Sequence (5'-3') & Location $^{*}$ & References \\
\hline IS900/150C & CCGCTAATTGAGAGATGCGATTGG & $141-164$ & (Vary et al., \\
\hline IS900/921 & AATCAACTCCAGCAGCGCGGCCTCG & $369-345$ & 1990) \\
\hline PCR probe & AGGTTGTGCCACAACCACCTCCGTA & $249-225$ & \\
\hline F1 & TGACGGTTACGGAGGTGGTT & $218-237$ & (Kim et al., \\
\hline $\mathrm{R} 1$ & ATGCAGTAATGGTCGGCCTT & $293-274$ & 2002) \\
\hline $\mathrm{F} 2$ & AATGACGGTTACGGAGGTGGT & $216-236$ & \\
\hline $\mathrm{R} 2$ & GCAGTAATGGTCGGCCTTACC & $291-271$ & \\
\hline P1 & CCGCCCAGACAGGTTGTGCCA & $259-239$ & \\
\hline $\mathrm{P} 2$ & TCCACGCCCGCCCAGACAGG & $266-247$ & \\
\hline F1 & CGGGTATGGCTTTCATGTGGT & $65-85$ & (O'Mahony \\
\hline R1 & GTCGATCGCCCACGTGAC & $420-403$ & and Hill, \\
\hline FL & CCACCTCCGTAACCGTCATTGTCCAGA & $235-209$ & 2004) \\
\hline LC Red640 & CAACCCAGCAGACGACCACGC & $207-187$ & \\
\hline Forward & GCTGATCGCCTTGCTCAT & $444-461$ & (Brey et al., \\
\hline Reverse & CGGGAGTTTGGTAGCCAGTA & $799-780$ & 2006) \\
\hline Probe Up & GAATACTTTCCGGCGCTGGAACG & $715-737$ & \\
\hline Probe Down & GCCTTCGACTACAACAAGAGCC & $739-760$ & \\
\hline Forward & CTTGAAGGGTGTTCGG & $12-27$ & (Jaravata et \\
\hline Reverse & ACCGTGTTGGACAGAC & $254-239$ & al., 2006) \\
\hline Red 640 & GGATCGCTGTGTAAGGACACG & $163-183$ & \\
\hline Fluorescein & ACCGCTAATTGAGAGATGCGA & $140-160$ & \\
\hline MPF & CCGCTAATTGAGAGATGCGATT & $141-162$ & (Herthnek \\
\hline MPR & CCAGACAGGTTGTGCCACAA & $255-236$ & and Bolske, \\
\hline IS900 probe & ACCTCCGTAACCGTCATTGTCCAGATCA & 233-206 & 2006) \\
\hline IS900qPCRF & GATGGCCGAAGGAGATTG & $96-113$ & (Slana et al., \\
\hline IS900qPCRR & CACAACCACCTCCGTAACC & $240-222$ & 2008) \\
\hline ISqPCRTM & ATTGGATCGCTGTGTAAGGACACGT & $160-184$ & \\
\hline IS900-for & TGCTGATCGCCTTGCTCA & $443-460$ & (Irenge et \\
\hline IS900-rev & GGGCCTGATCGGCGATGAT & $580-562$ & al., 2009) \\
\hline IS900-probe & CCGGGCAGCGGCTGCTTTATATTC & $467-490$ & \\
\hline
\end{tabular}

*Accoding to the published IS900 sequence of MAP K-10 (Acc. No. NC_00294) 


\subsection{Control Measures}

Presently, there is no satisfactory treatment for paratuberculosis available (Cocito et al., 1994). Therefore, management control strategies are considered to be the most suitable tool for controlling paratuberculosis. Good calving management is the first measurement to prevent or reduce transmission within the herd. Cows should calve in clean areas, free from manure, and calves should be reared separately from the adult herd.

Regarding the paratuberculosis situation, a number of new control schemes have been developed in different countries across the world. While the exception of the Nordic countries, where strict control measures were introduced to ensure a low prevalence of infection, most control schemes are on a voluntary basis. Due to the fact that control schemes are locally organised and approaches and funding depend on the local situation, a wide variety of new schemes were issued in recent years (Behr and Collins, 2010).

Currently, there exists no national paratuberculosis control scheme in Germany. However, guidelines or "Paratuberkuloseleitlinien" issued in 2005 by the government, form the basis for a voluntary control program.

The guidelines are based on three columns:

1. Hygienic measures to prevent spreading of MAP

2. Monitoring of MAP in herds

3. Monitoring of MAP nationwide

Aims of "Paratuberkuloseleitlinien" are as follows:

1. Standardising control measures in Germany

2. Reducing clinical cases and economic losses caused by MAP

3. Preventing spread of MAP

4. Decreasing prevalence of MAP 
The identification of infected animals is primarily based on ELISA serology and culture on animals older than 24 months, and confirmed by fecal culture, PCR or histology (Rossiter and Burhans, 1996). A complementary use of both assay principles will enhance the detection of subclinical MAP infections, especially if seronegative shedders are present in a herd (Rossiter and Burhans, 1996). Negative herds are only allowed to purchase animals from other non-suspected herds. From 1998 to 2012 a management and testing program of paratuberculosis was introduced financially supported by the fund of animal epidemic in lower Saxony "Niedersächsische Tierseuchenkasse". Farmers who volunteered for the program received financial support in investigation and culling.

In The Netherlands a new programme for MAP control (Dutch Paratuberculosis Programme) was launched in January 2006. This program is based on testing milk samples of all lactating cows or serum samples of all cattle more than three years of age, at 24 month intervals by ELISA. Herds are classified according to its paratuberculosis status. "Status A" includes herds with no positive results, "Status B" includes herds from which the test-positive cattle have been removed, and "Status C" includes herds with test-positive cattle remaining in the herd (Behr and Collins, 2010).

The USA and Australia also launched the "Uniform Program Standards for the Voluntary Bovine Johne's Disease Control Program” (VBJDCP) in 2005. The current MAP control program in the USA is based on three major elements: education, management, herd testing, and classification. Education about paratuberculosis includes group workshops, discussions with producers and the herd veterinarians, as well as publications on MAP. In Australia, paratuberculosis is managed under two separate subprograms of the National Johne's Disease Control Program: the National Bovine Johne's Disease Strategic Plan and the Ovine Johne's Disease Management Plan. In endemically infected regions, the responsibility has been transferred from the government regulatory programmes to individual risk assessment and management (Behr and Collins, 2010). 


\section{Studies performed}




\section{Chapter I}

Paper published

Veterinary Microbiology

Short Communication: Detection of Mycobacterium avium ssp. paratuberculosis in Ileocaecal Lymph Nodes Collected from Elderly Slaughter Cows using a seminested IS900 Polymerase Chain Reaction

Pia Münster ${ }^{1}$, Inger Völkel ${ }^{1}$, Wilhelm Wemheuer ${ }^{1}$, Jutta Petschenka ${ }^{2}$, Wiebke Wemheuer $^{2}$, Christina Steinbrunn ${ }^{3}$, Amely Campe ${ }^{3}$, Walter J. Schulz-Schaeffer ${ }^{2}$, Lothar Kreienbrock $^{3}$, and Claus-Peter Czerny ${ }^{1 *}$

Department of Animal Sciences, Institute of Veterinary Medicine, Division of Microbiology and Animal Hygiene, Faculty of Agricultural Sciences, Georg-AugustUniversity, Burckhardtweg 2, D-37077 Göttingen, Germany ${ }^{1}$. Department of Neuropathology, Medical Center Georg-August-University, Robert-Koch-Str. 40, D37099 Göttingen, Germany². Institute of Biometry, Epidemiology and Information Processing, WHO-Collaborating Centre for Research and Training in Veterinary Health, University of Veterinary Medicine, Bünteweg 2, D-30559 Hannover, Germany ${ }^{3}$.

*Corresponding author. Mailing address: Department of Animal Sciences, GeorgAugust-University, Burckhardtweg 2, D-37077 Göttingen, Germany. Phone: +49 55139 3375. Fax: +49 55139 13513. E-mail: cczerny@gwdg.de 


\begin{abstract}
The aim of this study was to investigate the occurrence of subclinical Mycobacterium avium ssp. paratuberculosis (MAP) infections at slaughter by testing ileocaecal lymph nodes with a semi-nested IS900 PCR. Tissue samples were available within the framework of a parallel study investigating BSE-susceptibility factors in members of BSE-cohorts in the German Federal State of Lower Saxony. Ileocaecal lymph nodes were collected over a 2-year sampling period from 99 slaughter cattle of a mean age of 6.5 years (5.5 to 7.5 years). A recently developed IS900 semi-nested polymerase chain reaction (snPCR) assay offering a sensitivity of 1 genome equivalent was used for the detection of MAP-DNA. Based on this snPCR, 17 out of the 99 samples gave positive results, indicating a MAP occurrence of $17.17 \%$ in the random sample. All PCR products were sequenced for screening of polymorphisms. Nucleotide homologies of 98.5-100\% were found with respect to the MAP K10 reference sequence IS900 (GenBank: AE16958). PCR analysis of ileocaecal lymph nodes collected from slaughter cattle proved to be a suitable technique to determine MAP occurrence in the local cattle population.
\end{abstract}

Keywords: Mycobacterium avium ssp. paratuberculosis, detection, tissue PCR, slaughter cattle, ileocaecal lymph node.

\title{
Acknowledgements
}

This work was funded by the Deutsche Forschungsgemeinschaft (German Research Foundation, DFG WA Cz 47/5-1) and by the Federal Ministry of Economics and Technology (KF2484201AJ9). We are grateful to Jessica Olbrich for critical review of the manuscript. 


\section{INTRODUCTION}

Mycobacterium avium ssp. paratuberculosis (MAP) is the infectious agent of Johne's disease primarily seen in ruminants. It is characterized by a degenerative chronic granulomatous inflammation of the intestinal tract. The resulting profuse diarrhea, emaciation and progressive weight loss have considerable economic impacts on dairy and beef industry (Raizman et al., 2009).

The generation of effective paratuberculosis control programs requires reliable data on MAP prevalence. Due to its long incubation time, MAP has a complex epidemiologic profile. Clinical symptoms are first seen in animals beyond the age of 2 years. It is assumed that for every cow showing disease manifestation at least 25 other animals are infected (Whitlock and Buergelt, 1996). Current diagnostic methods detect only $15 \%$ to $25 \%$ of those subclinically infected animals. Therefore, the true MAP prevalence might well exceed current estimates.

In the past, serological methods were commonly used to estimate MAP prevalences (Nielsen and Toft, 2009). Those assays are useful to determine systemic infections of herds in mid to late stages of the disease. However, since subclinical paratuberculosis infections are characterized by low-level stimulation of the humoral immune response probably resulting in negative antibody detection, serology might lead to false prevalence ratings.

Apart from serological methods, several studies used both culture and polymerase chain reaction (PCR) to measure MAP prevalence (Cetinkaya et al., 1996; Corti and Stephan, 2002; Haghkhah et al., 2008; O'Reilly et al., 2004; Stephan et al., 2002; Wells et al., 2009). Usually, feces or milk were investigated as sample matrices. However, shedding of MAP in feces or milk often also occurs intermittently. Therefore, diagnostic tests may lead to false negative results and infected animals could represent a potential source for later infections. Direct pathogen detection by PCR or culture at the primary site of bacterial multiplication seems to be the most suitable method. Intestinal tissues and mesenteric lymph nodes are generally accepted to be the main locus of MAP colonization (Stabel et al., 2009; Wu et al., 2007). Although, different target tissues e.g. distal jejunal lymph nodes might be a more appropriate site of sampling (Sweeney et al., 2006), we preferred to test the ileocaecal lymph node because it is often recommended for this reason and easily accessible during the slaughter process (Wells et al., 2009). 
It is well-known that IS900 PCR is more sensitive testing tissue samples post mortem than testing other clinical samples, e.g. feces, ante mortem (Stevenson and Sharp, 1997). Comparative investigations demonstrated that MAP isolation from ileocaecal lymph nodes and gut tissues is more efficient than fecal culture (Pavlik et al., 2000; Whitlock and Buergelt, 1996). For that reason, PCR examination of ileocaecal lymph nodes drawn from slaughter cattle seems to be the most suitable method of determining mycobacterial prevalence. Hence, the aim of this study was to investigate the occurrence of subclinical MAP infections during slaughtering. Data were composed by testing ileocaecal lymph nodes with an IS900 PCR. The present study used material available within the framework of a parallel study investigating BSE-susceptibility factors in members of BSE-cohorts in Lower Saxony. Tissue samples were drawn at the time of slaughter from 5.5 to 7.5 year-old cattle of Northern Germany between October 2008 and September 2010. Because MAP infections are more likely detected in cattle older than 5 years, those tissue samples were considered to be adequate and consequently used for our study.

\section{MATERIALS AND METHODS}

Animals and sampling. Ileocaecal lymph nodes were drawn from slaughter cows used as control group in a parallel study performed in Lower Saxony on the identification of preclinical bovine spongiform encephalopathy and possible susceptibility factors in BSE-cohorts. This group was composed of clinically healthy animals of a mean age of 6.5 years $(5.5$ to 7.5 years, median $=6.2$ years $)$ showing any signs of paratuberculosis. The abattoir was chosen due to its strategic geographical position in the North West of Lower Saxony. Between October 2008 and September 2010, tissue samples were collected at slaughter from cattle kept in three regions containing nine rural districts of Lower Saxony. The distribution of a maximum of 100 sampled cows over three regions was estimated according to bovine BSE-cases reported between 2000 and 2008. 99 ileocaecal lymph nodes gathered during slaughtering were available for the detection of MAP. 64 samples were obtained from region 1, while 24 and 12 animals were drawn from region 2 and 3, respectively. In order to exclude the influence of breeds, only German Holsteins were investigated in this study. 
DNA extraction. DNA was extracted for PCR analysis from tissue samples using a modified protocol of the QIAamp Blood Kit (Quiagen, Hilden, Germany). Briefly, lymph node aliquots of $1 \mathrm{~g}$ were incubated for $3 \mathrm{~h}$ at $56^{\circ} \mathrm{C}$ in $560 \mu 1$ tissue lysis buffer and $40 \mu 1$ proteinase K. After adding $600 \mu 1$ lysis buffer and mixing, the samples were incubated for $10 \mathrm{~min}$ on a shaker at $70^{\circ} \mathrm{C}$. The suspensions were centrifuged for $1 \mathrm{~min}$ at $15,871 \mathrm{rcf}$, before the supernatants were transferred into new tubes and $400 \mu \mathrm{l}$ ethanol (>99.8\%) were added. The mixtures were centrifuged through a QIAamp Spin Column and washed according to the kit manual. In a final step, DNA was eluted with $200 \mu \mathrm{l}$ elution buffer of $85^{\circ} \mathrm{C}$ and stored at $-20^{\circ} \mathrm{C}$ prior to use.

Semi-nested polymerase chain reaction, agarose gel electrophoresis, and sequencing. After DNA extraction PCR reactions were performed as described elsewhere (Schneider, 2003). In other words, PCR reactions were carried out in $25 \mu \mathrm{l}$ volumes, containing $2.5 \mu \mathrm{l}$ DNA template in a reaction mixture with one Ready-To-Go ${ }^{\mathrm{TM}}$ PCR bead (Amersham Pharmacia Biotech, Freiburg, Germany), $0.5 \mu 1$ Dimethylsulfoxid (DMSO), and $0.5 \mu \mathrm{l}$ upstream and downstream primers, respectively. PCR cycling started with an initial denaturation at $95^{\circ} \mathrm{C}$ for $3 \mathrm{~min}$, followed by 30 cycles of denaturation at $95^{\circ} \mathrm{C}$ for $30 \mathrm{sec}$, primer annealing at $64^{\circ} \mathrm{C}$ for $1 \mathrm{~min}$, primer elongation at $72^{\circ} \mathrm{C}$ for $1 \mathrm{~min}$, and finished after a final extension at $72^{\circ} \mathrm{C}$ for $8 \mathrm{~min}$. The second snPCR step was performed under the same conditions using $2.5 \mu \mathrm{l}$ of the first PCR mixture as template.

The primers MAPfor1 (5'-GTC GGC GTG GTC GTC TGC TGG GTT GAT-‘3) and MAPrev (5’-GCG CGG CAC GGC TCT TGT TGT AGT C-‘3) amplified a 587 bp fragment in the first run. The primer MAPrev served as reverse primer in the second step, too. Together with the forward primer MAPfor2 (5' - CGG GCG CAC GGT CCA TCA CG'3) a $278 \mathrm{bp}$ fragment was amplified in the second step. The primers were designed to bind to highly MAP specific sites of the IS900 located between nucleotides 183 and 769 (MAP K10) ( $\mathrm{Li}$ et al., 2005) excluding the amplification of IS900-like sequences (Cousins et al., 1999; Englund et al., 2002).

After snPCR $5 \mu$ of the amplicons were mixed with $2 \mu$ sample buffer and were separated on $1 \%$ agarose gels for $1 \mathrm{~h}$ at $120 \mathrm{~V}$. Subsequently, the amplicons were stained with ethidium bromide, before PCR products were detected by visualization under UV light. 
All amplicons were cloned into the $\mathrm{pCR}^{\circledR}$ 2.1-TOPO ${ }^{\circledR}$ plasmid vector (Invitrogen, Groningen, The Netherlands) and transformed into E. coli cells (Wizard ${ }^{\circledR}$ Plus SV Minipreps Purification System, Promega, Mannheim, Germany). After plasmid preparation from two clones per MAP amplicon purified DNA was used for sequencing both strands by an ABI Prism 3730 DNA Analyzer (Applied Biosystems, Darmstadt, Germany). DNA sequences were aligned to MAP K10 IS900 reference sequence (GenBank: AE16958) using the software "MegAlign" (DNA Star, Inc., Wisconsin, USA).

\section{RESULTS and DISCUSSION}

The aim of this study was to investigate the occurrence of subclinical MAP infections in German slaughter cattle using PCR. Since the intestinal lymphatic tissue is known to be the predominant locus of MAP multiplication, the ileocaecal lymph node was selected as target for snPCR analyses. Depending on MAP-concentration either the specific $278 \mathrm{bp}$ fragment alone or the two $278 \mathrm{bp}$ and $587 \mathrm{bp}$ fragments were amplified. In 17 of the 99 ileocaecal lymph nodes MAP-DNA was detected, indicating 17.17\% MAP positive cows (Figure 1).

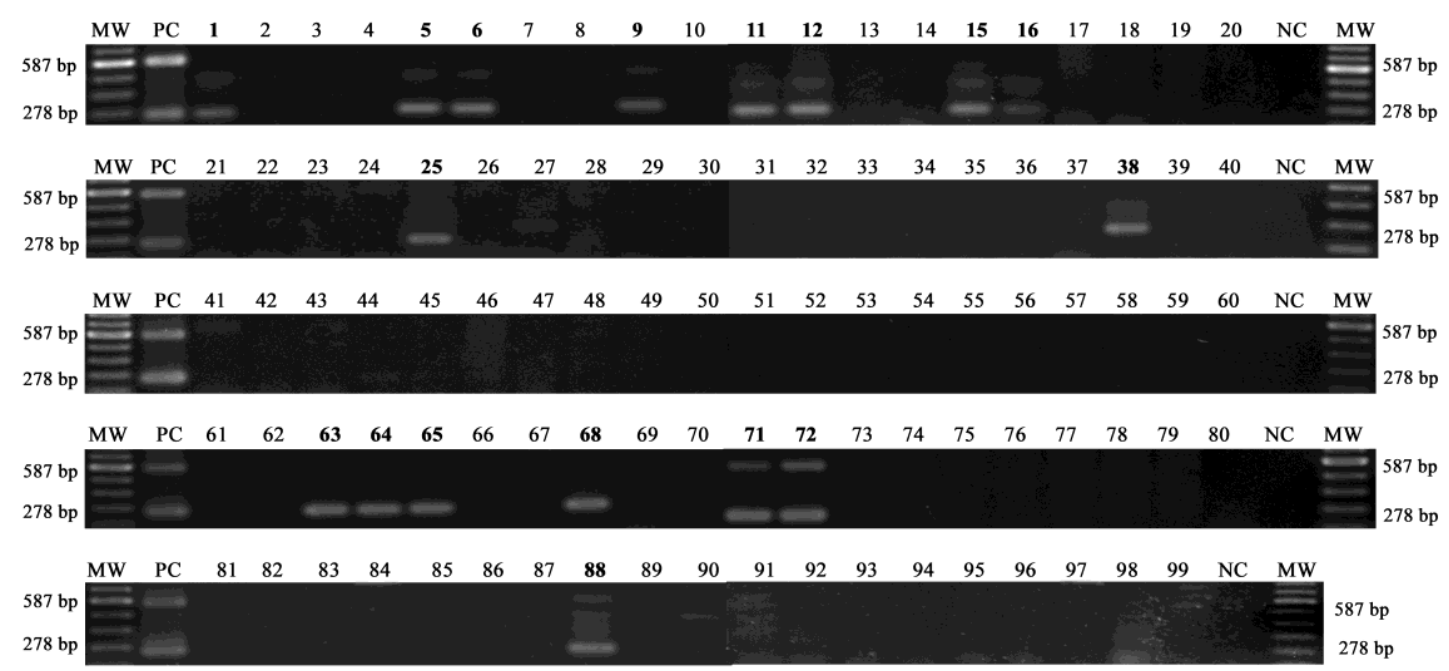

Figure 1: MAP-DNA isolated from ileocaecal lymph nodes was detected by an IS900 semi-nested PCR. Depending on MAP-concentration either the specific $278 \mathrm{bp}$ fragment alone or the two $278 \mathrm{bp}$ and $587 \mathrm{bp}$ fragments were amplified and were responsible for a positive validation. The PCR products were visualized on ethidium bromide stained agarose gels. MW, molecular weight marker; PC, positive control (MAP-DNA); Lanes 1-99, PCR positive and negative bovine ileocaecal lymph node samples; the 17 positive samples are highlighted; NC, negative control (sterile distilled water). To the left and right, sizes of PCR products are indicated. 
In 2009, 361 clinical cases of bovine paratuberculosis were reported in Germany (TSN Database - Germany). Even though most of these clinical cases have been reported in the German federal state of Lower Saxony (2009: $n=49)$, so far there is no study which estimates the MAP-prevalence in this region.

Between 1997 and 2007, four prevalence studies mainly based on serological methods investigated the MAP prevalence in Germany (Table 1) (Böttcher and Gangl, 2004; Böttcher, 1997; Donat, 2005; Hacker et al., 2004).

Table 1: Prevalence of MAP infection in German cattle based on serological methods

\begin{tabular}{|c|c|c|c|c|}
\hline Region/Rural district & ELISA & $\mathbf{n}$ & $(\%)$ & Reference \\
\hline $\begin{array}{l}\text { Mecklenburg-West } \\
\text { Pomerania }\end{array}$ & $\begin{array}{l}\text { Svanovir } \\
\text { (Sweden) }\end{array}$ & 59 & 12.2 & $\begin{array}{l}\text { (Hacker et al., } \\
\text { 2004) }\end{array}$ \\
\hline Bavaria & $\begin{array}{l}\text { HerdChek IDEXX } \\
\text { (Germany) } \\
\text { Pourquier } \\
\text { (France) }\end{array}$ & 2,748 & $\begin{array}{l}1.5 \\
0.9\end{array}$ & $\begin{array}{l}\text { (Böttcher and } \\
\text { Gangl, 2004) }\end{array}$ \\
\hline Saxony & $\begin{array}{l}\text { HerdChek IDEXX } \\
\text { (Germany) }\end{array}$ & 3,454 & 4.4 & (Donat, 2005) \\
\hline $\begin{array}{l}\text { North Rhine-Westphalia/ } \\
\text { Arnsberg }\end{array}$ & $\begin{array}{l}\text { in-house } \\
\text { (Germany) }\end{array}$ & 517 & 14.7 & (Böttcher, 1997) \\
\hline
\end{tabular}

It is worth mentioning that prevalence data calculated for North Rhine-Westphalia (14.7\%), Mecklenburg-Western Pomerania (12.2\%), Bavaria (0.9-1.5\%), and Saxony (4.4\%) seem to be quite low in comparison to the overall MAP prevalence in Europe. A recent study critically reviewed published data and re-estimated a prevalence of $20 \%$ based on serological studies carried out in France, Germany, Italy, and Turkey (Nielsen and Toft, 2009). It seems to be difficult to compare these studies with our results since the performance of ELISAs and PCR techniques might vary in different stages of a MAP infection due to their respective targets (antibodies and bacteria). Initially, paratuberculosis is a local disease restricted to gut tissues and the corresponding lymph nodes for years. Therefore, gut-associated lymphatic tissues are regarded to be the optimal sample matrix for direct pathogen detection in subclinically infected animals. Abattoir-based MAP prevalence studies using tissue PCR have already been published (Cetinkaya et al., 1996; Wells et al., 2009). MAP-prevalences of 3.5\% and 34\% were reported for South West England $(n=1553)$ and the USA $(n=330)$ using ileocaecal lymph nodes collected from adult cows. 
This is the first study using tissue PCR to determine the MAP occurrence in ileocaecal lymph nodes of German slaughter cattle. Because of the restricted random sample size used in our study the term occurrence is consequently assumed to be more appropriate than the term prevalence. The relatively high MAP occurrence of $17.17 \%$ in our study may result from the age-based pre-selection of animals. However, even though we used different matrices our results are comparable to those of a recent study analysing Suisse milk samples for MAP presence (Corti and Stephan, 2002). The examination of 1,384 bulk milk samples, drawn from different Suisse regions, provided 373 (19.7\%) positive results applying an IS900-based PCR assay (Corti and Stephan, 2002). Similarly, PCR application in bulk milk resulted in a herd-level prevalence of $11 \%$ reported in Southern Iran (Haghkhah et al., 2008).

Since the IS900 sequences of MAP are generally regarded to be highly conserved (Semret et al., 2006), these gene regions were used as targets for different molecular biological techniques. Nevertheless, unique single nucleotide polymorphisms (SNPs) were recently reviewed and DNA sequencing for the detection of polymorphisms has been considered to be promising for the differentiation of MAP strains (Castellanos et al., 2009). In order to detect polymorphisms, the $278 \mathrm{bp}$ fragments of all 17 positive samples covering nucleotide positions 492 and 769 within the 1,451 bp IS900 were sequenced in both directions. A comparison to the published MAP K10 IS900 reference sequence (GenBank: AE16958) revealed a homology degree of 98.5-100\%. While 15 isolates showed a $100 \%$ homology to the corresponding IS900 region, single nucleotide substitutions were found in two isolates (Figure 2, No. 5 and 9), at positions 504 (C $\rightarrow$ $\mathrm{T})$ and position $745(\mathrm{C} \rightarrow \mathrm{T})$. These nucleotide exchanges were found in both clones and in both strands indicating true strain specificity. Previous studies described unique SNPs in IS900 sequences (Castellanos et al., 2009). In comparison to the first published IS900 sequence (GenBank: X16293) six SNPs were found in MAP K10 (GenBank: AE16958) at positions 36, 37, 122, 123, 690, and 726. Nucleotide sequence variabilities were also confirmed between MAP-IS900 gene fragments amplified from leucocytes of cattle (GenBank: AY974345-AY974347) and sheep (GenBank: AY974348) (Bhide et al., 2006). Sequences obtained from sheep type isolates exhibited two ambiguities at base pair position 169 (T/C) and $216(\mathrm{G} / \mathrm{A})$ with respect to those of the cattle type. 
Although the high MAP specificity of the snPCR was confirmed previously by testing a collection of 17 mycobacterial reference strains as well as 16 other bacterial pathogens and commensals (Mobius et al., 2008; Schneider, 2003), we compared the sequences of the amplicons with the IS900-like sequence such as found in Mycobacterium ssp. 2333 (Englund et al., 2002). The MAP amplicons were clearly distinguishable and revealed a homology degree of 91.4-91.7\%. Even though the Mycobacterium ssp. 2333 strain was not in our collection, an amplification of the IS900-like sequence is unlikely, because of sequence homologies in the primer binding areas of $96.3 \%$ (MAP1for), $56 \%$ (MAP1rev), and 90\% (MAP2for). Furthermore, would the product sizes calculated theoretically be larger (694 bp and $329 \mathrm{bp}$ ) than in MAP strains. Therefore, sequencing of amplicons is not only a valuable tool to prove PCR specificity, but also leads to the classification of strain types. Apart from the distinction between so-called sheep- and cattle-associated MAP variants, research on genetically distinctive strains will provide data for efficient tracing-back in paratuberculosis epidemiology.

In conclusion, direct tissue sampling from abattoir cattle seems to be a suitable tool to determine the herd and inner-herd occurrence of subclinical MAP infections in a retrospective way. It is an attractive method to monitor the spread of paratuberculosis not only in elderly cattle, but probably also in the whole cattle population. In future a larger quantity of sampled animals is required to determine accurate MAP prevalence based on this technique. 


\section{REFERENCES}

Bhide, M., Chakurkar, E., Tkacikova, L., Barbuddhe, S., Novak, M., Mikula, I., 2006, IS900-PCR-based detection and characterization of Mycobacterium avium subsp. paratuberculosis from buffy coat of cattle and sheep. Vet Microbiol 112, 33-41.

Böttcher, J., Gangl, A., 2004, Mycobacterium avium ssp. paratuberculosis--combined serological testing and classification of individual animals and herds. $\mathrm{J}$ Vet Med B Infect Dis Vet Public Health 51, 443-448.

Böttcher, M., 1997, Kulturelle und serologische Untersuchungen zur Prävalenz der Paratuberkulose im Regierungsbezirk Arnsberg. Dissertation, Tierärztliche Hochschule Hannover, Germany, 99.

Castellanos, E., Aranaz, A., de Juan, L., Alvarez, J., Rodriguez, S., Romero, B., Bezos, J., Stevenson, K., Mateos, A., Dominguez, L., 2009, Single nucleotide polymorphisms in the IS900 sequence of Mycobacterium avium subsp. paratuberculosis are strain type specific. J Clin Microbiol 47, 2260-2264.

Cetinkaya, B., Egan, K., Harbour, D.A., Morgan, K.L., 1996, An abattoir-based study of the prevalence of subclinical Johne's disease in adult cattle in south west England. Epidemiol Infect 116, 373-379.

Corti, S., Stephan, R., 2002, Detection of Mycobacterium avium subspecies paratuberculosis specific IS900 insertion sequences in bulk-tank milk samples obtained from different regions throughout Switzerland. BMC Microbiol 2, 15.

Cousins, D.V., Whittington, R., Marsh, I., Masters, A., Evans, R.J., Kluver, P., 1999, Mycobacteria distenct from Mycobacterium avium subsp. paratuberculosis isolated from the faeces of ruminants possess IS900-like sequences detectable IS900 polymerase chain reaction: implications for diagnosis. Mol Cell Probes 13, 431-442.

Donat, K., Eulenberger, K. Kampfer, P., 2005, Blutserologische Untersuchungen zur Verbreitung von Mycobacterium avium spp. paratuberculosis is sächsischen Rinderbeständen. Tierärztliche Umschau 60, 497-501.

Englund, S., Bolske, G., Johansson, K.E., 2002, An IS900-like sequence found in a Mycobacterium sp. other than Mycobacterium avium subsp. paratuberculosis. FEMS Microbiol Lett 209, 267-271.

Hacker, U., Huttner, K., Konow, M., 2004, [Investigation of serological prevalence and risk factors of paratuberculosis in dairy farms in the state of MecklenburgWestpommerania, Germany]. Berl Munch Tierarztl Wochenschr 117, 140-144.

Haghkhah, M., Ansari-Lari, M., Novin-Baheran, A.M., Bahramy, A., 2008, Herd-level prevalence of Mycobacterium avium subspecies paratuberculosis by bulk-tank milk PCR in Fars province (southern Iran) dairy herds. Prev Vet Med 86, 8-13.

Li, L., Bannantine, J.P., Zhang, Q., Amonsin, A., May, B.J., Alt, D., Banerji, N., Kanjilal, S., Kapur, V., 2005, The complete genome sequence of Mycobacterium avium subspecies paratuberculosis. Proc Natl Acad Sci U S A 102, 12344-12349.

Mobius, P., Hotzel, H., Rassbach, A., Kohler, H., 2008, Comparison of 13 single-round and nested PCR assays targeting IS900, ISMav2, f57 and locus 255 for detection of Mycobacterium avium subsp. paratuberculosis. Vet Microbiol 126, 324-333.

Nielsen, S.S., Toft, N., 2009, A review of prevalences of paratuberculosis in farmed animals in Europe. Prev Vet Med 88, 1-14. 
O'Reilly, C.E., O'Connor, L., Anderson, W., Harvey, P., Grant, I.R., Donaghy, J., Rowe, M., O'Mahony, P., 2004, Surveillance of bulk raw and commercially pasteurized cows' milk from approved Irish liquid-milk pasteurization plants to determine the incidence of Mycobacterium paratuberculosis. Appl Environ Microbiol 70, 5138-5144.

Pavlik, I., Matlova, L., Bartl, J., Svastova, P., Dvorska, L., Whitlock, R., 2000, Parallel faecal and organ Mycobacterium avium subsp. paratuberculosis culture of different productivity types of cattle. Vet Microbiol 77, 309-324.

Raizman, E.A., Fetrow, J.P., Wells, S.J., 2009, Loss of income from cows shedding Mycobacterium avium subspecies paratuberculosis prior to calving compared with cows not shedding the organism on two Minnesota dairy farms. J Dairy Sci 92, 4929-4936.

Schneider, R., 2003. Entwicklung einer "seminested PCR" und einer "Real-Time-PCR" zum Nachweis von Mycobacterium avium ssp. paratuberculosis bei Rindern. Ludwig-Maximilians-Universität, München.

Semret, M., Turenne, C.Y., Behr, M.A., 2006, Insertion sequence IS900 revisited. J Clin Microbiol 44, 1081-1083.

Stabel, J.R., Palmer, M.V., Harris, B., Plattner, B., Hostetter, J., Robbe-Austerman, S., 2009, Pathogenesis of Mycobacterium avium subsp. paratuberculosis in neonatal calves after oral or intraperitoneal experimental infection. Vet Microbiol 136, 306-313.

Stephan, R., Buhler, K., Corti, S., 2002, Incidence of Mycobacterium avium subspecies paratuberculosis in bulk-tank milk samples from different regions in Switzerland. Vet Rec 150, 214-215.

Stevenson, K., Sharp, J.M., 1997, The contribution of molecular biology to Mycobacterium avium subspecies Paratuberculosis research. Vet J 153, 269286.

Sweeney, R.W., Uzonna, J., Whitlock, R.H., Habecker, P.L., Chilton, P., Scott, P., 2006, Tissue predilection sites and effect of dose on Mycobacterium avium subs. paratuberculosis organism recovery in a short-term bovine experimental oral infection model. Res Vet Sci 80, 253-259.

Wells, J.E., Bosilevac, J.M., Kalchayanand, N., Arthur, T.M., Shackelford, S.D., Wheeler, T.L., Koohmaraie, M., 2009, Prevalence of Mycobacterium avium subsp. paratuberculosis in ileocecal lymph nodes and on hides and carcasses from cull cows and fed cattle at commercial beef processing plants in the United States. J Food Prot 72, 1457-1462.

Whitlock, R.H., Buergelt, C., 1996, Preclinical and clinical manifestations of paratuberculosis (including pathology). Vet Clin North Am Food Anim Pract 12, 345-356.

Wu, C.W., Livesey, M., Schmoller, S.K., Manning, E.J., Steinberg, H., Davis, W.C., Hamilton, M.J., Talaat, A.M., 2007, Invasion and persistence of Mycobacterium avium subsp. paratuberculosis during early stages of Johne's disease in calves. Infect Immun 75, 2110-2119. 


\title{
Chapter II
}

Paper under review

Transboundary and Emerging Diseases

\begin{abstract}
A longitudinal study to characterize the distribution patterns of Mycobacterium avium ssp. paratuberculosis in semen, blood and feces of a naturally infected bull by IS900 semi-nested and quantitative real-time PCR
\end{abstract}

Pia Münster ${ }^{1}$, Inger Völkel ${ }^{1}$, Wilhelm Wemheuer ${ }^{2}$, Daniel Schwarz ${ }^{1}$, Susanne Döring $^{1 * *}$, and Claus-Peter Czerny ${ }^{1 *}$

Department of Animal Sciences, Institute of Veterinary Medicine, Division of Microbiology and Animal Hygiene, Faculty of Agricultural Sciences, Georg-AugustUniversity, Burckhardtweg 2, D-37077 Göttingen, Germany ${ }^{1}$. Division of Reproduction and Biotechnology, Department of Animal Sciences, Georg-August-University, D37077 Göttingen, Germany².

*Corresponding author. Mailing address: Department of Animal Sciences, GeorgAugust-University, Burckhardtweg 2, D-37077 Göttingen, Germany. Phone: +49 55139 3375. Fax: +49 55139 13513. E-mail: cczerny@gwdg.de

**Present address: Department of Farm Animal Behaviour and Husbandry, University of Kassel, Nordbahnhofstr. 1a, D-37213 Witzenhausen, Germany 


\section{ABSTRACT}

Johne's disease is caused by Mycobacterium avium ssp. paratuberculosis (MAP), and has been recognized as an important bacterial infection in ruminants. Although MAP has been detected in semen and within the reproductive organs of bulls, the bacterial distribution and shedding patterns are currently not well characterized. Our investigation was performed to detect and quantify MAP in feces, semen, and blood samples continuously drawn from a naturally infected but asymptomatic 18-month-old German Simmental breeding bull candidate over a period of 3 years (June 2007 November 2010). Qualitative and quantitative polymerase chain reaction (PCR) techniques were used to correlate the course and matrix specific amounts of MAP. In total, 65 sampling dates were selected. MAP was detected intermittently in all matrices with MAP-free intervals of up to 18 weeks by an IS900 semi-nested PCR. The number of MAP positive results from semen and blood samples was higher than from fecal samples. A quantitative polymerase chain reaction detected the highest MAP contents in feces $\left(10^{3}-10^{6} \mathrm{MAP} / \mathrm{g}\right)$, while lower amounts were found in semen and blood samples $\left(10^{2}-10^{5} \mathrm{MAP} / \mathrm{ml}\right)$. Although no significant agreement was calculated between the presence of MAP in feces and blood, a statistically significant positive correlation between its occurrence in semen and blood was determined $(r=0.38, p<0.05, n=29)$. The present study contributes to a more detailed understanding of MAP distribution patterns in feces, semen, and blood of a subclinically infected breeding bull candidate. It highlights the possible role of breeding bulls as a source of MAP transmission and indicates the need for further monitoring and hygienic measures to prevent the spread of the infection via semen.

Keywords: Mycobacterium avium ssp. paratuberculosis, detection, PCR, shedding pattern, semen, breeding bull.

\section{Acknowledgements}

This work was funded by the Federal Ministry of Economics and Technology under support code KF2484201AJ9. The authors wish to thank Simone Urstadt for her assistance in sample processing. We are grateful to Lynne Armstrong for completing the critical review of the manuscript. 


\section{INTRODUCTION}

Mycobacterium avium ssp. paratuberculosis (MAP) is the infectious agent of Johne's disease, a degenerative wasting disorder in ruminants causing chronic diarrhea, weight loss, decreased milk yield, reduced reproductive performance, and eventually death (Harris and Barletta, 2001). MAP is drawing increased attention worldwide due to tremendous economic losses in dairy and beef industries. The potential zoonotic role of MAP in human Morbus Crohn's (CD) is discussed controversially. Subclinically infected animals may involve even greater financial expenditure due to adverse health effects on a larger number of animals. Therefore, economic losses due to subclinical paratuberculosis are believed to be far more damaging at herd and industrial levels (Tiwari et al., 2008).

It is generally accepted that MAP is mainly transmitted to neonate calves through the fecal-oral route by subclinically or clinically infected cattle in a herd. However, vertical transmission of MAP via the uterus has been investigated before, too. The first report about a bovine fetal infection was published in 1929 (Alexejeff-Goloff, 1929), and the isolation of MAP from bovine semen was described for the first time in 1948 (Edmondson, 1948). In a recent study, the prevalence of fetal infections in cattle was determined through meta-analysis and the incidence of calves infected via the in utero route was estimated (Whittington and Windsor, 2009). The mean prevalence of infected fetuses among cows with the subclinical disease was $9 \%$ (95\% confidence limits 6$14 \%$ ), while it was increased to $39 \%$ (20-60\%) among clinically affected cows. The total prevalence of in utero infected calves among infected cows was 13\% (9-18\%). Later studies succeeded in isolating MAP from semen and reproductive organs of infected bulls and rams (Ayele et al., 2004; Eppleston and Whittington, 2001; Glawischnig et al., 2004; Larsen et al., 1981). There is evidence that the organism can survive semen conservation procedures using liquid nitrogen containing antibiotic additives (Larsen and Kopecky, 1970; Larsen et al., 1981). No further investigation has been done to prove this observation. It may be possible that bulls can be significant sources of the infection (Philpott, 1993). The MAP organism may be incorporated into a cow's reproductive tract by direct contact via mating or by indirect contact via artificial insemination. The contamination level of semen with MAP and the ability of the pathogen to elicit an infection in the host through the vaginal route are important criteria for risk assessment of MAP transmission by semen. However, the question if semen can transmit the disease via the uterus has not yet been investigated in detail (Eppleston and 
Whittington, 2001). Although MAP has been isolated from semen and reproductive organs of infected bulls (Ayele et al., 2004; Glawischnig et al., 2004; Larsen and Kopecky, 1970; Larsen et al., 1981), the bacterial distribution pattern during different stages of the infection is not well characterized in naturally infected animals.

The objective of our study was to detect and quantify MAP in feces, semen, and blood samples continuously drawn from a naturally infected 18-month-old German Simmental bull showing no clinical symptoms of paratuberculosis over a period of 3 years by qualitative and quantitative polymerase chain reaction (PCR) techniques.

\section{MATERIALS and METHODS}

Samples. In June 2007, the 18-month-old German Simmental breeding bull candidate (Bos primigenius taurus) was tested for BHV1, BVD, BT, brucellosis, leucosis, leptospirosis, paratuberculosis, and Q-fever in a routine survey as a perquisite to enter the breeding quarantine station. After the animal was tested positive for MAP antibodies by ELISA, it was subsequently retested and natural MAP infection was confirmed by ELISA and fecal snPCR. For further continuous examinations, the bull was kept isolated under quarantine conditions with constant feeding and environmental circumstances over a period of 42 months from June 2007 to November 2010. During this time, 65 sampling dates were chosen to collect fecal, semen, and blood samples, concurrently. Fecal samples were taken from the rectum using disposable gloves and transferred directly to plastic bottles. For semen collection using an artificial vagina, the bull mounted on a teaser. Both, the bull and the teaser were clipped routinely and washed regularly prior to sampling. The bull's sheath and collection tubes were washed, disinfected, and sterilized every collection day to exclude microbial contamination. Consistently, the order of sample recovery was as follows: Semen, collection, followed by blood withdrawal, and finally rectal fecal sampling. Raw semen samples were instantly placed into a thermal container and transported to the laboratory for further processing. Blood was collected under sterile precautions from the cocygeal vein. 
Culture and Ziehl-Neelsen staining. Culture was included in April 2008 to confirm a persistent MAP infection but performed only sporadically. In total, 40 fecal samples, 40 semen samples, and 2 blood samples were tested from April 2008 until November 2010 by culture. Feces, semen and blood samples were prepared immediately for bacterial culture carried out on Herrold's egg yolk medium (HEYM) obtained from Becton, Dickinson and Company (Germany). For decontamination, fecal aliquots (3 g) were suspended in $30 \mathrm{ml}$ of $0.75 \%$ hexadecylpyridinium chloride solution (HPC), whereas semen and blood fluids $(3-5 \mathrm{ml})$ were diluted with HPC using a ratio of 1:5. The samples were mixed for $30 \mathrm{~min}$ and incubated overnight at room temperature, before 0.1-0.2 $\mathrm{ml}$ of the sediment was inoculated to HEYM under sterile precautions and incubated for up to 16 weeks at $37^{\circ} \mathrm{C}$. Positive cultures were subcultured in HEYM with and without mycobactin to confirm slow growth rate and mycobactin dependence. For acid-fast staining, pre-treatment of feces and semen with Sputofluol ${ }^{\circledR}$ (Merck, Darmstadt, Germany) was carried out. The Ziehl-Neelsen staining technique was implemented under standard conditions using carbolfuchsin, hydrochloric alcohol and methylene blue.

DNA extraction. DNA was extracted from the different sample matrices (feces, semen, and blood) for PCR analysis using a modified protocol of the QIAamp Blood Kit (Quiagen, Hilden, Germany). Fecal samples were mixed 1:1 with PBS, mixed and ultrasonicated thrice for $10 \mathrm{sec}$ at $20 \mathrm{kHz}$ (Bendelin Sonoplus HD 2200, Berlin, Germany). Semen and blood samples were mixed and ultra-sonicated thrice for $10 \mathrm{sec}$ at $20 \mathrm{kHz}$ without PBS. Since a low MAP content was expected, fecal samples were divided into 4 aliquots of $1 \mathrm{~g}$ respectively. Semen and blood samples were divided into 2 aliquots $(2 \times$ $1 \mathrm{ml}$ ). Either $1 \mathrm{~g}$ or $1 \mathrm{ml}$ of the sample preparations were transferred to a tube containing $540 \mu \mathrm{l}$ lysis buffer. After mixing, the samples were incubated on a shaker at $37^{\circ} \mathrm{C}$ and $900 \mathrm{rpm}$ for $30 \mathrm{~min}$ followed by adding $60 \mu \mathrm{l}$ proteinase $\mathrm{K}$ and $600 \mu 1$ lysis buffer. The tubes were then incubated at $56^{\circ} \mathrm{C}$ for $30 \mathrm{~min}$ and for a further $15^{\circ} \mathrm{min}$ at $95^{\circ} \mathrm{C}$. All suspensions were centrifuged at $13,000 \mathrm{rpm}$ for $1 \mathrm{~min}$. The supernatants were transferred into new tubes, before $400 \mu 1$ ethanol $(\geq 99.8 \%$ ) was added and mixtures were centrifuged through a QIAamp Spin Column. Centrifugation and washing procedures were performed according to the corresponding kit manual. In a final step, DNA was eluted and resuspended in a $200 \mu$ l elution buffer at a temperature of $85^{\circ} \mathrm{C}$ and stored at $-20^{\circ} \mathrm{C}$ prior to use. 
Qualitative semi-nested polymerase chain reaction. A qualitative semi-nested PCR (snPCR) based on the insertion sequence IS900 was performed as described elsewhere (Münster et al., 2011; Schneider, 2003). Briefly, PCR reactions were carried out in $25 \mu 1$ volumes, containing a $2.5 \mu \mathrm{LNA}$ template in a reaction mixture with one Ready-ToGo $^{\text {TM }}$ PCR bead (Amersham Pharmacia Biotech, Freiburg, Germany), $0.5 \mu 1$ Dimethylsulfoxid (DMSO), and $0.5 \mu 1$ upstream and downstream primers, respectively. PCR cycling started with an initial denaturation at $95^{\circ} \mathrm{C}$ for $3 \mathrm{~min}$, followed by 30 cycles of denaturation at $95^{\circ} \mathrm{C}$ for $30 \mathrm{sec}$, primer annealing at $64^{\circ} \mathrm{C}$ for $1 \mathrm{~min}$, primer elongation at $72^{\circ} \mathrm{C}$ for $1 \mathrm{~min}$, and finished after a final extension at $72^{\circ} \mathrm{C}$ for $8 \mathrm{~min}$. The second snPCR step was performed under the same conditions using $2.5 \mu \mathrm{l}$ of the first PCR mixture as a template. The primers MAPfor1 (5'-GTC GGC GTG GTC GTC TGC TGG GTT GAT-‘3) and MAPrev (5’-GCG CGG CAC GGC TCT TGT TGT AGT C'3) amplified a $587 \mathrm{bp}$ fragment in the first run. The primer MAPrev served as a reverse primer in the second step, too. Together with the forward primer MAPfor2 (5'- CGG GCG CAC GGT CCA TCA CG'3), a 278 bp fragment was amplified in the second step. The primers were designed to bind to highly MAP-specific sites of the IS900, located between nucleotides 183 and 769 of the MAP K10 sequence ( $\mathrm{Li}$ et al., 2005), and excluding the amplification of IS900-like sequences (Cousins et al., 1999; Englund et al., 2002).

Quantitative real-time polymerase chain reaction. For quantification of MAP-DNA, the real-time PCR (rtPCR) based on the IS900 was performed as described elsewhere (Schneider, 2003). The primers MAPfor2/MAPrev amplifying the small $278 \mathrm{bp}$ of the snPCR and hybridization probes were applied. Hybridization probes were designed to hybridize side by side on the PCR product, allowing detection of specific PCR products. The oligonucleotide probes (MAP1a 5‘-CCT GAT CGG CGA TGA TCG CAG CGT CTT-FI-3‘; MAP1b 5‘-Rox-CGT CGG TCT TGC CTT CGC CGC G-P-3‘) were labeled with the fluorescent reporter dye fluorescein at the 3 ' end and with the quencher dye Rox at the 5' end. Oligonucleotides were synthesized by MWG Biotech (Ebersberg, Germany) and hybridization probes were synthesized by TIB MOLBIOL (Berlin, Germany). Amplification and fluorescence detection occurred on the Light Cycler ${ }^{\circledR} 480$ System using 96-well PCR plates (Roche Molecular Diagnostic, Mannheim, Germany). 
A total reaction volume of $20 \mu \mathrm{l}$ per well was used containing $2 \mu \mathrm{l}$ Faststart Light Cycler $^{\circledR}$ DNA Master Hybridization Probes (Roche Diagnostics, Mannheim, Germany), $2.4 \mu \mathrm{l} \mathrm{MgCl}_{2}$ stock solution $(25 \mathrm{mM}), 0.2 \mu \mathrm{l}$ upstream and downstream primers (10 pmol/ $\mu \mathrm{l}$ ), $0.4 \mu \mathrm{l}$ MAP1a probe and $0.8 \mu \mathrm{l}$ MAP1b probe, $12 \mu \mathrm{l}$ sterile water and $2 \mu \mathrm{l}$ of the extracted sample. The amplification started with an initial preincubation step at $95^{\circ} \mathrm{C}$ for $10 \mathrm{~min}$ to activate the DNA polymerase, followed by 50 cycles of $95^{\circ} \mathrm{C}$ for $10 \mathrm{sec}, 64^{\circ} \mathrm{C}$ for $10 \mathrm{sec}$, and $72^{\circ} \mathrm{C}$ for $20 \mathrm{sec}$. Fluorescence was measured within the F2/F1 channel after the annealing step of each cycle.

For the quantification of MAP-DNA isolated from feces, semen, and blood samples a MAP-DNA standard was used and titrated in $\log _{10}$ steps $(1 \mathrm{ng} / \mu \mathrm{l}$ to $1 \mathrm{fg} / \mu \mathrm{l})$. Genome equivalents detected by PCR were calculated by the MAP genome size of $4.7 \times 10^{6} \mathrm{bp}$ (Cocito et al., 1994). Considering the molecular weight of one base pair of $660 \mathrm{~g} \times \mathrm{mol}^{-}$ 1 and the Avogadro number of $6.022 \times 10^{23} \mathrm{~mol}^{-1}$, calculations resulted in one genome copy as equivalent to $5.15 \mathrm{fg}$ of DNA.

Gel electrophoresis, cloning and sequencing. After the semi-nested and real-time PCR runs, $5 \mu \mathrm{l}$ of the amplicons were mixed with a $2 \mu \mathrm{l}$ sample buffer and separated on $1 \%$ agarose gels for $1 \mathrm{~h}$ at $120 \mathrm{~V}$. After snPCR $5 \mu \mathrm{l}$ of the amplicons were mixed with a $2 \mu \mathrm{l}$ sample buffer and separated on $1 \%$ agarose gels for $1 \mathrm{~h}$ at $120 \mathrm{~V}$. Subsequently, amplicons were stained with ethidium bromide and visualized under UV light.

Two 278 bp amplicons of the fecal samples collected in August 2008 and March 2009 (Nos. 35 and 39) were cloned into the $\mathrm{pCR}^{\circledR}$ 2.1-TOPO ${ }^{\circledR}$ plasmid vector (Invitrogen, Groningen, The Netherlands) and transformed into E. coli cells (Wizard ${ }^{\circledR}$ Plus SV Minipreps Purification System, Promega, Mannheim, Germany). After plasmid preparation from two clones per MAP amplicon, purified DNA was used for sequencing of both strands by an ABI Prism 3730 DNA Analyzer (Applied Biosystems, Darmstadt, Germany). DNA sequences were aligned to IS900 GenBank entries (www.ncbi.nlm.nih.gov), using the sequence analysis software "MegAlign" (DNA Star, Inc., Wisconsin, USA). 
Enzyme-linked immunosorbent assay. Blood samples were collected concurrently with feces and semen and tested by ELISA for MAP-specific antibodies. During 2007 and 2008, a total of 35 serum samples were tested with the IDEXX-ELISA (IDEXX GmbH, Woerrstadt, Germany) according to the producer's manual. The final evaluation of serum samples was performed according to the following scheme: Serum samples < $15 \%$ negative $(-), 15 \%-<30 \%$ borderline $( \pm), \geq 30 \%$ positive $(+)$. Since 2009 , the IDEXX-ELISA was no longer available and replaced by the Pourquier-ELISA (Institut Pourquier SAS, Montpellier, France) for testing of 30 sera in 2009 and 2010. The evaluation of those serum samples was performed according to the following scheme: Serum samples $<60 \%$ negative $(-), 60 \%-<70 \%$ borderline $( \pm), \geq 70 \%$ positive $(+)$.

Statistical analysis. The Spearman's rank correlation coefficient (r) was calculated to analyze the correlation between the detection of MAP in fecal, semen, and blood samples by snPCR. The Spearman rank correlation coefficient is more robust and has been recommended if the data do not necessarily come from a bivariate normal distribution. Values of $\mathrm{p} \leq 0.05$ were considered significant for all tests. All analyzes was carried out with Microsoft Office Excel 2003 and Minitab Version 15.0 (Minitab Inc., State College, PA, USA).

\section{RESULTS}

General clinical condition of the bull during the examination period. An 18-monthold German Simmental breeding bull candidate naturally infected with MAP was investigated to characterize the distribution patterns of MAP. For monitoring the progress of the infection, samples were tested by ELISA and PCR techniques (Table 1). During the longitudinal study, the bull's general condition was good and the fecal consistency was normal. Over the whole study the overall quality of semen samples was good with volumes between 3 to $10.5 \mathrm{ml}$. Morphologically normal spermatozoa varied from 85 to $92 \%$, density was 0.4 to $1.6 \mathrm{million} / \mu \mathrm{l}$, and motility ranged from 65 to $70 \%$. The bull did not show any signs of paratuberculosis. However, it must be stated that the bull $(151 \mathrm{~cm} ; 862 \mathrm{~kg})$ remains small for his age and has shown poor growth performance. 
Table 1: Positive samples diagnosed by antibody ELISA and PCR for MAP detection in feces, semen, and blood collected from a subclinically infected bull over a period of 3 years.

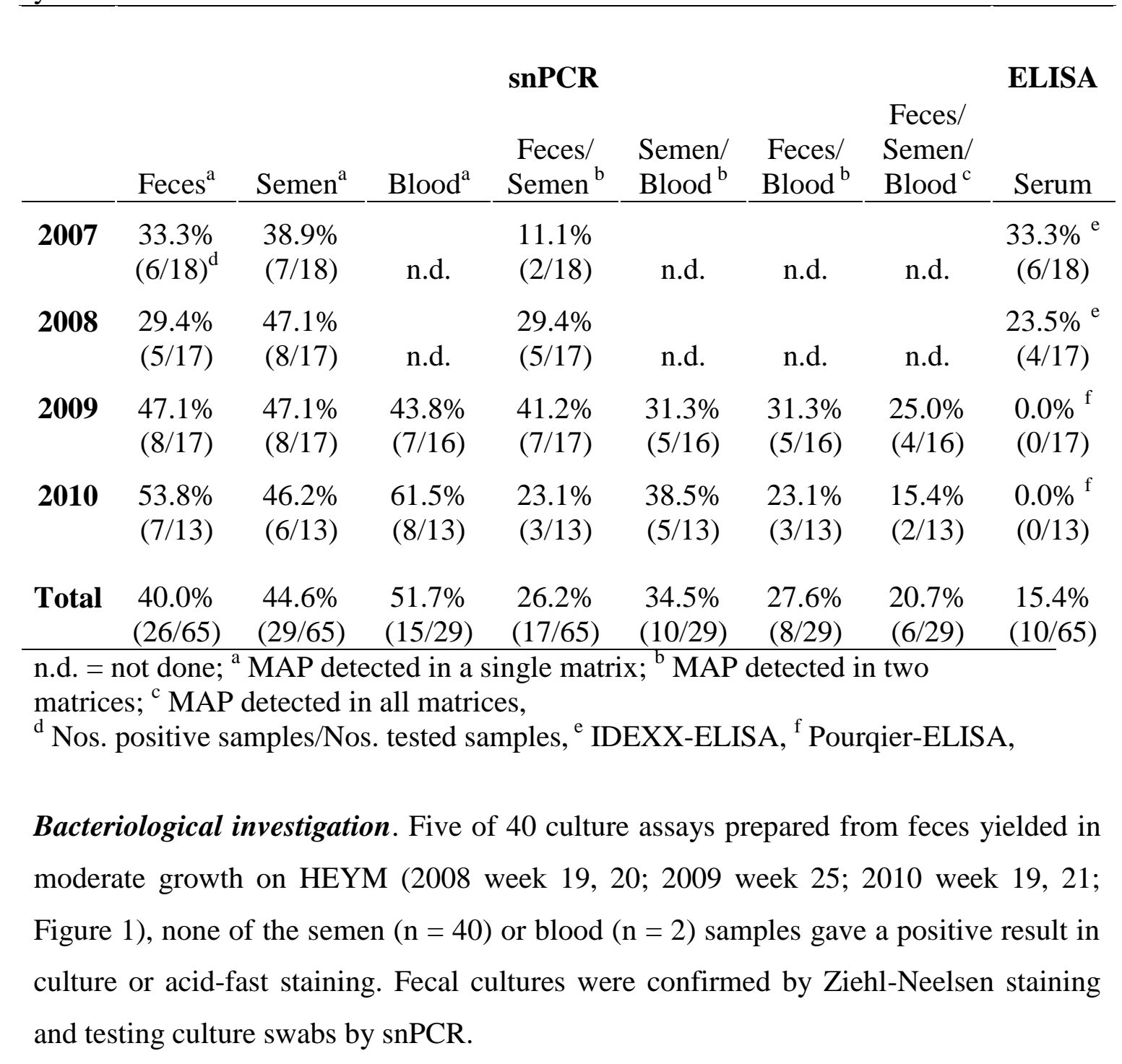

Qualitative semi-nested polymerase chain reaction. For the detection of MAP, fecal, semen, and blood samples were tested by a snPCR (Figure 1). 


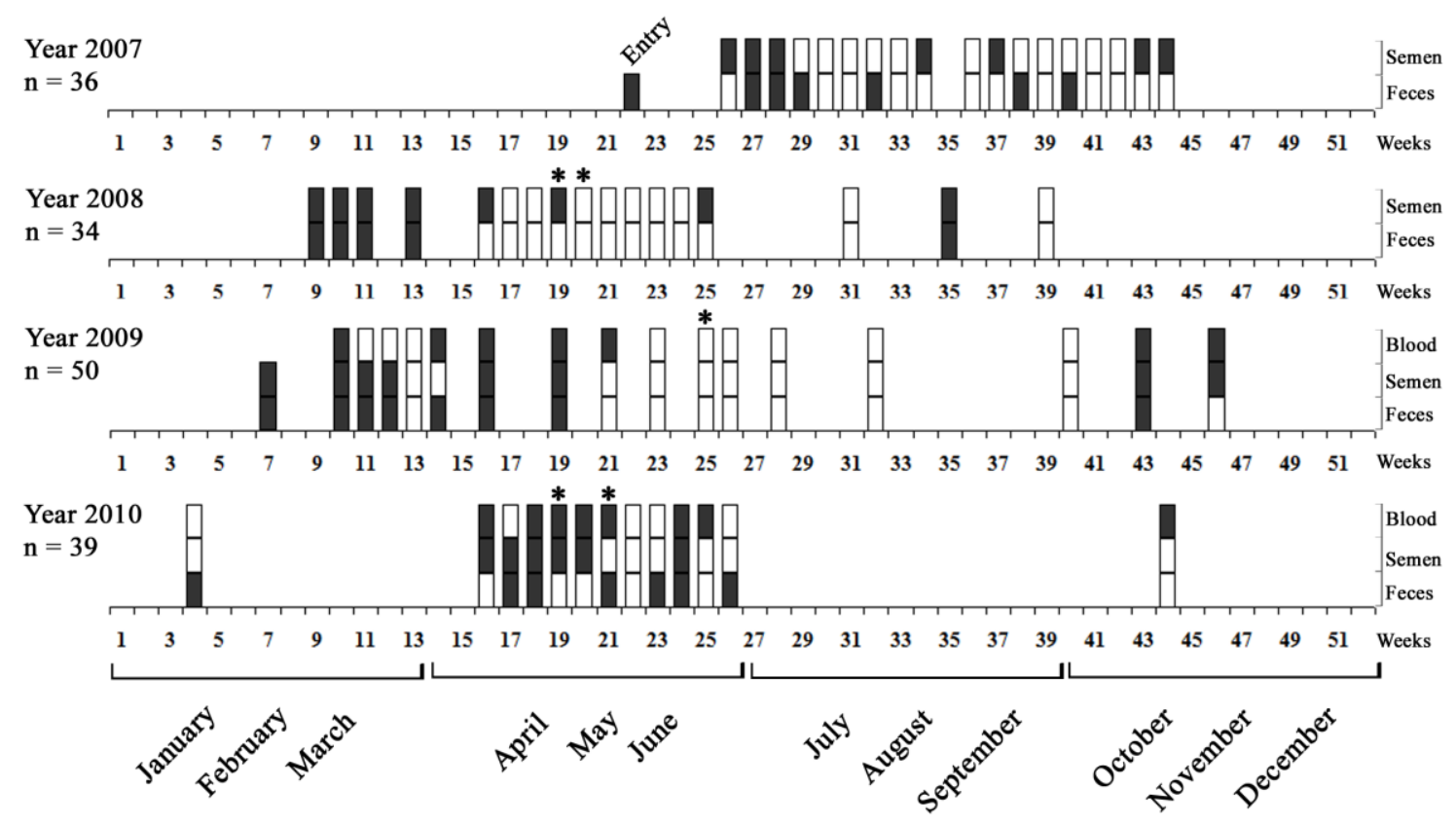

Figure 1: Over a period of 3 years (June 2007 - November 2010) 65 sampling dates were selected. The bars illustrate each sampling date with fecal sample (bottom), semen sample (central), and blood sample (top). PCR positive samples are shown in black. * Fecal culture positive.

PCR validation was done elsewhere (Möbius et al., 2008; Schneider, 2003). Depending on the MAP-concentration in the respective sample either the $278 \mathrm{bp}$ fragment alone (1 or 10 genome units) or both the $278 \mathrm{bp}$ and $587 \mathrm{bp}$ fragments ( $\geq 100$ genome units) got amplified.

In 2007, 18 fecal, semen, and blood samples were collected, respectively, over a period of 19 weeks (weeks 26-34, 36-44). The snPCR detected MAP in 6/18 (33.3\%) fecal and 7/18 (38.9\%) semen samples. Twice MAP was detected concurrently in feces and semen on weeks 27 and 28. On the remaining sampling dates MAP was not detected in any matrix (weeks 30, 31, 33, 36, 39, 41, and 42) or MAP was present in feces or semen (weeks 26, 29, 32, 34, 37-38, 40, 43-44).

In 2008, 17 fecal and semen samples, respectively, were drawn. In total, the snPCR detected 5/17 (29.4\%) positive fecal samples and 8/17 (47.1\%) positive semen samples. During the first quarter of 2008 (weeks 9-11, 13), both matrices (fecal and semen samples) investigated were tested MAP positive by snPCR. The following weeks, MAP was not present in feces, while MAP was detected thrice in semen (weeks 16, 19, 25). On week 35, MAP was identified again concurrently in feces and semen. 
In 2009, 17 sampling dates were chosen and 17 fecal, 17 semen, and 16 blood samples, respectively, were taken. In total, the snPCR detected 8/17 (47.1\%) positive fecal samples, 8/17 (47.1\%) positive semen samples, and 7/16 (43.8\%) positive blood samples. MAP occurred more frequently during the first quarter than in the middle of the year. MAP was detected concurrently in feces and semen on weeks 7, 16, 19. Subsequently, MAP was not detected in any matrix over a period of 18 weeks $(23,25-$ $26,28,32,40)$. On week 43, MAP was detected again concurrently in feces, semen, and blood. The number of PCR positive fecal samples increased from 5/17 (29.4\%) in 2008 to $8 / 17(47.1 \%)$ in 2009 whereas the number of positive semen specimens remained static $(47.1 \%)$.

In 2010, 13 sampling dates were chosen. In total, the snPCR detected 7/13 (53.8\%) positive fecal samples, 6/13 (46.2\%) positive semen samples, and 8/13 (61.5\%) positive blood samples. MAP was detected twice concurrently in feces, semen, and blood (weeks 18 and 24). Only once MAP was not detected in any matrix (week 22). Over the whole study, an increase in the number of PCR positive fecal samples from $33.3 \%$ in 2007 to $53.8 \%$ in 2010 could be recognized. From 2007 to 2008 the quantity of positive semen samples rose from $38.9 \%$ to $47.1 \%$ and remained approximately at this level until 2010 (Table 1). Although blood samples were tested by snPCR in 2009 and 2010 only, positive samples increased considerably from $43.8 \%$ to $61.5 \%$.

Quantitative real-time polymerase chain reaction. Only samples tested MAPpositive in snPCR were further quantified by a rtPCR assay, because validation data demonstrated that the rtPCR is less sensitive than the snPCR (Schneider, 2003) (Figure 2). In total, 50/70 samples were positive in the rtPCR and the amount of MAP ranged from $10^{3}$ to $10^{6}$ genome equivalents per $\mathrm{g}$ in feces and from $10^{2}$ to $10^{5}$ genome equivalents per $\mathrm{ml}$ in semen and blood. The rtPCR did not detect MAP-DNA in 6/26 fecal samples (Nos. 3, 4, 7, 12, 14, 64), 9/29 semen samples (Nos. 1, 3, 9, 11, 17, 18, $23,26,56$ ), and 5/15 blood samples (Nos. 44, 56, 58, 63, 65) taken over the whole period and giving positive snPCR results before. 


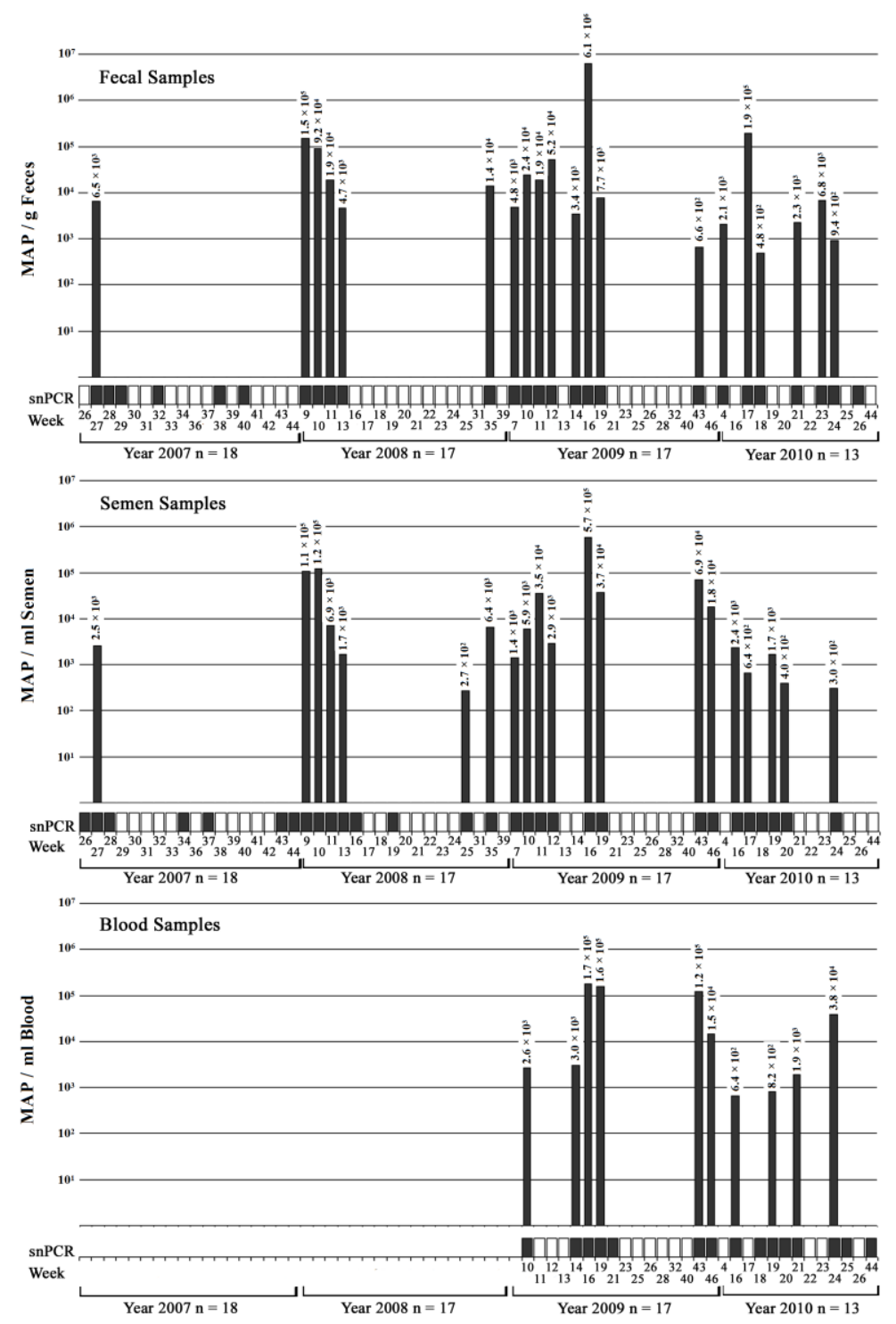

Figure 2: Detection of MAP in fecal, semen, and blood samples by quantitative realtime PCR. The concentration of MAP genomes present in feces, semen, and blood is stated above each bar. The corresponding results determined by snPCR are presented underneath. PCR positive samples are displayed in black.

In 2007, MAP was detected in only $1 / 6$ fecal and 1/7 semen samples (No. 2; week 27) with $6.5 \times 10^{3} \mathrm{MAP} / \mathrm{g}$ feces and $2.5 \times 10^{3} \mathrm{MAP} / \mathrm{ml}$ semen by rtPCR. In 2008, the $\mathrm{rtPCR}$ detected MAP in semen and feces four times in a row (No. 19-22; weeks 9-11, 13). In feces, the amount of MAP dropped within 5 weeks from $1.5 \times 10^{5} \mathrm{MAP} / \mathrm{g}$ (No. 19; week 9) to $4.7 \times 10^{3} \mathrm{MAP} / \mathrm{g}$ (No. 22, week 13). Similarly, the amount of MAP in semen dropped from $1.1 \times 10^{5} \mathrm{MAP} / \mathrm{ml}$ (No. 19; week 9) to $1.7 \times 10^{3} \mathrm{MAP} / \mathrm{ml}$ (No. 22, week 13) followed by a snPCR positive, but rtPCR negative sample (No. 23). In 2009, a notable peak of MAP genome equivalents was recognized in all the three matrices at the 
same time (No. 42; week 16) with $6.1 \times 10^{6} \mathrm{MAP} / \mathrm{g}$ feces, $5.7 \times 10^{5} \mathrm{MAP} / \mathrm{ml}$ semen, and $1.7 \times 10^{5} \mathrm{MAP} / \mathrm{ml}$ blood. Four weeks later MAP contents had declined in feces, semen, and blood $\left(7.7 \times 10^{3} \mathrm{MAP} / \mathrm{g}\right.$ feces, $3.7 \times 10^{4} \mathrm{MAP} / \mathrm{ml}$ semen, and $1.6 \times 10^{5}$ MAP/ml blood). In 2010, the amount of MAP in semen decreased from $2.4 \times 10^{3}$ $\mathrm{MAP} / \mathrm{ml}$ (No. 54; week 16) to $3.0 \times 10^{2} \mathrm{MAP} / \mathrm{ml}$ (No 62; week 24). In contrast to semen, the amount of MAP in blood increased from $6.4 \times 10^{2} \mathrm{MAP} / \mathrm{ml}$ (No. 54; week 16) to $3.8 \times 10^{4} \mathrm{MAP} / \mathrm{ml}$ (No 62 ; week 24 ), but never caught up with values seen in 2009. Although the amount of MAP in blood increased, the following two samples were rtPCR negative (No. 63-64; week 25-26).

Sequencing of the amplicons. Specificity of PCR amplifications (587 bp and $278 \mathrm{bp}$ ) was confirmed by gel electrophoresis. The high MAP specificity of the snPCR was confirmed previously by testing a collection of 17 mycobacterial reference strains as well as 16 other bacterial pathogens and commensals (Möbius et al., 2008; Schneider, 2003). However, for further identity confirmation, two $278 \mathrm{bp}$ amplicons of the fecal samples collected in August 2008 and March 2009 (Nos. 35 and 39) were cloned into the $\mathrm{pCR}^{\circledR}$ 2.1-TOPO ${ }^{\circledR}$ plasmid vector, sequenced, and aligned to the MAP K10 IS900 reference sequence (GenBank: AE16958). Nucleotide homologies of 100\% were ascertained for this fragment covering nucleotide positions 492 and 769 within the IS900.

Serological investigations. In 2007, 18 sera were tested by the Idexx-ELISA (Figure $3)$.

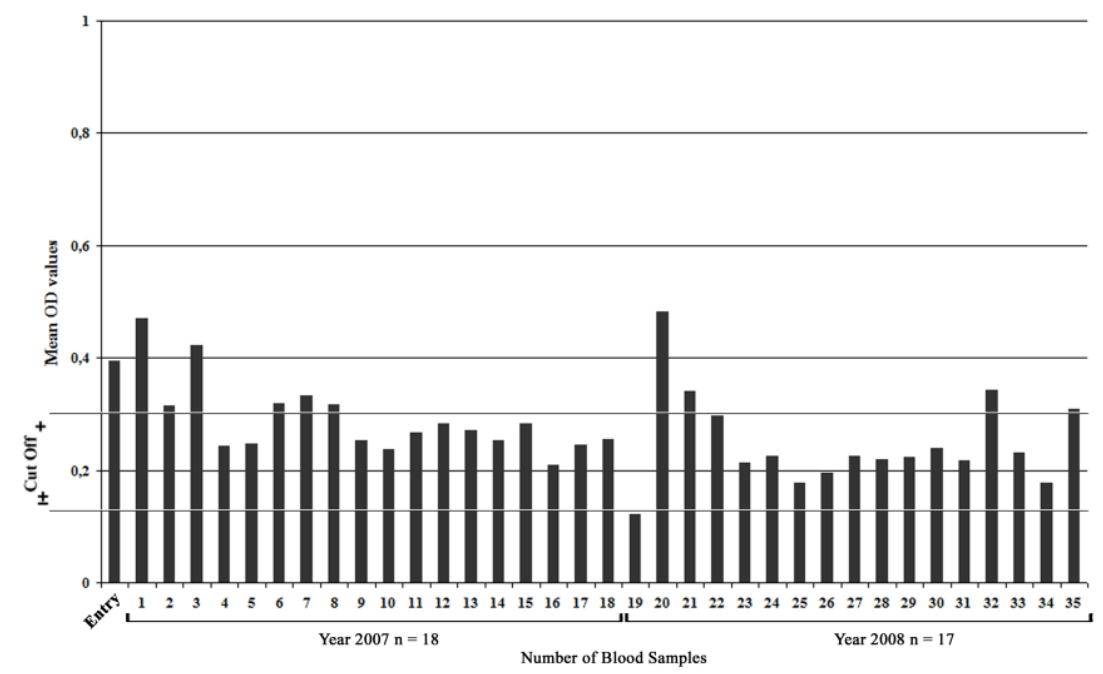

Figure 3: Antibody responses detected by the Idexx-ELISA in 2007 and $2008(\mathrm{n}=35)$. The final evaluation of serum samples was performed according to the following scheme: Serum samples $<0.15$ negative $(-), 0.15-<0.3$ borderline $( \pm), \geq 0.3$ positive $(+)$. 
In $6 / 18(33.3 \%)$ serum samples a humoral immune response to MAP infection was detected intermittently with OD values ranging from 0.314 to 0.471 (weeks 26-28 and 31-33). In 2008, the Idexx-ELISA detected MAP-antibodies in 4/17 (23.5\%) sera with OD values ranging from 0.309 to 0.482 (week 10-11, 25, and 39). Although, one serum was tested negative by the Idexx-ELISA, the remaining 24 sera (12/18 in 2007; 12/17 in 2008) were classified to be borderline with OD values from 0.178 to 0.297 . In 2009 , the Idexx-ELISA was no longer available and had to be replaced by the Pourquier-ELISA. No antibody response could be detected with OD values from 0.077 to 0.420 at any time in the 30 samples tested in 2009 and 2010.

Statistical analysis of results determined by SnPCR and ELISA. To analyze the correlation between MAP-shedding in course of the disease and matrix specific contents of MAP, the Spearman's rank correlation coefficient (r) was calculated (Table 2).

Table 2: Correlation among three matrices for detection of MAP by PCR.

\begin{tabular}{cll}
\hline Blood & Feces & Semen \\
\hline r & 0.03 & 0.38 \\
p-value & 0.864 & $0.041^{*}$ \\
n & 29 & 29 \\
Semen & & \\
r & 0.34 & \\
p-value & $0.005^{*}$ & \\
n & 65 & \\
\hline
\end{tabular}

${ }^{*}$ Statistically significant $(\mathrm{p}<0.05)$.

While MAP in feces did not correlate with MAP in blood $(\mathrm{r}=0.03 ; \mathrm{p}>0.05, \mathrm{n}=29)$, the correlation of MAP presence in feces and semen was statistically significant $(\mathrm{r}=0.34 ; \mathrm{p}<0.05, \mathrm{n}=65)$. There was a slightly higher correlation between dichotomous results obtained from semen and blood $(\mathrm{r}=0.38, \mathrm{p}<0.05, \mathrm{n}=29)$. In total, $40 \%(26 / 65)$ of the fecal samples, $44.6 \%$ (29/65) of the semen samples, and $51.7 \%$ $(15 / 29)$ of the blood samples were tested positive by snPCR (Table 1). The number of MAP positive results from semen or blood samples was, on average, higher than from fecal samples. On 17 days, MAP was detected concurrently in feces and semen, whereas MAP presence was identified twelve times exclusively in semen and nine times exclusively in feces. On 6 days, MAP was detected concurrently in all the three matrices feces, semen, and blood. As we tested only snPCR positive samples by rTCR, we did not calculate correlations between dichotomous results obtained by rtPCR. 
Dichotomous results by Idexx-ELISA tested in 2007 and 2008 correlated with results determined by snPCR. Correlations between MAP occurrence in feces and MAPantibody detection (OD value $>0.3)$ in blood $(\mathrm{r}=0.26, \mathrm{p}<0.05, \mathrm{n}=29)$ as well as between MAP presence in semen and MAP-antibody detection in blood $(r=0.23$, $\mathrm{p}<0.05, \mathrm{n}=29$ ) were significant.

\section{DISCUSSION}

Fecal-oral transmission of MAP is commonly accepted to be the dominant cause of paratuberculosis in livestock. However, MAP may also be transmitted between cattle via semen either by mating or artificial insemination (Buergelt and Williams, 2004; Sweeney, 1996). Despite the concern that MAP could be present in semen of breeding bulls, the risk of MAP transmission by semen in vivo has never been assessed. At the present time, little information is available in the literature regarding the distribution and shedding profile of MAP. Therefore, the scope of the current study was to determine the presence and quantity of MAP in feces, semen, and blood of a naturally and subclinically infected breeding bull candidate via semi-nested and real-time PCR.

It is generally accepted that an infected animal enters a silent phase for two or more years, during which MAP is not detectable in feces (Chiodini et al., 1984). According to our study, MAP in bovine feces and semen was already present at the age of 18 months. This being an unusual event for an animal at such a young age, recent case studies observed fecal shedding of MAP even in eight-month-old calves and in cattle prior to the age of two years (Antognoli et al., 2007; Weber et al., 2010). Therefore, the assumption that young stock is not infectious has to be reconsidered. Over the period of our investigation, MAP was detected intermittently rather than continuously including long periods of MAP absence. It was demonstrated that the maximum amount of MAP in rtPCR was greater in feces than in semen. A statistically significant weak-moderate correlation between the patterns of MAP presence in these two matrices was noticed. MAP was also detected intermittently in blood samples. This phenomenon has been demonstrated previously in the blood of ruminants infected clinically and subclinically (Barrington et al., 2003; Buergelt and Williams, 2004; Gwozdz et al., 2000; Juste et al., 2005), indicating that viable MAP bacteria in the blood may be responsible for disseminating the infection within the body. It is known that infected macrophages can carry MAP from the peripheral blood to other sites of the body (Ayele et al., 2004; Merkal, 1984). Uterus, fetus, mammary glands, and testes seem to be target tissues for 
the ongoing infection. Despite of the poor correlation between the presence of MAP in feces and blood, there was a statistically significant positive correlation in our study between MAP occurrence in semen and blood, indicating the association that further colonization occurs via the blood stream. However, MAP detection in blood samples seems to be a rare event (Bower et al., 2010; Pinedo et al., 2008) and the presence of DNA does not indicate, whether bacteria are viable or not. Since the scope of this study was not to compare PCR and culture, culture was carried out only sporadically between 2007 and 2010. Only five of 40 fecal samples gave positive results in culture. However, culture and snPCR disagreed in four of these five cases. Considering the bull being a naturally low shedder and taking the cluster formation of MAP within natural samples into account, it is explainable that these two different assays may give controversy results under those conditions. Due to its high sensitivity and easy performance, the method of choice for direct pathogen detection in feces and semen of breeding bulls is PCR, especially if carried out in matrices with low amounts of MAP. While selected PCR-positive fecal samples gave positive results in culture, too, isolation of MAP from semen or blood samples by culture was not successful due to a lack of clearly visible colonies on HEYM. MAP growth in culture by standard procedures is obviously difficult for matrices such as semen and blood, as there is very little information available from the literature. In former studies, MAP was isolated from only 1 of 7 blood samples collected from clinically infected cattle (Koenig et al., 1993). Two publications are available culturing MAP from bovine semen. In the first study MAP was detected in only 8 of 31 cultures of semen samples collected from a bull showing clinical signs over a period of 21 months (Larsen et al., 1981). In the second study culture was successful in only 1 of 100 semen samples from a subclinically infected bull (Ayele et al., 2004). The ability of Mycobacterium ssp. to adapt to environmental stress by entering a viable but non-cultivable state (VBNC) has been confirmed previously (Oliver, 2005). Bacteria in the VBNC state show a wide range of metabolic modifications including changes in the cell wall, down-regulation of DNA replication, or cell division. In animals passing subclinical stages of the disease, the most important environmental stress for MAP may be provided by the host's immune response. This phenomenon may explain the inability of MAP to develop colonies on culture media despite of positive results in PCR assays. 
Generally, it can be concluded that a diseased animal shedding $>10^{8}$ CFU MAP per day in feces contributes significantly to environmental contamination (Eamens et al., 2008). However, transmission among individuals or herds occurs mainly from a variable and unknown number of subclinically infected animals showing a shedder state. A quantitative rtPCR assay indicated that over the period of the investigation of the subclinically infected bull $10^{3}-10^{6} \mathrm{MAP} / \mathrm{g}$ feces, $10^{2}-10^{5} \mathrm{MAP} / \mathrm{ml}$ semen, and $10^{2}-10^{5}$ $\mathrm{MAP} / \mathrm{ml}$ blood were detectable. Comparatively, in a previous study with a naturally infected Piedmont breeding bull MAP concentrations from $10^{5}-10^{7}$ IS900 copies/g feces, $10^{2}-10^{4}$ IS 900 copies $/ \mathrm{ml}$ semen, and $10^{1}-10^{2}$ IS900 copies $/ \mathrm{ml}$ blood were found (Khol et al., 2010). Depending on the stage of the disease, MAP is shed in feces at various levels (Nielsen and Toft, 2006). Animals are commonly categorized corresponding to the number of colonies seen on solid media. In the literature, low shedders yielded in <10 CFU/tube and high-shedders in >50 CFU/tube (Wells et al., 2006). Other authors categorize shedders according to bacterial load per gram feces. Low shedders yield in $10^{3}-10^{5} \mathrm{MAP} / \mathrm{g}$ and high-shedders reach $10^{6}-10^{8} \mathrm{MAP} / \mathrm{g}$ (Eamens et al., 2008). Hence, according to the rtPCR the examined bull could be categorized into the level of low shedders. This assumption is underpinned by a low number of culture positive fecal samples and low concentrations of MAP-DNA in feces. Depending on MAP-concentration either the specific $278 \mathrm{bp}$ fragment alone or the two $278 \mathrm{bp}$ and $587 \mathrm{bp}$ fragments were amplified. In most of the samples taken from the bull, only the 278 bp band was visible in the agarose gels after snPCR, indicating low amounts of genome equivalents per sample. Furthermore, the rtPCR did not show for all specimens tested positive by snPCR an amplification curve. From the validation data it is also known that the rtPCR is less sensitive than the snPCR (Schneider, 2003), therefore, samples which were tested negative by the rtPCR assay contain MAP below its detection limit. Although endogenous systemic pathways are not well understood, it is known that the risks of MAP infections are age-dependent. While the infectious dose for neonates is considered to be low, it is quite high for adults. Early studies reported doses including $10^{3}$ MAP CFU/g (Gilmour, 1965), and 10 $60^{6}-10^{8}$ MAP CFU (Jorgensen, 1982; Whittington et al., 2000) to be infectious. Another review suggested a dosage of $5.0 \times 10^{1}-10^{3} \mathrm{CFU}$ in order to be infective in young calves (Chiodini, 1996). Experimental studies demonstrated that doses of $1.5 \times 10^{6}$ MAP CFU given orally to 21-day-old calves resulted in MAP infection of multiple tissues (Sweeney et al., 2006). Even though this study presents only data from one bull our results indicate that 
subclinically infected cattle may contain up to $6.1 \times 10^{6} \mathrm{MAP} / \mathrm{g}$ feces, $5.7 \times 10^{5}$ $\mathrm{MAP} / \mathrm{ml}$ semen, and $1.7 \times 10^{5} \mathrm{MAP} / \mathrm{ml}$ blood. Regarding artificial insemination, the minimal dose to infect a cow has not yet been investigated. Due to the small amount of MAP in semen, it has been argued that the transmission of MAP via semen is unlikely (Buergelt and Williams, 2004; Philpott, 1993). Although PCR verifies only the presence of DNA and does not indicate whether bacteria capable of infection, our results support the hypothesis that raw semen of subclinically infected bulls might contain $10^{3}-10^{5}$ $\mathrm{MAP} / \mathrm{ml}$, and can therefore pose a risk for contamination of the bovine uterine environment if MAP survives semen conservation procedures. Moreover, there has been evidence that serving adult cows with semen containing low amounts of MAP leads to hypersensitivity and abortion after performing the Johnin skin test (Merkal et al., 1982). Comparable to fecal shedding, the pattern and level of MAP presence in semen may differ between individuals at various stages of the disease.

Detectable antibody levels are present from mid to late stages of subclinical infections and ELISAs may give false-negative results in the early stage of the disease due to low detection limits. In our study, only 10 of 35 blood samples collected during 2007 and 2008 were positive in the Idexx-ELISA. With the understanding that a MAP infection is progressive, changing from a local to a systemic stage, it can be assumed that antibody responses in older animals will be found at a higher frequency. Although 15 of 29 blood samples collected during 2009 and 2010 were tested positive by PCR with MAP concentrations ranging from $10^{3}-10^{5}$ genome equivalents $/ \mathrm{ml}$ blood, the PourquierELISA did not detect humoral responses at any time. This can be explained by the fact that the new ELISA generation was developed under the prerequisite of $99 \%$ specificity, taking into account the risk that the overall sensitivity might be reduced. Indeed, previous studies reported that the Pourquier-ELISA is less sensitive compared to former commercial serum ELISAs (Collins et al., 2005; Dieguez et al., 2009). MAPantibodies are generally regarded to be detectable prior to the onset of bacterial shedding, assuming that a positive ELISA result might be a valuable tool to predict that an animal would subsequently become infectious (Nielsen, 2008). However, this assumption does not consider seronegative shedders. In our study, the bull showed repeatedly absent humoral antibody responses while 22 of 30 fecal, semen, and blood samples, respectively, collected during 2009 and 2010 were tested positive in at least one matrix by PCR. When blood samples with serological borderline ELISA percent values were regarded negative the agreement between ELISA and fecal snPCR was 
poor $(\mathrm{r}=0.26, \mathrm{p}<0.05)$. These results agree with a recent study testing 33 cows suspected to be infected with MAP and 30 cows classified as MAP free by three commercial serum ELISAs $(\kappa=0.02)$ (Khol et al., 2011). The reason for more frequent positive PCR than serological test results is probably due to paratuberculosis being mainly a local disease in the subclinical phase remaining restricted over years to the gut tissues. Therefore, MAP diagnosis cannot rely on a single test or particular matrix.

In conclusion, this study predominantly demonstrated that MAP-DNA can be detected intermittently in feces, semen, and blood of a subclinically infected breeding bull candidate with MAP-free intervals of up to 18 weeks. The results also suggest a significant correlation between MAP occurrence in semen and blood. Even though only bulls considered to be healthy are used for semen collection, the risk of MAP transmission cannot be excluded due to seronegative shedders showing no clinical signs of paratuberculosis. Despite lacking typical signs of clinical paratuberculosis, the investigated bull showed poor growth performance. It has been mentioned before that one effect of paratuberculosis is ill-thrift indicating that the failure to grow may be caused by MAP infection (Richardson and More, 2009). A persistent BVD infection being the cause of ill-thrift or backwardness was excluded by annual routine testing. Assuming that MAP testing is not a standard procedure for semen examination and that the quality of semen samples might be good despite of the presence of $10^{2}-10^{5} \mathrm{MAP} / \mathrm{ml}$ semen, as a precaution, semen-donor bulls should be tested for MAP on a regular basis. ELISAs which are currently available are highly specific, but reveal limitations for the early detection of MAP. Alternatively, PCR assays seem to be worthwhile for the fast and effective examination of MAP in semen.

Due to new information on the relevance of MAP in semen, the focus of breeding health management should not only be addressed to major epizootic diseases such as BHV1, BVD and BTV, but also to MAP as a pathogen with a potential for venereal transmission. Further investigations are required in order to determine the likelihood of vertical transmission following natural mating or artificial insemination to make a reliable risk assessment regarding the pathogen MAP in semen. This includes surveys on MAP resistance against antibiotic additives used in diluents for standard semen conservation. 


\section{REFERENCES}

Alexejeff-Goloff, N.A., 1929, Zur Frage der Pathogenese und Bazillenausscheidung bei Rinderparatuberculose. Zeitschrift für Infektionkrankheiten, Parasitaerekrankheiten und Hygiene der Haustiere 36, 313-317 Abstracted in Journal of Comparative Pathology 348:381-382.

Antognoli, M.C., Hirst, H.L., Garry, F.B., Salman, M.D., 2007, Immune response to and faecal shedding of Mycobacterium avium ssp. paratuberculosis in young dairy calves, and the association between test results in the calves and the infection status of their dams. Zoonoses Public Health 54, 152-159.

Ayele, W.Y., Bartos, M., Svastova, P., Pavlik, I., 2004, Distribution of Mycobacterium avium subsp. paratuberculosis in organs of naturally infected bull-calves and breeding bulls. Vet Microbiol 103, 209-217.

Barrington, G.M., Gay, J.M., Eriks, I.S., Davis, W.C., Evermann, J.F., Emerson, C., O'Rourke, J.L., Hamilton, M.J., Bradway, D.S., 2003, Temporal patterns of diagnostic results in serial samples from cattle with advanced paratuberculosis infections. J Vet Diagn Invest 15, 195-200.

Bower, K., Begg, D.J., Whittington, R.J., 2010, Optimisation of culture of Mycobacterium avium subspecies paratuberculosis from blood samples. J Microbiol Methods 80, 93-99.

Buergelt, C.D., Williams, J.E., 2004, Nested PCR on blood and milk for the detection of Mycobacterium avium subsp paratuberculosis DNA in clinical and subclinical bovine paratuberculosis. Aust Vet J 82, 497-503.

Chiodini, R.J., 1996, Immunology: resistance to paratuberculosis. Vet Clin North Am Food Anim Pract 12, 313-343.

Chiodini, R.J., Van Kruiningen, H.J., Merkal, R.S., 1984, Ruminant paratuberculosis (Johne's disease): the current status and future prospects. Cornell Vet 74, 218262.

Cocito, C., Gilot, P., Coene, M., de Kesel, M., Poupart, P., Vannuffel, P., 1994, Paratuberculosis. Clin Microbiol Rev 7, 328-345.

Collins, M.T., Wells, S.J., Petrini, K.R., Collins, J.E., Schultz, R.D., Whitlock, R.H., 2005, Evaluation of five antibody detection tests for diagnosis of bovine paratuberculosis. Clin Diagn Lab Immunol 12, 685-692.

Cousins, D.V., Whittington, R., Marsh, I., Masters, A., Evans, R.J., Kluver, P., 1999, Mycobacteria distenct from Mycobacterium avium subsp. paratuberculosis isolated from the faeces of ruminants possess IS900-like sequences detectable IS900 polymerase chain reaction: implications for diagnosis. Mol Cell Probes 13, 431-442.

Dieguez, F.J., Gonzalez, A.M., Menendez, S., Vilar, M.J., Sanjuan, M.L., Yus, E., Arnaiz, I., 2009, Evaluation of four commercial serum ELISAs for detection of Mycobacterium avium subsp. paratuberculosis infection in dairy cows. Vet $\mathbf{J}$ 180, 231-235.

Eamens, G.J., Walker, D.M., Porter, N.S., Fell, S.A., 2008, Radiometric pooled faecal culture for the detection of Mycobacterium avium subsp paratuberculosis in low-shedder cattle. Aust Vet J 86, 259-265.

Edmondson, J.E., Tallmonn, K.L., Herman, H.A., 1948, A study of the types of bacteria in bovine semen and their effect up on motility. Journal of Dairy Science 31, 681.

Englund, S., Bolske, G., Johansson, K.E., 2002, An IS900-like sequence found in a Mycobacterium sp. other than Mycobacterium avium subsp. paratuberculosis. FEMS Microbiol Lett 209, 267-271. 
Eppleston, J., Whittington, R.J., 2001, Isolation of Mycobacterium avium subsp paratuberculosis from the semen of rams with clinical Johne's disease. Aust Vet J 79, 776-777.

Gilmour, N.J., 1965, Recent research on Johne's disease. Vet Rec 77, 1322-1326.

Glawischnig, W., Awad-Masalmeh, M., Khaschabi, D., Schonbauer, M., 2004, [Detection of Mycobacterium avium subsp. paratuberculosis from the testicles of a clinically infected breeding animal]. Berl Munch Tierarztl Wochenschr 117, 136-139.

Gwozdz, J.M., Thompson, K.G., Murray, A., West, D.M., Manktelow, B.W., 2000, Use of the polymerase chain reaction assay for the detection of Mycobacterium avium subspecies paratuberculosis in blood and liver biopsies from experimentally infected sheep. Aust Vet J 78, 622-624.

Harris, N.B., Barletta, R.G., 2001, Mycobacterium avium subsp. paratuberculosis in Veterinary Medicine. Clin Microbiol Rev 14, 489-512.

Jorgensen, J.B., 1982, An improved medium for culture of Mycobacterium paratuberculosis from bovine faeces. Acta Vet Scand 23, 325-335.

Juste, R.A., Garrido, J.M., Geijo, M., Elguezabal, N., Aduriz, G., Atxaerandio, R., Sevilla, I., 2005, Comparison of blood polymerase chain reaction and enzymelinked immunosorbent assay for detection of Mycobacterium avium subsp. paratuberculosis infection in cattle and sheep. J Vet Diagn Invest 17, 354-359.

Khol, J.L., Geisbauer, E., Wassertheurer, M., Revilla-Fernandez, S., Damoser, J., Osterreicher, E., Dunser, M., Kleb, U., Baumgartner, W., 2011, Outcome of Three Commercial Serum ELISAs and Faecal Detection of Mycobacterium avium subsp. paratuberculosis in Consecutive Samples from a Cattle Herd with Low Prevalence of Paratuberculosis (Johne's Disease). Transbound Emerg Dis.

Khol, J.L., Kralik, P., Slana, I., Beran, V., Aurich, C., Baumgartner, W., Pavlik, I., 2010, Consecutive Excretion of Mycobacterium avium Subspecies paratuberculosis in Semen of a Breeding Bull Compared to the Distribution in Feces, Tissue and Blood by IS900 and F57 Quantitative Real-Time PCR and Culture Examinations. J Vet Med Sci.

Koenig, G.J., Hoffsis, G.F., Shulaw, W.P., Bech-Nielsen, S., Rings, D.M., St-Jean, G., 1993, Isolation of Mycobacterium paratuberculosis from mononuclear cells in tissues, blood, and mammary glands of cows with advanced paratuberculosis. Am J Vet Res 54, 1441-1445.

Larsen, A.B., Kopecky, K.E., 1970, Mycobacterium paratuberculosis in reproductive organs and semen of bulls. Am J Vet Res 31, 255-258.

Larsen, A.B., Stalheim, O.H., Hughes, D.E., Appell, L.H., Richards, W.D., Himes, E.M., 1981, Mycobacterium paratuberculosis in the semen and genital organs of a semen-donor bull. J Am Vet Med Assoc 179, 169-171.

Li, L., Bannantine, J.P., Zhang, Q., Amonsin, A., May, B.J., Alt, D., Banerji, N., Kanjilal, S., Kapur, V., 2005, The complete genome sequence of Mycobacterium avium subspecies paratuberculosis. Proc Natl Acad Sci U S A 102, 12344-12349.

Merkal, R.S., 1984, Paratuberculosis: advances in cultural, serologic, and vaccination methods. J Am Vet Med Assoc 184, 939-943.

Merkal, R.S., Miller, J.M., Hintz, A.M., Bryner, J.H., 1982, Intrauterine inoculation of Mycobacterium paratuberculosis into guinea pigs and cattle. Am J Vet Res 43, 676-678. 
Möbius, P., Hotzel, H., Rassbach, A., Kohler, H., 2008, Comparison of 13 single-round and nested PCR assays targeting IS900, ISMav2, f57 and locus 255 for detection of Mycobacterium avium subsp. paratuberculosis. Vet Microbiol 126, 324-333.

Münster, P., Volkel, I., Wemheuer, W., Petschenka, J., Wemheuer, W., Steinbrunn, C., Campe, A., Schulz-Schaeffer, W.J., Kreienbrock, L., Czerny, C.P., 2011, Detection of Mycobacterium avium ssp. paratuberculosis in ileocaecal lymph nodes collected from elderly slaughter cows using a semi-nested IS900 polymerase chain reaction. Vet Microbiol 154, 197-201.

Nielsen, S.S., 2008, Transitions in diagnostic tests used for detection of Mycobacterium avium subsp. paratuberculosis infections in cattle. Vet Microbiol 132, 274-282.

Nielsen, S.S., Toft, N., 2006, Age-specific characteristics of ELISA and fecal culture for purpose-specific testing for paratuberculosis. J Dairy Sci 89, 569-579.

Oliver, J.D., 2005, The viable but nonculturable state in bacteria. J Microbiol 43 Spec No, 93-100.

Philpott, M., 1993, The dangers of disease transmission by artificial insemination and embryo transfer. Br Vet J 149, 339-369.

Pinedo, P.J., Rae, D.O., Williams, J.E., Donovan, G.A., Melendez, P., Buergelt, C.D., 2008, Association among results of serum ELISA, faecal culture and nested PCR on milk, blood and faeces for the detection of paratuberculosis in dairy cows. Transbound Emerg Dis 55, 125-133.

Richardson, E., More, S., 2009, Direct and indirect effects of Johne's disease on farm and animal productivity in an Irish dairy herd. Ir Vet J 62, 526-532.

Schneider, F., 2003. Entwicklung einer "seminested PCR" und einer "Real-Time-PCR" zum Nachweis von Mycobacterium avium ssp. paratuberculosis bei Rindern (Development of a "semi-nested PCR" and a "real-time PCR" for the detection of Mycobacterium avium ssp. paratuberculosis in cattle) Ph.D. Dissertation. Ludwig-Maximilians-University, Munich, Bavaria, Germany,

Sweeney, R.W., 1996, Transmission of paratuberculosis. Vet Clin North Am Food Anim Pract 12, 305-312.

Sweeney, R.W., Uzonna, J., Whitlock, R.H., Habecker, P.L., Chilton, P., Scott, P., 2006, Tissue predilection sites and effect of dose on Mycobacterium avium subs. paratuberculosis organism recovery in a short-term bovine experimental oral infection model. Res Vet Sci 80, 253-259.

Tiwari, A., VanLeeuwen, J.A., Dohoo, I.R., Keefe, G.P., Weersink, A., 2008, Estimate of the direct production losses in Canadian dairy herds with subclinical Mycobacterium avium subspecies paratuberculosis infection. Can Vet J 49, 569576.

Weber, M.F., Kogut, J., de Bree, J., van Schaik, G., Nielen, M., 2010, Age at which dairy cattle become Mycobacterium avium subsp. paratuberculosis faecal culture positive. Prev Vet Med 97, 29-36.

Wells, S.J., Collins, M.T., Faaberg, K.S., Wees, C., Tavornpanich, S., Petrini, K.R., Collins, J.E., Cernicchiaro, N., Whitlock, R.H., 2006, Evaluation of a rapid fecal PCR test for detection of Mycobacterium avium subsp. paratuberculosis in dairy cattle. Clin Vaccine Immunol 13, 1125-1130.

Whittington, R.J., Reddacliff, L.A., Marsh, I., McAllister, S., Saunders, V., 2000, Temporal patterns and quantification of excretion of Mycobacterium avium subsp paratuberculosis in sheep with Johne's disease. Aust Vet J 78, 34-37.

Whittington, R.J., Windsor, P.A., 2009, In utero infection of cattle with Mycobacterium avium subsp. paratuberculosis: a critical review and meta-analysis. Vet $\mathrm{J} 179$, 60-69. 


\section{Chapter III}

Paper under review

Journal of Zoo and Wildlife Medicine

Brief Communication: Detection of Mycobacterium avium subspecies paratuberculosis by IS900-based PCR assays from an alpaca (Vicugna pacos) kept in a German zoological garden

Pia Münster ${ }^{1}$, Inger Völkel ${ }^{1}$, Aloys von Buchholz ${ }^{2}$ and Claus-Peter Czerny ${ }^{1 *}$

Department of Animal Sciences, Institute of Veterinary Medicine, Division of Microbiology and Animal Hygiene, Faculty of Agricultural Sciences, Georg-AugustUniversity, Burckhardtweg 2, D-37077 Göttingen, Germany ${ }^{1}$. Veterinary Clinic, Paschenaustrasse 51, D-48432 Rheine ${ }^{2}$.

*Corresponding author. Mailing address: Department of Animal Sciences, GeorgAugust-University, Burckhardtweg 2, D-37077 Göttingen, Germany. Phone: +49 55139 3375. Fax: +49 55139 3382. E-mail: cczerny@gwdg.de 


\begin{abstract}
An alpaca (Vicugna pacos) that was bred and kept in a German zoological garden exhibited clinical signs consistent with paratuberculosis. The presence of Mycobacterium avium ssp. paratuberculosis (MAP) was confirmed in feces and in the ileocecal lymph node by IS900-based PCR assays and culture. A bacterial burden of 7.6 $\times 10^{6} \mathrm{MAP} / \mathrm{g}$ in feces and $4.4 \times 10^{7} \mathrm{MAP} / \mathrm{g}$ in lymph node tissue was determined by an rtPCR. For further characterization, a conventional PCR was developed. After sequencing of the $864 \mathrm{bp}$ PCR amplicon covering nucleotide positions 13 and 876 within the IS900, the Alpaca isolate shared 100\% nucleotide homology with the bovine MAP-K10 IS900 reference sequence (GenBank: AE16958), giving indication to a cattle strain.

This report supports the present occurrence of MAP in German camelid populations and highlights the need to expand routine MAP surveillance to South American camelids.
\end{abstract}

Key words: Alpaca, Johne's disease, Vicugna pacos, Mycobacterium avium ssp. paratuberculosis, zoological garden.

Acknowledgement(s): This work was funded by the Federal Ministry of Economics and Technology under support code KF2484201AJ9. We are grateful to Lynne Armstrong for completing the critical review of the manuscript. 


\section{BRIEF COMMUNICATION}

Mycobacterium avium ssp. paratuberculosis (MAP) is the infectious agent of paratuberculosis, also known as Johne's disease, a degenerative wasting disorder which mainly appears in domestic and wild ruminants. Since paratuberculosis is primarily recognized in cattle, its greatest economic impact is on the dairy and beef industries. Nevertheless, sporadic cases have previously been identified in llamas (Lama glama), alpacas (Vicugna pacos), and guanacos (Lama guanicoe) (Belknap et al., 1994; Fecteau et al., 2009; Ridge et al., 1995; Salgado et al., 2009).

South American camelids (SACs) have always been popular for hobby breeding and are traditionally found as residents in petting zoos. Currently the market for alpaca fiber production is expanding worldwide. Thus, the focus on the health management of SACs should also include control of re-emerging diseases recently found to be spreading in cattle and other ruminants like bluetongue disease, tuberculosis, and paratuberculosis. Although, in their natural habitat, few cases of mycobacterial infections in SACs were published, they might be at a higher risk when held in close contact with other infected animal species, like in zoological gardens, in petting zoos or free-ranging on pastures (Belknap et al., 1994; Fecteau et al., 2009; Ridge et al., 1995; Salgado et al., 2009). Taking the current increased prevalence of MAP in European domestic ruminants into account, further investigation of this pathogen would be worthwhile with regard to the health assessment of SACs (Manning, 2001). The objective of this case report was to confirm paratuberculosis in a clinically-diseased alpaca by culture and different polymerase chain reaction (PCR) techniques. For further characterization, PCR amplicons were sequenced and aligned to GenBank entries.

In January 2009, an 11-year-old adult male alpaca (Vicugna pacos), which had been kept in a German zoological garden in North Rhine Westphalia for 10 years, was reported to the local veterinarian due to chronic weight loss and ill-thrift. Clinical investigation revealed dullness, a poor coat, pale and dry mucous membranes, dehydration, and severe weight loss resulting in life-threatening cachexia. Despite its poor body condition, the weak animal still showed normal appetite and had no signs of diarrhea. Auscultation revealed no abnormalities concerning heart, lung, or gastrointestinal movements. Peripheral lymph nodes showed no evident palpable enlargement. Teeth problems were excluded on examination, and coprological analysis of the feces was negative for endoparasites. During the following three days, the animal showed severe clinical symptoms, became listless, recumbent and reluctant to move. 
Since there had been sporadic cases of paratuberculosis in the Barabary sheep (Ammotragus lervia) herd of the zoological garden before, a laparotomy was conducted to confirm this tentative diagnosis by a guided biopsy of the ileocecal lymph node (ILN). Surgery was carried out using general anesthesia $(5 \mathrm{mg} / \mathrm{kg}$ Xylazin, $2.5 \mathrm{mg}$ Isoflurane in oxygen) and the right flank was chosen for abdominal access. After advancing the caecum, the whole ILN was extirpated. It was notably enlarged, the cut surface being moist and greasy. As far as visible, the intestines seemed to be thickened, and the majority of the mesenteric lymph nodes were enlarged, as well. Both feces and tissue sections of the ILN were delivered immediately to a laboratory which specializes in MAP diagnostics.

Both feces and sections of the ILN were submitted for culture and PCR. MAP cultures from fecal and tissue samples were performed on Herrold's egg yolk medium (HEYM) (BD $\mathrm{BBL}^{\mathrm{TM}}$, Heidelberg, Germany). Cultures prepared from both matrices yielded massive mycobacterial growth on HEYM, forming predominantly a confluent bacterial layer. Colony morphology on solid media was typical for MAP, showing small, raised and firm pale colonies with a waxy surface.

For the molecular detection of MAP, fecal and tissue samples were also tested directly by a semi-nested PCR (snPCR) and a real-time PCR (rtPCR) based on the insertion sequence IS900. Assays were performed, as described elsewhere (Münster et al., 2011; Schneider, 2003). Both PCR-techniques verified MAP infection in all sample matrices taken from the alpaca (Figure 1 and 2). 


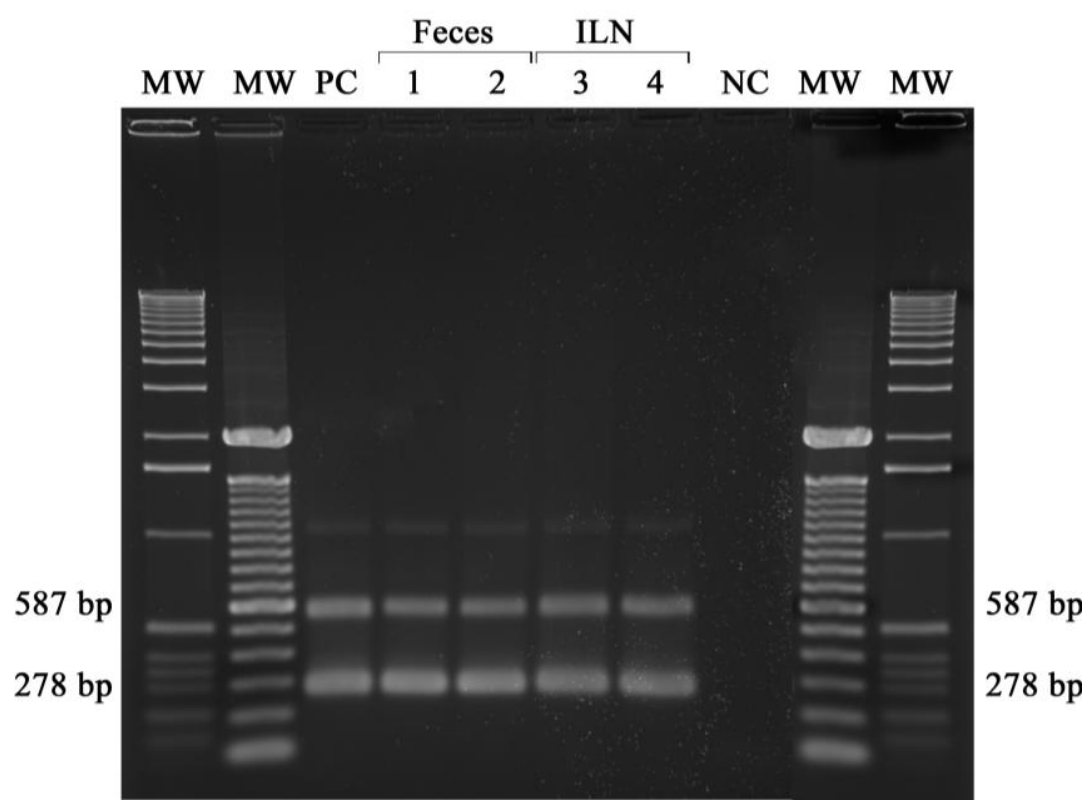

Figure 1: Detection of MAP-DNA in feces and tissue (ILN) collected from an alpaca (Vicugna pacos) by qualitative IS900 semi-nested PCR, amplifying a $587 \mathrm{bp}$ and a 278 bp fragment: MW, molecular weight marker; PC, positive control (MAP-DNA); 1-2 fecal sample; 3-4, tissue sample (ILN); NC, negative control (Aqua dest.); sizes of the PCR products are stated to the left and right.

To quantify MAP genomes per $\mathrm{g}$ in feces or tissue, genome equivalents detected by rtPCR were calculated by the MAP genome size of $4.7 \times 10^{6} \mathrm{bp} .^{3}$ The rtPCR revealed $7.6 \times 10^{6} \mathrm{MAP} / \mathrm{g}$ in feces and $4.4 \times 10^{7} \mathrm{MAP} / \mathrm{g}$ in lymphatic tissue.

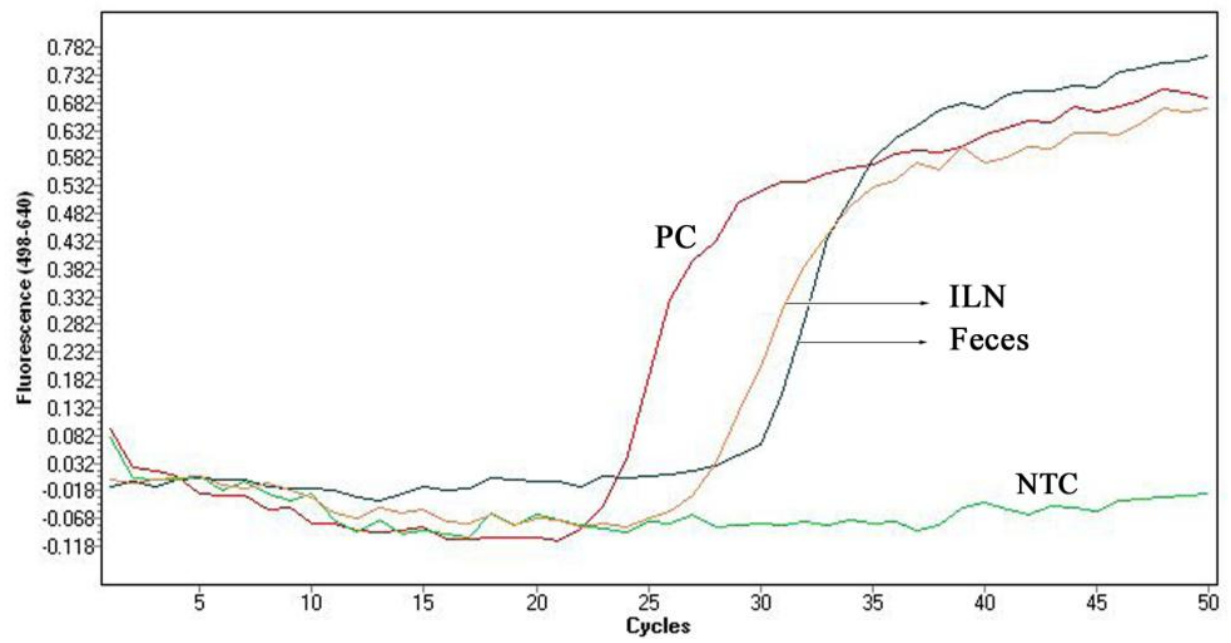

Figure 2: Detection of MAP-DNA in feces and tissue (ILN) collected from an alpaca (Vicugna pacos) by quantitative IS900 real-time PCR. Hybridization probes and primers MAPfor2/MAPrev amplifying a $278 \mathrm{bp}$ fragment were used. PC, positive control (MAP-DNA); NTC, negative control (Aqua dest.). 
For further characterization of the Alpaca isolate, primers were designed to amplify a PCR product of 864 bp covering IS900 nucleotides 13 and 876. Two 864 bp amplicons were cloned into the $\mathrm{pCR}^{\circledR} 2.1-\mathrm{TOPO}^{\circledR}$ plasmid vector (Invitrogen, Groningen, The Netherlands) and sequenced. A comparison with the published bovine MAP K10 IS900 reference sequence (GenBank: AE16958) revealed a homology degree of 100\%.

The current study supports earlier reports of alpacas being susceptible to MAP infection and exhibiting clinical and pathological findings consistent with paratuberculosis. Regarding clinical signs, previous studies reported diarrhea, chronic weight loss and hypoproteinemia both in animals younger than 2 years and in adults (Fecteau et al., 2009; Ridge et al., 1995). However, in the current case report, obvious clinical symptoms were limited to progressive weakness and weight loss despite a concomitant good appetite. The assumption that not all alpacas seem to develop diarrhea in the final stage of paratuberculosis is concordant to former studies that diagnosed MAP infection in a herd of ten alpacas using fecal culture and the caprine AGID assay. Only five out of ten MAP-positive animals showed weight loss and diarrhea (Fecteau et al., 2009). Another report on three cases of paratuberculosis in alpacas indicated that one animal had diarrhea for at least three months, whereas two animals did not (Ridge et al., 1995). Similarly, diarrhea is uncommon in infected sheep, goats, bison, and possibly other nondomestic hoofstock species (Manning, 2001). However, any animal may become cachectic in the final phases of paratuberculosis. Since emaciation is not pathognomonic for paratuberculosis, important differential diagnoses in alpacas may also include endoparasites (Ostertagiosis, Dicrocoeliosis), damage to teeth, hypocuprosis, trace element deficiencies (selenium/vitamin E), and tuberculosis.

Although endogenous systemic pathways of the infection are not well understood, it is a well-known fact that the risk of MAP infection is both quantity and age-dependent. The infective quantity for calves is considered to be $10^{3}$ colony-forming units (CFU)/animal, but in the case of camelids, the minimal dose rate required to infect an animal has not yet been investigated (Whittington et al., 2001). By applying rtPCR, the bacterial burden in the feces of the clinically-infected alpaca was determined to be $7.6 \times 10^{6}$ $\mathrm{MAP} / \mathrm{g}$ in feces, supported by fecal culture yielding rich growth on HEYM. MAP was also detected in the ILN, with MAP concentrations of $4.4 \times 10^{7}$ genome equivalents/g in tissue. 
The isolation of MAP from both fecal and tissue samples, in combination with corresponding clinical signs, confirms true infection and excludes mere transit of ingested bacteria. The reduced bacterial shedding compared to cattle may be due to individual differences, but could also be linked to specific species' features regarding pathogenesis or disease course.

Since certain regions of the IS900 sequences of MAP are generally regarded to be highly conserved, unique single nucleotide polymorphisms (SNPs) were recently reviewed and DNA sequencing for the detection of polymorphisms has been considered to be promising for the differentiation of MAP strains. ${ }^{2}$ Sequence ambiguities at positions 169 (T/C) and 216 (G/A) are characteristic of MAP strains isolated from sheep. The 864 bp PCR product covered both positions. Clear cytosine and adenine peaks at those loci in the alpaca isolate gave indication to a cattle strain. Therefore, sequencing of amplicons is not only a valuable tool to prove PCR specificity, but may also lead to the classification of strain types and may provide data for efficient tracingback in paratuberculosis epidemiology.

Camelids are often popular as zoo residents and represent a substantial individual value. For genetic and economic animal health reasons, exchanges among herds are of major importance for the industry as well as for zoological gardens. The transfer of individuals who are potential MAP carriers or even shedders may present the greatest risk of introducing paratuberculosis into a herd. Additionally, interspecies transmission due to close contact with other infected domesticated or wildlife species is of great significance, both in free-ranging alpacas kept on pastures as well as in zoological gardens.

An essential requirement for effective control of paratuberculosis is the rapid identification of asymptomatic carriers and shedders which represent a constant source of infection. Diagnosis in goats, deer, and camelids is still based primarily on bacterial culture, requiring a long cultivation period of 4 to 16 weeks. Some strains (sheep and bison) are more difficult to be isolated than others, requiring cultivation times of up to one year (Juste et al., 1991). Interspecies transmission is still not well understood, but it can be assumed that sheep strains are likely to occur in alpacas, as a recent study concluded that all isolates from alpacas were of the sheep type (Münster et al., 2011) Alternatively, PCR assays for direct pathogen detection seem to be worthwhile for a fast and effective examination of MAP in feces, regardless of cattle, sheep or bison types. 
This report supports the present occurrence of MAP in German camelid populations and indicates the need to expand routine MAP surveillance to SACs. Furthermore, sequencing of PCR products can be used successfully for research on genetically distinctive strains. In suspected clinical cases biopsied sections of ILN tissue may be a suitable diagnostic matrix intra vitam or postmortem next to fecal samples.

Further investigations are required for a reliable risk assessment regarding the true importance of the pathogen MAP in current European alpaca populations.

\section{REFERENCES}

Belknap, E.B., D.M. Getzy, L.W. Johnson, R.P. Ellis, G.L. Thomson, and W.P. Shulaw. 1994. Mycobacterium paratuberculosis infection in two llamas. J. Am. Vet. Assoc. 204: 1805-1808.

Castellanos, E., A. Aranaz, L. de Juan, J. Alvarez, S. Rodriguez, B. Romero, J. Bezos, K. Stevenson, A., Mateos, and L. Dominguez. 2009. Single nucleotide polymorphisms in the IS900 sequence of Mycobacterium avium subsp. paratuberculosis are strain type specific. J. Clin. Microbiol. 47: 2260-2264.

Cocito, C., P. Gilot, M. Coene, M. de Kesel, P. Poupart, P. Vannuffel. 1994. Paratuberculosis. Clin. Microbiol. Rev. 7: 328-345.

Cousins, D.V., S.N. Williams, A. Hope, and G.J. Eamens. 2000. DNA fingerprinting of Australian isolates of Mycobacterium avium subsp. paratuberculosis using IS900 RFLP. Aust. Vet. J. 78: 184-190.

Fecteau, M.E., J. Ross, B.S. Tennent-Brown, P.L. Habecker, S. Sreevatsan, R.W. Sweeney, and R.H. Whitlock. 2009. Mycobacterium avium ssp. paratuberculosis high shedding in an adult female alpaca, and its implication for the rest of the herd. J. Vet. Intern. Med. 23: 1311-1314.

Juste, R.A., J.C. Marco, C. Saez de Ocariz, and J.J. Aduriz. 1991. Comparison of different media for the isolation of small ruminant strains of Mycobacterium paratuberculosis. Vet. Microbiol. 28: 385-390.

Manning, E.J. 2001. Mycobacterium avium subspecies paratuberculosis: a review of current knowledge. J. Zoo Wildl. Med. 32: 293-304.

Münster, P., I. Völkel, W. Wemheuer, J. Petschenka, W. Wemheuer, C. Steinbrunn, A. Campe, W.J. Schulz-Schaeffer, L. Kreienbrock, and C.P. Czerny. 2011. Detection of Mycobacterium avium ssp. paratuberculosis in ileocaecal lymph nodes collected from elderly slaughter cows using a semi-nested IS900 polymerase chain reaction. Vet. Microbiol. 154: 197-201.

Ridge, S.E., J.T. Harkin, R.T. Badman, A.M. Mellor, and J.W. Larsen. 1995. Johne's disease in alpacas (Lama pacos) in Australia. Aust. Vet. J. 72: 150-153.

Salgado, M., D. Herthnek, G. Bolske, S. Leiva, and J. Kruze. 2009. First isolation of Mycobacterium avium subsp. paratuberculosis from wild guanacos (Lama guanicoe) on Tierra del Fuego Island. J. Wildl. Dis. 45: 295-301.

Schneider, F. 2003. Entwicklung einer "seminested PCR" und einer "Real-Time PCR" zum Nachweis von Mycobacterium avium ssp. paratuberculosis bei Rindern. Ph.D. Dissertation, Ludwig-Maximilians-University, Munich, Germany.

Whittington, R.J., and E.S. Sergeant. 2001. Progress towards understanding the spread, detection and control of Mycobacterium avium subsp paratuberculosis in animal populations. Aust. Vet. J. 79: 267-278. 


\section{Chapter IV}

Paper submitted

Veterinary Microbiology

\section{Distribution of Mycobacterium avium ssp. paratuberculosis in a German zoological} garden determined by IS900 semi-nested and quantitative real-time PCR

Pia Münster ${ }^{1}$, Kim Fechner ${ }^{1}$, Inger Völkel ${ }^{1}$, Aloys von Buchholz ${ }^{2}$, and Claus-Peter Czerny $^{1 *}$

Department of Animal Sciences, Institute of Veterinary Medicine, Division of Microbiology and Animal Hygiene, Faculty of Agricultural Sciences, Georg-AugustUniversity, Burckhardtweg 2, D-37077 Göttingen, Germany ${ }^{1}$. Veterinary Clinic, Paschenaustrasse 51, D-48432 Rheine, Germany².

*Corresponding author. Mailing address: Department of Animal Sciences, GeorgAugust-University, Burckhardtweg 2, D-37077 Göttingen, Germany. Phone: +49 55139 3375. Fax: +49 55139 13513. E-mail: cczerny@gwdg.de 


\section{ABSTRACT}

A German zoological garden with recent history of clinical paratuberculosis in Barbary sheep (Ammotragus lervia) and alpacas (Lama pacos) was selected to estimate the distribution of Mycobacterium avium ssp. paratuberculosis (MAP) infections in 21 mammalian and avian species. Pooled fecal samples from individual animals of each species were tested for the presence of MAP. A previously developed IS900 seminested PCR (snPCR) assay, amplifying a $587 \mathrm{bp}$ and $278 \mathrm{bp}$ fragment, was used for the detection of MAP-DNA. Based on this SnPCR, 14 out of the 21 species tested positive for MAP in feces, indicating a MAP occurrence of $66.7 \%$ in the examined samples. All animals were asymptomatic at the time of sampling. Shedding of MAP was observed in ruminants and camelids as well as in non-ruminants such as equines, primates, rodents, and birds. Moreover, quantitative real-time PCR demonstrated that the concentration of MAP-DNA was within the range of $10^{3}-10^{6}$ MAP per $\mathrm{g}$ feces and that the highest quantity was shed by primates such as Black-and-white ruffed lemurs (Varecia variegata) and Cottontop tamarins (Saguinus oedipus). For the purpose of screening polymorphisms in all detected isolates of each species, the smaller PCR products of 278 bp were sequenced. Nucleotide homologies of $93.9 \%$ and $100 \%$ were found in the amplicons with respect to the MAP-K10 reference sequence IS900 (GenBank: AE16958).

This is the first survey investigating the presence of MAP in a German zoo which includes non-ruminants. The results of the present study confirm the wide host range of MAP and demonstrate that MAP occurs more frequently in zoo animals than expected. In order to restrict further spread of MAP in European zoos, additional investigations regarding the existing transmission pathways of MAP in zoos are recommended.

Keywords: Germany; Mycobacterium avium ssp. paratuberculosis; PCR; Zoological garden.

\section{Acknowledgements}

This work was funded by the Federal Ministry of Economics and Technology under support code KF2484201AJ9. We are grateful to Lynne Armstrong for completing the critical review of the manuscript. 


\section{INTRODUCTION}

Mycobacterium avium ssp. paratuberculosis (MAP) is the infectious agent of Johne's disease, a degenerative chronic granulomatous inflammation of the intestinal tract causing diarrhea, weight loss, reduced reproductive performance, and eventually death (Harris and Barletta, 2001). Since paratuberculosis is primarily recognized in domestic ruminants, its greatest economic effect is seen in the dairy and beef industry. Nevertheless, it has also been reported in a wide range of other domesticated, wild, and zoo animals including non-ruminants (Beard et al., 2001a; Greig et al., 1999).

The epidemiology of MAP, particularly regarding inter-species transmission and the role of wildlife reservoirs, is not well understood. There is evidence that free-ranging wildlife including non-ruminants has become increasingly important in the transmission and maintenance of MAP. Known wildlife reservoirs are rabbits in Scotland (Beard et al., 2001b; Greig et al., 1997) and a wide spectrum of free-ranging birds and mammals in the USA (Corn et al., 2005). Previous studies, which employed molecular genetic typing techniques, demonstrated the concept of natural inter-species transmission of MAP between wildlife and domestic ruminants (Florou et al., 2008; Greig et al., 1999; Stevenson et al., 2009).

The presence of MAP in wildlife reservoirs and the possibility of inter-species transmission may have important implications for the control of the disease and may interfere with final stages of bovine eradication programs. Increased wildlife popularity has also led to greater transfer of wildlife and the development of captive wildlife industries. Data on MAP occurrence in animals other than ruminants is required prior to the generation of effective and comprehensive paratuberculosis control programs. Captured wildlife may provide fundamental knowledge in terms of the inter-species transmission of MAP. Although studies on the occurrence of MAP in fecal samples of zoo ruminants have already been published (Erume et al., 2001; Vansnick et al., 2005; Weber et al., 1992), little data concerning its distribution in zoological gardens is available. Therefore, the aim of this study was to evaluate the presence of MAP in captured wildlife and to provide further information on the role of inter-species transmission pathways. This is the first survey conducted to investigate the occurrence of MAP in a German zoo including non-ruminants with a history of clinical paratuberculosis in Barbary sheep (Ammotragus lervia) and alpacas (Lama pacos). 


\section{MATERIALS AND METHODS}

Animals and sampling. Fecal samples were taken from mammalian and avian species kept in a zoological garden in Western Germany (North Rhine Westphalia). The 13 ha (32.5 acre) zoo was founded in 1937 and it specializes in primate and avian husbandry. The animal park, with 1,065 animals representing 102 species, is famous for its naturallooking exhibits. Zoo staff members are grouped into three different working teams and are responsible for feeding, cleaning, and maintenance in a distinctive district.

The zoo was chosen for this study due to its known clinical paratuberculosis history. In winter 2008/2009, zoo residents such as Barbary sheep (Ammotragus lervia) and alpaca (Lama pacos) exhibited clinical signs of paratuberculosis and tested positive for MAP in feces by snPCR. In the current survey, pooled fecal samples of approximately $100 \mathrm{~g}$ from each species were collected during a single routine inspection tour for a better risk assessment of MAP presence within the animal collections. Fresh fecal samples, clearly related to the respective species, were picked up randomly from compounds using disposable gloves and transferred immediately to plastic jar. Certain facilities of the chosen zoo harbour diverse species (Figure 1). Facilities of Old World monkeys (Cercopithecidae) (No. 3), bears (Ursidae) (No. 8), tigers (Panthera tigris) (No. 24), and Barbary macaques (Macaca sylvanus) (No.28) were not accessible for sampling due to management reasons, and therefore excluded from this study. Animals such as storks (Ciconiidae) (No.5), penguins (Sphenisciformes) (No. 6), seals (Phoca vitulina) (No. 7), coatis (Nasua) (No.9), flamingos (Phoenicopteriformes) (No. 10), prairie dogs (Cynomys ludovicianus) (No. 15), and tortoises (Testudo) (No. 18) were also omitted due to the difficulty encountered when entering their compounds. Sampled species included ruminants (No. 2, 16), camelids (No. 20, 23, 25), equines (No. 17, 19), primates (No. 2, 11, 12, 26), rodents (No. 11, 23), macropods (No. 22), and birds (No. 13, 21, 22, 27). Specimens were stored at $-20^{\circ} \mathrm{C}$ and were kept frozen until tested by semi-nested PCR.

DNA extraction. DNA was extracted for PCR analysis from fecal samples using a modified protocol of the QIAamp Blood Kit (Quiagen, Hilden, Germany). Fecal samples weighing approximately $100 \mathrm{~g}$ were mixed 1:1 with PBS, vortexed and ultrasonicated thrice for $10 \mathrm{sec}$ at $20 \mathrm{kHz}$ (Bendelin Sonoplus HD 2200, Berlin, Germany). Since a low MAP content was expected, 10 aliquots of $1 \mathrm{~g}$ were taken from each pooled fecal sample. Subsequently, $1 \mathrm{~g}$ of the sample preparation was transferred to a tube containing $540 \mu \mathrm{l}$ lysis buffer. Following mixing, the samples were incubated on a 
shaker at $37^{\circ} \mathrm{C}$ and $900 \mathrm{rpm}$ for $30 \mathrm{~min}$, after which $60 \mu \mathrm{l}$ proteinase $\mathrm{K}$ and $600 \mu \mathrm{l}$ lysis buffer were added. Subsequently, the tubes were incubated at $56^{\circ} \mathrm{C}$ for $30 \mathrm{~min}$ and for a further $15 \mathrm{~min}$ at $95^{\circ} \mathrm{C}$. Centrifugation and washing procedures were performed according to the corresponding kit manual. In a final step, DNA was eluted and resuspended in $200 \mu$ l elution buffer at a temperature of $85^{\circ} \mathrm{C}$ and stored at $-20^{\circ} \mathrm{C}$ prior to use.

Qualitative IS900 semi-nested polymerase chain reaction. A qualitative semi-nested PCR (snPCR), based on the insertion sequence IS900, was performed as described elsewhere (Münster et al., 2011; Schneider, 2003). PCR reactions were carried out in $25 \mu 1$ volumes containing a $2.5 \mu$ DNA template in a reaction mixture with one ReadyTo-Go $^{\text {TM }}$ PCR bead (Amersham Pharmacia Biotech, Freiburg, Germany), $0.5 \mu 1$ Dimethylsulfoxid (DMSO), and $0.5 \mu 1$ upstream and downstream primers, respectively. PCR cycling began with an initial denaturation at $95^{\circ} \mathrm{C}$ for 3 min followed by 30 cycles of denaturation at $95^{\circ} \mathrm{C}$ for $30 \mathrm{sec}$, primer annealing at $64^{\circ} \mathrm{C}$ for $1 \mathrm{~min}$, primer elongation at $72^{\circ} \mathrm{C}$ for $1 \mathrm{~min}$, and finished after a final extension at $72^{\circ} \mathrm{C}$ for $8 \mathrm{~min}$. The second snPCR step was performed under the same conditions using $2.5 \mu$ l of the first PCR mixture as a template. The primers MAPfor 1 (5'-GTC GGC GTG GTC GTC TGC TGG GTT GAT-‘3) and MAPrev (5'-GCG CGG CAC GGC TCT TGT TGT AGT C'3) amplified a $587 \mathrm{bp}$ fragment in the first run. The primer MAPrev also served as a reverse primer in the second step. Together with the forward primer MAPfor2 (5'- CGG GCG CAC GGT CCA TCA CG'3), a 278 bp fragment was amplified in the second step. Quantitative IS900 real-time polymerase chain reaction. For the quantification of MAP-DNA, a real-time PCR (rtPCR) assay based on the IS900 was performed as described elsewhere (Schneider, 2003). The primers MAPfor2/MAPrev, amplifying the small $278 \mathrm{bp}$ of the snPCR and oligonucleotide probes (MAP1a 5'-CCT GAT CGG CGA TGA TCG CAG CGT CTT-FI-3'; MAP1b 5'-Rox-CGT CGG TCT TGC CTT CGC CGC G-P-3‘), were applied. Oligonucleotides were synthesized by MWG Biotech (Ebersberg, Germany). Amplification and fluorescence detection occurred on the Light Cycler $^{\circledR} 480$ System using 96-well PCR plates (Roche Molecular Diagnostic, Mannheim, Germany). A total reaction volume of $20 \mu \mathrm{l}$ per well was used containing $2 \mu$ Faststart Light Cycler ${ }^{\circledR}$ DNA Master Hybridization Probes (Roche Diagnostics, Mannheim, Germany), $2.4 \mu \mathrm{l} \mathrm{MgCl}_{2}$ stock solution $(25 \mathrm{mM}), 0.2 \mu \mathrm{l}$ upstream and downstream primers $(10 \mathrm{pmol} / \mu \mathrm{l}), 0.4 \mu \mathrm{l}$ MAP1a probe and $0.8 \mu \mathrm{l}$ MAP1b probe as 
well as $12 \mu \mathrm{l}$ sterile water and $2 \mu \mathrm{l}$ of the extracted sample. The amplification process started with an initial pre-incubation step at $95^{\circ} \mathrm{C}$ for $10 \mathrm{~min}$, followed by 50 cycles at $95^{\circ} \mathrm{C}$ for $10 \mathrm{sec}, 64^{\circ} \mathrm{C}$ for $10 \mathrm{sec}$, and $72^{\circ} \mathrm{C}$ for $20 \mathrm{sec}$. Fluorescence was measured within the F2/F1 channel after the annealing step of each cycle. Samples were applied three times and average crossing points $(\mathrm{Cp})$ as well as standard deviations were calculated. Only $\mathrm{Cp}$-values < 40 were included for data interpretation.

For the quantification of MAP-DNA isolated from fecal samples, a MAP-DNA standard was employed and titrated in $\log _{10}$ steps $(1 \mathrm{ng} / \mu \mathrm{l}$ to $1 \mathrm{fg} / \mu \mathrm{l})$. Genome equivalents, detected by PCR, were calculated by the MAP genome size of $4.7 \times 10^{6}$ bp (Cocito et al., 1994). Assuming the molecular weight of one base pair is $660 \mathrm{~g}^{\circ} \mathrm{mol}^{-1}$ and the Avogadro number $6.022 \times 10^{23} \mathrm{~mol}^{-1}$, calculations resulted in one genome copy equivalent to $5.15 \mathrm{fg}$ of DNA.

Qualitative IS901 polymerase chain reaction. In order to exclude Mycobacterium avium ssp avium (MAA) infection, all fecal samples positive in snPCR were tested by IS901 MAA-PCR (Miller et al., 1999). PCR reactions were carried out in $25 \mu 1$ volumes, containing a $2.5 \mu \mathrm{l}$ DNA template in a reaction mixture with one Ready-To$\mathrm{Go}^{\mathrm{TM}}$ PCR bead, $0.5 \mu \mathrm{l}$ upstream and downstream primers $(10 \mathrm{pmol} / \mu \mathrm{l})$, respectively. PCR cycling started with an initial denaturation at $94^{\circ} \mathrm{C}$ for $10 \mathrm{~min}$, followed by 50 cycles of denaturation at $94^{\circ} \mathrm{C}$ for $1 \mathrm{~min}$, primer annealing at $65^{\circ} \mathrm{C}$ for $15 \mathrm{sec}$, primer elongation at $72^{\circ} \mathrm{C}$ for $2 \mathrm{~min}$, and finished after a final extension at $72^{\circ} \mathrm{C}$ for $10 \mathrm{~min}$. The primers IS901for (5'-AAG CCG AGG TGG TGT ATG T-‘3) and IS901rev (5'AGG GAA GAT GGC GGT GAG CAT-‘3) amplified a 257 bp fragment.

Gel electrophoresis, cloning and sequencing. After PCR runs, $5 \mu \mathrm{l}$ of the amplicons were mixed with a $2 \mu \mathrm{l}$ sample buffer and separated on $1 \%$ agarose gels for $1 \mathrm{~h}$ at 120 V. Subsequently, amplicons were stained with ethidium bromide before PCR products were visualized under UV light. PCR amplicons of $278 \mathrm{bp}$ were cloned into the $\mathrm{pCR}^{\circledR}$ 2.1-TOPO ${ }^{\circledR}$ plasmid vector (Invitrogen, Groningen, The Netherlands) and transformed into E. coli cells (Wizard ${ }^{\circledR}$ Plus SV Minipreps Purification System, Promega, Mannheim, Germany). After plasmid preparation from two clones per MAP amplicon, purified DNA was used for sequencing both strands by an ABI Prism 3730 DNA Analyzer (Applied Biosystems, Darmstadt, Germany). DNA sequences were aligned to IS900 sequences from GenBank entries (www.ncbi.nlm.nih.gov) using the sequence analysis software "MegAlign" (DNA Star, Inc., Wisconsin, USA). 


\section{RESULTS}

The aim of this study was to investigate the occurrence of MAP in fecal samples collected from zoo animals by PCR assays. In total, samples from 21 mammalian and avian species were collected, pooled for each species, and tested for MAP by qualitative snPCR and quantitative rtPCR (Table 1). At the time of sampling, no clinical cases of paratuberculosis were evident and the fecal consistence was representative for the respective species.

Table 1: Detection of MAP in pooled fecal samples collected from different animal species by IS 900 semi-nested and quantitative real-time PCR.

\begin{tabular}{|c|c|c|c|}
\hline \multirow[b]{2}{*}{ Species (English) } & \multirow[b]{2}{*}{ Species (Latin) } & \multicolumn{2}{|c|}{ Results } \\
\hline & & $\mathrm{snPCR}^{\mathrm{a}}$ & $\mathrm{rtPCR}^{\mathrm{b}}$ \\
\hline Barbary Sheep & Ammotragus lervia & $0 / 10$ & n.d. \\
\hline Sitatunga Antelope & Tragelaphus spekii & $2 / 10$ & -- \\
\hline West African Dwarf Goat & Capra aegagrus $f$. hircus & $2 / 10$ & $31.07 \pm 0.15$ \\
\hline Alpaca & Lama pacos & $0 / 10$ & n.d. \\
\hline Bactrian Camel & Camelus bactrianus & $1 / 10$ & -- \\
\hline Llama & Lama glama & $0 / 10$ & n.d. \\
\hline Chapman's Zebra & Equus quagga chapmani & $1 / 10$ & -- \\
\hline Shetland Pony & Equus f. caballus & $0 / 10$ & n.d. \\
\hline Black-and-white Ruffed Lemur & Varecia variegata & $10 / 10$ & $28.65 \pm 0,17$ \\
\hline Cottontop Tamarin & Saguinus oedipus & $10 / 10$ & $35.26 \pm 0.18$ \\
\hline Gelada Baboons & Theropithecus gelada & $1 / 10$ & $39.72 \pm 0.27$ \\
\hline Gibbons & Hylobatidae & $0 / 10$ & n.d. \\
\hline Ring-tailed Lemur & Lemur catta & $0 / 10$ & n.d. \\
\hline Desmarest's Hutia & Capromys pilorides & $7 / 10$ & $36.25 \pm 0.36$ \\
\hline Patagonian Cavies & Dolichotis patagonum & $4 / 10$ & $35.90 \pm 0.31$ \\
\hline $\mathrm{Emu}$ & Dromaius novaehollandiae & $1 / 10$ & -- \\
\hline Parrots & Ara & $2 / 10$ & $36.35 \pm 2.55$ \\
\hline Shorebirds & Ciconiiformes & $0 / 10$ & n.d. \\
\hline Snowy Owl & Bubo scandiacus & $2 / 10$ & -- \\
\hline Vulturine Guineafowl & Acryllium vulturinum & $2 / 10$ & -- \\
\hline Wallaby & Macropodidae & $6 / 10$ & $37.31 \pm 0.21$ \\
\hline
\end{tabular}

\footnotetext{
${ }^{a}$ No. positive aliquots/No. tested aliquots of a pooled fecal sample

${ }^{\mathrm{b}}$ Average Crossing points (Cp) with standard deviation, based on three runs n.d. = not done if samples were negative by snPCR; -- = no amplification curve detected
} 
Detection of MAP-DNA in feces. Taking into account the cluster formation of MAP, DNA was extracted from 10 aliquots of each pooled sample to compensate nonhomogeneous bacterial distribution patterns. Collectively, 210 fecal sample aliquots (21 species) tested by snPCR. The MAP specific $278 \mathrm{bp}$ fragment, alone or both the $278 \mathrm{bp}$ and $587 \mathrm{bp}$ fragments, were amplified in 51 of the 210 fecal aliquots, depending on DNA concentration. Accordingly, 14 of the 21 species tested positive for MAP by snPCR, indicating a MAP occurrence of $66.7 \%$ in the pooled samples (Figure 1).

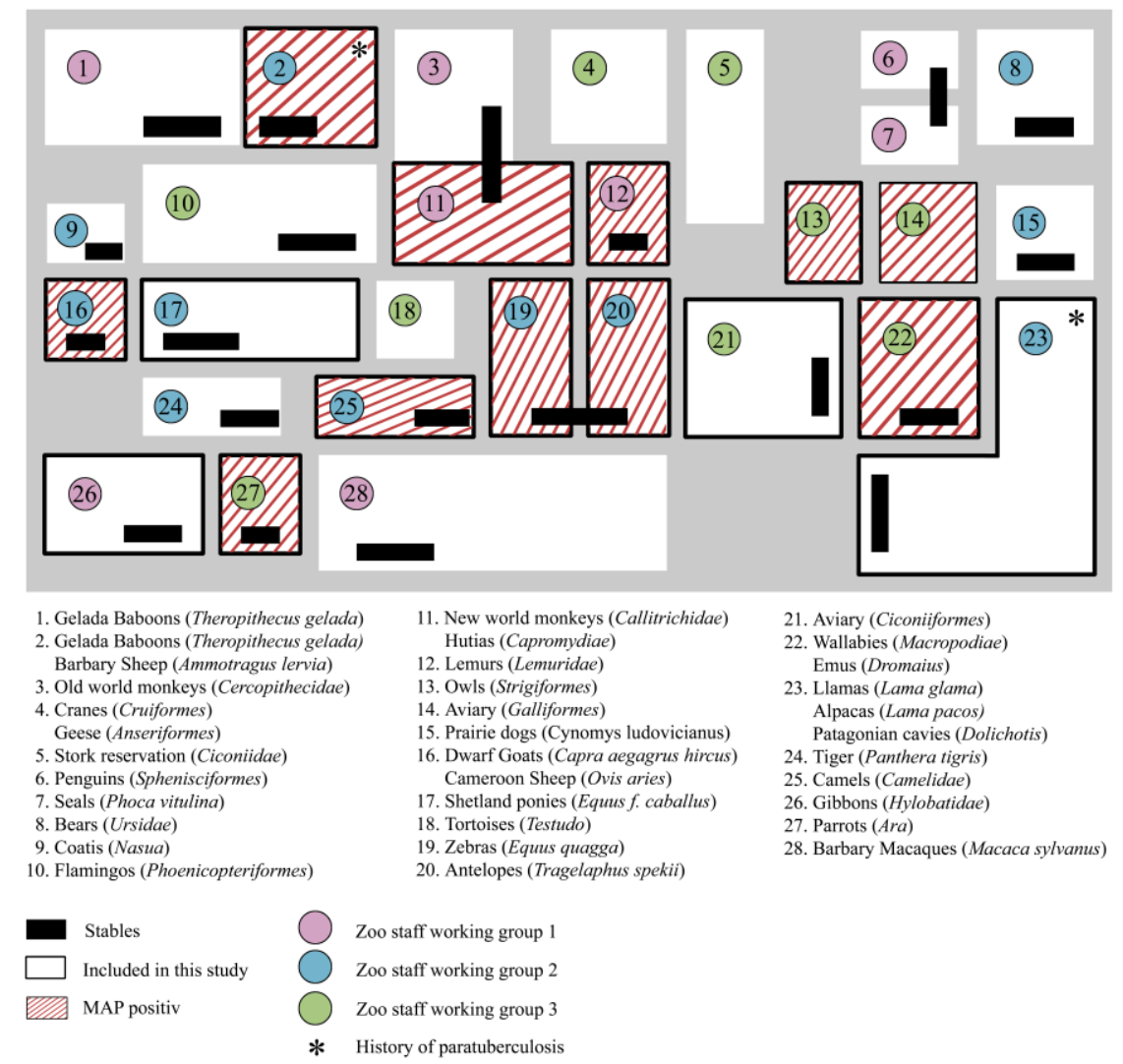

Figure 1: Schematic map of the investigated zoo showing included and excluded compounds as well as exhibits which tested positive for MAP. Zoo employees are responsible for different districts (Zoo staff working group 13 ) and enter certain animal enclosures for feeding, cleaning, and maintenance.

In total, $13.3 \%$ of the ruminant fecal sample aliquots tested positive by snPCR. These included 2 of 10 sample aliquots drawn from Sitatunga antelopes (Tragelaphus spekii) and 2 of 10 sample aliquots drawn from West African dwarf goats (Capra aegagrus hircus). No MAP-DNA was detected in feces collected from Barbary sheep (Ammotragus lervia). 
MAP was also present in $3.3 \%$ of the examined aliquots collected from camelids. While Bactrian camels (Camelus bactrians) tested positive in 1 of 10 sample aliquots, no MAP-DNA was detected in feces drawn from alpacas (Lama pacos) and llamas (Lama glama).

Equidae were identified to shed MAP, too. The snPCR detected one (5.0\%) positive equine fecal sample aliquot in Chapman Zebras (Equus quagga chapmani). No positive result was determined in fecal samples collected from Shetland ponies (Equus ferus caballus).

MAP-DNA was detected in $42.0 \%$ fecal specimen aliquots collected from primates. Primates such as Black-and-white ruffed lemurs (Varecia variegata) and Cottontop tamarins (Saguinus Oedipus) were shown to shed high amounts of MAP. While MAP was present in all 10 fecal sample aliquots drawn from Black-and-white ruffed lemurs and Cottontop tamarins, only 1 of 10 fecal sample aliquots from Gelada baboons (Theropithecus gelada) were positive by snPCR. MAP shedding was neither detected in gibbons (Hylobatidae) nor in Ring-tailed lemurs (Lemur catta).

Rodents investigated included Desmarest's hutias (Capromys pilorides) and Patagonian cavies (Dolichotis patagonum). MAP was detected by snPCR in 7 of 10 (70.0\%) sample aliquots drawn from Desmarest's hutias and in 4 of $10(40.0 \%)$ sample aliquots drawn from Patagonian cavies.

Wallabies (Macropodidae) belonging to macropods tested positive in 6 of $10(60.0 \%)$ fecal sample aliquots.

Furthermore, birds were determined to be positive by snPCR. In total, $14.0 \%$ fecal sample aliquots collected from birds tested positive by snPCR. MAP was detected by snPCR in 2 of 10 sample aliquots drawn from Snowy owls (Bubo scandiacus), parrots (Ara), and Vulturine guineafowls (Acryllium vulturinum), respectively. Only 1 of 10 sample aliquots collected from emus (Dromaius novaehollandiae) contained MAP. Shorebirds (Charadriiformes) were not identified to shed MAP.

Detection of MAA-DNA in feces. In order to exclude Mycobacterium avium ssp. avium (MAA) infection, all fecal samples positive in snPCR were examined by IS901 MAAPCR (Miller et al., 1999). While MAA-DNA was detected in fecal sample aliquots drawn from Desmarest's hutias (6 sample aliquots), none of the other species tested positive for MAA (Figure 2). 
Quantification of MAP-DNA in feces. Only samples tested MAP-positive in SnPCR were quantified by a rtPCR assay, because validation data demonstrated rtPCR to be less sensitive than snPCR (Schneider, 2003). In total, 51 of 210 fecal aliquots, representing 14 different mammalian and avian species, were investigated (Figure 2).

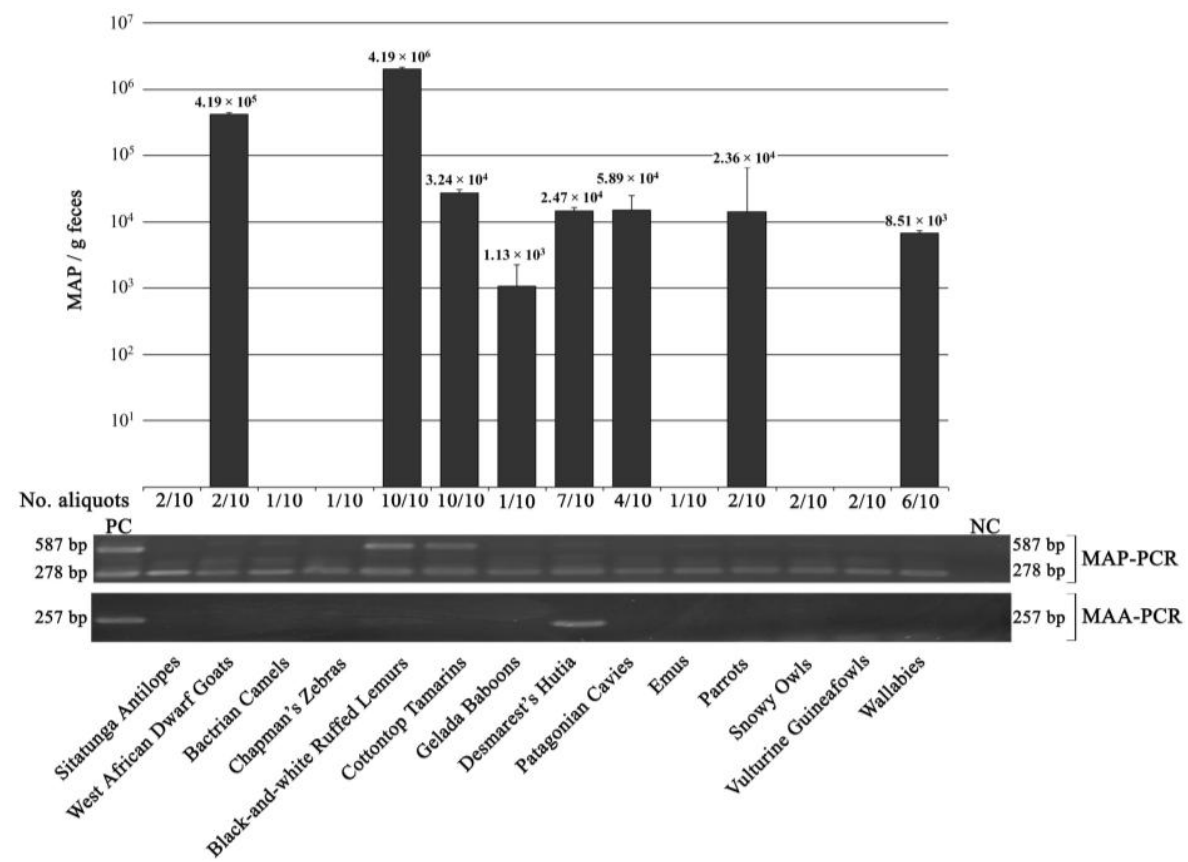

Figure 2: Detection and quantification of MAP-DNA in pooled fecal samples by qualitative semi-nested and quantitative real-time PCR. Pooled fecal samples drawn from zoo animals of each species were divided into 10 aliquots, respectively, and tested by snPCR. In all samples tested positive by snPCR, MAP-DNA was quantified by rtPCR. The mean value for an assay carried out in triplicate and, the interassay coefficient of variation were calculated. The average MAP particle number detected in feces was calculated by MAP genome size and is stated above each column. The corresponding number of sample aliquots, tested positive by snPCR, as well as the corresponding gels showing the amplification products generated by MAP-snPCR (587 bp and $278 \mathrm{bp}$ ) and MAA-PCR (257 bp), are presented underneath. PC, Positive control (MAP-DNA/MAA-DNA); NC, Negative control (Aqua dest.).

The less sensitive rtPCR supported snPCR results in only 40 of the 51 tested sample aliquots. Data analyses resulted in comparable $\mathrm{Cp}$-values for all runs and the assay proved to be reproducible as the coefficient of variation was statistically low $( \pm 0.15$ 2.55) (Table 1). 
West African dwarf goats were the only ruminant species which tested positive with $4.19 \times 10^{5} \mathrm{MAP} / \mathrm{g}$ feces by rtPCR. Despite positive snPCR results in camelids (Bactrian camels) and equines (Chapman zebras), rtPCR failed to detect MAP in fecal samples. All primates with MAP positive snPCR results were confirmed to be positive by rtPCR, too. Black-and-white ruffed lemurs shed the highest concentration of MAP with feces $\left(4.91 \times 10^{6} \mathrm{MAP} / \mathrm{g}\right)$, while the lowest number was found in fecal samples obtained from Gelada baboons $\left(1.13 \times 10^{3} \mathrm{MAP} / \mathrm{g}\right)$ and Cottontop tamarins $\left(3.24 \times 10^{4} \mathrm{MAP} / \mathrm{g}\right)$. Rodents such as Desmarest's hutias and Patagonian cavies shed $2.47 \times 10^{4} \mathrm{MAP} / \mathrm{g}$ in feces and $5.89 \times 10^{4} \mathrm{MAP} / \mathrm{g}$ in feces, respectively. In Wallabies, MAP was also detected by $\mathrm{rtPCR}$ with $8.51 \times 10^{3} \mathrm{MAP} / \mathrm{g}$ in feces. Among birds, only parrots were confirmed by rtPCR to shed $2.36 \times 10^{4} \mathrm{MAP} / \mathrm{g}$ in feces.

Sequencing of amplicons. The specificity and quality of PCR amplification products (587 bp and $278 \mathrm{bp}$ ) was confirmed by gel electrophoresis. For further identity confirmation and in order to detect polymorphisms, the $278 \mathrm{bp}$ fragments were sequenced and aligned to the MAP K10 IS900 reference sequence (GenBank: AE16958). Two sequences of each isolate were analyzed. Thirteen of the 14 isolates (26 sequences) revealed a nucleotide homology of $100 \%$ for the $278 \mathrm{bp}$ fragment, covering nucleotide positions 492 and 769 within the IS900. In addition, 17 single nucleotide substitutions were found in one avian isolate (both sequences) obtained from Snowy owls at positions $513(\mathrm{~T} \rightarrow \mathrm{G}), 522(\mathrm{~T} \rightarrow \mathrm{C}), 582(\mathrm{G} \rightarrow \mathrm{C}), 590(\mathrm{~A} \rightarrow \mathrm{G}), 603(\mathrm{~T} \rightarrow \mathrm{G}), 609$ $610(\mathrm{CG} \rightarrow \mathrm{TA}), 615(\mathrm{C} \rightarrow \mathrm{T}), 618(\mathrm{~T} \rightarrow \mathrm{C}), 627(\mathrm{~A} \rightarrow \mathrm{C}), 661(\mathrm{C} \rightarrow \mathrm{G}), 678(\mathrm{G} \rightarrow \mathrm{C}), 698$ $(\mathrm{A} \rightarrow \mathrm{T}), 717(\mathrm{~A} \rightarrow \mathrm{G}), 729-730(\mathrm{GC} \rightarrow \mathrm{TT})$, and $754(\mathrm{C} \rightarrow \mathrm{T})$, resulting in a homology degree of $93.9 \%$.

\section{DISCUSSION}

Domestic ruminants are commonly accepted to be primary reservoirs of paratuberculosis. However, MAP may also occur in an extended range of other animals including non-ruminants. Although there is evidence that MAP can be found in a wide host range, little information regarding the occurrence and distribution of MAP in wildlife and zoological gardens is available in literature. Therefore, the scope of the current study was to estimate the occurrence of MAP by PCR in randomly pooled fecal samples of different species including non-ruminants, kept in a German zoo with a known history of paratuberculosis. 
Our study confirms that MAP is apparently present in zoological gardens. These results are in agreement with earlier studies investigating the occurrence of MAP in different zoo ruminants. A MAP-occurrence of $10.9 \%(n=174)$ was reported for Germany using fecal culture (Weber et al., 1992). PCR studies investigating mesenteric lymph nodes and intestinal tissues reported MAP-occurrences of $57 \%(\mathrm{n}=33)$ and $6.3 \%(\mathrm{n}=48)$ for Austria and Belgium, respectively (Erume et al., 2001; Vansnick et al., 2005).

Due to surveys that mainly focused on species well-known to be susceptible to paratuberculosis, MAP was primarily identified in domestic and exotic ruminants in the past. Although the transmission rate from wildlife to domestic animals is unknown, our results demonstrated that shedding of MAP occurs in ruminants as well as in nonruminants such as camelids, equines, primates, rodents, and birds. Common housing conditions in zoo facilities, including crowding of animals and different species running on the same pasture, represent significant risk factors for MAP infection. In the zoo investigated, Chapman zebras (Equus quagga chapmani) are located right next to Sitatunga antelopes (Tragelaphus spekii), sharing one stable. Both species were tested MAP positive. MAP-DNA was also found in the Australian collection harbouring emus (Dromaius novaehollandiae) and wallabies (Macropodidae). The pens for llamas and alpacas are located close by, and there is a walk-through exhibit harbouring Patagonian cavies (Dolichotis patagonum). Although MAP was not detected in llamas (Lama glama), fecal samples collected from alpacas (Lama pacos) and Patagonian cavies (Dolichotis patagonum) tested positive for MAP. Furthermore, Gelada baboons, (Theropithecus gelada) with MAP positive results by fecal snPCR, share two hills with Barbary sheep (Ammotragus lervia). Although these sheep did not shed MAP at the time of sampling, inter-species transmission cannot be excluded due to intermittent shedding patterns, characteristic for this pathogen. Across from the sheep, the monkey house not only harbours Cottontop tamarins (Saguinus oedipus), but also Desmarest's hutias (Capromys pilorides). In both species, MAP was detected in feces, indicating inter-species transmission. Notably, the Desmarest's hutias (Capromys pilorides) were shown to be co-infected by MAA. Although multiple infections with mycobacterial species seem to be rare, natural concomitant infections with MAP/M. caprae in goats have been reported on previous occasions (Alvarez et al., 2008). These findings indicate that the presence of other mycobacterial species in a MAP-infected population cannot be excluded and must be taken into account particularly in terms of specificity of applied detection assays. According to our results, MAP was widespread in the zoo and 
could be detected in all genera investigated. This study implies that cross-species infection of MAP had probably occurred in the investigated zoo and confirms MAP to be a pathogen not only shed by true ruminants, but also by camelids, primates, macropods, rodents, and birds. MAP has been detected previously in rodent and avian species (Beard et al., 2001a; Corn et al., 2005). Birds or rodents could act as spillover hosts, transmitting the infection to other species, but requiring periodic input from maintenance hosts. Occasionally, this may play a crucial epidemiological role for spillback transmission to potential maintenance hosts. Eradication of MAP in the bovine population probably requires management of the infection in both maintenance hosts and spillover hosts.

Since MAP was widespread in the zoo, further hygienic measures seem to be necessary. While control of paratuberculosis in cattle is usually based on testing and culling of infected animals, this method is not appropriate for zoo animals and particularly not for endangered species. Therefore, the focus should be on prevention of infection by enforcing strict hygiene standards. The investigated zoological garden employs three groups of authorized staff that are responsible for different districts. However, no epidemiological link between MAP occurrence and staff working groups could be demonstrated, indicating alternative sources of MAP transmission, most likely via free ranging wildlife or direct contact between neighbouring species. Therefore, wildlife access to feed storage areas and zoo animals should be banned and barriers should be installed. This is especially important with respect to rodents. Furthermore, it is known that MAP possesses potential mechanisms to survive and disseminate in the environment (Rowe and Grant, 2006). Recent studies demonstrated spatial and temporal spread of MAP in a cattle farm environment through bio-aerosols or the survival of MAP in biofilms on livestock watering trough materials (Cook et al., 2010; Eisenberg et al., 2010). Consequently, routine hygienic measures should not only include a limited number of authorized staff members with restricted access to the enclosures, but also regular cleaning and disinfection, as well as the use of protective clothing and utensils, that are not removed from the respective area. An effective measure may be to prevent the introduction of infections from exogenous sources by testing all animals for MAP on arrival at quarantine quarters. Despite the fact that this is not always practicable in daily zoo routine due to time and economic reasons, MAP diagnosis cannot rely on a single test, as diagnostic assays reveal limitations for the early detection of MAP. Serological methods were used regularly to detect MAP infection in ruminant species. 
However, blood sampling is less appropriate for captured wildlife due to fixation stress. At present, there are no available serological tests adapted to species other than domestic ruminants. In addition, seronegative shedders which contaminate the environment are seen frequently (Khol et al., 2011). Several studies used both culture and PCR for MAP detection (Motiwala et al., 2004; Vansnick et al., 2005). Culture requires costly selective media and a long cultivation period for up to one year. It must be considered that the efficiency of bacterial culture is also strain dependent (Garrido et al., 2000; Juste et al., 1991). Therefore, the method of choice for direct pathogen detection is PCR, especially when carried out in pooled samples. Nested or semi-nested PCR technique, a two step amplification procedure, may even increase the sensitivity of efficient amplification. The great potential of nested or semi-nested PCRs has been shown recently (Erume et al., 2001; Münster et al., 2011). Although the snPCR used in the current study requires considerable efforts to prevent cross-contamination and, therefore, would not be recommended for routine diagnosis laboratories, it is a highly appreciated method to confirm MAP in samples requiring a high degree of sensitivity and specificity. Nowadays, rtPCR is the method of choice for direct pathogen detection due to speed, high sample throughput, and a reduced risk of cross-contamination.

In particular, the introduction of new zoo animals which may be sub-clinically infected and shed MAP could present problems for paratuberculosis surveillance and control programs. Animals are frequently exchanged between zoos, and stress during transport may enhance the risk of MAP shedding. The long incubation period prior to visible clinical signs may cause a considerable spread of the infection in a former paratuberculosis free collection. Little is known about pathogenesis and the course of the infection in wild and zoo animals. In our study, all animals were asymptomatic at the time of sampling. Although alpacas and sheep kept in the zoo showed a history of paratuberculosis, no distinctive signs of paratuberculosis have ever been recorded for animals other than ruminants or camelids. It could be assumed that MAP might replicate in non-ruminants without triggering clinical signs of paratuberculosis. However, previous studies reported histopathological lesions consistent with MAP in rabbits (Oryctolagus cuniculus), mice (Apodemus sylvaticus), foxes (Vulpes vulpes), weasels (Mustela nivalis), stoats (Mustela erminea), and crows (Corvus corone) (Angus, 1990; Beard et al., 2001a; Greig et al., 1999; Greig et al., 1997). Clinical paratuberculosis was also confirmed in a colony of stumptail macaques (Macaca arctoides) and in a mandrill (Papio sphinx) (McClure et al., 1987; Zwick et al., 2002). 
The clinical and pathologic findings in these species were comparable with those reported for paratuberculosis in ruminants. There are also many parallels which can be drawn between the findings of MAP infection in animals, and Morbus Crohn's (CD) disease in humans (Mendoza et al., 2009). In recent years, a controversy regarding the potential zoonotic role of MAP in human $\mathrm{CD}$ and its importance as a public health issue has emerged. Despite the lacking aetiological evidence between MAP and CD, it is suggested that animals in close contact with humans should be free of this pathogen. With regard to visitor safety, animals kept in children zoos, in particular, should be monitored for MAP. Although the disease is assumed to be predominant in domestic ruminants, our study indicates that other animals, commonly kept in petting zoos, such as equines, rodents, and birds, should be also be subject to MAP monitoring.

Although endogenous systemic pathways of the infection are not well understood, it is known that the risk of MAP infection is dose-dependent. Especially young animals are thought to be highly susceptible to MAP due to their immature immune systems. For ruminants, it is assumed that a diseased animal sheds up to $10^{12}$ CFU MAP per day in feces and the infective dose for calves is considered to be $10^{3} \mathrm{CFU} /$ animal (Whittington and Sergeant, 2001). Regarding non-ruminants, the minimal infective dose for an animal is yet to be investigated. Comparable to domestic ruminants, the pattern and level of MAP shedding in feces may differ within species and individuals. Although PCR cannot distinguish between dead or alive bacteria and does not indicate whether bacteria are capable of infection, our results support the hypothesis that sub-clinically infected zoo animals shed $10^{3}$ to $10^{6} \mathrm{MAP} / \mathrm{g}$ feces. Moreover, it was demonstrated that the highest amount of MAP was detected in primates. This assumption is underpinned by a high number of positive fecal sample aliquots in snPCR. These findings may indicate a high susceptibility to MAP infection and lead to the assumption that primates are maintenance hosts which contribute significantly to environmental contamination. In contrast, despite a positive result recorded by SnPCR, no MAP-DNA was detected by rtPCR in equines. rtPCR is considered to be less sensitive than snPCR, thus, samples tested positive in snPCR but negative in rtPCR, containing MAP below the detection limit. It could be assumed that transmission of the MAP infection via equines is unlikely due to the low concentration of MAP in feces. However, shedding of MAP in feces occurs intermittently with differing MAP concentrations. Diagnostic tests may therefore lead to temporarily negative results and infected animals could represent a potential source of later infections. 
At the time of each outbreak of paratuberculosis, efforts should be made to isolate and classify the strain type for efficient tracing-back in paratuberculosis epidemiology. Unique single nucleotide polymorphisms (SNPs) within the IS900 sequence were recently reviewed, and DNA sequencing for the detection of polymorphisms has been considered to be promising for the differentiation of MAP strains (Castellanos et al., 2009). In order to detect polymorphisms, the selected $278 \mathrm{bp}$ fragments of all 14 positive samples, covering nucleotide positions 492 and 769 within the 1,451 bp IS900, were sequenced. While 13 isolates showed a $100 \%$ homology with the corresponding MAP K10 IS900 reference sequence (GenBank: AE16958), seventeen single nucleotide substitutions were found in one avian isolate. These nucleotide exchanges were found in two clones and in both strands of each clone, indicating true strain specificity. Previous studies described unique SNPs in IS900 sequences (Castellanos et al., 2009). Nucleotide sequence variabilities were confirmed between MAP-IS900 gene fragments, amplified from leucocytes of cattle (GenBank: AY974345-AY974347) and sheep (GenBank: AY974348) (Bhide et al., 2006). Sequences obtained from sheep-type isolates exhibited two ambiguities at base pair position 169 (T/C) and $216(\mathrm{G} / \mathrm{A})$ with respect to those of the cattle type (Semret et al., 2006). Therefore, sequencing of amplicons is not only a valuable tool to prove PCR specificity, but it also leads to the differentiation of strain types. Apart from the distinction between so-called sheep and cattle-associated MAP variants, research on genetically distinctive strains will provide data for efficient tracing-back in paratuberculosis epidemiology.

In conclusion, the results of the present study confirm the wide host range of MAP and demonstrate that MAP occurs more frequently in zoo animals than previously suspected. In order to determine the occurrence of MAP in different animal species and control MAP in European zoos, further investigations concerning the potential transmission and spread of MAP in zoos are recommended.

\section{REFERENCES}

Alvarez, J., de Juan, L., Bezos, J., Romero, B., Saez, J.L., Reviriego Gordejo, F.J., Briones, V., Moreno, M.A., Mateos, A., Dominguez, L., Aranaz, A., 2008, Interference of paratuberculosis with the diagnosis of tuberculosis in a goat flock with a natural mixed infection. Vet Microbiol 128, 72-80.

Angus, K.W., 1990, Intestinal lesions resembling paratuberculosis in a wild rabbit (Oryctolagus cuniculus). J Comp Pathol 103, 101-105. 
Beard, P.M., Daniels, M.J., Henderson, D., Pirie, A., Rudge, K., Buxton, D., Rhind, S., Greig, A., Hutchings, M.R., McKendrick, I., Stevenson, K., Sharp, J.M., 2001a, Paratuberculosis infection of nonruminant wildlife in Scotland. J Clin Microbiol 39, 1517-1521.

Beard, P.M., Rhind, S.M., Buxton, D., Daniels, M.J., Henderson, D., Pirie, A., Rudge, K., Greig, A., Hutchings, M.R., Stevenson, K., Sharp, J.M., 2001b, Natural paratuberculosis infection in rabbits in Scotland. J Comp Pathol 124, 290-299.

Bhide, M., Chakurkar, E., Tkacikova, L., Barbuddhe, S., Novak, M., Mikula, I., 2006, IS900-PCR-based detection and characterization of Mycobacterium avium subsp. paratuberculosis from buffy coat of cattle and sheep. Vet Microbiol 112, 33-41.

Castellanos, E., Aranaz, A., de Juan, L., Alvarez, J., Rodriguez, S., Romero, B., Bezos, J., Stevenson, K., Mateos, A., Dominguez, L., 2009, Single nucleotide polymorphisms in the IS900 sequence of Mycobacterium avium subsp. paratuberculosis are strain type specific. J Clin Microbiol 47, 2260-2264.

Cocito, C., Gilot, P., Coene, M., de Kesel, M., Poupart, P., Vannuffel, P., 1994, Paratuberculosis. Clin Microbiol Rev 7, 328-345.

Cook, K.L., Britt, J.S., Bolster, C.H., 2010, Survival of Mycobacterium avium subsp. paratuberculosis in biofilms on livestock watering trough materials. Vet Microbiol 141, 103-109.

Corn, J.L., Manning, E.J., Sreevatsan, S., Fischer, J.R., 2005, Isolation of Mycobacterium avium subsp. paratuberculosis from free-ranging birds and mammals on livestock premises. Appl Environ Microbiol 71, 6963-6967.

Eisenberg, S.W., Nielen, M., Santema, W., Houwers, D.J., Heederik, D., Koets, A.P., 2010, Detection of spatial and temporal spread of Mycobacterium avium subsp. paratuberculosis in the environment of a cattle farm through bio-aerosols. Vet Microbiol 143, 284-292.

Erume, J., Spergser, J., Rosengarten, R., 2001, Rapid detection of Mycobacterium avium subsp. paratuberculosis from cattle and zoo animals by nested PCR. Afr Health Sci 1, 83-89.

Florou, M., Leontides, L., Kostoulas, P., Billinis, C., Sofia, M., Kyriazakis, I., Lykotrafitis, F., 2008, Isolation of Mycobacterium avium subspecies paratuberculosis from non-ruminant wildlife living in the sheds and on the pastures of Greek sheep and goats. Epidemiol Infect 136, 644-652.

Garrido, J.M., Cortabarria, N., Oguiza, J.A., Aduriz, G., Juste, R.A., 2000, Use of a PCR method on fecal samples for diagnosis of sheep paratuberculosis. Vet Microbiol 77, 379-386.

Greig, A., Stevenson, K., Henderson, D., Perez, V., Hughes, V., Pavlik, I., Hines, M.E., 2nd, McKendrick, I., Sharp, J.M., 1999, Epidemiological study of paratuberculosis in wild rabbits in Scotland. J Clin Microbiol 37, 1746-1751.

Greig, A., Stevenson, K., Perez, V., Pirie, A.A., Grant, J.M., Sharp, J.M., 1997, Paratuberculosis in wild rabbits (Oryctolagus cuniculus). Vet Rec 140, 141-143.

Harris, N.B., Barletta, R.G., 2001, Mycobacterium avium subsp. paratuberculosis in Veterinary Medicine. Clin Microbiol Rev 14, 489-512.

Juste, R.A., Marco, J.C., Saez de Ocariz, C., Aduriz, J.J., 1991, Comparison of different media for the isolation of small ruminant strains of Mycobacterium paratuberculosis. Vet Microbiol 28, 385-390. 
Khol, J.L., Geisbauer, E., Wassertheurer, M., Revilla-Fernandez, S., Damoser, J., Osterreicher, E., Dunser, M., Kleb, U., Baumgartner, W., 2011, Outcome of Three Commercial Serum ELISAs and Faecal Detection of Mycobacterium avium subsp. paratuberculosis in Consecutive Samples from a Cattle Herd with Low Prevalence of Paratuberculosis (Johne's Disease). Transbound Emerg Dis.

McClure, H.M., Chiodini, R.J., Anderson, D.C., Swenson, R.B., Thayer, W.R., Coutu, J.A., 1987, Mycobacterium paratuberculosis infection in a colony of stumptail macaques (Macaca arctoides). J Infect Dis 155, 1011-1019.

Mendoza, J.L., Lana, R., Diaz-Rubio, M., 2009, Mycobacterium avium subspecies paratuberculosis and its relationship with Crohn's disease. World J Gastroenterol $15,417-422$.

Miller, J.M., Jenny, A.L., Ellingson, J.L., 1999, Polymerase chain reaction identification of Mycobacterium avium in formalin-fixed, paraffin-embedded animal tissues. $\mathbf{J}$ Vet Diagn Invest 11, 436-440.

Motiwala, A.S., Amonsin, A., Strother, M., Manning, E.J., Kapur, V., Sreevatsan, S., 2004, Molecular epidemiology of Mycobacterium avium subsp. paratuberculosis isolates recovered from wild animal species. J Clin Microbiol 42, 1703-1712.

Münster, P., Volkel, I., Wemheuer, W., Petschenka, J., Wemheuer, W., Steinbrunn, C., Campe, A., Schulz-Schaeffer, W.J., Kreienbrock, L., Czerny, C.P., 2011, Detection of Mycobacterium avium ssp. paratuberculosis in ileocaecal lymph nodes collected from elderly slaughter cows using a semi-nested IS900 polymerase chain reaction. Vet Microbiol 154, 197-201.

Rowe, M.T., Grant, I.R., 2006, Mycobacterium avium ssp. paratuberculosis and its potential survival tactics. Lett Appl Microbiol 42, 305-311.

Schneider, F., 2003. Entwicklung einer "seminested PCR" und einer "Real-Time-PCR" zum Nachweis von Mycobacterium avium ssp. paratuberculosis bei Rindern (Development of a "semi-nested PCR" and a "real-time PCR" for the detection of Mycobacterium avium ssp. paratuberculosis in cattle) Ph.D. Dissertation. Ludwig-Maximilians-University, Munich, Bavaria, Germany,

Semret, M., Turenne, C.Y., Behr, M.A., 2006, Insertion sequence IS900 revisited. J Clin Microbiol 44, 1081-1083.

Stevenson, K., Alvarez, J., Bakker, D., Biet, F., de Juan, L., Denham, S., Dimareli, Z., Dohmann, K., Gerlach, G.F., Heron, I., Kopecna, M., May, L., Pavlik, I., Sharp, J.M., Thibault, V.C., Willemsen, P., Zadoks, R.N., Greig, A., 2009, Occurrence of Mycobacterium avium subspecies paratuberculosis across host species and European countries with evidence for transmission between wildlife and domestic ruminants. BMC Microbiol 9, 212.

Vansnick, E., Vercammen, F., Bauwens, L., D'Haese, E., Nelis, H., Geysen, D., 2005, A survey for Mycobacterium avium subspecies paratuberculosis in the Royal Zoological Society of Antwerp. Vet J 170, 249-256.

Weber, A., Gurke, R., Bauer, K., Schreyer, K., 1992, [Bacterial studies on the occurrence of Mycobacterium paratuberculosis in fecal samples of zoo ruminants]. Berl Munch Tierarztl Wochenschr 105, 161-164.

Whittington, R.J., Sergeant, E.S., 2001, Progress towards understanding the spread, detection and control of Mycobacterium avium subsp paratuberculosis in animal populations. Aust Vet J 79, 267-278.

Zwick, L.S., Walsh, T.F., Barbiers, R., Collins, M.T., Kinsel, M.J., Murnane, R.D., 2002, Paratuberculosis in a mandrill (Papio sphinx). J Vet Diagn Invest 14, 326328. 


\section{Author's contribution}

Chapter I: Short Communication: Detection of Mycobacterium avium ssp. paratuberculosis in Ileocaecal Lymph Nodes Collected from Elderly Slaughter Cows using a semi-nested IS900 Polymerase Chain Reaction.

The author PM established the matrix specific PCR adaptation, helped with sample preparation, investigated the tissue samples, performed sequencing and was the primary writer of the manuscript.

Chapter II: A longitudinal study to characterize the distribution patterns of Mycobacterium avium ssp. paratuberculosis in semen, blood and feces of a naturally infected bull by IS900 semi-nested and quantitative real-time PCR.

The author PM established the matrix specific PCR adaptation, investigated fecal, semen, and blood samples, performed sequencing, did the statistical analyses, and was the primary writer of the manuscript.

Chapter III: Brief Communication: Detection of Mycobacterium avium ssp. paratuberculosis by IS900-based PCR assays from an alpaca (Vicugna pacos) kept in a German zoological garden.

The author PM was responsible for the molecular analysis of clinical sample matrices, designed the PCR system for strain-type differentiation, performed sequencing, and was the primary writer of the manuscript.

Chapter IV: Distribution of Mycobacterium avium ssp. paratuberculosis in a German zoological garden by IS900 semi-nested and quantitative real-time PCR.

The author PM coordinated and supervised the study, collected fecal samples, performed sequencing and was the primary writer of the manuscript. 


\section{General Discussion}

Since paratuberculosis remains a significant problem for the dairy and beef business due to considerable economic impacts, the cattle industry has focused on MAP surveillance and eradication programs. The decision-making process in the development of a paratuberculosis control program is supported by diagnostic as well as epidemiological data. That includes studies on test characteristics and improvement as well as prevalence estimates, monitoring, and surveillance.

MAP detection by PCR is available since two decades and will be the method of choice for direct pathogen detection in future due to speed and high sample throughput. In the present thesis recently developed IS900 semi-nested (snPCR) and quantitative IS900 real-time PCR (rtPCR) assays were used for the detection and quantification of MAP (Schneider, 2003). The application of the snPCR is a reliable method to confirm MAP in clinical samples independent of the matrices investigated and primarily recommended for research requiring a high sensitivity and specificity. The rTCR is a qualitative and quantitative PCR technique for DNA quantification and represents an advanced version of the conventional PCR method. The primary objective of this thesis was to evaluate molecular biological methods for the sensitive and specific detection of MAP and to contribute to a more detailed understanding of paratuberculosis by providing epidemiological data regarding the distribution of MAP.

To generate an efficient national paratuberculosis control program, information about regional prevalences is required. Although European estimates of the burden of paratuberculosis in livestock are uncertain, the prevalence is thought to be significant (Nielsen and Toft, 2009). In addition, an increase of MAP presence is strongly supported by modelling studies (Kudahl et al., 2008). Infected cattle need to be identified accurately and in early stages of the disease. Failure to do so will lead to continued transmission of MAP and underestimated MAP frequency. Currently available ante mortem diagnostic methods reveal limitations for the early detection of MAP. Additionally, prevalence estimates of MAP vary widely due to differences in diagnostic tests and sampling methodology. Alternatively, PCR assays seem to be worthwhile for the direct pathogen detection at the primary site of bacterial multiplication. 
This thesis (Publication I) gave some important baseline information about MAP occurrence in Lower Saxony. The occurrence of MAP infection in elderly cows was investigated by testing ileocaecal lymph nodes (ILN) at slaughter. It demonstrated that direct tissue sampling from abattoir cattle seems to be a suitable tool to determine the herd and inner-herd occurrence of subclinical MAP infections post mortem in a retrospective way. It is an attractive method to monitor the spread of paratuberculosis not only in elderly cattle, but probably also in the whole cattle population. In future, a larger quantity of sampled animals is required to determine accurate MAP prevalence in Germany as well as Europe based on this technique. Intestinal tissues and mesenteric lymph nodes are generally accepted to be the main locus of MAP colonization (Stabel et al., 2009; Wu et al., 2007). Although, different target tissues, e.g., distal jejunal lymph nodes might be a more appropriate site of sampling (Sweeney et al., 2006), we preferred to use the ILN because it is often recommended to determine MAP occurrence (Wells et al., 2009). Recent studies demonstrated that the ILN was frequently culture-negative (Koo et al., 2004; Sweeney et al., 2006). Sampling multiple intestinal sites rather than just the ILN should therefore be considered for further investigation. Due to a relatively high MAP occurrence of $17.17 \%$ in ILN of German slaughter cattle; this thesis demonstrates paratuberculosis to be an important disease. Because of its economic significance and for consumer protection, it highlights the need for governmental action with reference to harmonized eradication programs at federal level.

Initiating successful programs also require sound information about the distribution patterns as well as transmission pathways of MAP. Disease control recommendations for cattle reflect the fact that the fecal-oral transmission of MAP is commonly accepted to be the dominant maintenance of paratuberculosis in livestock. Paratuberculosis control programs are mainly based on 'test and cull' strategies. However, literature and dissatisfied results indicate that eradication is not possible using only these strategies. These reports indicate that MAP may be transmitted via other possible routes that are not controlled by routine hygienic measures. MAP infection due to vertical transmission could be one significant risk and may hamper control programs mainly focusing on hygienic measurements and calving practices. This being usually considered to be insignificant, a recent simulation modelling evaluated that the addition of vertical transmission has a significant influence on the persistence of MAP on farms (Mitchell et al., 2008). 
MAP may also be transmitted between cattle via semen either by mating or artificially insemination (Sweeney, 1996). Despite of the concern that MAP could be present in semen of breeding bulls, the risk of transmitting MAP via semen has never been assessed before. Currently, little information is available in the literature regarding shedding patterns of MAP. Therefore, one main objective of the current study (Publication II) was to characterize the pattern and quantity of mycobacterial shedding in feces, semen, and blood via snPCR and rtPCR. The presence, amount of contamination of semen with MAP, and the ability of the pathogen to establish infection in the host via the vaginal route determines the risk of transmission of MAP by semen. It is generally accepted that an infected animal enters a silent phase for two or more years, during which MAP is not detectable in feces (Chiodini et al., 1984). According to our study, MAP in bovine feces and semen was already present at the age of 18 months. This is an unusual event for an animal at such a young age. However, recent case studies observed fecal shedding of MAP even in eight-month-old calves and in cattle prior to the age of two years (Antognoli et al., 2007; Weber et al., 2010). Assuming that MAP testing is not a standard procedure for semen examination and that the quality of semen samples might be good despite of the presence of $10^{2}-10^{5} \mathrm{MAP} / \mathrm{ml}$ semen, as a precaution, semen-donor bulls should be tested for MAP on a regularly basis. PCR assays seem to be a valuable and effective alternative to serological tests and worthwhile for the fast and effective examination of MAP in semen. However, PCR does not differentiate between dead or alive bacteria. In future, rapid assays to detect viable MAP in milk as well as semen are required. To understand the consequences of inutero infection further knowledge about the mechanism of access of MAP to the uterus, the influence of the immune status of the cow on utero transmission and the efficacy of vaccination, application of diagnostic tests, and clinical outcome are necessary.

Another significant risk hampering the control of the disease could be the horizontal transmission route via interspecies transmission. Domestic ruminants are commonly accepted to be primary reservoirs of paratuberculosis. However, it has also been reported in a wide range of other domesticated, wild, and zoo animals including nonruminants (Beard et al., 2001a; Greig et al., 1999). 
Even though recent reports have also demonstrated that paratuberculosis is a potential health risk for South American camelids (Barrington et al., 1997; Belknap et al., 1994; Salgado et al., 2009), little information is available in the literature regarding MAP infection in alpacas (Fecteau et al., 2009; Lucas et al., 2003; Miller et al., 2000; Ridge et al., 1995). Hence, another aim of this thesis (Publication III) was to confirm the occurrence of MAP in an alpaca (Vicugna pacos) that was bred and kept in a German zoological garden exhibiting clinical signs consistent with paratuberculosis. The presence of MAP was confirmed in feces and in the ILN by IS900-based PCR assays and culture. In suspected clinical cases biopsied sections of ILN tissue proved to be a suitable diagnostic matrix intra vitam or post mortem next to fecal samples. This first report of paratuberculosis in a local alpaca also supports the present occurrence of MAP in German camelid populations and indicates the need to expand routine MAP surveillance to South American camelids. Although, in their natural habitat, cases of mycobacterial infections in South American camelids may be a rare occurrence, they are at a higher risk when held in close contact to other infected animal species, like in zoological gardens, in petting zoos, or free-ranging on pastures. Further investigations should aim to elicit the disease course in camelids and the shedding pattern of MAP in feces at different stages of the infection. Systematic antigen-based routine monitoring of alpaca herds is required for a reliable risk assessment regarding the true importance of the pathogen MAP in current European alpaca populations. Additionally at the time of each outbreak of paratuberculosis, efforts should be made to isolate and classify the strain type for efficient tracing-back in paratuberculosis epidemiology. Unique single nucleotide polymorphisms (SNPs) within the IS900 sequence were recently reviewed and DNA sequencing for the detection of polymorphisms has been considered to be promising for the differentiation of MAP strains (Castellanos et al., 2009). To detect polymorphisms, the $864 \mathrm{bp}$ fragments of the alpaca isolate, covering nucleotide positions 13 and 876 within the 1,451 bp IS900, were sequenced. Previous studies described unique IS900 nucleotide sequence ambiguities at positions 169 (T/C) and 216 (G/A) between MAP-strains isolated from cattle and sheep (Semret et al., 2006). The $864 \mathrm{bp}$ PCR product covered both positions. Clear cytosine and adenine peaks at those loci in the alpaca isolate gave indication to a cattle strain. Therefore, sequencing of amplicons is a valuable tool to classify strain types and may provide data for efficient tracing-back in paratuberculosis epidemiology. 
The epidemiology of MAP particularly regarding interspecies transmission and the role of wildlife populations, that often share the same habitats as livestock, are not well understood. Determination of MAP prevalences should, therefore, not only be restricted to domesticated ruminants or camelids. Reliable data on MAP occurrence and clinical infections in various species other than ruminants is required prior to the generation of effective and comprehensive paratuberculosis control programs in cattle and other livestock animals. Accordingly, a survey for the occurrence of MAP in this zoological garden due to its known clinical paratuberculosis history was arranged (Publication IV). According to our study, 14 out of 21 species were tested positive by fecal snPCR, indicating a MAP occurrence of $66.7 \%$ in the species population tested and confirming that MAP is apparently present in zoological gardens. These results are in agreement with earlier studies investigating the occurrence of MAP in different zoo ruminants. A MAP-occurrence of $10.9 \%(n=174)$ was reported for one zoo located in Germany using fecal culture (Weber et al., 1992). PCR studies investigating mesenteric lymph nodes and intestinal tissues reported MAP-occurrences of 57\% $(\mathrm{n}=33)$ and $6.3 \%(\mathrm{n}=$ 48) for Austria and Belgium, respectively (Erume et al., 2001; Vansnick et al., 2005). Free-ranging and captured wildlife become increasingly important in the transmission of MAP and may delay the final success of eradication programs. Birds or rodents could act as spillover hosts, transmitting the infection to other species, but requiring periodic input from maintenance hosts. Occasionally, this may play a crucial epidemiological role for spillback transmission to potential maintenance hosts. Eradication of MAP in the bovine population probably requires management of the infection in both maintenance hosts and spillover hosts. Only single investigations have been performed regarding transmission of MAP infection between livestock and wildlife. Monitoring wildlife is challenging as population sizes are often unknown and random sampling is difficult. In future, a method for estimating population densities and sampling of different wildlife species has to be established. The established system shall be used to collect data about MAP distribution and its range of host species. Screening wildlife species from different parts of Germany or Europe by means of molecular diagnostic techniques assess prevalence in nature and may give hinds which animal species and ecosystems are affected. Identification of the origin of infection or environmental sources as well as detection of other species (e.g., wild rabbits) shedding MAP could help veterinarians and cattle owners to focus on more sophisticated control measures. 
This thesis demonstrated that PCR analysis is generally a suitable technique to determine MAP occurrence in the local cattle or zoo population and contributes to a more detailed understanding of MAP distribution. The present study confirms a high occurrence of MAP infection in slaughtered cows and the wide host spectrum of MAP. Multiple factors such as vertical and horizontal transmission in combination with MAP shedding in young animals might explain the maintenance of infections in herds. Therefore, both the elimination of paratuberculosis by the "test and cull" strategy as well as the assumption that young stock is not infectious have to be reconsidered. To reduce further spread of MAP, additional monitoring and hygienic measures to prevent the spread of the infection via semen or wildlife are probably required. In addition, investigations about the existing horizontal and vertical transmission pathways of MAP are recommended.

In future, due to the economic significance of paratuberculosis and for consumer protection, governmental action with reference to harmonized eradication programs at federal level is indispensable. Supplementary, the epidemiology of paratuberculosis and the need for required hygienic measures is often difficult for farmers to understand. It is therefore very important to inform and educate, and consequently try to change the attitude and behaviour of farmers. Communication to and between farmers about paratuberculosis will therefore be also an essential part of an effective paratuberculosis control program. Therefore, an educational instrument in the form of a website should be designed, which gives detailed information about the disease and options for controlling it. Furthermore, in future small working groups should be organized in which farmers gain knowledge and can exchange experiences about the control of paratuberculosis. Most control programs are voluntary, and therefore it is considered important that programs are not only epidemiological effective but also economically attractive. 


\subsection{Conclusion}

The concluding remarks of this dissertation were:

1. The presented snPCR and rtPCR are reliable methods to confirm MAP in clinical and environmental samples independent of the matrices investigated.

2. Based on the tissue snPCR 17 out of the 99 samples gave positive results indicating a MAP occurrence of $17.17 \%$ in the random sample.

3. The PCR examination of ileocaecal lymph nodes collected from slaughter cattle used in this study proved to be a valuable technique to determine epidemiological prevalences in the cattle population.

4. The relative high MAP occurrence of $17.17 \%$ in ileocecal lymph nodes of German slaughter cattle highlights the need for governmental action

5. In a longitudinal study intermittent shedding of MAP-DNA in feces, semen and blood samples was observed by snPCR in a naturally infected breeding bull candidate (Bos primigenius taurus).

6. Although no significant relationship was found between the pattern of MAP shedding in feces and blood, a statistically significant agreement between the pattern in semen and blood was detected $(r=0.38, \mathrm{p}<0.05, \mathrm{n}=29)$.

7. Quantitative $\mathrm{rtPCR}$ revealed that the highest concentration of MAP was shed with feces $\left(10^{3}-10^{6} \mathrm{MAP} / \mathrm{g}\right)$, while the lowest concentration was found in semen and blood samples $\left(10^{2}-10^{5} \mathrm{MAP} / \mathrm{ml}\right)$.

8. Since MAP in bovine feces and semen was already present at the age of 18 months, the assumption that young stock is not infectious has to be reconsidered.

9. Viable MAP bacteria in the blood may disseminate the infection within the body being probably a pathogen with a potential for venereal transmission. 
10. Due to serological negative shedders, MAP diagnosis cannot rely on a single test or particular matrix.

11. Camelids such as alpacas (Vicugna pacos) are susceptible to MAP infection exhibiting clinical and pathological findings consistent with paratuberculosis.

12. Sequencing of PCR products can be used successfully for research on genetically distinctive strains.

13. In the survey on the occurrence of MAP in a German zoo, 14 out of the 21 pooled fecal samples gave positive results, indicating a MAP occurrence of $66.7 \%$ in the species population tested.

14. Shedding of MAP occurs in ruminants as well as non-ruminants such as equines, birds, primates, and rodents.

15. Eradication of MAP probably requires management of both the infection in maintenance hosts as well as spillover hosts.

16. MAP might replicate in non-ruminants without triggering clinical signs of paratuberculosis.

17. The concentration of MAP-DNA was in the range of $10^{3}-10^{7}$ MAP per $g$ feces, wheras the highest quantity was shed by primates.

18. The wide host spectrum of MAP demonstrated in the zoo study confirmed that paratuberculosis occurs more frequently in zoo animals than suspected. 


\subsection{Future prospects}

The future prospects of this dissertation are:

1. Development of a rapid assay to detect viable MAP in milk as well as semen.

2. Monitoring shedding patterns of MAP in a clinical infected breeding bull.

3. Determination of accurate MAP prevalence in Germany as well as Europe.

4. Monitoring wildlife reservoirs and its impact on MAP control programs.

5. Molecular characterisation of MAP-strains isolated from cattle and zoo animals. 


\section{Summary}

Mycobacterium avium ssp. paratuberculosis (MAP) is the infectious agent of Johne's disease, a degenerative wasting disorder primarily appearing in domestic and wildlife ruminants. MAP occurs in most parts of the world. Because of considerable economic impacts in dairy and beef industry MAP is drawing increased attention worldwide. The aim of this study was to investigate the occurrence of MAP in different matrices from cattle and zoo animals by qualitative and quantitative PCR techniques. One main objective was to characterize, quantify and correlate MAP shedding in feces, semen, and blood continuously drawn from a breeding bull candidate subclinically infected with MAP and kept isolated under quarantine conditions at the Department of Animal Science. Previously developed IS900 semi-nested PCR (snPCR) and quantitative realtime PCR (rtPCR) assays were used for the detection and quantification of MAP.

The occurrence of MAP infection in elderly cows was investigated by testing ileocaecal lymph nodes after slaughter. Tissue samples from elderly cows were available within the framework of a parallel study investigating BSE-susceptibility factors in members of BSE-cohorts in the German Federal State of Lower Saxony. Ileocaecal lymph nodes were collected over a 2-year sampling period from 99 slaughter cattle of a mean age of 6.5 years (5.5 to 7.5 years). Based on the snPCR, 17 out of the 99 samples gave positive results, indicating a MAP occurrence of $17.17 \%$ in the random sample. All PCR products were sequenced for screening of polymorphisms. Nucleotide homologies of 98.5-100\% were found with respect to the MAP K10 reference sequence IS900 (GenBank: AE16958).

The distribution of MAP in zoo animals was confirmed by analyzing fecal samples from different mammalian and avian species kept in a German zoological garden. An alpaca (Vicugna pacos) that was bred and kept in this German zoological garden exhibited clinical signs typical for paratuberculosis. The pathogen was identified by snPCR as well as Ziehl-Neelsen staining and culture. The quantitative detection revealed $7.6 \times 10^{6}$ MAP-particle/g feces and $4.4 \times 10^{7}$ MAP-particle/g lymph node tissue. For characterisation and phylogenetic analyses, an 864 bp PCR amplicon covering nucleotide positions 13 and 876 within the 1,453 bp IS900 was sequenced. For all IS900 sequence fragments nucleotide homologies of $100 \%$ were ascertained to the bovine MAP K10 IS900 reference sequence (GenBank: AE16958), therefore, giving indication to a cattle strain. Accordingly, a survey on the occurrence of inter-species transmission of MAP in this zoological garden with clinical paratuberculosis was arranged by testing 
feces of 21 different mammalian and avian species. Based on the snPCR, 14 out of the 21 pooled fecal samples gave positive results, indicating a MAP occurrence of $66.7 \%$ in the German zoological garden. Yet all animals were asymptomatic at the time of sampling. According to the results, shedding of MAP with $10^{3}-10^{6}$ genomes/g feces occurs in ruminants as well as non-ruminants such as camelids, equines, primates, rodents, macropods, and birds. Moreover, it was demonstrated that the amount of MAP was lower in ruminants than in primates. All PCR products were sequenced for screening of polymorphisms. Nucleotide homologies of $93.9 \%$ and $100 \%$ were found with respect to the MAP K10 reference sequence IS900 (GenBank: AE16958).

To characterize distribution pattern of MAP in semen, blood, and feces an 18-month-old German Simmental bull (Bos primigenius taurus) naturally infected with MAP was investigated in a longitudinal study. In total, 65 sampling dates were chosen over a period of 3 years (June 2007 - November 2010). In all matrices investigated intermittent MAP shedding, with MAP-free intervals of at least 5 to 18 weeks, was detected by snPCR. The number of MAP positive results drawn from semen or blood samples was, on average, higher than that from fecal samples. Although no significant relationship was found between the pattern of MAP shedding in feces and blood, a high agreement between the pattern in semen and blood was detected $(\mathrm{r}=0.38, \mathrm{p}<0.05, \mathrm{n}=$ 29). Quantitative $\mathrm{rtPCR}$ revealed shedding of $10^{2}-10^{6} \mathrm{MAP} / \mathrm{g}$ in feces and $10^{2}-10^{5}$ $\mathrm{MAP} / \mathrm{ml}$ in semen and in blood.

In conclusion, PCR analysis of ileocaecal lymph nodes collected from slaughter cattle or camelids and testing pooled fecal samples drawn from different zoo residents proved to be a suitable technique to determine MAP occurrence in the local cattle or zoo population. The present study confirms a high prevalence of MAP infection in slaughtered cows and zoo animals as well as the wide host spectrum of MAP. Further, this thesis contributes to a more detailed understanding of MAP distribution, highlights the possible role of breeding bulls as a source of MAP transmission and indicates the need for additional monitoring and hygienic measures to prevent the spread of the infection via semen. This thesis highlights the need for governmental action with reference to harmonized eradication programs at federal level. In order to restrict further spread of MAP in European wildlife and zoos, further investigations about existing species transmission pathways of MAP are recommended. 


\section{Zusammenfassung}

Mycobacterium avium ssp. paratuberculosis (MAP) ist der Erreger der Paratuberkulose, auch Johne'sche Krankheit genannt, die überwiegend adulte Haus- und Wildwiederkäuer befällt. Die Paratuberkulose tritt weltweit auf. Wegen z.T. gravierender wirtschaftlicher Verluste in der Milch- und Fleischindustrie, wird ihr immer mehr Beachtung geschenkt. Ziel dieser Studie war es, das Vorkommen von MAP in Rindern und Zootieren mittels qualitativen und quantitativen PCR-Techniken zu erfassen. Dabei war ein Schwerpunkt, die Klärung des Ausscheidungsverhaltens von MAP in Kot, Sperma und Blut eines subklinisch infizierten Zuchtbullenanwärters, der im Großtier-Isolierstall des Departments für Nutztierwissenschaften gehalten wurde. Zum Nachweis und zur Quantifizierung wurde eine bereits entwickelte IS900 seminested PCR (snPCR) und quantitative real-time PCR (rtPCR) verwendet.

Das Vorkommen von MAP in älteren Kühen wurde durch molekularbiologische Untersuchungen von Ileocaecallymphknoten nach der Schlachtung ermittelt. Die Gewebeproben von älteren Kühen waren im Rahmen einer parallelen BSE-Studie zur Erkennung präklinischer Formen der Bovinen Spongiformen Enzephalopathie (BSE) in niedersächsischen BSE-Kohortentieren und Nachkommen gewonnen worden. Ileocaecallymphknoten wurden über einen Zeitraum von 2 Jahren von 99 Rindern eines durchschnittlichen Schlachtalters von 6,5 Jahren (5,5 bis 7,5) entnommen. Mittels snPCR wurde bei 17 der 99 (17,17\%) untersuchten Schlachtrinder MAP-DNA im Lymphknoten nachgewiesen. Zusätzlich wurden IS900-spezifische PCR-Amplifikate zur Sequenzierung kloniert und mit Sequenzen von MAP-Referenzstämmen verglichen. Die Sequenzen der Amplifikate stimmten mit der publizierten Sequzenz des MAP Referenzstammes MAP K-10 (GenBank: AE16958) zu 98,5-100\% überein.

Die Verbreitung von MAP in Zootieren wurde durch Untersuchung von Kotproben verschiedener Säugetiere und Vögel aus einem deutschen Zoo bestätigt. Ein Alpaka (Vicugna pacos), welches in diesem Zoo gezüchtet und gehalten wurde, zeigte für Paratuberkulose typische klinische Symptome. Der Erreger wurde qualitativ mittels snPCR sowie Ziehl-Neelsen Färbung und Kultur nachgewiesen. Der quantitative Nachweis ergab Werte von 7.6 × $10^{6}$ MAP-Partikel/g Kot und $4.4 \times 10^{7}$ MAP-Partikel/g Lymphgewebe. Für eine Charakterisierung und phylogenetische Vergleichsanalysen, wurde ein 864 bp PCR-Amplifikat, welches die Nukleotidpositionen 13 bis 876 der 1453 bp großen IS900-Sequenz abdeckt, zur Sequenzierung kloniert. Die IS900Sequenzen aller Amplifikate stimmten mit der publizierten MAP-K-10- 
Referenzsequenz (GenBank: AE16958) zu 100\% überein und gaben somit Hinweise auf einen Rinderstamm. Demzufolge wurde in diesem Zoo eine Studie zur Vorkommenshäufigkeit von MAP und zur Interspeziesverbreitung durchgeführt. Sammelkot von 21 verschiedenen Säugetieren und Vögeln wurde mittels snPCR auf MAP untersucht. Bei 14 der $21(66,7 \%)$ verschiedenen Tierarten konnte MAP mit $10^{3}$ $10^{6} \mathrm{Partikel} / \mathrm{g}$ im Kot nachgewiesen werden. Zum Zeitpunkt der Untersuchung waren alle Tiere klinisch unauffällig. Zu den positiv getesteten Zootieren gehörten neben Wiederkäuern auch Paarhufer, Einhufer, Primaten, Nagetiere und Vögel. Zusätzlich wurde eine geringere Menge an MAP-DNA im Kot von Wiederkäuern als von Primaten gefunden. Die IS900-Sequenzen der Amplifikate stimmten mit der publizierten MAP K10 Referenzsequenz (GenBank: AE16958) zu 93,9 und 100\% überein.

Zum besseren Verständnis des Ausscheidungsverhaltens von MAP in Sperma, Blut und Kot wurde ein subklinisch mit MAP infizierter, 18 Monate alter Fleckviehbulle (Bos primigenius taurus) in einer Langzeitstudie untersucht. Insgesamt wurden 65 Beprobungstage über einen Zeitraum von 3 Jahren (Juni 2007 - November 2010) ausgewählt. Mittels snPCR konnte der Erreger in allen untersuchten Matrices intermittierend mit MAP freien Intervallen von 5 bis 18 Wochen nachgewiesen werden. Die Anzahl der positiv getesteten Sperma- und Blutproben war im Durchschnitt höher als die Anzahl der positiv getesteten Kotproben. Auch wenn kein signifikanter Unterschied zwischen dem Verteilungsmuster von MAP im Kot und Blut festgestellt wurde, konnte eine hohe Signifikanz zwischen dem Ausscheidungsverhaltens von MAP in Sperma und Blut gezeigt werden $(\mathrm{r}=0.38, \mathrm{p}<0.05, \mathrm{n}=29)$. Mittels quantitativer rtPCR wurden $10^{2}-10^{6} \mathrm{MAP} / \mathrm{g}$ Kot und $10^{2}-10^{5} \mathrm{MAP} / \mathrm{ml}$ Sperma bzw. Blut ermittelt.

Die vorliegende Studie zeigt die Praxistauglichkeit einer PCR zur Prävalenzerhebung von MAP in Lymphknoten von Schlachtrindern und Kameliden sowie Kotproben von Zootieren. Diese Arbeit bestätigt ein hohes Vorkommen von MAP bei Schlachtrindern sowie Zootieren und eine speziesübergreifende Verbreitung von MAP über die Gruppe der Wiederkäuer hinaus. Ferner trägt diese Arbeit zu einem besseren Verständnis der MAP Verbreitung bei, stellt Besammungsbullen als potentielle Infektionsquelle für MAP dar und verdeutlicht den Bedarf an erweiterten Überwachungs- und Hygienemaßnahmen zur Prävention der Infektion mittels Sperma. Diese Arbeit verdeutlicht den Bedarf einer stärkeren und standardisierten Bekämpfung der Paratuberkulose auf Bundesebene. Aufgrund der weiten Verbreitung von MAP sind weitere Untersuchungen zur speziesübergreifenden Übertragung empfehlenswert. 


\section{References}

Alexejeff-Goloff, N.A., 1929, Zur Frage der Pathogenese und Bazillenausscheidung bei Rinderparatuberculose. Zeitschrift für Infektionkrankheiten, Parasitärkrankheiten und Hygiene der Haustiere 36, 313-317 Abstracted in Journal of Comparative Pathology 348:381-382.

Alinovi, C.A., Wu, C.C., Lin, T.L., 2009, In utero Mycobacterium avium subspecies paratuberculosis infection of a pygmy goat. Vet Rec 164, 276-277.

Alonso-Hearn, M., Molina, E., Geijo, M., Vazquez, P., Sevilla, I., Garrido, J.M., Juste, R.A., 2009, Isolation of Mycobacterium avium subsp. paratuberculosis from muscle tissue of naturally infected cattle. Foodborne Pathog Dis 6, 513-518.

Amstutz, H.E., 1984, Bovine paratuberculosis: an update. Mod Vet Pract 65, 134-135.

Anderson, J.L., Meece, J.K., Koziczkowski, J.J., Clark, D.L., Jr., Radcliff, R.P., Nolden, C.A., Samuel, M.D., Ellingson, J.L., 2007, Mycobacterium avium subsp. paratuberculosis in scavenging mammals in Wisconsin. J Wildl Dis 43, 302308.

Angus, K.W., 1990, Intestinal lesions resembling paratuberculosis in a wild rabbit (Oryctolagus cuniculus). J Comp Pathol 103, 101-105.

Antognoli, M.C., Hirst, H.L., Garry, F.B., Salman, M.D., 2007, Immune response to and faecal shedding of Mycobacterium avium ssp. paratuberculosis in young dairy calves, and the association between test results in the calves and the infection status of their dams. Zoonoses Public Health 54, 152-159.

Atala, N., Akcay, E., 2001, Turkiye genelinde sgr paratuberkulozu prevalansnn ELISA ile arastrlmas (in Turkish, with English abstract). Etlik Veteriner Mikrobiyoloji Dergisi 12, 39-48.

Ayele, W.Y., Bartos, M., Svastova, P., Pavlik, I., 2004, Distribution of Mycobacterium avium subsp. paratuberculosis in organs of naturally infected bull-calves and breeding bulls. Vet Microbiol 103, 209-217.

Ayele, W.Y., Svastova, P., Roubal, P., Bartos, M., Pavlik, I., 2005, Mycobacterium avium subspecies paratuberculosis cultured from locally and commercially pasteurized cow's milk in the Czech Republic. Appl Environ Microbiol 71, 1210-1214.

Bang, B., 1906, Chronische pseudotuberkulöse Darmentzündung beim Rinde. Berl Munch Tierarztl Wochenschr 42, 759-763.

Bannantine, J.P., Baechler, E., Zhang, Q., Li, L., Kapur, V., 2002, Genome scale comparison of Mycobacterium avium subsp. paratuberculosis with Mycobacterium avium subsp. avium reveals potential diagnostic sequences. J Clin Microbiol 40, 1303-1310.

Barrington, G.M., Parish, S.M., Tyler, J.W., 1997, Chronic weight loss in an immunodeficient adult llama. J Am Vet Med Assoc 211, 294-295; discussion 296-298.

Bauerfeind, R., Benazzi, S., Weiss, R., Schliesser, T., Willems, H., Baljer, G., 1996, Molecular characterization of Mycobacterium paratuberculosis isolates from sheep, goats, and cattle by hybridization with a DNA probe to insertion element IS900. J Clin Microbiol 34, 1617-1621.

Beard, P.M., Daniels, M.J., Henderson, D., Pirie, A., Rudge, K., Buxton, D., Rhind, S., Greig, A., Hutchings, M.R., McKendrick, I., Stevenson, K., Sharp, J.M., 2001a, Paratuberculosis infection of nonruminant wildlife in Scotland. J Clin Microbiol 39, 1517-1521. 
Beard, P.M., Rhind, S.M., Buxton, D., Daniels, M.J., Henderson, D., Pirie, A., Rudge, K., Greig, A., Hutchings, M.R., Stevenson, K., Sharp, J.M., 2001b, Natural paratuberculosis infection in rabbits in Scotland. J Comp Pathol 124, 290-299.

Behr, M.A., Collins, D.M., 2010, Paratuberculosis Organism, Disease, Control. CAB International, Oxfordshire, Cambridge.

Belknap, E.B., Getzy, D.M., Johnson, L.W., Ellis, R.P., Thompson, G.L., Shulaw, W.P., 1994, Mycobacterium paratuberculosis infection in two llamas. J Am Vet Med Assoc 204, 1805-1808.

Benazzi, S., Berrada, J., Schliesser, T., 1995, First report of paratuberculosis (Johne's disease) in sheep in Morocco. Zentralbl Veterinarmed B 42, 339-344.

Benedictus, A., Mitchell, R.M., Linde-Widmann, M., Sweeney, R., Fyock, T., Schukken, Y.H., Whitlock, R.H., 2008, Transmission parameters of Mycobacterium avium subspecies paratuberculosis infections in a dairy herd going through a control program. Prev Vet Med 83, 215-227.

Berghaus, R.D., Farver, T.B., Anderson, R.J., Jaravata, C.C., Gardner, I.A., 2006, Environmental sampling for detection of Mycobacterium avium ssp. paratuberculosis on large California dairies. J Dairy Sci 89, 963-970.

Bhide, M., Chakurkar, E., Tkacikova, L., Barbuddhe, S., Novak, M., Mikula, I., 2006, IS900-PCR-based detection and characterization of Mycobacterium avium subsp. paratuberculosis from buffy coat of cattle and sheep. Vet Microbiol 112, 33-41.

Billman-Jacobe, H., Carrigan, M., Cockram, F., Corner, L.A., Gill, I.J., Hill, J.F., Jessep, T., Milner, A.R., Wood, P.R., 1992, A comparison of the interferon gamma assay with the absorbed ELISA for the diagnosis of Johne's disease in cattle. Aust Vet J 69, 25-28.

Boelaert, F., Walravens, K., Biront, P., Vermeersch, J.P., Berkvens, D., Godfroid, J., 2000, Prevalence of paratuberculosis (Johne's disease) in the Belgian cattle population. Vet Microbiol 77, 269-281.

Bolster, C.H., Cook, K.L., Haznedaroglu, B.Z., Walker, S.L., 2009, The transport of Mycobacterium avium subsp. paratuberculosis through saturated aquifer materials. Lett Appl Microbiol 48, 307-312.

Bosshard, C., Stephan, R., Tasara, T., 2006, Application of an F57 sequence-based realtime PCR assay for Mycobacterium paratuberculosis detection in bulk tank raw milk and slaughtered healthy dairy cows. J Food Prot 69, 1662-1667.

Böttcher, M., 1997, Kulturelle und serologische Untersuchungen zur Prävalenz der Paratuberkulose im Regierungsbezirk Arnsberg. Dissertation, Tierärztliche Hochschule Hannover, Germany, 99.

Böttcher, J., Gangl, A., 2004, Mycobacterium avium ssp. paratuberculosis--combined serological testing and classification of individual animals and herds. J Vet Med B Infect Dis Vet Public Health 51, 443-448.

Bower, K., Begg, D.J., Whittington, R.J., 2010, Optimisation of culture of Mycobacterium avium subspecies paratuberculosis from blood samples. J Microbiol Methods 80, 93-99.

Brey, B.J., Radcliff, R.P., Clark, D.L., Jr., Ellingson, J.L., 2006, Design and development of an internal control plasmid for the detection of Mycobacterium avium subsp. paratuberculosis using real-time PCR. Mol Cell Probes 20, 51-59.

Buergelt, C.D., Ginn, P.E., 2000, The histopathologic diagnosis of subclinical Johne's disease in North American bison (Bison bison). Vet Microbiol 77, 325-331.

Buergelt, C.D., Hall, C., McEntee, K., Duncan, J.R., 1978, Pathological evaluation of paratuberculosis in naturally infected cattle. Vet Pathol 15, 196-207. 
Bull, T.J., McMinn, E.J., Sidi-Boumedine, K., Skull, A., Durkin, D., Neild, P., Rhodes, G., Pickup, R., Hermon-Taylor, J., 2003, Detection and verification of Mycobacterium avium subsp. paratuberculosis in fresh ileocolonic mucosal biopsy specimens from individuals with and without Crohn's disease. J Clin Microbiol 41, 2915-2923.

Castellanos, E., Aranaz, A., de Juan, L., Alvarez, J., Rodriguez, S., Romero, B., Bezos, J., Stevenson, K., Mateos, A., Dominguez, L., 2009, Single nucleotide polymorphisms in the IS900 sequence of Mycobacterium avium subsp. paratuberculosis are strain type specific. J Clin Microbiol 47, 2260-2264.

Cetinkaya, B., Egan, K., Harbour, D.A., Morgan, K.L., 1996, An abattoir-based study of the prevalence of subclinical Johne's disease in adult cattle in south west England. Epidemiol Infect 116, 373-379.

Cetinkaya, B., Muz, A., Ertas, H.B., Öngör, H., Sezen, I.Y., Gülcü, H.B., 2000, Sut ineklerinde paratuberkuloz prevalansnn polimeraz zincir reaksiyonu (PZR) ile saptanmas (in Turkish, with English abstract). Turk Veterinerlik ve Hayvanclk Dergisi 24, 371-379.

Chamberlin, W.M., Naser, S.A., 2006, Integrating theories of the etiology of Crohn's disease. On the etiology of Crohn's disease: questioning the hypotheses. Med Sci Monit 12, RA27-33.

Chiodini, R.J., 1996, Immunology: resistance to paratuberculosis. Vet Clin North Am Food Anim Pract 12, 313-343.

Chiodini, R.J., Chamberlin, W.M., Sarosiek, J., McCallum, R.W., 2012, Crohn's disease and the mycobacterioses: a quarter century later. Causation or simple association? Crit Rev Microbiol 38, 52-93.

Chiodini, R.J., Rossiter, C.A., 1996, Paratuberculosis: a potential zoonosis? Vet Clin North Am Food Anim Pract 12, 457-467.

Chiodini, R.J., Van Kruiningen, H.J., Merkal, R.S., 1984, Ruminant paratuberculosis (Johne's disease): the current status and future prospects. Cornell Vet 74, 218262.

Choy, E., Whittington, R.J., Marsh, I., Marshall, J., Campbell, M.T., 1998, A method for purification and characterisation of Mycobacterium avium subsp. paratuberculosis from the intestinal mucosa of sheep with Johne's disease. Vet Microbiol 64, 51-60.

Clark, D.L., Jr., Anderson, J.L., Koziczkowski, J.J., Ellingson, J.L., 2006, Detection of Mycobacterium avium subspecies paratuberculosis genetic components in retail cheese curds purchased in Wisconsin and Minnesota by PCR. Mol Cell Probes 20, 197-202.

Clarke, C.J., 1997, The pathology and pathogenesis of paratuberculosis in ruminants and other species. J Comp Pathol 116, 217-261.

Cobrin, G.M., Abreu, M.T., 2005, Defects in mucosal immunity leading to Crohn's disease. Immunol Rev 206, 277-295.

Cocito, C., Gilot, P., Coene, M., de Kesel, M., Poupart, P., Vannuffel, P., 1994, Paratuberculosis. Clin Microbiol Rev 7, 328-345.

Collins, D.M., Cavaignac, S., de Lisle, G.W., 1997, Use of four DNA insertion sequences to characterize strains of the Mycobacterium avium complex isolated from animals. Mol Cell Probes 11, 373-380.

Collins, D.M., Gabric, D.M., De Lisle, G.W., 1989, Identification of a repetitive DNA sequence specific to Mycobacterium paratuberculosis. FEMS Microbiol Lett 51, 175-178. 
Collins, D.M., Gabric, D.M., de Lisle, G.W., 1990, Identification of two groups of Mycobacterium paratuberculosis strains by restriction endonuclease analysis and DNA hybridization. J Clin Microbiol 28, 1591-1596.

Collins, D.M., Hilbink, F., West, D.M., Hosie, B.D., Cooke, M.M., de Lisle, G.W., 1993a, Investigation of Mycobacterium paratuberculosis in sheep by faecal culture, DNA characterisation and the polymerase chain reaction. Vet Rec 133, 599-600.

Collins, D.M., Stephens, D.M., de Lisle, G.W., 1993b, Comparison of polymerase chain reaction tests and faecal culture for detecting Mycobacterium paratuberculosis in bovine faeces. Vet Microbiol 36, 289-299.

Collins, M.T., 1994, Clinical approach to control of bovine paratuberculosis. J Am Vet Med Assoc 204, 208-210.

Collins, M.T., 1996, Diagnosis of paratuberculosis. Vet Clin North Am Food Anim Pract 12, 357-371.

Collins, M.T., Angulo, A., Buergelt, C.D., Hennager, S.G., Hietala, S.K., Jacobson, R.H., Whipple, D.L., Whitlock, R.H., 1993c, Reproducibility of a commercial enzyme-linked immunosorbent assay for bovine paratuberculosis among eight laboratories. J Vet Diagn Invest 5, 52-55.

Collins, M.T., Eggleston, V., Manning, E.J., 2010, Successful control of Johne's disease in nine dairy herds: results of a six-year field trial. J Dairy Sci 93, 1638-1643.

Collins, M.T., Wells, S.J., Petrini, K.R., Collins, J.E., Schultz, R.D., Whitlock, R.H., 2005, Evaluation of five antibody detection tests for diagnosis of bovine paratuberculosis. Clin Diagn Lab Immunol 12, 685-692.

Cook, K.L., Britt, J.S., 2007, Optimization of methods for detecting Mycobacterium avium subsp. paratuberculosis in environmental samples using quantitative, real-time PCR. J Microbiol Methods 69, 154-160.

Cook, K.L., Britt, J.S., Bolster, C.H., 2010, Survival of Mycobacterium avium subsp. paratuberculosis in biofilms on livestock watering trough materials. Vet Microbiol 141, 103-109.

Corn, J.L., Manning, E.J., Sreevatsan, S., Fischer, J.R., 2005, Isolation of Mycobacterium avium subsp. paratuberculosis from free-ranging birds and mammals on livestock premises. Appl Environ Microbiol 71, 6963-6967.

Corti, S., Stephan, R., 2002, Detection of Mycobacterium avium subspecies paratuberculosis specific IS900 insertion sequences in bulk-tank milk samples obtained from different regions throughout Switzerland. BMC Microbiol 2, 15.

Cosnes, J., 2004, Tobacco and IBD: relevance in the understanding of disease mechanisms and clinical practice. Best Pract Res Clin Gastroenterol 18, 481496.

Crawford, G.C., Ziccardi, M.H., Gonzales, B.J., Woods, L.M., Fischer, J.K., Manning, E.J., Mazet, J.A., 2006, Mycobacterium avium subspecies paratuberculosis and Mycobacterium avium subsp. avium infections in a tule elk (Cervus elaphus nannodes) herd. J Wildl Dis 42, 715-723.

Dalziel, T.K., 1913, Chronic interstitial enteritis. BMJ ii, 1068-1070.

de Juan, L., Alvarez, J., Romero, B., Bezos, J., Castellanos, E., Aranaz, A., Mateos, A., Dominguez, L., 2006, Comparison of four different culture media for isolation and growth of type II and type I/III Mycobacterium avium subsp. paratuberculosis strains isolated from cattle and goats. Appl Environ Microbiol 72, 5927-5932. 
de Juan, L., Mateos, A., Dominguez, L., Sharp, J.M., Stevenson, K., 2005, Genetic diversity of Mycobacterium avium subspecies paratuberculosis isolates from goats detected by pulsed-field gel electrophoresis. Vet Microbiol 106, 249-257.

de Lisle, G.W., Seguin, P., Samagh, B.S., Corner, A.H., Duncan, J.R., 1980, Bovine paratuberculosis I. A herd study using complement fixation and intradermal tests. Can J Comp Med 44, 177-182.

de Lisle, G.W., Yates, G.F., Collins, D.M., 1993, Paratuberculosis in farmed deer: case reports and DNA characterization of isolates of Mycobacterium paratuberculosis. J Vet Diagn Invest 5, 567-571.

de Lisle, G.W., Yates, G.F., Montgomery, H., 2003, The emergence of Mycobacterium paratuberculosis in farmed deer in New Zealand - a review of 619 cases. N Z Vet J 51, 58-62.

Deutz, A., Spergser, J., Wagner, P., Rosengarten, R., Kofer, J., 2005, [Mycobacterium avium subsp. paratuberculosis in wild animal species and cattle in Styria/Austria]. Berl Munch Tierarztl Wochenschr 118, 314-320.

Dieguez, F.J., Arnaiz, I., Sanjuan, M.L., Vilar, M.J., Lopez, M., Yus, E., 2007, Prevalence of serum antibodies to Mycobacterium avium subsp. paratuberculosis in cattle in Galicia (northwest Spain). Prev Vet Med 82, 321326.

Dierckins, M.S., Sherman, D.M., Gendron-Fitzpatrick, A., 1990, Probable paratuberculosis in a Sicilian ass. J Am Vet Med Assoc 196, 459-461.

Domingue, G.J., Sr., Woody, H.B., 1997, Bacterial persistence and expression of disease. Clin Microbiol Rev 10, 320-344.

Donaghy, J.A., Linton, M., Patterson, M.F., Rowe, M.T., 2007, Effect of high pressure and pasteurization on Mycobacterium avium ssp. paratuberculosis in milk. Lett Appl Microbiol 45, 154-159.

Donaghy, J.A., Totton, N.L., Rowe, M.T., 2004, Persistence of Mycobacterium paratuberculosis during manufacture and ripening of cheddar cheese. Appl Environ Microbiol 70, 4899-4905.

Donat, K., Eulenberger, K. Kampfer, P., 2005, Blutserologische Untersuchungen zur Verbreitung von Mycobacterium avium spp. paratuberculosis is sächsischen Rinderbeständen. Tierärztliche Umschau 60, 497-501.

Doran, T., Tizard, M., Millar, D., Ford, J., Sumar, N., Loughlin, M., Hermon-Taylor, J., 1997, IS900 targets translation initiation signals in Mycobacterium avium subsp. paratuberculosis to facilitate expression of its hed gene. Microbiology $143(\mathrm{Pt}$ 2), 547-552.

Doran, T.J., Davies, J.K., Radford, A.J., Hodgson, A.L., 1994, Putative functional domain within ORF2 on the Mycobacterium insertion sequences IS900 and IS902. Immunol Cell Biol 72, 427-434.

Doyle, T.M., Spears, H.N., 1951, A Johne's disease survey. Vet Rec 63, 355-359.

Dukes, T.W., Glover, G.J., Brooks, B.W., Duncan, J.R., Swendrowski, M., 1992, Paratuberculosis in saiga antelope (Saiga tatarica) and experimental transmission to domestic sheep. J Wildl Dis 28, 161-170.

Eamens, G.J., Walker, D.M., Porter, N.S., Fell, S.A., 2008, Radiometric pooled faecal culture for the detection of Mycobacterium avium subsp paratuberculosis in low-shedder cattle. Aust Vet J 86, 259-265.

Eamens, G.J., Whittington, R.J., Marsh, I.B., Turner, M.J., Saunders, V., Kemsley, P.D., Rayward, D., 2000, Comparative sensitivity of various faecal culture methods and ELISA in dairy cattle herds with endemic Johne's disease. Vet Microbiol 77, 357-367. 
Ebert, E.C., Bhatt, B.D., Liu, S., Das, K.M., 1991, Induction of suppressor cells by Mycobacterium paratuberculosis antigen in inflammatory bowel disease. Clin Exp Immunol 83, 320-325.

Edmondson, J.E., Tallmonn, K.L., Herman, H.A., 1948, A study of the types of bacteria in bovine semen and their effect up on motility. Journal of Dairy Science 31, 681.

Eisenberg, S.W., Nielen, M., Santema, W., Houwers, D.J., Heederik, D., Koets, A.P., 2010, Detection of spatial and temporal spread of Mycobacterium avium subsp. paratuberculosis in the environment of a cattle farm through bio-aerosols. Vet Microbiol 143, 284-292.

Ellingson, J.L., Anderson, J.L., Koziczkowski, J.J., Radcliff, R.P., Sloan, S.J., Allen, S.E., Sullivan, N.M., 2005, Detection of viable Mycobacterium avium subsp. paratuberculosis in retail pasteurized whole milk by two culture methods and PCR. J Food Prot 68, 966-972.

Elson, C.O., Cong, Y., Weaver, C.T., Schoeb, T.R., McClanahan, T.K., Fick, R.B., Kastelein, R.A., 2007, Monoclonal anti-interleukin 23 reverses active colitis in a T cell-mediated model in mice. Gastroenterology 132, 2359-2370.

Eltholth, M.M., Marsh, V.R., Van Winden, S., Guitian, F.J., 2009, Contamination of food products with Mycobacterium avium paratuberculosis: a systematic review. J Appl Microbiol 107, 1061-1071.

Englund, S., Ballagi-Pordany, A., Bolske, G., Johansson, K.E., 1999, Single PCR and nested PCR with a mimic molecule for detection of Mycobacterium avium subsp. paratuberculosis. Diagn Microbiol Infect Dis 33, 163-171.

Eppleston, J., Whittington, R.J., 2001, Isolation of Mycobacterium avium subsp paratuberculosis from the semen of rams with clinical Johne's disease. Aust Vet J 79, 776-777.

Erume, J., Spergser, J., Rosengarten, R., 2001, Rapid detection of Mycobacterium avium subsp. paratuberculosis from cattle and zoo animals by nested PCR. Afr Health Sci 1, 83-89.

Fang, Y., Wu, W.H., Pepper, J.L., Larsen, J.L., Marras, S.A., Nelson, E.A., Epperson, W.B., Christopher-Hennings, J., 2002, Comparison of real-time, quantitative PCR with molecular beacons to nested PCR and culture methods for detection of Mycobacterium avium subsp. paratuberculosis in bovine fecal samples. J Clin Microbiol 40, 287-291.

Fecteau, M.E., Ross, J., Tennent-Brown, B.S., Habecker, P.L., Sreevatsan, S., Sweeney, R.W., Whitlock, R.H., 2009, Mycobacterium avium ssp. paratuberculosis high shedding in an adult female alpaca, and its implications for the rest of the herd. J Vet Intern Med 23, 1311-1314.

Florou, M., Leontides, L., Kostoulas, P., Billinis, C., Sofia, M., Kyriazakis, I., Lykotrafitis, F., 2008, Isolation of Mycobacterium avium subspecies paratuberculosis from non-ruminant wildlife living in the sheds and on the pastures of Greek sheep and goats. Epidemiol Infect 136, 644-652.

Gao, A., Mutharia, L., Chen, S., Rahn, K., Odumeru, J., 2002, Effect of pasteurization on survival of Mycobacterium paratuberculosis in milk. J Dairy Sci 85, 31983205.

Gasteiner, J., Wenzl, H., Fuchs, K., Jark, U., Baumgartner, W., 1999, Serological crosssectional study of paratuberculosis in cattle in Austria. Zentralbl Veterinarmed B 46, 457-466.

Gilmour, N.J., 1965, Recent research on Johne's disease. Vet Rec 77, 1322-1326. 
Gilmour, N.J., 1976, The pathogenesis, diagnosis and control of Johne's disease. Vet Rec 99, 433-434.

Glawischnig, W., Awad-Masalmeh, M., Khaschabi, D., Schonbauer, M., 2004, [Detection of Mycobacterium avium subsp. paratuberculosis from the testicles of a clinically infected breeding animal]. Berl Munch Tierarztl Wochenschr 117, 136-139.

Glawischnig, W., Steineck, T., Spergser, J., 2006, Infections caused by Mycobacterium avium subspecies avium, hominissuis, and paratuberculosis in free-ranging red deer (Cervus elaphus hippelaphus) in Austria, 2001-2004. J Wildl Dis 42, 724731.

Godfroid, J., Delcorps, C., Irenge, L.M., Walravens, K., Marche, S., Gala, J.L., 2005, Definitive differentiation between single and mixed mycobacterial infections in red deer (Cervus elaphus) by a combination of duplex amplification of p34 and f57 sequences and Hpy188I enzymatic restriction of duplex amplicons. J Clin Microbiol 43, 4640-4648.

Grant, I.R., 2005, Zoonotic potential of Mycobacterium avium ssp. paratuberculosis: the current position. J Appl Microbiol 98, 1282-1293.

Grant, I.R., Ball, H.J., Rowe, M.T., 2002a, Incidence of Mycobacterium paratuberculosis in bulk raw and commercially pasteurized cows' milk from approved dairy processing establishments in the United Kingdom. Appl Environ Microbiol 68, 2428-2435.

Grant, I.R., Hitchings, E.I., McCartney, A., Ferguson, F., Rowe, M.T., 2002b, Effect of commercial-scale high-temperature, short-time pasteurization on the viability of Mycobacterium paratuberculosis in naturally infected cows' milk. Appl Environ Microbiol 68, 602-607.

Grant, I.R., Williams, A.G., Rowe, M.T., Muir, D.D., 2005, Efficacy of various pasteurization time-temperature conditions in combination with homogenization on inactivation of Mycobacterium avium subsp. paratuberculosis in milk. Appl Environ Microbiol 71, 2853-2861.

Green, E.P., Moss, M.T., Hermon-Taylor, J., McFadden, J.J., 1989a, Insertion elements in mycobacteria. Acta Leprol 7 Suppl 1, 239-242.

Green, E.P., Tizard, M.L., Moss, M.T., Thompson, J., Winterbourne, D.J., McFadden, J.J., Hermon-Taylor, J., 1989b, Sequence and characteristics of IS900, an insertion element identified in a human Crohn's disease isolate of Mycobacterium paratuberculosis. Nucleic Acids Res 17, 9063-9073.

Greig, A., Stevenson, K., Henderson, D., Perez, V., Hughes, V., Pavlik, I., Hines, M.E., 2nd, McKendrick, I., Sharp, J.M., 1999, Epidemiological study of paratuberculosis in wild rabbits in Scotland. J Clin Microbiol 37, 1746-1751.

Greig, A., Stevenson, K., Perez, V., Pirie, A.A., Grant, J.M., Sharp, J.M., 1997, Paratuberculosis in wild rabbits (Oryctolagus cuniculus). Vet Rec 140, 141-143.

Gronesova, P., Ficova, M., Mizakova, A., Kabat, P., Trnka, A., Betakova, T., 2008, Prevalence of avian influenza viruses, Borrelia garinii, Mycobacterium avium, and Mycobacterium avium subsp. paratuberculosis in waterfowl and terrestrial birds in Slovakia, 2006. Avian Pathol 37, 537-543.

Gumber, S., Whittington, R.J., 2007, Comparison of BACTEC 460 and MGIT 960 systems for the culture of Mycobacterium avium subsp. paratuberculosis $\mathrm{S}$ strain and observations on the effect of inclusion of ampicillin in culture media to reduce contamination. Vet Microbiol 119, 42-52. 
Gwozdz, J.M., 2006, Comparative evaluation of two decontamination methods for the isolation of Mycobacterium avium subspecies paratuberculosis from faecal slurry and sewage. Vet Microbiol 115, 358-363.

Gwozdz, J.M., Reichel, M.P., Murray, A., Manktelow, W., West, D.M., Thompson, K.G., 1997, Detection of Mycobacterium avium subsp. paratuberculosis in ovine tissues and blood by the polymerase chain reaction. Vet Microbiol 57, 233-244.

Hacker, U., Huttner, K., Konow, M., 2004, [Investigation of serological prevalence and risk factors of paratuberculosis in dairy farms in the state of MecklenburgWestpommerania, Germany]. Berl Munch Tierarztl Wochenschr 117, 140-144.

Harris, N.B., Barletta, R.G., 2001, Mycobacterium avium subsp. paratuberculosis in Veterinary Medicine. Clin Microbiol Rev 14, 489-512.

Hendrick, S.H., Duffield, T.E., Kelton, D.E., Leslie, K.E., Lissemore, K.D., Archambault, M., 2005, Evaluation of enzyme-linked immunosorbent assays performed on milk and serum samples for detection of paratuberculosis in lactating dairy cows. J Am Vet Med Assoc 226, 424-428.

Hermon-Taylor, J., Bull, T.J., Sheridan, J.M., Cheng, J., Stellakis, M.L., Sumar, N., 2000, Causation of Crohn's disease by Mycobacterium avium subspecies paratuberculosis. Can J Gastroenterol 14, 521-539.

Herthnek, D., Bolske, G., 2006, New PCR systems to confirm real-time PCR detection of Mycobacterium avium subsp. paratuberculosis. BMC Microbiol 6, 87.

Herthnek, D., Englund, S., Willemsen, P.T., Bolske, G., 2006, Sensitive detection of Mycobacterium avium subsp. paratuberculosis in bovine semen by real-time PCR. J Appl Microbiol 100, 1095-1102.

Hole, N.H., 1953, The diagnosis of Johne's disease. In: Proceedings of the XV International Veterinary Congress, 173-177.

Hope, A.F., Kluver, P.F., Jones, S.L., Condron, R.J., 2000, Sensitivity and specificity of two serological tests for the detection of ovine paratuberculosis. Aust Vet J 78, 850-856.

Ikiz, S., Bagcigil, A.F., Seyyal, A.K., Ozgur, N.Y., Lgaz, A., 2005, Paratuberculosis in cattle in Turkey detected by PCR. Medycyna Weterynaryjna 61, 881-883.

Ikonomopoulos, J., Gazouli, M., Pavlik, I., Bartos, M., Zacharatos, P., Xylouri, E., Papalambros, E., Gorgoulis, V., 2004, Comparative evaluation of PCR assays for the robust molecular detection of Mycobacterium avium subsp. paratuberculosis. J Microbiol Methods 56, 315-321.

Ikonomopoulos, J., Pavlik, I., Bartos, M., Svastova, P., Ayele, W.Y., Roubal, P., Lukas, J., Cook, N., Gazouli, M., 2005, Detection of Mycobacterium avium subsp. paratuberculosis in retail cheeses from Greece and the Czech Republic. Appl Environ Microbiol 71, 8934-8936.

Irenge, L.M., Walravens, K., Govaerts, M., Godfroid, J., Rosseels, V., Huygen, K., Gala, J.L., 2009, Development and validation of a triplex real-time PCR for rapid detection and specific identification of $M$. avium sub sp. paratuberculosis in faecal samples. Vet Microbiol 136, 166-172.

Jaravata, C.V., Smith, W.L., Rensen, G.J., Ruzante, J.M., Cullor, J.S., 2006, Detection of Mycobacterium avium subsp. paratuberculosis in bovine manure using Whatman FTA card technology and Lightcycler real-time PCR. Foodborne Pathog Dis 3, 212-215.

Jark, U., Ringena, I., Franz, B., Gerlach, G.F., Beyerbach, M., Franz, B., 1997, Development of an ELISA technique for serodiagnosis of bovine paratuberculosis. Vet Microbiol 57, 189-198. 
Johne, H.A., Fortingham, L., 1895, Ein eigentümlicher Fall von Tuberkulose beim Rind. Dtsch. Z. Thiermed. Vergl. Path. 21, 438-454.

Johnson-Ifearulundu, Y.J., Kaneene, J.B., 1997, Relationship between soil type and Mycobacterium paratuberculosis. J Am Vet Med Assoc 210, 1735-1740.

Jorgensen, J.B., 1977, Survival of Mycobacterium paratuberculosis in slurry. Nord Vet Med 29, 267-270.

Jorgensen, J.B., 1982, An improved medium for culture of Mycobacterium paratuberculosis from bovine faeces. Acta Vet Scand 23, 325-335.

Judge, J., Kyriazakis, I., Greig, A., Allcroft, D.J., Hutchings, M.R., 2005, Clustering of Mycobacterium avium subsp. paratuberculosis in rabbits and the environment: how hot is a hot spot? Appl Environ Microbiol 71, 6033-6038.

Jungersen, G., Huda, A., Hansen, J.J., Lind, P., 2002, Interpretation of the gamma interferon test for diagnosis of subclinical paratuberculosis in cattle. Clin Diagn Lab Immunol 9, 453-460.

Juste, R.A., Marco, J.C., Saez de Ocariz, C., Aduriz, J.J., 1991, Comparison of different media for the isolation of small ruminant strains of Mycobacterium paratuberculosis. Vet Microbiol 28, 385-390.

Jörgensen, J.B., Jensen, P.T., 1978, Enzyme-Linked Immunosorbent Assay (ELISA) for detection antybodies to Mycobacterium paratuberculosis in cattle. Acta Vet Scand 19, 310-312.

Kalis, C.H., Barkema, H.W., Hesselink, J.W., van Maanen, C., Collins, M.T., 2002, Evaluation of two absorbed enzyme-linked immunosorbent assays and a complement fixation test as replacements for fecal culture in the detection of cows shedding Mycobacterium avium subspecies paratuberculosis. J Vet Diagn Invest 14, 219-224.

Kalis, C.H., Collins, M.T., Hesselink, J.W., Barkema, H.W., 2003, Specificity of two tests for the early diagnosis of bovine paratuberculosis based on cell-mediated immunity: the Johnin skin test and the gamma interferon assay. Vet Microbiol 97, 73-86.

Kanazawa, K., Haga, Y., Funakoshi, O., Nakajima, H., Munakata, A., Yoshida, Y., 1999, Absence of Mycobacterium paratuberculosis DNA in intestinal tissues from Crohn's disease by nested polymerase chain reaction. J Gastroenterol 34, 200-206.

Kaser, A., Lee, A.H., Franke, A., Glickman, J.N., Zeissig, S., Tilg, H., Nieuwenhuis, E.E., Higgins, D.E., Schreiber, S., Glimcher, L.H., Blumberg, R.S., 2008, XBP1 links ER stress to intestinal inflammation and confers genetic risk for human inflammatory bowel disease. Cell 134, 743-756.

Kim, S.G., Shin, S.J., Jacobson, R.H., Miller, L.J., Harpending, P.R., Stehman, S.M., Rossiter, C.A., Lein, D.A., 2002, Development and application of quantitative polymerase chain reaction assay based on the ABI 7700 system (TaqMan) for detection and quantification of Mycobacterium avium subsp. paratuberculosis. $\mathbf{J}$ Vet Diagn Invest 14, 126-131.

Kim, Y.G., Bech-Nielsen, S., Gordon, J.C., Slemons, R.D., Spangler, E., 1989, Comparison of two methods for isolation of Mycobacterium paratuberculosis from bovine fecal samples. Am J Vet Res 50, 1110-1113.

Koo, H.C., Park, Y.H., Hamilton, M.J., Barrington, G.M., Davies, C.J., Kim, J.B., Dahl, J.L., Waters, W.R., Davis, W.C., 2004, Analysis of the immune response to Mycobacterium avium subsp. paratuberculosis in experimentally infected calves. Infect Immun 72, 6870-6883. 
Kopecky, K.E., Larsen, A.B., Merkal, R.S., 1967, Uterine infection in bovine paratuberculosis. Am J Vet Res 28, 1043-1045.

Kopecna, M., Heroldova, M., Mrlik, V., Kralova, A., Pavlik, I., 2008, The wildlife hosts of Mycobacterium avium subsp. paratuberculosis in the Czech Republic during the years 2002-2007. Vet Med (Praha) 53, 420-426.

Kopecna, M., Ondrus, S., Literak, I., Klimes, J., Horvathova, A., Moravkova, M., Bartos, M., Trcka, I., Pavlik, I., 2006, Detection of Mycobacterium avium subsp. paratuberculosis in two brown bears in the central European Carpathians. J Wildl Dis 42, 691-695.

Kruip, T.A., Muskens, J., van Roermund, H.J., Bakker, D., Stockhofe-Zurwieden, N., 2003, Lack of association of Mycobacterium avium subsp. paratuberculosis with oocytes and embryos from moderate shedders of the pathogen. Theriogenology 59, 1651-1660.

Kudahl, A.B., Nielsen, S.S., Ostergaard, S., 2008, Economy, efficacy, and feasibility of a risk-based control program against paratuberculosis. J Dairy Sci 91, 45994609.

Köhler, H., Burkert, B. 2003. Validierung von ELISAs zum Nachweis von Antikörpern gegen Mycobacterium avium ssp. paratuberculosis bei Rindern (IVD-Info der BFAV Insel Riems), pp. 6-9.

Lambeth, C., Reddacliff, L.A., Windsor, P., Abbott, K.A., McGregor, H., Whittington, R.J., 2004, Intrauterine and transmammary transmission of Mycobacterium avium subsp paratuberculosis in sheep. Aust Vet J 82, 504-508.

Lambrecht, R.S., Carriere, J.F., Collins, M.T., 1988, A model for analyzing growth kinetics of a slowly growing Mycobacterium sp. Appl Environ Microbiol 54, 910-916.

Lambrecht, R.S., Collins, M.T., 1992, Mycobacterium paratuberculosis. Factors that influence mycobactin dependence. Diagn Microbiol Infect Dis 15, 239-246.

Lamont, E.A., Bannantine, J.P., Armien, A., Ariyakumar, D.S., Sreevatsan, S., 2012, Identification and Characterization of a Spore-Like Morphotype in Chronically Starved Mycobacterium avium Subsp. Paratuberculosis Cultures. PLoS One 7, e30648.

Larsen, A.B., Kopecky, K.E., 1970, Mycobacterium paratuberculosis in reproductive organs and semen of bulls. Am J Vet Res 31, 255-258.

Larsen, A.B., Miller J.M., 1978, Mammary gland exposure of cows to Mycobacterium paratuberculosis. American Journal of Veterinary Research 39, 1972-1974.

Larsen, A.B., Stalheim, O.H., Hughes, D.E., Appell, L.H., Richards, W.D., Himes, E.M., 1981, Mycobacterium paratuberculosis in the semen and genital organs of a semen-donor bull. J Am Vet Med Assoc 179, 169-171.

Lawrence, S.H., Schulkins, T., 1956, Serum transaminase levels following prolonged surgical anesthesia. Anesthesiology 17, 531-535.

Lepper, A.W., Wilks, C.R., Kotiw, M., Whitehead, J.T., Swart, K.S., 1989, Sequential bacteriological observations in relation to cell-mediated and humoral antibody responses of cattle infected with Mycobacterium paratuberculosis and maintained on normal or high iron intake. Aust Vet J 66, 50-55.

Li, L., Bannantine, J.P., Zhang, Q., Amonsin, A., May, B.J., Alt, D., Banerji, N., Kanjilal, S., Kapur, V., 2005, The complete genome sequence of Mycobacterium avium subspecies paratuberculosis. Proc Natl Acad Sci U S A 102, 1234412349. 
Lucas, J.N., Cousins, D.V., Mills, A.J., Van Wijk, J.G., 2003, Identification of Mycobacterium avium subsp avium in an alpaca with lesions resembling paratuberculosis. Aust Vet J 81, 567-569.

Lugton, I., 1999, Mucosa-associated lymphoid tissues as sites for uptake, carriage and excretion of tubercle bacilli and other pathogenic mycobacteria. Immunol Cell Biol 77, 364-372.

Maio, E., Carta, T., Balseiro, A., Sevilla, I.A., Romano, A., Ortiz, J.A., Vieira-Pinto, M., Garrido, J.M., de la Lastra, J.M., Gortazar, C., 2011, Paratuberculosis in European wild rabbits from the Iberian Peninsula. Res Vet Sci 91, 212-218.

Manning, E.J., Collins, M.T., 2001, Mycobacterium avium subsp. paratuberculosis: pathogen, pathogenesis and diagnosis. Rev Sci Tech 20, 133-150.

Manning, E.J., Kucera, T.E., Gates, N.B., Woods, L.M., Fallon-McKnight, M., 2003, Testing for Mycobacterium avium subsp. paratuberculosis infection in asymptomatic free-ranging tule elk from an infected herd. J Wildl Dis 39, 323328.

Manning, E.J., Steinberg, H., Rossow, K., Ruth, G.R., Collins, M.T., 1998, Epizootic of paratuberculosis in farmed elk. J Am Vet Med Assoc 213, 1320-1322, 12801321.

Marco, I., Ruiz, M., Juste, R., Garrido, J.M., Lavin, S., 2002, Paratuberculosis in freeranging fallow deer in Spain. J Wildl Dis 38, 629-632.

Matthews, P.R., Sargent, A., 1977, The isolation of Mycobacteria from the brown hare (Lepus europaeus). Br Vet J 133, 399-404.

McClure, H.M., Chiodini, R.J., Anderson, D.C., Swenson, R.B., Thayer, W.R., Coutu, J.A., 1987, Mycobacterium paratuberculosis infection in a colony of stumptail macaques (Macaca arctoides). J Infect Dis 155, 1011-1019.

Meadus, W.J., Gill, C.O., Duff, P., Badoni, M., Saucier, L., 2008, Prevalence on beef carcasses of Mycobacterium avium subsp. paratuberculosis DNA. Int J Food Microbiol 124, 291-294.

Mendoza, J.L., Lana, R., Diaz-Rubio, M., 2009, Mycobacterium avium subspecies paratuberculosis and its relationship with Crohn's disease. World J Gastroenterol 15, 417-422.

Merkal, R.S., 1973, Laboratory diagnosis of bovine paratuberculosis. J Am Vet Med Assoc 163, 1100-1102.

Merkal, R.S., Kopecky, K.E., Larsen, A.B., 1970, Immunologic mechanisms in bovine paratuberculosis. Am J Vet Res 31, 475-485.

Merkal, R.S., Kopecky, K.E., Larsen, A.B., Thurston, J.R., 1964, Improvements In The Techniques For Primary Cultivation Of Mycobacterium Paratuberculosis. Am J Vet Res 25, 1290-1294.

Merkal, R.S., Larsen, A.B., 1962, Improved methods for primary cultivation of Mycobacterium paratuberculosis. Am J Vet Res 23, 1307-1309.

Merkal, R.S., McCullough, W.G., 1982, A new mycobactin, mycobactin J, from Mycobacterium paratuberculosis. Curr Microbiol 7, 333-335.

Merkal, R.S., Miller, J.M., Hintz, A.M., Bryner, J.H., 1982, Intrauterine inoculation of Mycobacterium paratuberculosis into guinea pigs and cattle. Am J Vet Res 43, 676-678.

Merkal, R.S., Miller, J.M., Hintz, A.M., Bryner, J.H., 1981, Intrauterine inoculation of Mycobacterium paratuberculosis into guinea pigs and cattle. Am J Vet Res 43, 676-678. 
Meylan, M., Nicolet, J., Busato, A., Burnens, A., Martig, J., 1995, [The prevalence of paratuberculosis in the Plateau de Diesse region]. Schweiz Arch Tierheilkd 137, 22-25.

Millar, D.S., Withey, S.J., Tizard, M.L., Ford, J.G., Hermon-Taylor, J., 1995, Solidphase hybridization capture of low-abundance target DNA sequences: application to the polymerase chain reaction detection of Mycobacterium paratuberculosis and Mycobacterium avium subsp. silvaticum. Anal Biochem 226, 325-330.

Miller, D.S., Collins, M.T., Smith, B.B., Anderson, P.R., Kramsky, J., Wilder, G., Hope, A., 2000, Specificity of four serologic assays for Mycobacterium avium ss paratuberculosis in llamas and alpacas: a single herd study. J Vet Diagn Invest 12, 345-353.

Mitchell, R.M., Whitlock, R.H., Stehman, S.M., Benedictus, A., Chapagain, P.P., Grohn, Y.T., Schukken, Y.H., 2008, Simulation modeling to evaluate the persistence of Mycobacterium avium subsp. paratuberculosis (MAP) on commercial dairy farms in the United States. Prev Vet Med 83, 360-380.

Moss, M.T., Green, E.P., Tizard, M.L., Malik, Z.P., Hermon-Taylor, J., 1991, Specific detection of Mycobacterium paratuberculosis by DNA hybridisation with a fragment of the insertion element IS900. Gut 32, 395-398.

Motiwala, A.S., Amonsin, A., Strother, M., Manning, E.J., Kapur, V., Sreevatsan, S., 2004, Molecular epidemiology of Mycobacterium avium subsp. paratuberculosis isolates recovered from wild animal species. J Clin Microbiol 42, 1703-1712.

Motiwala, A.S., Strother, M., Amonsin, A., Byrum, B., Naser, S.A., Stabel, J.R., Shulaw, W.P., Bannantine, J.P., Kapur, V., Sreevatsan, S., 2003, Molecular epidemiology of Mycobacterium avium subsp. paratuberculosis: evidence for limited strain diversity, strain sharing, and identification of unique targets for diagnosis. J Clin Microbiol 41, 2015-2026.

Mullis, K.B., Faloona, F.A., 1987, Specific synthesis of DNA in vitro via a polymerasecatalyzed chain reaction. Methods Enzymol 155, 335-350.

Muskens, J., Barkema, H.W., Russchen, E., van Maanen, K., Schukken, Y.H., Bakker, D., 2000, Prevalence and regional distribution of paratuberculosis in dairy herds in The Netherlands. Vet Microbiol 77, 253-261.

Muskens, J., Elbers, A.R., van Weering, H.J., Noordhuizen, J.P., 2003, Herd management practices associated with paratuberculosis seroprevalence in Dutch dairy herds. J Vet Med B Infect Dis Vet Public Health 50, 372-377.

Naser, S.A., Ghobrial, G., Romero, C., Valentine, J.F., 2004, Culture of Mycobacterium avium subspecies paratuberculosis from the blood of patients with Crohn's disease. Lancet 364, 1039-1044.

Nielsen, S.S., Kolmos, B., Christoffersen, A.B., 2004, Comparison of contamination and growth of Mycobacterium avium subsp. paratuberculosis on two different media. J Appl Microbiol 96, 149-153.

Nielsen, S.S., Toft, N., 2009, A review of prevalences of paratuberculosis in farmed animals in Europe. Prev Vet Med 88, 1-14.

Norby, B., Fosgate, G.T., Manning, E.J., Collins, M.T., Roussel, A.J., 2007, Environmental mycobacteria in soil and water on beef ranches: association between presence of cultivable mycobacteria and soil and water physicochemical characteristics. Vet Microbiol 124, 153-159.

O'Doherty, A., O'Grady, D., O'Farrell, K., Smith, T., Egan, J., 2002, Survey of Johne's disease in imported animals in the Republic of Ireland. Vet Rec 150, 634-636. 
O'Mahony, J., Hill, C., 2004, Rapid real-time PCR assay for detection and quantitation of Mycobacterium avium subsp. paratuberculosis DNA in artificially contaminated milk. Appl Environ Microbiol 70, 4561-4568.

O'Reilly, C.E., O'Connor, L., Anderson, W., Harvey, P., Grant, I.R., Donaghy, J., Rowe, M., O'Mahony, P., 2004, Surveillance of bulk raw and commercially pasteurized cows' milk from approved Irish liquid-milk pasteurization plants to determine the incidence of Mycobacterium paratuberculosis. Appl Environ Microbiol 70, 5138-5144.

Ogura, Y., Bonen, D.K., Inohara, N., Nicolae, D.L., Chen, F.F., Ramos, R., Britton, H., Moran, T., Karaliuskas, R., Duerr, R.H., Achkar, J.P., Brant, S.R., Bayless, T.M., Kirschner, B.S., Hanauer, S.B., Nunez, G., Cho, J.H., 2001, A frameshift mutation in NOD2 associated with susceptibility to Crohn's disease. Nature 411, 603-606.

Oliver, J.D., 2005, The viable but nonculturable state in bacteria. J Microbiol 43 Spec No, 93-100.

Owen, W.J., Thoen, C.O., 1983, Experimental exposure of cattle to Mycobacterium paratuberculosis orally and intrauterine with attempted culture of the organism and detection of humoral antibodies. Proceedings of the United States Animal Health Association 87, 570-581.

Pavlik, I., Bartl, J., Dvorska, L., Svastova, P., du Maine, R., Machackova, M., Yayo Ayele, W., Horvathova, A., 2000, Epidemiology of paratuberculosis in wild ruminants studied by restriction fragment length polymorphism in the Czech Republic during the period 1995-1998. Vet Microbiol 77, 231-251.

Perry, G.H., Vivanco, H., Holmes, I., Gwozdz, J.M., Bourne, J., 2006, No evidence of Mycobacterium avium subsp. paratuberculosis in in vitro produced cryopreserved embryos derived from subclinically infected cows. Theriogenology 66, 1267-1273.

Petit, E., 2001, Enquete serologique sur la paratuberculose bovine menee dans I'Yonne lors de la campagne (In French, with English abstract). Epidemiol. Sante Anim. 40, 23-39.

Philpott, M., 1993, The dangers of disease transmission by artificial insemination and embryo transfer. Br Vet J 149, 339-369.

Pickup, R.W., Rhodes, G., Arnott, S., Sidi-Boumedine, K., Bull, T.J., Weightman, A., Hurley, M., Hermon-Taylor, J., 2005, Mycobacterium avium subsp. paratuberculosis in the catchment area and water of the River Taff in South Wales, United Kingdom, and its potential relationship to clustering of Crohn's disease cases in the city of Cardiff. Appl Environ Microbiol 71, 2130-2139.

Pickup, R.W., Rhodes, G., Bull, T.J., Arnott, S., Sidi-Boumedine, K., Hurley, M., Hermon-Taylor, J., 2006, Mycobacterium avium subsp. paratuberculosis in lake catchments, in river water abstracted for domestic use, and in effluent from domestic sewage treatment works: diverse opportunities for environmental cycling and human exposure. Appl Environ Microbiol 72, 4067-4077.

Poupart, P., Coene, M., Van Heuverswyn, H., Cocito, C., 1993, Preparation of a specific RNA probe for detection of Mycobacterium paratuberculosis and diagnosis of Johne's disease. J Clin Microbiol 31, 1601-1605.

Quirke, P., 2001, Antagonist. Mycobacterium avium subspecies paratuberculosis is a cause of Crohn's disease. Gut 49, 757-760. 
Raizman, E.A., Wells, S.J., Godden, S.M., Bey, R.F., Oakes, M.J., Bentley, D.C., Olsen, K.E., 2004, The distribution of Mycobacterium avium ssp. paratuberculosis in the environment surrounding Minnesota dairy farms. J Dairy Sci 87, 2959-2966.

Raizman, E.A., Wells, S.J., Jordan, P.A., DelGiudice, G.D., Bey, R.R., 2005, Mycobacterium avium subsp. paratuberculosis from free-ranging deer and rabbits surrounding Minnesota dairy herds. Can J Vet Res 69, 32-38.

Rajeev, S., Zhang, Y., Sreevatsan, S., Motiwala, A.S., Byrum, B., 2005, Evaluation of multiple genomic targets for identification and confirmation of Mycobacterium avium subsp. paratuberculosis isolates using real-time PCR. Vet Microbiol 105, 215-221.

Rasmussen, R., 2001, Quantification on the LightCycler Meuer S., Wittwer, C., Nakagawara, K. (Eds.) Rapid cycle Real-time PCR, Methods and Applications. Springer, Heidelberg, Germany, 21-34 pp.

Reichel, M.P., Kittelberger, R., Penrose, M.E., Meynell, R.M., Cousins, D., Ellis, T., Mutharia, L.M., Sugden, E.A., Johns, A.H., de Lisle, G.W., 1999, Comparison of serological tests and faecal culture for the detection of Mycobacterium avium subsp. paratuberculosis infection in cattle and analysis of the antigens involved. Vet Microbiol 66, 135-150.

Reischl, U., Lehn, N., Sanden, G.N., Loeffelholz, M.J., 2001, Real-time PCR assay targeting IS481 of Bordetella pertussis and molecular basis for detecting Bordetella holmesii. J Clin Microbiol 39, 1963-1966.

Ridge, S., 1993, New Strategies for the Control and Eradication of Bovine Johne's DiseaseAttwood, $81 \mathrm{p}$.

Ridge, S.E., Harkin, J.T., Badman, R.T., Mellor, A.M., Larsen, J.W., 1995, Johne's disease in alpacas (Lama pacos) in Australia. Aust Vet J 72, 150-153.

Riggio, M.P., Gibson, J., Lennon, A., Wray, D., MacDonald, D.G., 1997, Search for Mycobacterium paratuberculosis DNA in orofacial granulomatosis and oral Crohn's disease tissue by polymerase chain reaction. Gut 41, 646-650.

Ris, D.R., Hamel, K.L., Ayling, J.M., 1988, The detection of Mycobacterium paratuberculosis in bovine faeces by isolation and the comparison of isolation with the examination of stained smears by light microscopy. N Z Vet J 36, 112114.

Robbe-Austerman, S., Gardner, I.A., Thomsen, B.V., Morrical, D.G., Martin, B.M., Palmer, M.V., Thoen, C.O., Ewing, C., 2006, Sensitivity and specificity of the agar-gel-immunodiffusion test, ELISA and the skin test for detection of paratuberculosis in United States Midwest sheep populations. Vet Res 37, 553564.

Robbi, C., Rossi, I., Nardelli, S., Rossi, E., Toson, M., Marangon, S., Vincenzi, G., Vicenzoni, G., 2002, Prevalenza di Paratubercolosi (Johnes disease) nella popolazione di bovine da latte della Regione Veneto (in Italian, with English abstract). Atti della Societa Italiana di Buiatria 34, 283-288.

Rogall, T., Wolters, J., Flohr, T., Bottger, E.C., 1990, Towards a phylogeny and definition of species at the molecular level within the genus Mycobacterium. Int J Syst Bacteriol 40, 323-330.

Rohde, R.F., Shulaw, W.P., 1990, Isolation of Mycobacterium paratuberculosis from the uterine flush fluids of cows with clinical paratuberculosis. J Am Vet Med Assoc 197, 1482-1483.

Rolle, M., Mayr, A. 2002. Medizinische Mikrobiologie, Infektions- und Seuchenlehre (Stuttgart, Enke Verlag). 
Rossiter, C.A., Burhans, W.S., 1996, Farm-specific approach to paratuberculosis (Johne's disease) control. Vet Clin North Am Food Anim Pract 12, 383-415.

Rowe, M.T., Grant, I.R., 2006, Mycobacterium avium ssp. paratuberculosis and its potential survival tactics. Lett Appl Microbiol 42, 305-311.

Salgado, M., Herthnek, D., Bolske, G., Leiva, S., Kruze, J., 2009, First isolation of Mycobacterium avium subsp. paratuberculosis from wild guanacos (Lama guanicoe) on Tierra del Fuego Island. J Wildl Dis 45, 295-301.

Salgado, M., Manning, E.J., Collins, M.T., 2005, Performance of a Johne's disease enzyme-linked immunosorbent assay adapted for milk samples from goats. J Vet Diagn Invest 17, 350-354.

Salgado, M., Manning, E.J., Monti, G., Bolske, G., Soderlund, R., Ruiz, M., Paredes, E., Leiva, S., Van Kruningen, H., Kruze, J., 2011, European hares in Chile: a different lagomorph reservoir for Mycobacterium avium subsp. paratuberculosis? J Wildl Dis 47, 734-738.

Sanderson, J.D., Moss, M.T., Tizard, M.L., Hermon-Taylor, J., 1992, Mycobacterium paratuberculosis DNA in Crohn's disease tissue. Gut 33, 890-896.

Scanu, A.M., Bull, T.J., Cannas, S., Sanderson, J.D., Sechi, L.A., Dettori, G., Zanetti, S., Hermon-Taylor, J., 2007, Mycobacterium avium subspecies paratuberculosis infection in cases of irritable bowel syndrome and comparison with Crohn's disease and Johne's disease: common neural and immune pathogenicities. J Clin Microbiol 45, 3883-3890.

Schneider, F., 2003. Entwicklung einer "seminested PCR" und einer "Real-Time-PCR" zum Nachweis von Mycobacterium avium ssp. paratuberculosis bei Rindern (Development of a "semi-nested PCR" and a "real-time PCR" for the detection of Mycobacterium avium ssp. paratuberculosis in cattle) Ph.D. Dissertation. Ludwig-Maximilians-University, Munich, Bavaria, Germany,

Schonenbrucher, H., Abdulmawjood, A., Failing, K., Bulte, M., 2008, New triplex realtime PCR assay for detection of Mycobacterium avium subsp. paratuberculosis in bovine feces. Appl Environ Microbiol 74, 2751-2758.

Schwartz, D., Shafran, I., Romero, C., Piromalli, C., Biggerstaff, J., Naser, N., Chamberlin, W., Naser, S.A., 2000, Use of short-term culture for identification of Mycobacterium avium subsp. paratuberculosis in tissue from Crohn's disease patients. Clin Microbiol Infect 6, 303-307.

Sechi, L.A., Scanu, A.M., Molicotti, P., Cannas, S., Mura, M., Dettori, G., Fadda, G., Zanetti, S., 2005, Detection and Isolation of Mycobacterium avium subspecies paratuberculosis from intestinal mucosal biopsies of patients with and without Crohn's disease in Sardinia. Am J Gastroenterol 100, 1529-1536.

Seitz, S.E., Heider, L.E., Heuston, W.D., Bech-Nielsen, S., Rings, D.M., Spangler, L., 1989, Bovine fetal infection with Mycobacterium paratuberculosis. J Am Vet Med Assoc 194, 1423-1426.

Semret, M., Turenne, C.Y., Behr, M.A., 2006, Insertion sequence IS900 revisited. J Clin Microbiol 44, 1081-1083.

Sevilla, I., Garrido, J.M., Geijo, M., Juste, R.A., 2007, Pulsed-field gel electrophoresis profile homogeneity of Mycobacterium avium subsp. paratuberculosis isolates from cattle and heterogeneity of those from sheep and goats. BMC Microbiol 7, 18.

Shanahan, F., O'Mahony, J., 2005, The mycobacteria story in Crohn's disease. Am J Gastroenterol 100, 1537-1538. 
Sherman, D.M., Markham, R.J., Bates, F., 1984, Agar gel immunodiffusion test for diagnosis of clinical paratuberculosis in cattle. J Am Vet Med Assoc 185, 179182.

Shin, S.J., Cho, D., Collins, M.T., 2008, Diagnosis of bovine paratuberculosis by a novel enzyme-linked immunosorbent assay based on early secreted antigens of Mycobacterium avium subsp. paratuberculosis. Clin Vaccine Immunol 15, 1277-1281.

Singh, A.V., Singh, S.V., Makharia, G.K., Singh, P.K., Sohal, J.S., 2008, Presence and characterization of Mycobacterium avium subspecies paratuberculosis from clinical and suspected cases of Crohn's disease and in the healthy human population in India. Int J Infect Dis 12, 190-197.

Sivakumar, P., Tripathi, B.N., Singh, N., 2005, Detection of Mycobacterium avium subsp. paratuberculosis in intestinal and lymph node tissues of water buffaloes (Bubalus bubalis) by PCR and bacterial culture. Vet Microbiol 108, 263-270.

Slana, I., Kralik, P., Kralova, A., Pavlik, I., 2008, On-farm spread of Mycobacterium avium subsp. paratuberculosis in raw milk studied by IS900 and F57 competitive real time quantitative PCR and culture examination. Int J Food Microbiol 128, 250-257.

Slana, I., Liapi, M., Moravkova, M., Kralova, A., Pavlik, I., 2009, Mycobacterium avium subsp. paratuberculosis in cow bulk tank milk in Cyprus detected by culture and quantitative IS900 and F57 real-time PCR. Prev Vet Med 89, 223226.

Smith, S.I., West, D.M., Wilson, P.R., de Lisle, G.W., Collett, M.G., Heuer, C., Chambers, J.P., 2011, Detection of Mycobacterium avium subsp. paratuberculosis in skeletal muscle and blood of ewes from a sheep farm in New Zealand. N Z Vet J 59, 240-243.

Sohal, J.S., Sheoran, N., Narayanasamy, K., Brahmachari, V., Singh, S., Subodh, S., 2009, Genomic analysis of local isolate of Mycobacterium avium subspecies paratuberculosis. Vet Microbiol 134, 375-382.

Spahr, U., Schafroth, K., 2001, Fate of Mycobacterium avium subsp. paratuberculosis in Swiss hard and semihard cheese manufactured from raw milk. Appl Environ Microbiol 67, 4199-4205.

Stabel, J.R., 1996, Production of gamma-interferon by peripheral blood mononuclear cells: an important diagnostic tool for detection of subclinical paratuberculosis. $\mathbf{J}$ Vet Diagn Invest 8, 345-350.

Stabel, J.R., 2008, Pasteurization of colostrum reduces the incidence of paratuberculosis in neonatal dairy calves. J Dairy Sci 91, 3600-3606.

Stabel, J.R., Bannantine, J.P., 2005, Development of a nested PCR method targeting a unique multicopy element, ISMap02, for detection of Mycobacterium avium subsp. paratuberculosis in fecal samples. J Clin Microbiol 43, 4744-4750.

Stabel, J.R., Palmer, M.V., Harris, B., Plattner, B., Hostetter, J., Robbe-Austerman, S., 2009, Pathogenesis of Mycobacterium avium subsp. paratuberculosis in neonatal calves after oral or intraperitoneal experimental infection. Vet Microbiol 136, 306-313.

Stabel, J.R., Whitlock, R.H., 2001, An evaluation of a modified interferon-gamma assay for the detection of paratuberculosis in dairy herds. Vet Immunol Immunopathol $79,69-81$. 
Stark, K.D., Frei-Staheli, C., Frei, P.P., Pfeiffer, D.U., Danuser, J., Audige, L., Nicolet, J., Strasser, M., Gottstein, B., Kihm, U., 1997, [Frequency and cost of health problems in Swiss dairy cows and their calves (1993-1994)]. Schweiz Arch Tierheilkd 139, 343-353.

Stephan, R., Buhler, K., Corti, S., 2002, Incidence of Mycobacterium avium subspecies paratuberculosis in bulk-tank milk samples from different regions in Switzerland. Vet Rec 150, 214-215.

Stephan, R., Schumacher, S., Tasara, T., Grant, I.R., 2007, Prevalence of Mycobacterium avium subspecies paratuberculosis in Swiss raw milk cheeses collected at the retail level. J Dairy Sci 90, 3590-3595.

Stevenson, K., Alvarez, J., Bakker, D., Biet, F., de Juan, L., Denham, S., Dimareli, Z., Dohmann, K., Gerlach, G.F., Heron, I., Kopecna, M., May, L., Pavlik, I., Sharp, J.M., Thibault, V.C., Willemsen, P., Zadoks, R.N., Greig, A., 2009, Occurrence of Mycobacterium avium subspecies paratuberculosis across host species and European countries with evidence for transmission between wildlife and domestic ruminants. BMC Microbiol 9, 212.

Stevenson, K., Sharp, J.M., 1997, The contribution of molecular biology to Mycobacterium avium subspecies paratuberculosis research. Vet J 153, 269286.

Sugden, E.A., Stilwell, K., Michaelides, A., 1997, A comparison of lipoarabinomannan with other antigens used in absorbed enzyme immunoassays for the serological detection of cattle infected with Mycobacterium paratuberculosis. J Vet Diagn Invest 9, 413-417.

Sweeney, R.W., 1996, Transmission of paratuberculosis. Vet Clin North Am Food Anim Pract 12, 305-312.

Sweeney, R.W., Uzonna, J., Whitlock, R.H., Habecker, P.L., Chilton, P., Scott, P., 2006, Tissue predilection sites and effect of dose on Mycobacterium avium subs. paratuberculosis organism recovery in a short-term bovine experimental oral infection model. Res Vet Sci 80, 253-259.

Sweeney, R.W., Whitlock, R.H., Rosenberger, A.E., 1992, Mycobacterium paratuberculosis isolated from fetuses of infected cows not manifesting signs of the disease. Am J Vet Res 53, 477-480.

Tasara, T., Stephan, R., 2005, Development of an F57 sequence-based real-time PCR assay for detection of Mycobacterium avium subsp. paratuberculosis in milk. Appl Environ Microbiol 71, 5957-5968.

Thoen, C.O., Richards, W.D., Jarnagin, J.L., 1977, Mycobacteria isolated from exotic animals. J Am Vet Med Assoc 170, 987-990.

Thompson, B.R., Clark, R.G., Mackintosh, C.G., 2007, Intra-uterine transmission of Mycobacterium avium subsp paratuberculosis in subclinically affected red deer (Cervus elaphus). N Z Vet J 55, 308-313.

Tizard, M.L., Moss, M.T., Sanderson, J.D., Austen, B.M., Hermon-Taylor, J., 1992, $\mathrm{p} 43$, the protein product of the atypical insertion sequence IS900, is expressed in Mycobacterium paratuberculosis. J Gen Microbiol 138 Pt 8, 1729-1736.

Turenne, C.Y., Collins, D.M., Alexander, D.C., Behr, M.A., 2008, Mycobacterium avium subsp. paratuberculosis and $M$. avium subsp. avium are independently evolved pathogenic clones of a much broader group of $M$. avium organisms. J Bacteriol 190, 2479-2487. 
Twort, F.W., Ingram, G.L.Y., 1912, A method for isolating and cultivating the Mycobacterium enteritidis chronicae pseudotuberculosae bovis johne and some experiments on the preparation of a diagnostic vaccine for pseudotuberculous enteritis of bovines. Proc Roy Soc 84, 517-543.

van Kooten, H.C., Mackintosh, C.G., Koets, A.P., 2006, Intra-uterine transmission of paratuberculosis (Johne's disease) in farmed red deer. N Z Vet J 54, 16-20.

Vansnick, E., Vercammen, F., Bauwens, L., D'Haese, E., Nelis, H., Geysen, D., 2005, A survey for Mycobacterium avium subspecies paratuberculosis in the Royal Zoological Society of Antwerp. Vet J 170, 249-256.

Vary, P.H., Andersen, P.R., Green, E., Hermon-Taylor, J., McFadden, J.J., 1990, Use of highly specific DNA probes and the polymerase chain reaction to detect Mycobacterium paratuberculosis in Johne's disease. J Clin Microbiol 28, 933937.

Vicenzoni, G., Filippi, L., Dolci, P., Corro, M., Job, L., Robbi, C., Mutinelli, F., Marangon, S., 1999, Prevalenza del Mycobacterium paratuberculosis in bovine macellate in provincia di Verona (In Italian, with English abstract). Atti della Societa Italiana di Buiatria 31, 277-281.

Ward, M.P., Perez, A.M., 2004, Association between soil type and paratuberculosis in cattle herds. Am J Vet Res 65, 10-14.

Weber, A., Gurke, R., Bauer, K., Schreyer, K., 1992, [Bacterial studies on the occurrence of Mycobacterium paratuberculosis in fecal samples of zoo ruminants]. Berl Munch Tierarztl Wochenschr 105, 161-164.

Weber, M.F., Kogut, J., de Bree, J., van Schaik, G., Nielen, M., 2010, Age at which dairy cattle become Mycobacterium avium subsp. paratuberculosis faecal culture positive. Prev Vet Med 97, 29-36.

Weber, M.F., Nielen, M., Velthuis, A.G., van Roermund, H.J., 2008, Milk quality assurance for paratuberculosis: simulation of within-herd infection dynamics and economics. Vet Res 39, 12.

Wells, J.E., Bosilevac, J.M., Kalchayanand, N., Arthur, T.M., Shackelford, S.D., Wheeler, T.L., Koohmaraie, M., 2009, Prevalence of Mycobacterium avium subsp. paratuberculosis in ileocecal lymph nodes and on hides and carcasses from cull cows and fed cattle at commercial beef processing plants in the United States. J Food Prot 72, 1457-1462.

Whan, L., Ball, H.J., Grant, I.R., Rowe, M.T., 2005, Occurrence of Mycobacterium avium subsp. paratuberculosis in untreated water in Northern Ireland. Appl Environ Microbiol 71, 7107-7112.

Whipple, D.L., Callihan, D.R., Jarnagin, J.L., 1991, Cultivation of Mycobacterium paratuberculosis from bovine fecal specimens and a suggested standardized procedure. J Vet Diagn Invest 3, 368-373.

Whitlock, R.H., Buergelt, C., 1996, Preclinical and clinical manifestations of paratuberculosis (including pathology). Vet Clin North Am Food Anim Pract 12, 345-356.

Whitlock, R.H., Wells, S.J., Sweeney, R.W., Van Tiem, J., 2000, ELISA and fecal culture for paratuberculosis (Johne's disease): sensitivity and specificity of each method. Vet Microbiol 77, 387-398.

Whittington, R., Marsh, I., Choy, E., Cousins, D., 1998, Polymorphisms in IS1311, an insertion sequence common to Mycobacterium avium and M. avium subsp. paratuberculosis, can be used to distinguish between and within these species. Mol Cell Probes 12, 349-358. 
Whittington, R.J., 2009, Factors affecting isolation and identification of Mycobacterium avium subsp. paratuberculosis from fecal and tissue samples in a liquid culture system. J Clin Microbiol 47, 614-622.

Whittington, R.J., Marsh, I., McAllister, S., Turner, M.J., Marshall, D.J., Fraser, C.A., 1999, Evaluation of modified BACTEC 12B radiometric medium and solid media for culture of Mycobacterium avium subsp. paratuberculosis from sheep. J Clin Microbiol 37, 1077-1083.

Whittington, R.J., Marsh, I.B., Reddacliff, L.A., 2005, Survival of Mycobacterium avium subsp. paratuberculosis in dam water and sediment. Appl Environ Microbiol 71, 5304-5308.

Whittington, R.J., Marsh, I.B., Taylor, P.J., Marshall, D.J., Taragel, C., Reddacliff, L.A., 2003, Isolation of Mycobacterium avium subsp paratuberculosis from environmental samples collected from farms before and after destocking sheep with paratuberculosis. Aust Vet J 81, 559-563.

Whittington, R.J., Marsh, I.B., Whitlock, R.H., 2001a, Typing of IS 1311 polymorphisms confirms that bison (Bison bison) with paratuberculosis in Montana are infected with a strain of Mycobacterium avium subsp. paratuberculosis distinct from that occurring in cattle and other domesticated livestock. Mol Cell Probes 15, 139-145.

Whittington, R.J., Marshall, D.J., Nicholls, P.J., Marsh, I.B., Reddacliff, L.A., 2004, Survival and dormancy of Mycobacterium avium subsp. paratuberculosis in the environment. Appl Environ Microbiol 70, 2989-3004.

Whittington, R.J., Reddacliff, L.A., Marsh, I., McAllister, S., Saunders, V., 2000, Temporal patterns and quantification of excretion of Mycobacterium avium subsp paratuberculosis in sheep with Johne's disease. Aust Vet J 78, 34-37.

Whittington, R.J., Taragel, C.A., Ottaway, S., Marsh, I., Seaman, J., Fridriksdottir, V., 2001b, Molecular epidemiological confirmation and circumstances of occurrence of sheep (S) strains of Mycobacterium avium subsp. paratuberculosis in cases of paratuberculosis in cattle in Australia and sheep and cattle in Iceland. Vet Microbiol 79, 311-322.

Whittington, R.J., Windsor, P.A., 2009, In utero infection of cattle with Mycobacterium avium subsp. paratuberculosis: a critical review and meta-analysis. Vet J 179, 60-69.

Willemsen, P.T., Westerveen, J., Dinkla, A., Bakker, D., van Zijderveld, F.G., Thole, J.E., 2006, Secreted antigens of Mycobacterium avium subspecies paratuberculosis as prominent immune targets. Vet Microbiol 114, 337-344.

Wu, C.W., Livesey, M., Schmoller, S.K., Manning, E.J., Steinberg, H., Davis, W.C., Hamilton, M.J., Talaat, A.M., 2007, Invasion and persistence of Mycobacterium avium subsp. paratuberculosis during early stages of Johne's disease in calves. Infect Immun 75, 2110-2119.

Wu, C.W., Schramm, T.M., Zhou, S., Schwartz, D.C., Talaat, A.M., 2009, Optical mapping of the Mycobacterium avium subspecies paratuberculosis genome. BMC Genomics 10, 25.

Yadav, D., Singh, S.V., Singh, A.V., Sevilla, I., Juste, R.A., Singh, P.K., Sohal, J.S., 2008, Pathogenic 'Bison-type' Mycobacterium avium subspecies paratuberculosis genotype characterized from riverine buffalo (Bubalus bubalis) in North India. Comp Immunol Microbiol Infect Dis 31, 373-387.

Zwick, L.S., Walsh, T.F., Barbiers, R., Collins, M.T., Kinsel, M.J., Murnane, R.D., 2002, Paratuberculosis in a mandrill (Papio sphinx). J Vet Diagn Invest 14, 326328. 


\section{Appendix}




\section{List of Publications}

This thesis is based on the work contained in the following papers:

I Münster, P., Völkel, I., Wemheuer, W., Petschenka, J., Wemheuer, W., Steinbrunn, C., Campe, A., Schulz-Schaeffer, W.J. Kreienbrock, L., and Czerny, C.-P. (2011): Short Communication: Detection of Mycobacterium avium ssp. paratuberculosis in ileocaecal lymph nodes collected from elderly slaughter cows using a semi-nested polymerase chain reaction. Vet Microbiol 154, 197201

II Münster, P., Völkel, I., Wemheuer, W. Schwarz, D, Döring, S., and Czerny, C.P. (2012): Longitudinal study on characterization of shedding patterns of Mycobacterium avium ssp. paratuberculosis in a naturally infected breeding bull by polymerase chain reaction assays. Transbound Emerg Dis. (Under review) Manuscript ID: TBED-OA-150-11

III Münster, P., Völkel, I., v. Buchholz, A., and Czerny, C.-P. (2012): Brief Communication: Detection of Mycobacterium avium ssp. paratuberculosis by IS900-based PCR assays from an alpaca (Vicugna pacos) kept in a German zoological garden. J Zoo Wildl Med (Under review) Manuscript ID: 2011-11325

IV Münster, P., Fechner, K., Völkel, I., Buchholz, A., and Czerny, C.-P. (2012): Distribution of Mycobacterium avium ssp. paratuberculosis in a German zoological garden by IS900 semi-nested and quantitative real-time PCR. Vet Microbiol (Under review) Manuscript ID: VETMIC-D-12-6750 


\section{List of Presentations}

I 4. Arbeitstagung zu Mykobakterieninfektionen (13. - 14.05.2009 in Jena): MÜNSTER, P., K. JURCZINSKY, A. v. BUCHHOLZ, C.-P. CZERNY: "Seminested und quantitative ,real-time“-PCR-Verfahren zum Schnellnachweis von Mycobacterium avium ssp. paratuberculosis in Kot-, Organ- und Umweltproben sowie molekulare Differenzierung von Wiederkäuer- und Zootierisolaten"

II 28. AVID-Tagung "Bakteriologie" (16. - 18.09.2009 in Banz): MÜNSTER, P., S. URSTADT, I. VÖLKEL, W. WEMHEUER, C.-P. CZERNY: "Quantitative und semi-quantitative PCR-Verfahren zur Detektion von Mycobacterium avium ssp. paratuberculosis im Sperma von Besamungsbullen"

III 30. AVID-Tagung „Bakteriologie“ (05. - 07.10.2011 in Banz): MÜNSTER, P., I. VÖLKEL, W. WEMHEUER, J. PETSCHENKA, W. WEMHEUER, C. STEINBRUNN, A. CAMPE, W.J. SCHULZ-SCHÄFFER, L. KREIENBROCK, C.-P. CZERNY: "Molekularbiologische Untersuchungen zum Vorkommen von Mycobacterium avium ssp. paratuberculosis in Lymphknoten von Schlachtrindern"

IV 10. Jahrestagung der Deutschen Gesellschaft für Zootier-, Wildtier- und Exotenmedizin (30.11. - 04.12.2011 in Stuttgart):

MÜNSTER P., I. VÖLKEL, K. FECHNER, A. v. BUCHHOLZ, K. JURCZYNSKI, O. BEHLERT, K. TESCHNER, C.-P. CZERNY: "Molekularbiologische Untersuchungen zum Vorkommen von Mycobacterium avium ssp. paratuberculosis in Kotproben von Zootieren“

V $\quad 1^{\text {th }}$ International Colloquium on Paratuberculosis (05.-10.02.2012, Sydney): MÜNSTER, P., S. URSTADT, I. VÖLKEL, D. SCHWARZ, A.T. KUHLEN, S. DÖRING, C.-P. CZERNY: “A longitudinal study to characterize the shedding patterns of Mycobacterium avium ssp. paratuberculosis in a naturally infected breeding bull by polymerase chain reaction assays" 


\section{List of Poster}

I Göttingen International Health Network (23.-24.05.2011, Göttingen): MÜNSTER, P., I. VÖLKEL, F., SCHNEIDER, S. DÖRING, K. FECHNER, W. WEMHEUER, C.-P. CZERNY: “Mycobacterium avium ssp. paratuberculosis Occurrence and Epidemiology"

II $\quad \mathbf{1 1}^{\text {th }}$ International Colloquium on Paratuberculosis (05.-10.02.2012, Sydney): MÜNSTER, P., S. URSTADT, I. VÖLKEL, D. SCHWARZ, A.T. KUHLEN, S. DÖRING, C.-P. CZERNY: “A longitudinal study to characterize the shedding patterns of Mycobacterium avium ssp. paratuberculosis in a naturally infected breeding bull by polymerase chain reaction assays" 


\section{Curriculum Vitae}

\section{Pia Münster}

*27. February 1982 in Düsseldorf

\section{Work experience}

Since 02/2009

Research assistant,

Georg-August-University Göttingen, Germany

\section{University}

02/2009 - 03/2012 Ph.D. Program for Agricultural Sciences,

Georg-August-University Göttingen, Germany

10/2003 - 08/2008 Degree Agro-Biology, University Hohenheim, Germany

Specialisation: Farm Animal Biology

Courses: $\quad$ Environmental and Animal Hygiene

Parasitology

Animal Production in the Tropics and Subtropics

02/2006 - 06/2006 Study Abroad, University of Queensland, Australia

07/2006 - 11/2006 Study Abroad, Massey University, New Zealand

\section{Stay Abroad}

10/2002 - 08/2003 Work and Travel, Australia

\section{School}

$06 / 2002$

General qualification for university entrance

Grammar school, Velbert-Langenberg, Germany 


\section{Acknowledgements}

The present thesis was undertaken at the German Georg-August-University Göttingen, Department of Animal Sciences, Division Microbiology and Animal Hygiene. This work was funded by the Federal Ministry of Economics and Technology (KF2484201AJ9).

I am grateful to Prof. Claus-Peter Czerny, my main supervisor, for giving me the opportunity to do my doctor's degree in paratuberculosis diagnostic and epidemiology research. During my graduation I could acquire better insight into my field of interest.

I am thankful to Prof. Matthias Gauly and Prof. Engel Hessel for accepting and taking over the co-reference of my thesis.

I am particularly grateful to Sina Stein, Daniel Schwarz, Christoph Braun, and Tobias Uhlig for their help and friendship. Working in their company has been a much more enjoyable experience.

I wish to thank Simone Urstadt, Sebastian Schimkowiak, Tina Althaus, Thomas Kinder and Wilhelm Wemheuer. I could not have done this research without their assistance.

I am also very thankful to Inger Völkel, for the scientific supervision with useful discussions and constructive suggestions as well as for support, motivation and critical review of my manuscripts.

Finally, I am extremely grateful to my parents, Brigitte and Wolfgang Münster and my sister Kim Münster for their encouragement and support not only during this degree, but throughout my education. 


\section{Declaration}

1. I, hereby, declare that this Ph.D. dissertation has not been presented to any other examination body either in its present or a similar form.

Furthermore, I also affirm that I have not applied for a $\mathrm{Ph} . \mathrm{D}$. at any other higher school of education.

Göttingen,

(Signature)

(Name in block capitals)

2. I, hereby, solemnly declare that this dissertation was undertaken independently and without any unauthorised aid.

Göttingen,

(Signature)

(Name in block capitals) 